\title{
Evaluation of the Prompt Alerting Systems at Four Nuclear Power Stations
}

Prepared by D. A. Towers, G. S. Anderson, D. N. Keast/BB\&N

J. L. Kenoyer, A. E. Desrosiers/PNL

Bolt Beranek and Newman, Inc.

Pacific Northwest Laboratory

Prepared for

U.S. Nuclear Regulatory

Commission 
This report was prepared as an account of work sponsored by an agency of the United States Government. Neither the United States Government nor any agency thereot, or any of their employees, makes any warranty, expressed or implied, or assumes any legal liability of re. sponsibility for any third party's use, or the results of such use, of any information, apparatus, product or process disclosed in this report, or represents that its use by such third party would not infringe privately owned rights.

\section{Availability of Reference Materials Cited in NRC Publications}

Most documents cited in NRC publications will be available from one of the following sources:

1. The NRC Public Document Room, 1717 H Street, N.W. Washington, DC 20555

2. The NRC/GPO Sales Program, U.S. Nuclear Regulatory Commission, Washington, DC 20555

\section{The National Technical Information Service, Springfield, VA 22161}

Although the listing that follows represents the majority of documents cited in NRC publications, it is not intended to be exhaustive.

Referenced documents available for inspection and copving for a fee from the NRC Public Document Room include NRC correspondence and iriternal NRC memoranda; NRC Office of Inspection and Enforcement bulletins, circulars, information notices, inspection and investigation notices: Licensee Event Reports; vendor reports and correspondence; Commission papers; and applicant and licensee documents and correspondence.

The following documents in the NUREG series are available for purchase from the NRC/GPO Sales Program: formal NRC staff and contractor reports, NRC-sponsored conference procecdings, and NRC booklets and brochures. Also available are Regulatory Guides, NRC regulations in the Code of Federal Regulations, and Nuclear Regulatory Commission Issuances.

Documents available from the National Technical Information Service include NUREG series reports and technical reports prepared by other federal agencies and reports prepared by the Atomic Energy Commission, forerunner agency to the Nuclear Regulatory Commission.

Documents available from public and special technical libraries include all open literature items, such as books, journal and periodical articles, and transactions. Federal Register notices, federal and state legislation, and congressional reports can usually be obtained from these libraries.

Documents such as theses, dissertations, foreign reports and translations, and non-NRC conference proceedings are available for purchase from the organization sponsoring the publication cited.

Single copies of NRC draft reports are available free upon written request to the Division of Technical Information and Document Control, U.S. Nuclear Regulatory Commission, Washington, DC 20555.

Copies of industry codes and standards used in a substantive manner in the NAC regulatory process are maintained at the NRC Library, 7920 Norfolk Avenue, Bethesda, Maryland, and are available there for reference use by the public. Codes and standards are usually copyrighted and may be purchased from the originating organization or, if they are American National Standarcs, from the American National Standards Institute, 1430 Broadway, New York, NY 10018.

GPO Printed copy price: $\quad \$ 8.00$ 
NUREG/CR-2655

PNL-4226

\section{Evaluation of the Prompt Alerting Systems at Four Nuclear Power Stations}

Manuscript Completed: February 1982

Date Published: September 1982

Prepared by

D. A. Towers, G. S. Anderson, D. N. Keast/BB\&N

J. L. Kenoyer, A. E. Desrosiers/PNL

Bolt Beranek and Newman, Inc.

10 Moulton Street

Cambridge, MA 02238

Pacific Northwest Laboratory

Richland, WA 99352

\section{Prepared for}

Division of Emergency Preparedness

Office of Inspection and Enforcement

U.S. Nuclear Regulatory Commission

Washington, D.C. 20555

NRC FIN B2311 


\section{ABSTRACT}

This report presents evaluations of the prompt notification siren systems at the following four U.S. nuclear power facilities: Trojan, Three Mile Island, Indian Point, and Zion. The objective of these evaluations was to provide examples of an analytical procedure for predicting siren-system effectiveness under specific conditions in the 10 -mile emergency planning zone (EPZ) surrounding nuclear power plants. This analytical procedure is discussed in report number PNL-4227. 

The purpose of this study was to provide examples of the analytical procedure developed in PNL-4227 for the evaluation of the effectiveness of siren systems for alerting the public in the vicinity of a nuclear power plant.

Evaluations of the prompt alerting siren systems at four U.S. nuclear power facilities are presented in this report. These facilities are Trojan, Three Mile Island, Indian Point, and Zion. Site-specific information was used for each system evaluation. The analytical procedure is summarized and details of computations for each evaluation are given. 



\section{TABLE OF CONTENTS}

page

Section 1. InTRODUCTION...........................

2. EVALUATION OF THE PROMPT ALERTING

SYSTEM FOR THE TROJAN NUCLEAR POWER STATION.....2-1

2.1 Estimating Siren Sound Levels

Out of Doors at Listener Sites............

2.2 Estimating Indoor Sound Levels of Sirens....2-6

2.3 Assumptions about Chance of Alert.........2-8

2.4 Alerting People Out of Doors..............

2.5 Alerting People Indoors................ 15

2.6 Alerting People in Motor Vehicles.........2-19

3. EVALUATION OF THE PROMPT ALERTING SYSTEM

FOR THE THREE MILE ISLAND NUCLEAR POWER

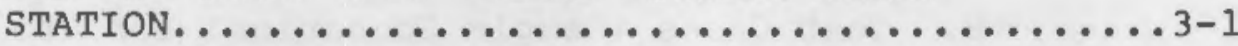

3.1 Estimating Siren Sound Levels

Out of Doors at Listener Sites..............1

3.2 Estimating Indoor Sound Levels of Sirens....3-7

3.3 Assumptions about Chance of Alert.......... 3-9

3.4 Alerting People Out of Doors.............11

3.5 Alerting People Indoors................. 16

3.6 Alerting People in Motor Vehicles.........3-18

4. EVALUATION OF THE PROMPT ALERTING SYSTEM

FOR THE INDIAN POINT NUCLEAR POWER STATION.....4-1

4.1 Estimating Siren Sound Levels

Out of Doors at Listener Sites...........4-1

4.2 Estimating Indoor Sound Levels of Sirens....4-5

4.3 Assumptions about Chance of Alert........4-8

4.4 Alerting People Out of Doors...........4-10

4.5 Alerting People Indoors.............. 4-15

4.6 Alerting People in Motor Vehicles.........4-19 
TABLE OF CONTENTS (Cont.)

page

5. EVALUATION OF THE PROMPT ALERTING SYSTEM

FOR THE ZION NUCLEAR POWER STATION.......... 5-1

5.1 Estimating Siren Sound Levels

Out of Doors at Listener Sites........... 5-1

5.2 Estimating Indoor Sound Levels of Sirens....5-8

5.3 Assumptions about Chance of Alert.........5-9

5.4 Alerting People Out of Doors............

5.5 Alerting People Indoors.............. 5-17

5.6 Alerting People in Motor Vehicles........5-23

APPENDIX A. Population-Weighted Random Selection of

Listening Points at Trojan Site................

B. Test Cases (Sample Scenarios) for Trojan

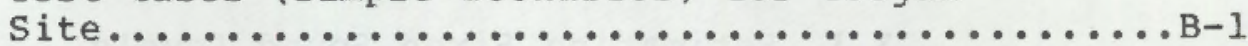

C. Siren Locations for Trojan EPZ................

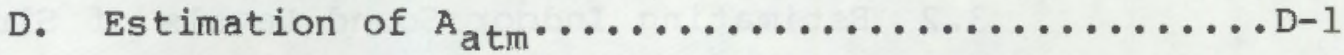

E. Dependence of Alert Upon Siren Duration.........E-1

F. Random Selection of Population-Weighted

Listening Points at Three Mile Island Site.......F-l

G. Test Cases (Sample Scenarios) for Three

Mile Island Site..........................

H. Siren Locations for Three Mile Island EPZ ........H-1

I. Analysis Input/Output Data for Three

Mile Island............................ I-1

J. Random Selection of Population-Weighted

Listening Points at Indian Point Site........... J-1

K. Sample Scenarios for Evaluation of Siren

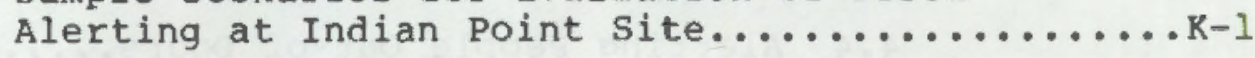

L. Siren Locations for Indian Point EPz..........L-I

M. Analysis Input/Output Data for Indian Point.......M-1

N. Random Selection of Population-Weighted

Listening Points at Zion Site................

o. Sample Scenarios for Evaluation of Siren

Alerting at zion.........................

P. Siren Locations for Zion EPZ...................

Q. Analysis Input/Output Data for Zion............ Q-1 


\section{LIST OF FIGURES}

page

FIGURE 2-1. Flow of computations.................... 2-9

2-2. Chance of alert for awakening people asleep.....2-11

2-3. Distributions for detection by people

out of doors............................ 2-14

2-4. Chance of alert for people indoors at home

(4-minute stationary siren)............... 2-17

2-5. Chance of alert for people indoors at home

(4-minute rotating siren) ................ 2-18

3-1. Flow of computations...................... 3-10

3-2. Chance of alert for awakening people asleep.....3-12

3-3. Distributions for detection by people

out of doors...........................

3-4. Chance of alert for people indoors at home

(4-minute stationary siren) ................. 3-19

3-5. Chance of alert for people indoors at home

(4-minute rotating siren)................... 20

3-6. Chance of alert for people indoors at work

in commercial/institutional establishments......3-2l

4-1. Flow of computations.....................4-9

4-2. Chance of alert for awakening people asleep.....4-11

4-3. Chance of alert for people indoors

(4-minute rotating siren)................4-14

4-4. Chance of alert for people indoors at home

(4-minute rotating siren) ...............4-17

4-5. Chance of alert for people indoors at work

in commercial/institutional establishments.....4-18

5-1. Flow of computations..................... 5-10

5-2. Chance of alert for awakening people asleep.....5-12

5-3. Chance of alert for people outdoors

(4-minute stationary siren) ............... 5-15

5-4. Chance of alert for people outdoors

(4-minute rotating siren)................ 5-16

5-5. Chance of alert for people indoors at home

(4-minute stationary siren).............. 5-20 


\section{LIST OF FIGURES (Cont.)}

5-6. Chance of alert for people indoors at home (4-minute rotating siren)............... 5-21

5-7. Chance of alert for people indoors at work in commercial/institutional establishments.....5-22 


\section{LIST OF TABLES}

page

TABLE 2.1 Summary of Trojan siren system

evaluation results......................2-2

2. 2 Meterological conditions for the four sample scenarios used to evaluate the Trojan siren system..................... 2-5

2.3 Atmospheric attenuation ( $\mathrm{A}_{\mathrm{atm}}$ ) caused by wind and temperature gradients............ 2-7

2.4 Siren alerting ability for generalized categories of outdoor environments........... 2-13

2.5 Assumed activities and background noise environments for people indoors..............

2.6 Siren alerting for motorists..............2-20

3.1 Summary of TMI siren system evaluation results.................................

3.2 Meteorological conditions for the four scenarios used to evaluate the TMI siren system.............................. 3-6

3.3 Calculation of atmospheric attenuation, Aatm' caused by wind and temperature gradients (see appendix $D$ for details) ............... 3-8

3.4 Siren alerting ability for generalized categories of outdoor environments...........3-14

3.5 Assumed activities and background noise environments for people indoors............3-17

3.6 Siren alerting for motorists.............. 3-22

4.1 Summary of Indian point siren system evaluation results......................4-2

4.2 Meteorological conditions for the four sample scenarios used to evaluate the Indian Point siren system................4-6

4.3 Calculation of atmospheric attenuation, $A^{\text {atm, }}$, caused by wind and temperature gradients (see appendix $D$ for details) ...............4-7

4.4 Minimum background noise levels for generalized categories of outdoor environments (see Fig. 4-3 for distributions) ............4-13 


\section{LIST OF TABLES (Cont.)}

page

4.5 Assumed activities and bacground noise environments for people indoors...........4-16

4.6 Siren alerting for motorists...............4-20

5.1 Summary of $\mathrm{Z}$ ion siren system evaluation results............................. 5-2

5.2 Meteorological conditions for the four sample scenarios used to evaluate the $\mathrm{z}$ ion siren system..................... 5-6

5.3 Calculation of atmospheric attenuation, $\mathrm{A}_{\mathrm{atm}}$ ' caused by wind and temperature gradients (see Appendix D for details)................ 5-7

5.4 Minimum background noise levels for generalized categories of outdoor environments

(see Figs. 5-3 and 5-4 for distributions) ...... 5-13

5.5. Assumed activities and background noise environments for people indoors............ 5-18

5.6. Minimum background noise levels for generalized categories of indoor activities/ environments.......................... 5-19

5.7. Siren alerting for motorists.............. 5-24 


\section{FOREWORD}

The work presented in this report was prepared by Bolt, Beranek and Newnan Incorporated under subcontract No. B-A2740-A-V which, in turn, was funded under a Related Services Agreement with the U.S. Department of Energy Contract DE-ACO6-76RLO 1830. 



\section{INTRODUCTION}

This report presents evaluations of the prompt alerting siren systems at the following four U.S. nuclear power stations:

- Trojan (Oregon)

- Three Mile Island (Pennsylvania)

- Indian Point (New York)

- Zion (Illinois)

The purpose of these evaluations was to aid in the development of an analytical procedure for predicting siren-system effectiveness under defined conditions in the vicinity of nuclear power plants. The resulting analytical procedure is outlined in a separate report [1].

Because the analysis procedure evolved over the course of the four above evaluations, some of the calculations differ somewhat from one site evaluation to another. For example, all of the calculations for the Trojan evaluation were done manually. As a result, some broad generalizations regarding estimations of parameters such as shielding, air absorption, and atmospheric attenuation were adopted in order to render the analysis tractable. Subsequent evaluations employed a computer program, resulting in more precise calculations. In addition, the analyses for Trojan and Three Mile Island employed many different background noise level categories for the estimation of siren detectability outdoors. However, the results of these evaluations indicated that such a specific description of outdoor noise environments was not warranted, and therefore subsequent analyses used a more generalized estimation procedure for outdoor detectability. 
As a result of the evolutionary process described above, the results of the four evaluations, although quite similar, are not directly comparable. With this qualification, the remaining sections of this report summarize the methods and results of the four evaluations. 


\section{EVALUATION OF THE PROMPT ALERTING SYSTEM FOR THE TROJAN NUCLEAR PONER STATION}

This section summarizes the evaluation of the siren alerting system for the Trojan Nuclear Power Station. The procedure that was used consists of a detailed analysis of siren alerting capability at each of 50 randomly chosen listener locations, under four different "sample scenario" conditions. The random selection process for listener sites is described in Appendix $A$ and the four test cases (sample scenarios) are included in Appendix B. The analysis is based on siren location as shown on maps provided in Appendix $C$.

The results of the evaluation for Trojan are summarized in Table 2.1 and indicate that the chance of alert is estimated to vary between 658 and 1008 , depending on the sample scenario under consideration. The remainder of this section describes the procedure used to arrive at this conclusion.

\subsection{Estimating Siren Sound Levels out of Doors at Listener Sites}

The first step in the procedure is to determine the siren in the vicinity of each selected listener site that is expected to produce the highest sound level at that site for each sample scenario. This choice is not always obvious, because the sound level caused by a particular siren at a given listener site depends not only on the sound output of the siren and its distance from the 1 istener, but also on shielding and atmospheric effects (particularly wind direction). Therefore, it is generally necessary to evaluate several sirens in the vicinity of each listener site in order to determine the dominant one. As a general rule, the closest, highest-rated, nonshielded sirens are selected for evaluation at each site. Furthermore, sirens should be chosen such that they are distributed north, south, east, and west of the site (or in any other four mutually perpendicular directions) 
TABLE 2.1. SUMMARY OF TROJAN SIREN SYSTEM EVALUATION RESULTS.

\begin{tabular}{|c|c|c|c|c|}
\hline \multirow{2}{*}{} & \multicolumn{2}{|c|}{ Scenario } & \multicolumn{3}{|c|}{ Chance of Alert } \\
\cline { 2 - 5 } & \multicolumn{1}{c|}{ Description } & $\begin{array}{c}\text { Urban } \\
(\%)\end{array}$ & $\begin{array}{c}\text { Rural } \\
(\%)\end{array}$ & $\begin{array}{c}\text { Population- } \\
\text { Weighted Average* } \\
(\%)\end{array}$ \\
\hline \hline No. & $\begin{array}{c}\text { Warm Summer Weekend Day } \\
\text { (clear to partly cloudy) }\end{array}$ & 100 & 100 & 100 \\
\hline 2 & $\begin{array}{l}\text { Summer Weekday Night } \\
\text { (clear to partly cloudy) }\end{array}$ & 78 & 72 & 76 \\
\hline 3 & $\begin{array}{l}\text { Winter Weekday Evening } \\
\text { (cool, damp, and overcast) }\end{array}$ & 97 & 89 & 95 \\
\hline 4 & $\begin{array}{l}\text { Winter Night } \\
\text { (during rainstorm) }\end{array}$ & 67 & 60 & 65 \\
\hline
\end{tabular}

*Based on a total urban population of 46,000 and a total rural population of 18,600 . 
where possible to account for different wind directions. For the Trojan analysis, one to four sirens were evaluated at each of the 501 istener sites. Sites at which only one siren was considered were located so close to the chosen siren that the selection of additional sirens was obviously not warranted.

The next step in the procedure is to establish the outdoor sound level produced by the selected sirens at each listener location. This is accomplished by applying adjustments to the rated sound level of the siren as follows:

$$
L(1 \text { istener })=L(\text { siren })-A_{d}-A_{S}-A_{a i r}-A_{a t m} \text {, }
$$

where $\mathrm{L}$ (listener) is the outdoor siren sound pressure level at the listener site $(d B), L(s i r e n)$ is rated sound pressure level of the siren at $100 \mathrm{ft}(\mathrm{dB}), \mathrm{A}_{\mathrm{d}}$ is the distance attenuation $(\mathrm{dB}), \mathrm{A}_{\mathbf{S}}$ is shielding attenuation $(d B), A_{a i r}$ is the air absorption (dB), and $A_{a t m}$ is the atmospheric attenuation caused by wind and temperature gradients (dB).

The rated sound pressure levels for the Trojan sirens were obtained from the manufacturer's literature as follows:

\section{Federal Signal Corporation}

$\begin{array}{lll}\text { Rotating "Thunderbolt" sirens } & =125 \mathrm{dBC} \text { a } 100 \mathrm{ft} \\ \text { Stationary Model STA10 or STL10 sirens } & =115 \mathrm{dBC} \text { \& } 100 \mathrm{ft} \\ \text { Stationary Model } 5 \text { sirens } & & =107 \mathrm{dBC} \text { a } 100 \mathrm{ft} \\ \text { Stationary Model } 2 \text { sirens } & & =102 \mathrm{dBC} \text { e } 100 \mathrm{ft} \\ \text { Stationary Model LCS-1 sirens } & =86 \mathrm{dBC} \text { ค } 100 \mathrm{ft}\end{array}$

The first two adjustments (for distance and shielding) are the same for all four test cases and are based on information obtained from USGS maps. Distance attenuation beyond $100 \mathrm{ft}$ is 
calculated by assuming sound propagation from an acoustic point source with a reduction of $6 \mathrm{~dB}$ per distance doubled. It is calculated as follows:

$$
A_{d}=20 \log _{10}\left(\frac{d}{100}\right) \text {, }
$$

where $d$ is the siren-to-listener distance ( $f t$ ).

Shielding attenuation $\left(A_{S}\right)$ is estimated based on the degree of break in the line-of-sight from siren-to-listener. Sirens are assumed to be at a height of $50 \mathrm{ft}$ above terrain level and the listeners at a height of $5 \mathrm{ft}$. The break in line-of-sight is obtained by using ground contour information from USGs maps. For the Trojan analysis, a shielding attenuation of $15 \mathrm{~dB}$ was included if the break in line-of-sight was $50 \mathrm{ft}$ or more. Otherwise, no attenuation was assumed.

The corrections for air absorption and atmospheric effects depend on the meteorological conditions for the particular scenario. The assumed conditions for the Trojan site are provided in Table 2.2 for the four test cases, based on local weather information.* In terms of air absorption, these conditions indicate attenuations ranging between 0.6 and $0.9 \mathrm{~dB}$ per $1000 \mathrm{ft}$, depending on the scenario $[2,3]$. For simplicity in the analysis, an average value of $0.8 \mathrm{~dB}$ per $1000 \mathrm{ft}$ was assumed for all cases. Thus,

$$
A_{\text {air }}=\frac{0.8 \mathrm{~d}}{1000}
$$

where $d$ is the siren-to-listener distance (ft).

\footnotetext{
* Trojan Plant Environmental Impact Report - Amendment L, Fig. 2.3-4, Table 2.3-13 (March 1973).
} 
TABLE 2.2. METEOROLOGICAL CONDITIONS FOR THE FOUR SAMPLE SCENARIOS USED TO EVALUATE THE TROJAN SIREN SYSTEM.

\begin{tabular}{|c|c|c|c|c|}
\hline $\begin{array}{l}\text { Scenario } \\
\text { No. }\end{array}$ & Wind Conditions* & $\begin{array}{c}\text { Temperature } \\
\text { Gradient }\end{array}$ & $\begin{array}{l}\text { Relative } \\
\text { Humidity } \\
(\%)\end{array}$ & $\begin{array}{l}\text { Temperature } \\
\quad\left({ }^{\circ} \mathrm{F}\right)\end{array}$ \\
\hline 1 & $\begin{array}{l}10 \mathrm{mph} \text { from the north through- } \\
\text { out the region, except upslope } \\
\text { in the canyons }\end{array}$ & $\begin{array}{l}-2^{\circ} \mathrm{C} / 100 \mathrm{~m} \\
\mathrm{Class} \mathrm{A}\end{array}$ & 50 & 75 \\
\hline 2 & $\begin{array}{l}5 \mathrm{mph} \text { from the south in the } \\
\text { river valley, downslope in the } \\
\text { canyons }\end{array}$ & $\begin{array}{l}+1.5^{\circ} \mathrm{C} / 100 \mathrm{~m} \\
\text { Class } \mathrm{E}\end{array}$ & 90 & 55 \\
\hline 3 & $\begin{array}{l}3 \text { mph from the south, calm in } \\
\text { the canyons }\end{array}$ & $\begin{array}{l}+1^{\circ} \mathrm{C} / 100 \mathrm{~m} \\
\text { Class } \mathrm{E}\end{array}$ & 80 & 55 \\
\hline 4 & $\begin{array}{l}15 \mathrm{mph} \text { from the south, } 5 \mathrm{mph} \\
\text { downslope in the canyons }\end{array}$ & $\begin{array}{l}+1^{\circ} \mathrm{C} / 100 \mathrm{~m} \\
\text { Class E }\end{array}$ & 90 & 35 \\
\hline
\end{tabular}

*Note: Weather data from the Trojan Plant indicate occasional conditions when the wind speed at lower elevations exceeds that at higher elevations. This unusual occurrence is assumed to be a measurement artifact, and has been ignored in this analysis. 
The adjustment for atmospheric gradient effects ( $A_{a t m}$ ) is based on siren-to-listener azimuth with respect to wind direction and on wind and temperature gradient characteristics. Table 2.3 summarizes the calculation procedure for determining $A_{a t m}$ for each scenario at the Trojan site. A more detailed description of the estimation procedure for $A_{a t m}$ can be found in Appendix D.

Application of the above calculations yields the estimated outdoor sound pressure level for various sirens at each sample listener site, for each of the four scenarios. For the balance of the analysis, only the highest siren level at each listener site is generally used. An exception to this rule is made at listener sites where the sound level of a stationary siren is estimated to be between 0 and $6 \mathrm{~dB}$ lower than the sound level of a rotating-type siren, which had been determined to be the loudest siren. In such cases, the stationary siren was selected for further analysis. The reason for this exception is that the maximum sound level produced by a rotating siren is not continuous, and thus the total acoustic energy at the listener (as measured by the single event noise exposure level, or SEL) is approximately 6 dB less than for a stationary (i.e., continuous) siren with the same maximum sound level.

\section{2 Estimating Indoor Sound Levels of Sirens}

The result of the above calculations is a single outdoor siren sound pressure level at each of the 50 sample listener locations for each of the four test cases. Corresponding indoor levels are then obtained by subtracting typical values for residential building sound attenuation. For test cases 1 and 2 (summer), residential windows were assumed to be partly open; for test cases 3 and 4 (winter) residential windows were assumed to be closed. For the frequency region within the $500 \mathrm{~Hz}$ octave 

TABLE 2.3. ATMOSPHERIC ATTENUATION (A ${ }_{\text {atm }}$ ) CAUSED BY WIND
AND TEMPERATURE GRADIENTS.

\begin{tabular}{|c|c|c|c|}
\hline $\begin{array}{l}\text { Sample } \\
\text { Scenario } \\
\text { No. }\end{array}$ & $\begin{array}{l}\text { Listener Site } \\
\text { Postion with Respect } \\
\text { to Siren Position* }\end{array}$ & $\begin{array}{l}\text { Siren-to- } \\
\text { Listener } \\
\text { Distance }(f t)\end{array}$ & $\begin{array}{l}A_{a} \text { tm } \\
(\mathrm{dB})\end{array}$ \\
\hline \multirow{3}{*}{1} & Upwind & $\begin{aligned} 0 & -1000 \\
1000 & -2000 \\
& >2000\end{aligned}$ & $\begin{array}{r}0 \\
10 \\
20 \\
\end{array}$ \\
\hline & Crosswind & $\begin{array}{l}0-4000 \\
>4000\end{array}$ & $\begin{array}{r}0 \\
10\end{array}$ \\
\hline & Downwind & (a.11) & 0 \\
\hline \multirow[t]{3}{*}{2} & Upwind & $\begin{array}{c}0-1000 \\
1000-2000 \\
>2000 \\
\end{array}$ & $\begin{array}{r}0 \\
10 \\
20 \\
\end{array}$ \\
\hline & Crosswind & (a11) & 0 \\
\hline & Downwind & (all) & 0 \\
\hline 3 & \multicolumn{3}{|c|}{ Same as Scenario No. 2, except $A_{a t m}=0$ in canyons } \\
\hline 4 & \multicolumn{3}{|l|}{ Same as Scenario No. 2} \\
\hline
\end{tabular}

* Defined with respect to the smaller angle $(\phi)$ between the source-to-receiver directional vector and the wind directional vector as follows: Downwind for $\phi=0-45^{\circ}$

Crosswind for $\phi=45^{\circ}-135^{\circ}$

Upwind for $\phi=135^{\circ}-180^{\circ}$. 
band, the sound attenuation into buildings is estimated to be 16 $\mathrm{dB}$ for test cases 1 and 2 and $27 \mathrm{~dB}$ for test cases 3 and 4 [4].

\section{3 Assumptions about Chance of Alert}

The outdoor and indoor siren levels calculated by the above procedure provide some of the information required for the analysis of the chance of alert. In addition, it is necessary to know the level of interfering background noise at the listener locations.

Figure 2-1 is a flow chart of the analysis computations. The analysis is divided into components (rows) that correspond to the possible activities of people for the various scenarios. The major components relate to people (1) at home (outside or inside), (2) at work, or (3) in motor vehicles. The chance of alert is estimated for each activity component and is then multiplied by the fraction of people likely to be engaged in that activity (activity fraction). The results are summed to obtain the overall chance of alert for each listener location and for each test case. Overall chances of alert for the various scenario (test case) conditions are then obtained by averaging the chances for all rural and/or urban sample listener sites. Note that all estimates assume siren signal duration of 4 minutes; an average of the " 3 to 5 minutes" called for in Appendix 3 of NUREG-0654. The effects of different siren signal durations are discussed in Appendix $\mathrm{E}$.

Siren detectability is a function of the siren signal level and of the background noise level in a "critical frequency band" centered at the signal frequency. For this analysis, outdoor and indoor detectability is estimated based on the signal-to-noise $(\mathrm{S} / \mathrm{N})$ difference in the $630-\mathrm{Hz} 1 / 3$-octave frequency band. The 


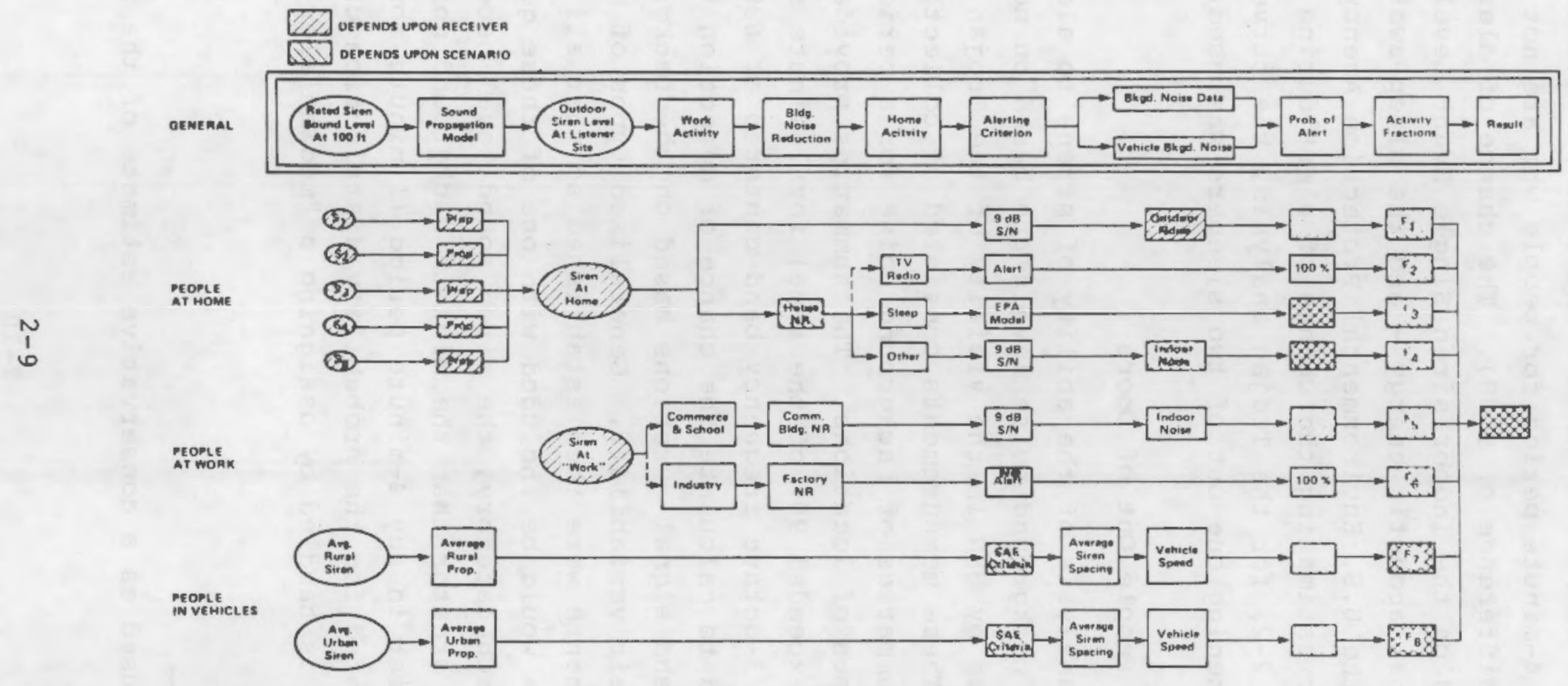

FIG. 2-1. FLOW OF COMPUTATIONS. 
chosen criterion for alerting is that the given signal level must be $9 \mathrm{~dB}$ or more above the minimum background noise level at any time during a 4-minute period for people who are not sleeping (i.e., a $S / N$ difference of $9 \mathrm{~dB}$ ). The chance of alert during sleep is based on the indoor siren Single Event Level (SEL) - a measure of total acoustic energy - and the sleep-awakening model developed by the U.S. Environmental Protection Agency [5]. The graph used for estimating the chance of alert during sleep is shown in Fig. 2-2; for the Trojan analysis, the curve for the chance of awakening one out of two sleepers was used.

\subsection{Alerting People Out of Doors}

For the analysis of the ability of sirens to alert people out of doors, background noise levels are based on noise measurements conducted by BBN in the vicinity of the Trojan Plant in March 1981. These measurements consisted of collecting 1-minute statistical summaries of background noise for a period of 1 hour at various types of locations. The summaries provide the $L_{90}$ (sound level exceeded $90 \%$ of the time) for 1 -minute samples of data in the 1/3-octave frequency band centered at $630 \mathrm{~Hz}$. * The data were used to calculate the chance of detection for various siren levels and signal durations based on the background noise levels and their variability. Generalized types of background noise environments were then established so that all sample listener sites would be included with one of these general categories. In each category, the siren sound level necessary to alert is $9 \mathrm{~dB}$ greater than the minimum background noise level that could exist in any 4-minute period ( 1 minute for rotating sirens), adjusted for the probability distribution of such minima. This is handled by assigning a "median alerting level"

\footnotetext{
*The $L_{90}$ was used as a conservative estimate of the minimum sound level?
} 


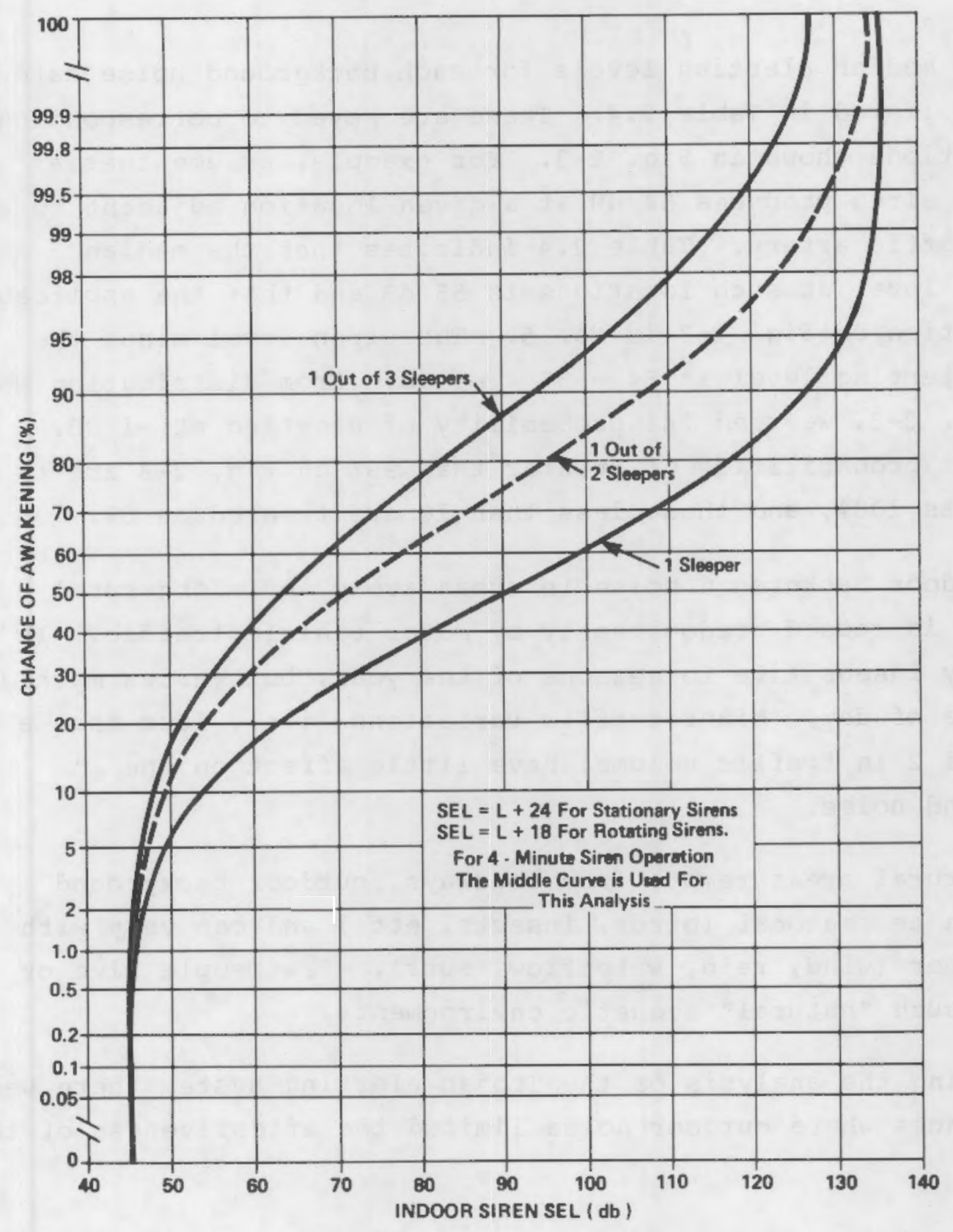

FIG. 2-2. CHANCE OF ALERT FOR ANARENING PEOPLE ASLEEP. 
for each background noise category and adjusting these levels in accordance with probability distributions generalized from the data.

The median alerting levels for each background noise category are listed in Table 2.4. These are keyed to corresponding distributions shown in Fig. 2-3. For example, assume that a rotating siren produces $54 \mathrm{~dB}$ at a given location adjacent to a major traffic artery. Table 2.4 indicates that the median alerting level at such locations is $55 \mathrm{~dB}$ and that the applicable distribution on Fig. $2-3$ is No. 5. The siren level minus the median alerting level is $54-55=-1 \mathrm{~dB}$. From distribution No. 5 on Fig. 2-3, we read 24 \% probability of alerting at $-1 \mathrm{~dB}$. Note that probabilities of greater than $99 \%$ on Fig. 2-3 are treated as 1008 , and those less than 18 are treated as 08 .

Outdoor background noise in urban areas and along rural roadways is caused predominantly by motor vehicle traffic. It is generally insensitive to seasons of the year, but varies markedly with time of day. Minor traffic variations (i.e., less than a factor of 2 in traffic volume) have little effect on the background noise.

In rural areas remote from roadways, outdoor background noise can be seasonal (birds, insects, etc.) and can vary with the weather (wind, rain, waterflow, surf). Few people live or work in such "natural" acoustic environments.

During the analysis of the Trojan alerting system there were no instances where outdoor noise limited the effectiveness of the sirens.

Note that results are given separately for stationary sirens and rotating sirens. This is because rotating sirens would actually produce their estimated sound level during about one 


\section{TABLE 2.4. SIREN ALERTING ABILITY FOR GENERALIZED CATEGORIES OF OUTDOOR ENVIRONMENTS.}

\begin{tabular}{|c|c|c|c|c|}
\hline \multirow[b]{2}{*}{$\begin{array}{l}\text { Generalized Background } \\
\text { Noise Environment }\end{array}$} & \multicolumn{2}{|c|}{ Median Alerting Level $(\mathrm{dB})$} & \multicolumn{2}{|c|}{ Applicable Distribution ${ }^{2}$} \\
\hline & $\begin{array}{l}\text { Rotating } \\
\text { Siren } \\
\text { (4 min) }\end{array}$ & $\begin{array}{c}\text { Stationary } \\
\text { Siren } \\
(4 \text { min })\end{array}$ & $\begin{array}{l}\text { Rotating } \\
\text { Siren } \\
(4 \text { min })\end{array}$ & $\begin{array}{c}\text { Stationary } \\
\text { Siren } \\
(4 \text { min) }\end{array}$ \\
\hline $\begin{array}{l}\text { I. URBAN } \\
\text { A. Adjacent to Major Traffic Artery } \\
\text { B. Remote from Major Traffic Artery }\end{array}$ & $\begin{array}{l}55 \\
48\end{array}$ & $\begin{array}{l}53 \\
46\end{array}$ & $\begin{array}{l}\text { No. } 5 \\
\text { No. } 5\end{array}$ & $\begin{array}{l}\text { No. } 3 \\
\text { No. } 4\end{array}$ \\
\hline $\begin{array}{l}\text { II. RURAL } \\
\text { A. Within View of Major Noise Sources } \\
\text { 1. Highway I- } 5^{2} \\
\text { 2. Highway US }-30^{3} \\
\text { 3. Port of Longview } \\
\text { B. Remote rrom Mejor Noise Sources } \\
\text { 1. No Wind or Weter Flow Noise } \\
\text { 2. Subject to Wind Noise } \\
\text { 3. Subject to Water Flow Noise }\end{array}$ & $\begin{array}{l}41 \\
45 \\
57\end{array}$ & $\begin{array}{l}61 \\
48 \\
52\end{array}$ & $\begin{array}{l}\text { No. } 3 \\
\text { No. } 5 \\
\text { No. } 1\end{array}$ & $\begin{array}{l}\text { No. } 4 \\
\text { No. } 4 \\
\text { No. } 2 \\
\text { No. } 1 \\
\text { No. } 3 \\
\text { No. } 1\end{array}$ \\
\hline III. INDUSTRIAI ${ }^{5}$ & 55 & 54 & No. 4 & No. 2 \\
\hline
\end{tabular}

NOTES:

1. See Fig. 2-3.

2. Alerting levels apply for sites within $500 \mathrm{ft}$, with view angle $(\theta)$ or $180^{\circ}$ to highway; beyond $500 \mathrm{ft}$, levels should be reduced by $10 \log 1 \mathrm{~g}(\mathrm{D} / 500)$, where $\mathrm{D}=\mathrm{dist}$. from highrey in $\mathrm{ft}$; for view angles less than $180^{\circ}$, levels should be further reduced by $1010 \mathrm{~g} 10$ (180/ 9 ).

3. Alerting levels apply for sites within $1600 \mathrm{ft}$, with view angle $(\theta)$ of $180^{\circ}$ to highway; beyond $1600 \mathrm{ft}$, levels should be reduced by $10 \log _{10}(\mathrm{D} / 1600)$, where $\mathrm{D}=\mathrm{dist}$. from highway In It; for view angles less than $180^{\circ}$, levels should be further reduced by $1010 \mathrm{~g} 10$ ( $\left.180 / \theta\right)$.

4. Alerting levels apply at $300 \mathrm{ft}$ from stream; for other distances a just levels by 10 logio ( $300 /$ distance).

5. Alertine levels apply at $1000 \mathrm{ft}$ from source; for other distances adjust levels by $20 \mathrm{log} 10$ (2000/distance). 


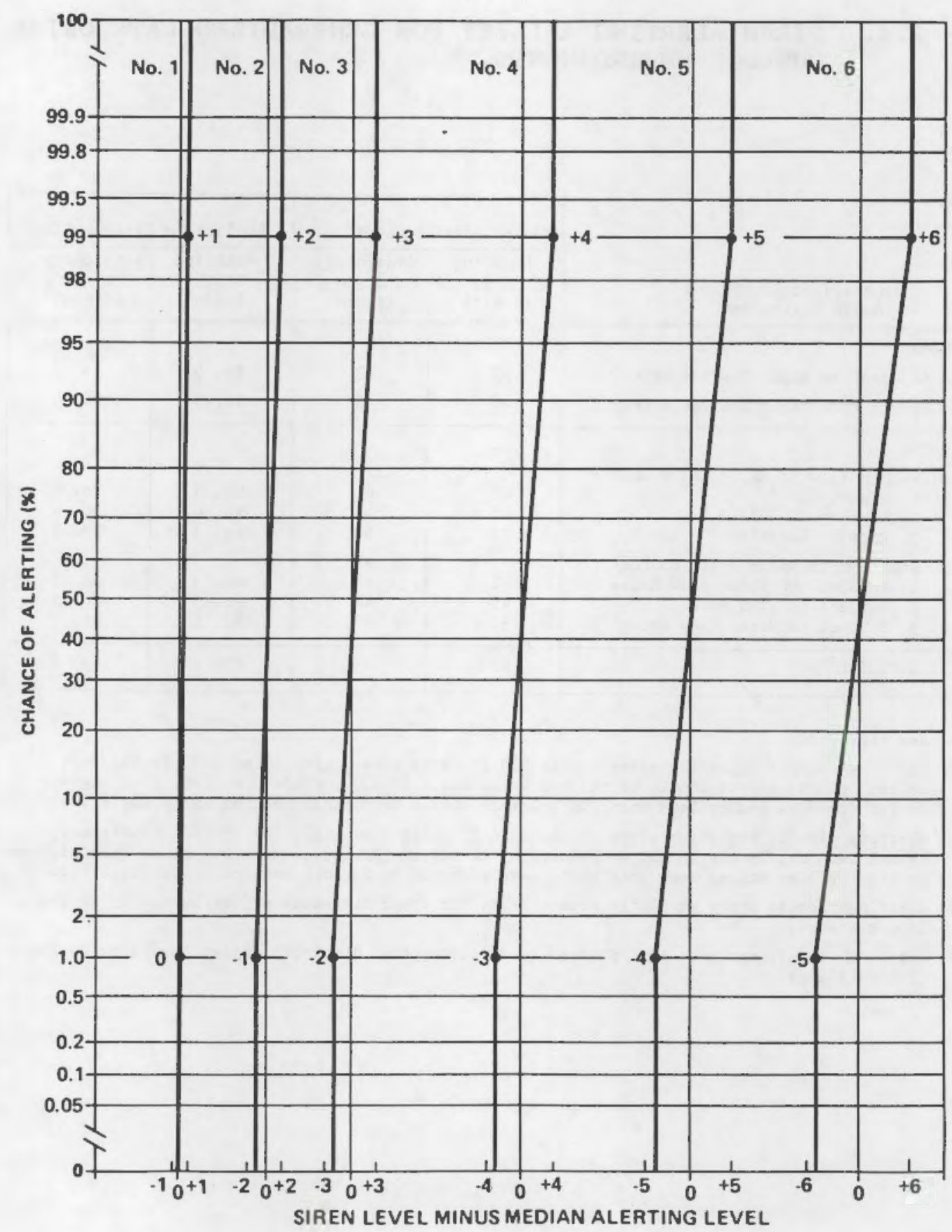

FIG. 2-3. DISTRIBUTIONS FOR DETECTION BY PEOPLE OUT OF DOORS. 
quarter of the presumed 4-minute operating time at any particular listener location. Thus, the results for rotating sirens are based on 1-minute statistics rather than on 4-minute statistics.

In summary, information regarding siren type, estimated siren sound level, background noise category at the listener site, and test-case conditions are used in conjunction with Table 2.4 and Fig. 2-3 to estimate the chance of siren detection outdoors.

\subsection{Alerting People Indoors}

For the analysis of alerting people indoors at home, three types of activities are considered. These are (1) listening to radio or $T V$, (2) sleeping, or (3) other activities that range from quiet to noisy situations. Table 2.5 provides the percentages assumed for various activities for each scenario.

For people listening to radio or $T V$, the chance of alert is 1008. For people sleeping, the chance of alert is calculated from the indoor siren SEL using the relationship shown in Fig. 2-2 for the chance of awakening one out of two sleepers. For all other indoor activities, the chance of alert is based on classifications of actual indoor background noise measurements under a wide variety of conditions.

Results for test cases 1 and 3 are provided in Fig. 2-4 for 4-minute stationary sirens and in Fig. 2-5 for 4-minute rotating sirens. Thus, given the siren type, indoor siren level, and test case condition, these figures are used to estimate the chance of alert for indoor activities other than sleeping or listening to radio or $\mathrm{TV}$. 


\section{TABLE 2.5. ASSUMED ACTIVITIES AND BACKGROUND NOISE ENVIRONMENTS FOR PEOPLE INDOORS.}

\begin{tabular}{|c|c|c|c|c|c|c|c|}
\hline \multirow[b]{3}{*}{ Scenario } & \multicolumn{7}{|c|}{ Percentages of People Engaged in Various Activities Indoors (x) } \\
\hline & \multirow[b]{2}{*}{$\begin{array}{l}\text { At Place } \\
\text { of Business }\end{array}$} & \multirow[b]{2}{*}{$\begin{array}{l}\text { Listening to } \\
\text { TV/Radio }\end{array}$} & \multirow[b]{2}{*}{ sleeping } & \multicolumn{4}{|c|}{ Indoor Moise Environment } \\
\hline & & & & $\begin{array}{l}\text { Obviously } \\
\text { Noisy }\end{array}$ & $\begin{array}{l}\text { Busy and } \\
\text { Active }\end{array}$ & Isolated" & $\begin{array}{l}\text { Obvinusly } \\
\text { Quiet" }\end{array}$ \\
\hline $\begin{array}{l}\text { 1. War Gumer Weekend } \\
\text { Day (clear to partly } \\
\text { cloudy) }\end{array}$ & -- & 50 & -- & -- & 15 & 10 & 25 \\
\hline $\begin{array}{l}\text { 2. 6ummer Weekday N1Ght } \\
\text { (clear to partly } \\
\text { eloudy) }\end{array}$ & 5 & -- & 95 & -- & - & -- & $\cdots$ \\
\hline $\begin{array}{l}\text { 3. Winter Weekday During } \\
\text { Evening Conwut ing } \\
\text { lourn (cool, demp, } \\
\text { overcast) }\end{array}$ & -- & 20 & -- & 5 & 50 & 20) & 5 \\
\hline $\begin{array}{l}\text { 4. Wirter Night During } \\
\text { Rujngtorm }\end{array}$ & 5 & -- & 95 & -- & -- & -- & -4 \\
\hline
\end{tabular}

NOTES:

1. Vacuum cleaning, dishwnsher, slıover, velit fan $\mathrm{crl}$, etc.

2. Dinner conversotion, kilcien work, playing music, chlldren at play, etc.

3. Noise-producing nctivity in adjacent room, soft bnckgreund music, ele.

4. Reading, study, eating alone. 


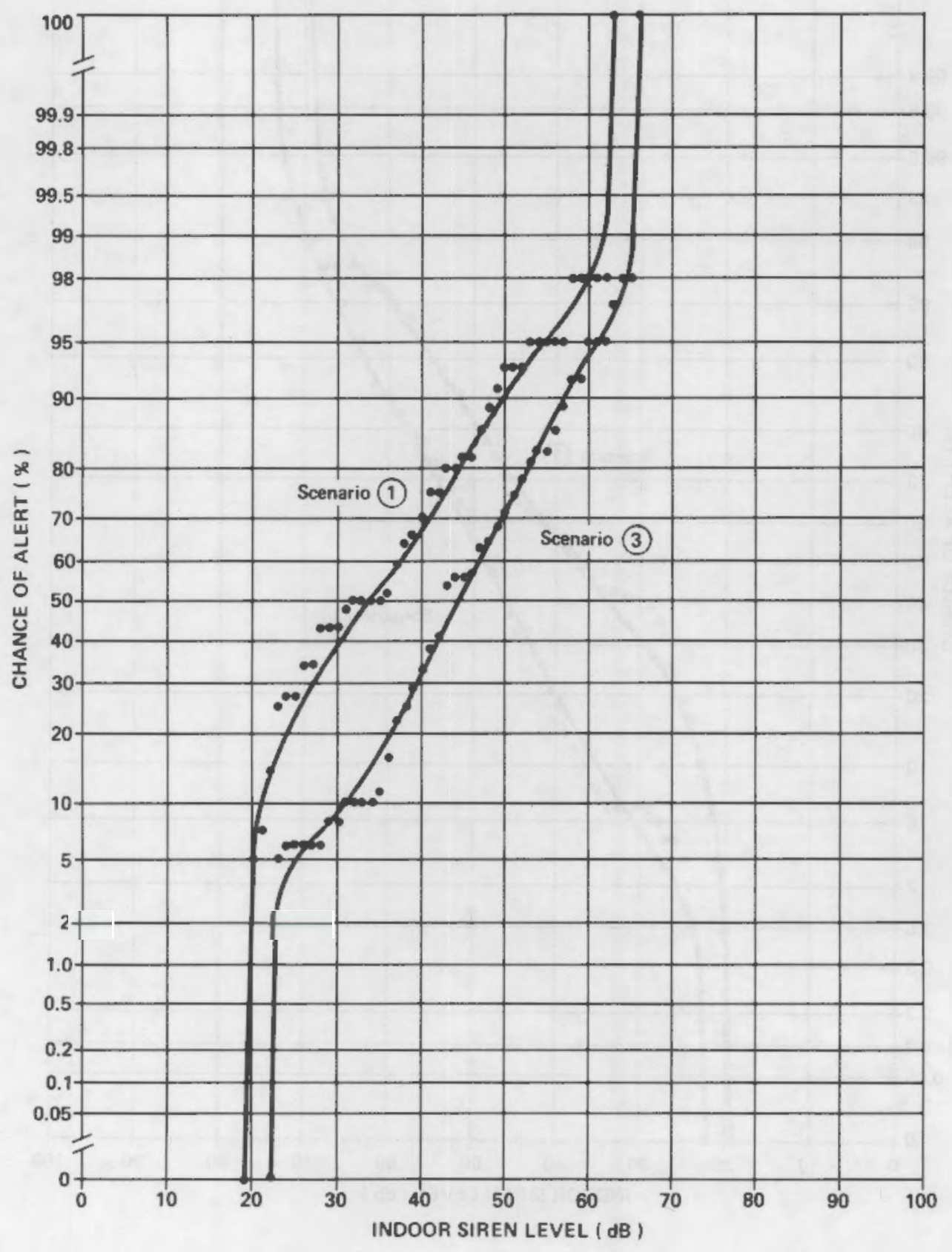

FIG. 2-4. CHANCE OF ALERT FOR PEOPLE INDOORS AT HOME (4-MINUTE STATIONARY SIREN). 


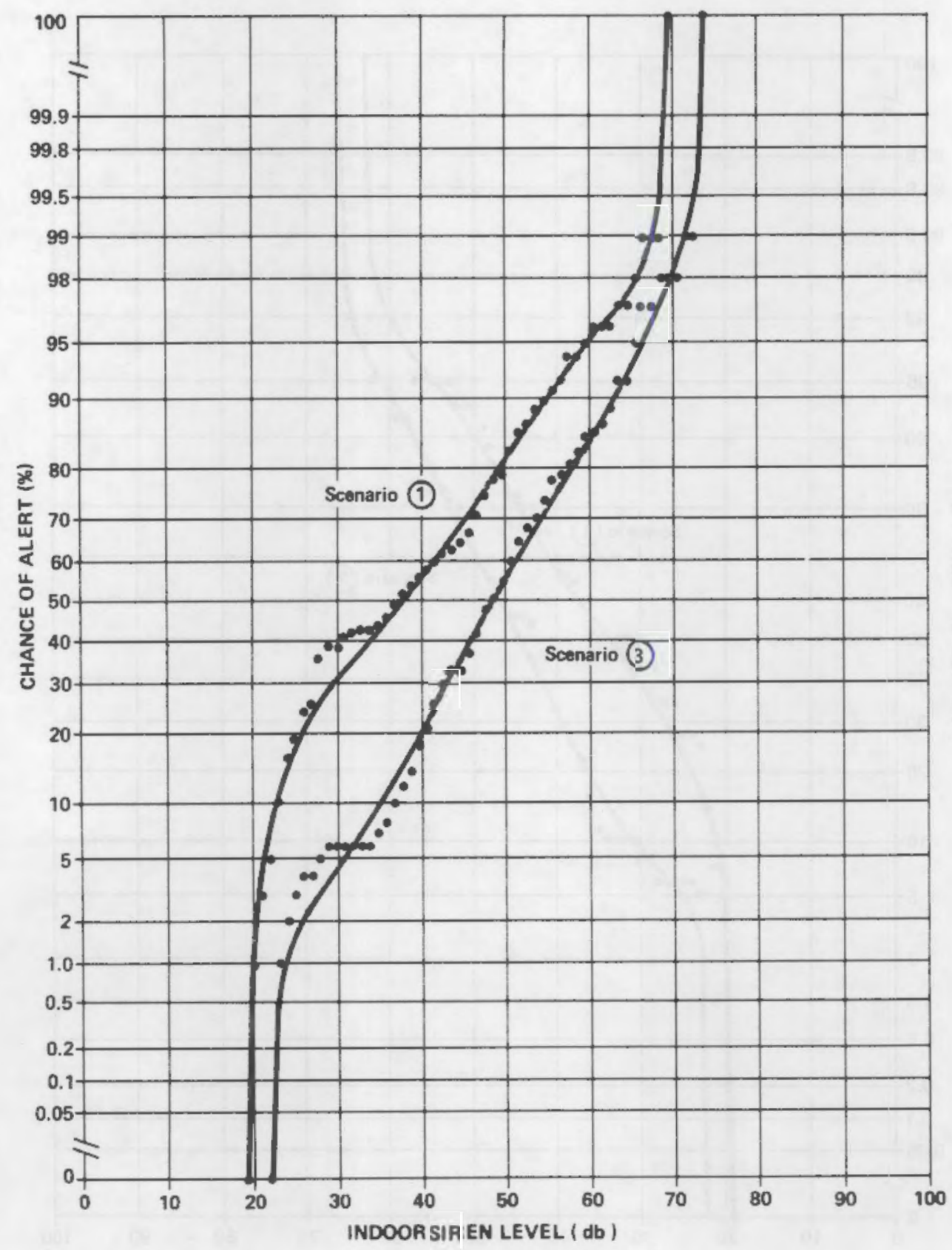

FIG. 2-5. CHANCE OF ALERT FOR PEOPLE INDOORS AT HOME (4-MINUTE ROTATING SIREN). 
For the analysis of alerting at work, two activity categories are considered: (1) commercial/institutional, and (2) industrial environments. In the case of Trojan, only the nighttime scenarios (test cases 2 and 4 ) include people at work. For these cases, essentially all nighttime work was assumed to occur in industrial environments and none of these people is likely to be alerted because of building attenuation and high background noise levels. Thus, the chance of alert was assumed to be 0 o at work at night for the Trojan analysis. In actuality, it is possible that these people would be alerted by some means (phone, radio) other than sirens, and hence our estimates may be low as a result.

\subsection{Alerting People in Motor Vehicles}

The analysis for the alerting of motorists is based on the assumption of an average siren signal strength and spacing throughout the EPZ. The probability that a motorist will pass within the alert range of a siren during its 4-minute operation is estimated as follows:

$$
C=\frac{2 R+d}{L} \times 100 \text { (not to exceed } 100 \% \text { ) }
$$

where $C$ is the chance of alert ( 8$), R$ is the maximum alert distance ( $f t$ ), d is distance traveled in 4 minutes ( $f t$ ), and $L$ is the average siren spacing ( $f t$ ). Separate analyses were carried out for urban and rural areas of the Trojan EPZ.

The average urban siren produces a sound level of $125 \mathrm{~dB}$ at $100 \mathrm{ft}$, and the average rural siren produces a sound level of 119 $\mathrm{dB}$ at $100 \mathrm{ft}$. Alerting ability was evaluated by using the results of a study for the Society of Automotive Engineers (SAE) [6]. Siren alerting levels for speeds of $55 \mathrm{mph}$ and $30 \mathrm{mph}$ with windows shut or open were first determined from the SAE study results. The average siren source levels for rural and urban 
areas were then reduced to alerting levels in accordance with the propagation models from current NRC guidelines (i.e., $10 \mathrm{~dB}$ / double distance) [7]. In this manner, the maximum alert distance (R) was calculated for each driving condition. The distance traveled in 4 minutes (d) was calculated based on speed for each case, and the average siren spacing (L) was estimated to be 4,785 ft for urban areas and $6,895 \mathrm{ft}$ for rural areas.

The calculations of alerting ability for motorists are summarized in Table 2.6. The results indicate that the chance of alert is expected to be 1008 for all conditions applicable to the Trojan analysis.

TABLE 2.6. SIREN ALERTING FOR MOTORISTS.

\begin{tabular}{|c|c|c|c|c|c|c|c|}
\hline Area & $\begin{array}{l}\text { Vehicle } \\
\text { Speed } \\
\text { (Imph) }\end{array}$ & $\begin{array}{l}\text { Vehicle } \\
\text { Window } \\
\text { Condition }\end{array}$ & $\begin{array}{l}\text { Regd. Signal } \\
\text { for Alert } \\
\text { (dB) }\end{array}$ & $\begin{array}{l}\text { Max. Alert } \\
\text { Dist., R } \\
\text { (ft) }\end{array}$ & $\begin{array}{l}\text { 4-min } \\
\text { Travel } \\
\text { dist.. d } \\
\text { (ft) }\end{array}$ & $\begin{array}{l}\text { Avg. Siren } \\
\text { Spacing, L } \\
\text { (ft) }\end{array}$ & $\begin{array}{l}\text { Chance } \\
\text { of Alert } \\
\text { ( } 8 \text { ) }\end{array}$ \\
\hline \multirow[t]{2}{*}{ URBAN } & 55 & $\begin{array}{l}\text { closed } \\
\text { open }\end{array}$ & $\begin{array}{l}96 \\
90\end{array}$ & $\begin{array}{c}750 \\
1130\end{array}$ & $\begin{array}{l}19,360 \\
19,360\end{array}$ & $\begin{array}{l}4785 \\
4785\end{array}$ & $\begin{array}{l}100 \\
100\end{array}$ \\
\hline & 30 & $\begin{array}{l}\text { closed } \\
\text { open }\end{array}$ & $\begin{array}{l}89 \\
86\end{array}$ & $\begin{array}{l}1210 \\
1500\end{array}$ & $\begin{array}{l}10,560 \\
10,560\end{array}$ & $\begin{array}{l}4785 \\
4785\end{array}$ & $\begin{array}{l}100 \\
100\end{array}$ \\
\hline \multirow{2}{*}{ RURAL } & 55 & $\begin{array}{l}\text { closed } \\
\text { open }\end{array}$ & $\begin{array}{l}96 \\
90\end{array}$ & $\begin{array}{l}490 \\
750\end{array}$ & $\begin{array}{l}19,360 \\
19,360\end{array}$ & $\begin{array}{l}6895 \\
6895\end{array}$ & $\begin{array}{l}100 \\
100\end{array}$ \\
\hline & 30 & $\begin{array}{l}\text { closed } \\
\text { open }\end{array}$ & $\begin{array}{l}89 \\
86\end{array}$ & $\begin{array}{l}800 \\
980\end{array}$ & $\begin{array}{l}10,560 \\
10,560\end{array}$ & $\begin{array}{l}6895 \\
6895\end{array}$ & $\begin{array}{l}100 \\
100\end{array}$ \\
\hline
\end{tabular}




\section{EVALUATION OF THE PROMPT ALERTING SYSTEM FOR THE THREE MILE ISLAND NUCLEAR POMER STATION}

This section summarizes the evaluation of the siren alerting system for the Three Mile Island Nuclear Power Station (TMI). The procedure that was used consists of a detailed analysis of siren alerting capability at each of 50 randomly chosen listener locations, under four different "sample scenario" conditions. The random selection process for listener sites is described in Appendix $F$ and the four test cases (sample scenarios) are included in Appendix G. The analysis is based on existing and proposed siren locations as of 30 June 1981. Maps that shown the siren locations are provided in Appendix $\mathrm{H}$.

The results of the evaluation for TMI are summarized in Table 3.1 and indicate that the chance of alert is estimated to vary between $49 \%$ and $90 \%$ depending on the sample scenario under consideration. The remainder of this report describes the procedure used to arrive at this conclusion. Input and output data for the analysis are included in Appendix I.

\subsection{Estimating Siren Sound Levels Out of Doors at Listener Sites}

The first step in the procedure is to determine the siren in the vicinity of each selected listener site that is expected to produce the highest sound level at that site for each sample scenario. This choice is not always obvious, because the sound level caused by a particular siren at a given listener site depends not only on the sound output of the siren and its distance from the listener, but also on shielding and atmospheric effects (particularly wind direction). Therefore, it is generally necessary to evaluate several sirens in the vicinity of each listener site in order to determine the dominant one. As a general rule, the closest, highest-rated, nonshielded sirens are selected for evaluation at each site. Furthermore, sirens are 
TABLE 3.1. SUMMARY OF TMI SIREN SYSTEM EVALUATION RESULTS.

\begin{tabular}{|c|c|c|c|c|}
\hline \multirow{2}{*}{\multicolumn{2}{|c|}{ Scenario }} & \multicolumn{3}{|c|}{ Chance of Alert } \\
\hline & & \multirow{2}{*}{$\begin{array}{l}\text { Urban } \\
(\%)\end{array}$} & \multirow{2}{*}{$\underset{(\%)}{\text { Rural }}$} & \multirow{2}{*}{$\begin{array}{c}\text { Population- } \\
\text { Weighted Average } \\
(\%)\end{array}$} \\
\hline No. & Description & & & \\
\hline 1 & $\begin{array}{l}\text { Warm Summer Weekday After- } \\
\text { noon (clear to partly cloudy) }\end{array}$ & 96 & 88 & 90 \\
\hline 2 & $\begin{array}{l}\text { Summer Weekday Night } \\
\text { (clear to partly cloudy) }\end{array}$ & 82 & 66 & 70 \\
\hline 3 & $\begin{array}{l}\text { Winter Weekday Evening } \\
\text { (cold and overcast) }\end{array}$ & 89 & 76 & 80 \\
\hline 4 & $\begin{array}{l}\text { Winter Night } \\
\text { (during snowfall) }\end{array}$ & 66 & 42 & 49 \\
\hline
\end{tabular}

*Based on a total urban population of 46,573 and a total rural population of 119,722 . 
chosen such that they are distributed north, south, east, and west of the site (or in any other four mutually perpendicular directions) where possible to account for different wind directions. For the TMI analysis, four or six sirens were evaluated at 46 of the 50 listener sites. Only two or three sirens were considered at the remaining four sites. These sites were either located at the fringes of the EPZ such that sirens could not be chosen in all directions, or they were located so close to one or two sirens that the selection of additional sirens was obviously not warranted.

The next step in the procedure is to establish the outdoor sound level produced by the selected sirens at each listener location. This is accomplished by applying adjustments to the rated sound level of the siren as follows:

$$
L(l \text { istener })=L(\text { siren })-A_{d}-A_{s}-A_{a i r}-A_{a t m} \text { ' }
$$

where $L(1$ istener) is the outdoor siren sound pressure level at the listener site $(d B), L(s i r e n)$ is rated sound pressure level of the siren at $100 \mathrm{ft}(\mathrm{dB}), \mathrm{A}_{\mathrm{d}}$ is the distance attenuation $(\mathrm{dB}), \mathrm{A}_{\mathrm{S}}$ is shielding attenuation (dB), Aair is the air absorption (dB), and $A_{a t m}$ is the atmospheric attenuation caused by wind and temperature gradients ( $d B$ ).

The rated sound pressure levels for the TMI sirens were estimated based on anechoic chamber performance data, obtained with the cooperation of the Metropolitan Edison Company. These data indicate sound pressure levels of $142.9 \mathrm{dBC}$ and $145 \mathrm{dBC}$ for stationary and rotating sirens respectively, measured at a distance of 2 meters. These levels were reduced by $23.7 \mathrm{~dB}$ to extrapolate to the level at a distance of 100 feet (see distance adjustment discussion below) and then increased by $3 \mathrm{~dB}$ to account for the presence of a ground plane for sirens in the 
field. The resulting rated sound pressure levels at $100 \mathrm{ft}$ are therefore $122 \mathrm{~dB}$ for TMI stationary sirens and $124 \mathrm{~dB}$ for TMI rotating sirens.

The first two adjustments (for distance and shielding) are the same for all four test cases and are based on information obtained from USGS maps. Distance attenuation beyond $100 \mathrm{ft}$ is calculated by assuming sound propagation from an acoustic point source with a reduction of $6 \mathrm{~dB}$ per distance doubled. It is calculated as follows:

$$
A_{d}=20 \log _{10}\left(\frac{d}{100}\right),
$$

where $d$ is the siren-to-listener distance (ft).

Shielding attenuation $\left(A_{S}\right)$ is estimated using the following formula for the attenuation of a rigid straight barrier for sound incident from a point source [2]:

$$
A_{S}= \begin{cases}20 \log \frac{\sqrt{2 \pi N}}{\tanh \sqrt{2 \pi N}}+5 d B & \text { for } N>-0.2 \\ 0 \mathrm{~dB} & \text { for } N<-0.2\end{cases}
$$

$\mathrm{N}$ is the Fresnel number (dimensionless):

$$
N= \pm \frac{2}{\lambda}(A+B-d)
$$

Where $\lambda=$ wavelength of sound, ft (1.79 ft for $630-\mathrm{Hz}$ siren tone)

$\mathrm{d}=$ straight-line distance between source and receiver, ft

$\mathrm{A}+\mathrm{B}=$ shortest path length of wave travel over the barrier between source and receiver, ft

+ sign = receiver in the shadow zone (i.e., barrier obstructs line-of-sight) 
- sign = receiver in the bright zone (i.e., barrier doesn't obstruct line-of-sight)

When $\mathrm{N}$ is negative, the above equation for $\mathrm{A}_{\mathbf{s}}$ is evaluated by replacing $\mathrm{N}$ with $|\mathrm{N}|$, and by replacing tanh with tan.

Shielding attenuation is 1 imited to a maximum of $24 \mathrm{~dB}$ based upon a large body of experimental data. For the TMI analysis, sirens are assumed to be at a height of $52 \mathrm{ft}$ above terrain level, listener sites are assumed to be at a height of $5 \mathrm{ft}$ above terrain level, and barrier heights are obtained from ground contour information on USGS maps.

The adjustments for air absorption and atmospheric effects depend on the meteorological conditions for the particular scenario. The assumed conditions for the TMI site are provided in Table 3.2 for the four test cases, based on local weather information. * In terms of air absorption, these conditions indicate the following attenuation rates based upon temperature and relative humidity [3]:

$\begin{array}{cc}\text { Scenario } & \text { Aair (dB per } 1000 \mathrm{ft} \text { ) } \\ 1 & 0.88 \\ 2 & 0.79 \\ 3 & 0.55 \\ 4 & 0.64\end{array}$

The adjustment for atmospheric gradient effects ( $A_{a t m}$ ) is based on siren-to-listener azimuth with respect to wind direction

\footnotetext{
*Three Mile Island Nuclear Station Unit 2 Environmental Impact Report, Chapter 2.
} 
TABLE 3.2. METEOROLOGICAL CONDITIONS FOR THE FOUR SAMPLE

SCENARIOS USED TO EVALUATE THE TMI SIREN SYSTEM.

\begin{tabular}{|c|c|c|c|c|}
\hline $\begin{array}{c}\text { Scenario } \\
\text { No. }\end{array}$ & Wind Conditions* & $\begin{array}{c}\text { Temperature } \\
\text { Gradient }\end{array}$ & $\begin{array}{l}\text { Relative } \\
\text { Humidity } \\
(\%)\end{array}$ & $\begin{array}{l}\text { Temperature } \\
\left({ }^{\circ} \mathrm{F}\right)\end{array}$ \\
\hline 1 & $5 \mathrm{mph}$ from the east & $\begin{array}{l}-1.00 \mathrm{~F} / 100 \mathrm{ft} \\
\text { Class A }\end{array}$ & 65 & 85 \\
\hline 2 & $5 \mathrm{mph}$ from the northwest & $\begin{array}{l}+0.5^{\circ} \mathrm{F} / 100 \mathrm{ft} \\
\text { Class } \mathrm{E}\end{array}$ & 80 & 65 \\
\hline 3 & $3 \mathrm{mph}$ from the southeast & $\begin{array}{l}-0.5^{\circ} \mathrm{F} / 100 \mathrm{ft} \\
\mathrm{Class} \mathrm{D}\end{array}$ & 70 & 40 \\
\hline 4 & $15 \mathrm{mph}$ from the west & $\begin{array}{l}-0.5^{\circ} \mathrm{F} / 100 \mathrm{ft} \\
\text { Class D }\end{array}$ & 90 & 25 \\
\hline
\end{tabular}

*At $100 \mathrm{ft}$ above ground level. 
and on wind and temperature gradient characteristics. Table 3.3 summarizes the calculation procedure for determining $A_{a t m}$ for each scenario at the TMI site. A more detailed description of the estimation procedure for $A_{a t m}$ can be found in Appendix $D$.

Application of the above calculations yields the estimated outdoor sound pressure level for various sirens at each sample listener site, for each of the four scenarios. For the balance of the analysis, only the highest siren level at each listener site is generally used. An exception to this rule is made at listener sites where the sound level of a stationary siren is estimated to be between 0 and $6 \mathrm{~dB}$ lower than the sound level of a rotating-type siren, which had been determined to be the loudest siren. In such cases, the stationary siren was selected for further analysis. The reason for this exception is that the maximum sound level produced by a rotating siren is not continuous, and thus the total acoustic energy at the listener (as measured by the single event noise exposure level, or SEL) is approximately $6 \mathrm{~dB}$ less than for a stationary (i.e., continuous) siren with the same maximum sound level.

\subsection{Estinating Indoor Sound Levels of Sirens}

The result of the above calculations is a single outdoor siren sound pressure level at each of the 50 sample listener locations for each of the four test cases. Corresponding indoor levels are then obtained by subtracting typical values for residential building sound attenuation. For test cases 1 and 2 (sumer), residential windows were assumed to be partly open; for test cases 3 and 4 (winter) residential windows and storm windows were assumed to be closed. For the frequency region within the $500 \mathrm{~Hz}$ octave band, the sound attenuation into buildings is estimated to be $16 \mathrm{~dB}$ for test cases 1 and 2 and $31 \mathrm{~dB}$ for test cases 3 and 4 [4]. For commercial buildings, the outdoor-to-indoor 


\section{TABLE 3.3. CALCULATION OF ATHOSPHERIC ATTENUATION, Aatm' CAUSED BY WIND AND TEMPERATURE GRADIENTS (SEE APPENDIX D FOR DETAILS).}

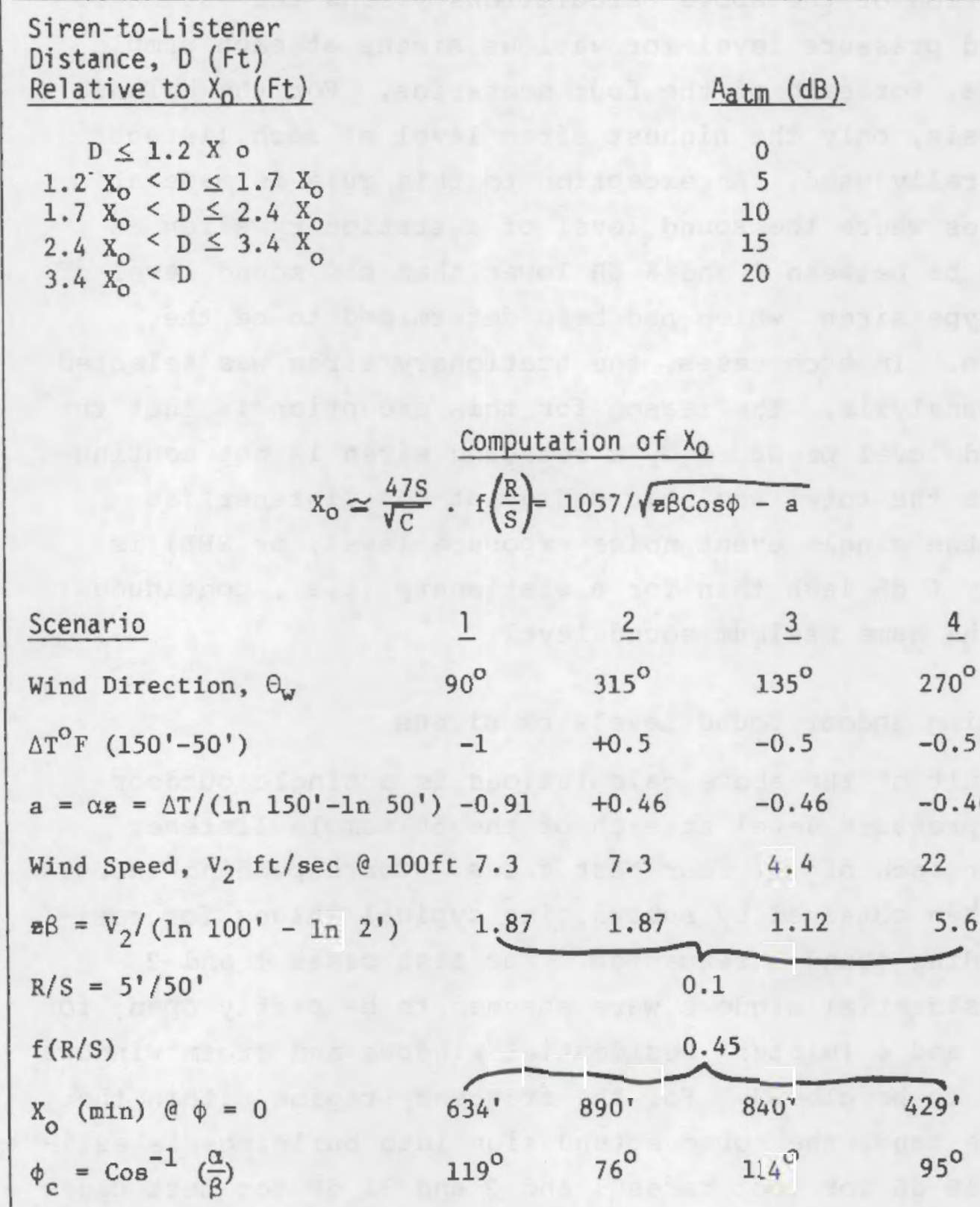

10

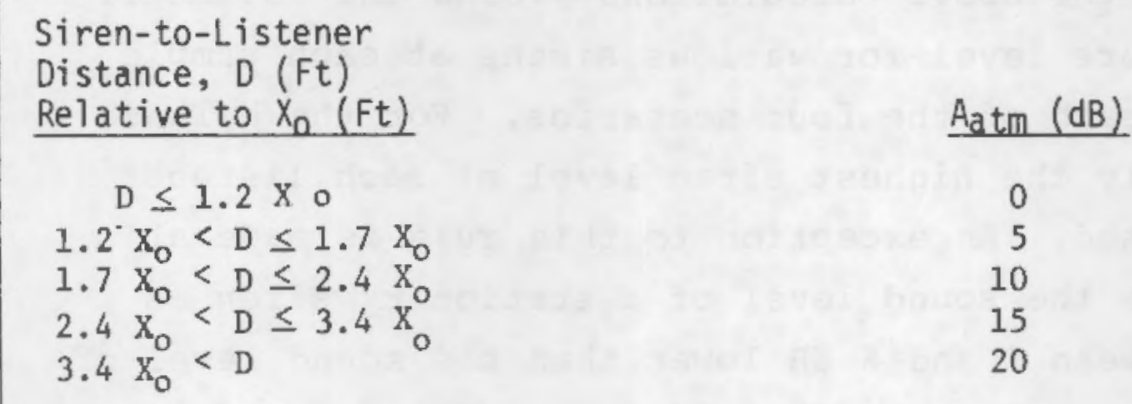

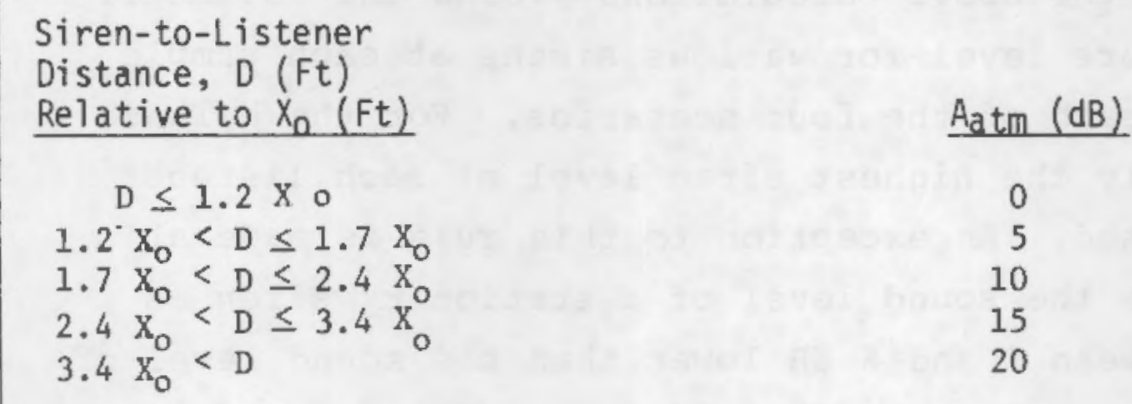

$$
x_{0} \simeq \frac{47 S}{\sqrt{C}} \cdot f\left(\frac{R}{S}\right)=1057 / \sqrt{x \beta \operatorname{Cos} \phi-a}
$$

Scenario

Wind Direction, $\theta_{w}$

$\Delta \mathrm{T}^{\circ} \mathrm{F}\left(150^{\prime}-50^{\prime}\right)$

$\mathrm{a}=\alpha_{\varepsilon}=\Delta \mathrm{T} /\left(\ln 150^{\prime}-\ln 50^{\prime}\right)-0.91$

Wind Speed, $v_{2} \mathrm{ft} / \mathrm{sec}$ e $100 \mathrm{ft} 7.3$

$\varepsilon \beta=v_{2} /\left(\ln 100^{\prime}-\ln 2^{\prime}\right)$

$R / S=5^{\prime} / 50^{\prime}$

1.87

1.87

7.3

$315^{\circ}$

$+0.5$

$+0.46$

$-0.46$

3

$\underline{4}$

$f(R / S)$

$x_{0}(m \in n) @ \phi=0$

$\phi_{c}=\cos ^{-1}\left(\frac{\alpha}{\beta}\right)$ 
noise reduction is estimated to be $31 \mathrm{~dB}$, assuming closed and sealed windows for all four scenarios.

\subsection{Assumptions about Chance of Alert}

The outdoor and indoor siren levels calculated by the above procedure provide some of the information required for the analysis of the chance of alert. In addition, it is necessary to know the level of interfering background noise at the listener locations.

Figure 3-1 is a flow chart of the analysis computations. The analysis is divided into components (rows) that correspond to the possible activities of people for the various scenarios. The major components relate to people (1) at home (outside or inside), (2) at work, or (3) in motor vehicles. The chance of alert is estimated for each activity component and is then multiplied by the fraction of people likely to be engaged in that activity (activity fraction). The results are summed to obtain the overall chance of alert for each listener location and for each test case. Overall chances of alert for the various scenario (test case) conditions are then obtained by averaging the chances for all rural and/or urban sample listener sites. Note that all estimates assume siren signal duration of 4 minutes: an average of the " 3 to 5 minutes" called for in Appendix 3 of NUREG-0654. The effects of different siren signal durations are discussed in Appendix E.

Siren detectability is a function of the siren signal level and of the background noise level in a "critical frequency band" centered at the signal frequency. For this analysis, outdoor and indoor detectability is estimated based on the signal-to-noise 


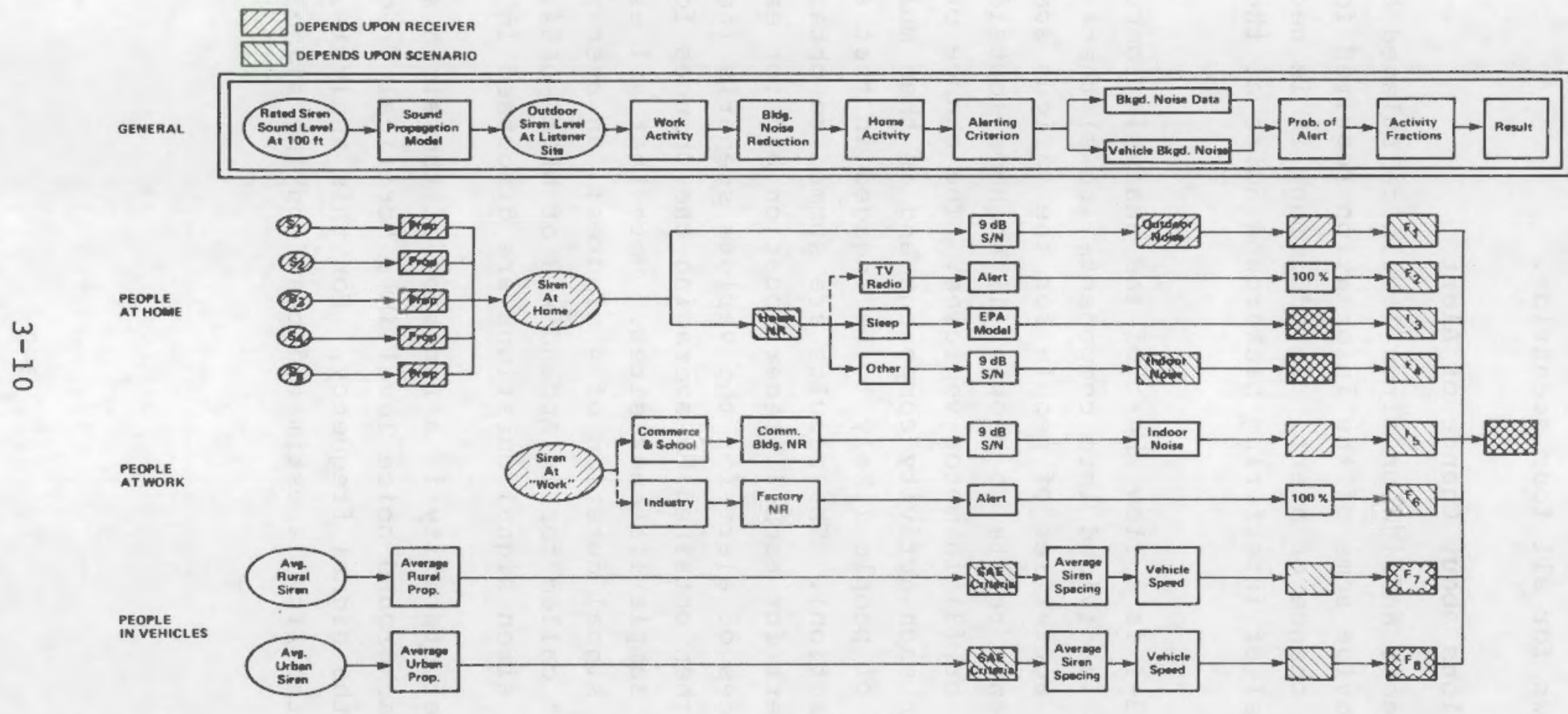

FIG. 3-1. FLOW OF COMPUTATIONS. 
$(\mathrm{S} / \mathrm{N})$ difference in the $630-\mathrm{Hz} 1 / 3$-octave frequency band. The chosen criterion for alerting is that the given signa: level must be $9 \mathrm{~dB}$ or more above the minimum background noise level at any time during a 4-minute period for people who are not sleeping (i.e., a $\mathrm{S} / \mathrm{N}$ difference of $9 \mathrm{~dB}$ ). The chance of alert while sleeping is based on the indoor siren single Event Level (SEL) - a measure of total acoustic energy - and the sleep awakening model developed by the U.S. Environmental Protection Agency [5]. The graph used for estimating the chance of alert during sleep is shown in Fig. 3-2; for the Three Mile Island analysis, the curve for the chance of awakening one out of two sleepers was used.

\subsection{Alerting People Out of Doors}

For the analysis of the ability of sirens to alert people out of doors, background noise levels are based on noise measurements conducted by $\mathrm{BBN}$ in the vicinity of the Trojan Nuclear Plant in Oregon, near the Susquehanna steam Electric station in Pennsylvania, and upon the body of data in BBN files. The data typically consisted of statistical summaries of background noise at various types of locations. The summaries provide the $\mathrm{L}_{90}$ (sound level exceeded 908 of the time) for 1-minute samples of data in the 1/3octave frequency band centered at $630 \mathrm{~Hz}{ }^{*}$. The data were used to calculate the chance of detection for various siren levels and signal durations based on the background noise levels and their variability. Generalized types of background noise environments were then established so that all sample listener sites would be included with one of these general categories. In each category, the siren sound level necessary to alert is 9 dB greater than the minimum background noise level that could exist in any 4-minute period ( 1 minute for rotating sirens), adjusted for the probabil-

*The $L_{90}$ was used as a conservative estimate of the minimum sound 


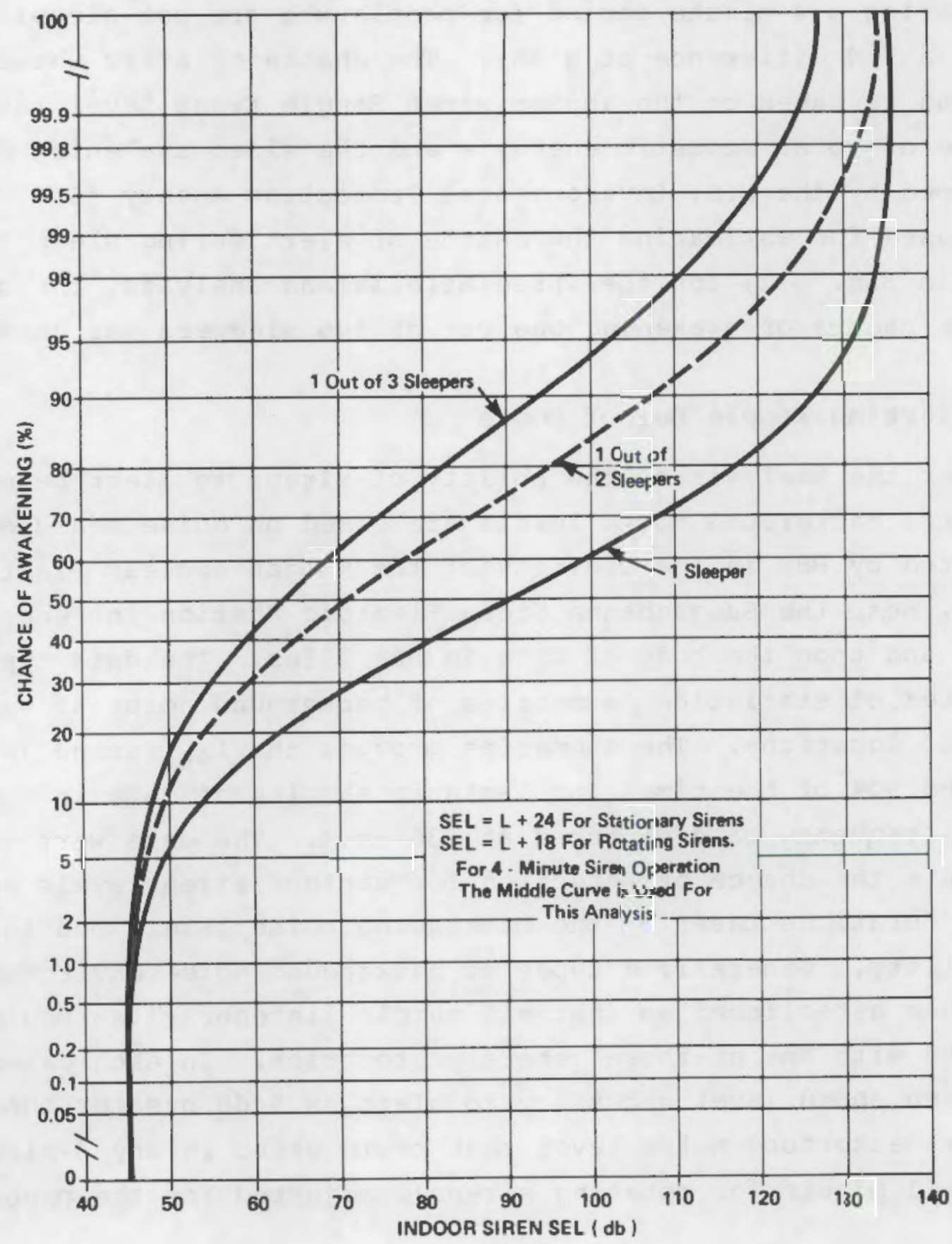

FIG. 3-2. CHANCE OF ALERT FOR ANAKENING PEOPLE ASLEEP. 
ity distribution of such minima. This is handled by assigning a "median alerting level" for each background noise category and adjusting these levels in accordance with probability distributions generalized from the data.

The median alerting levels for each background noise category are 1 isted in Table 3.4. These are keyed to corresponding distributions shown in Fig. 3-3. For example, assume that a rotating siren produces $53 \mathrm{~dB}$ at a given urban location during the daytime adjacent to a major traffic artery. Table 3.4 indicates that the median alerting level at such locations is $54 \mathrm{~dB}$ and that the applicable distribution on Fig. $3-3$ is No. 5. The siren level minus the median alerting level is $53-54=-1 \mathrm{~dB}$. From distribution No. 5 on Fig. 3-3, we read 248 probability of alerting at $-1 \mathrm{~dB}$. Note that probabilities of greater than 998 on Fig. 3-3 are treated as 1008 , and those less than 18 are treated as $0 \%$.

Outdoor background noise in urban areas and along rural roadways is caused predominantly by motor vehicle traffic. It is generally insensitive to seasons of the year, but varies markedly with time of day. Minor traffic variations (i.e., less than a factor of 2 in traffic volume) have 1 ittle effect on the background noise.

In rural areas remote from roadways, outdoor background noise can be seasonal (birds, insects, etc.) and can vary with the weather (wind, rain, waterflow, surf). Few people live or work in such "natural" acoustic environments. As shown in Table 3.4, rural, non-roadway background noise is selected to be dependent on windspeed.

Note that results are given separately for stationary sirens and rotating sirens. This is because rotating sirens would actually produce their estimated sound level during about one quarter of the presumed 4-minute operating time at any particular listener 


\section{TABLE 3.4. SIREN ALERTING ABILITY FOR GENERALIZED CATEGORIES OF OUTDOOR ENVIRONMENTS.}

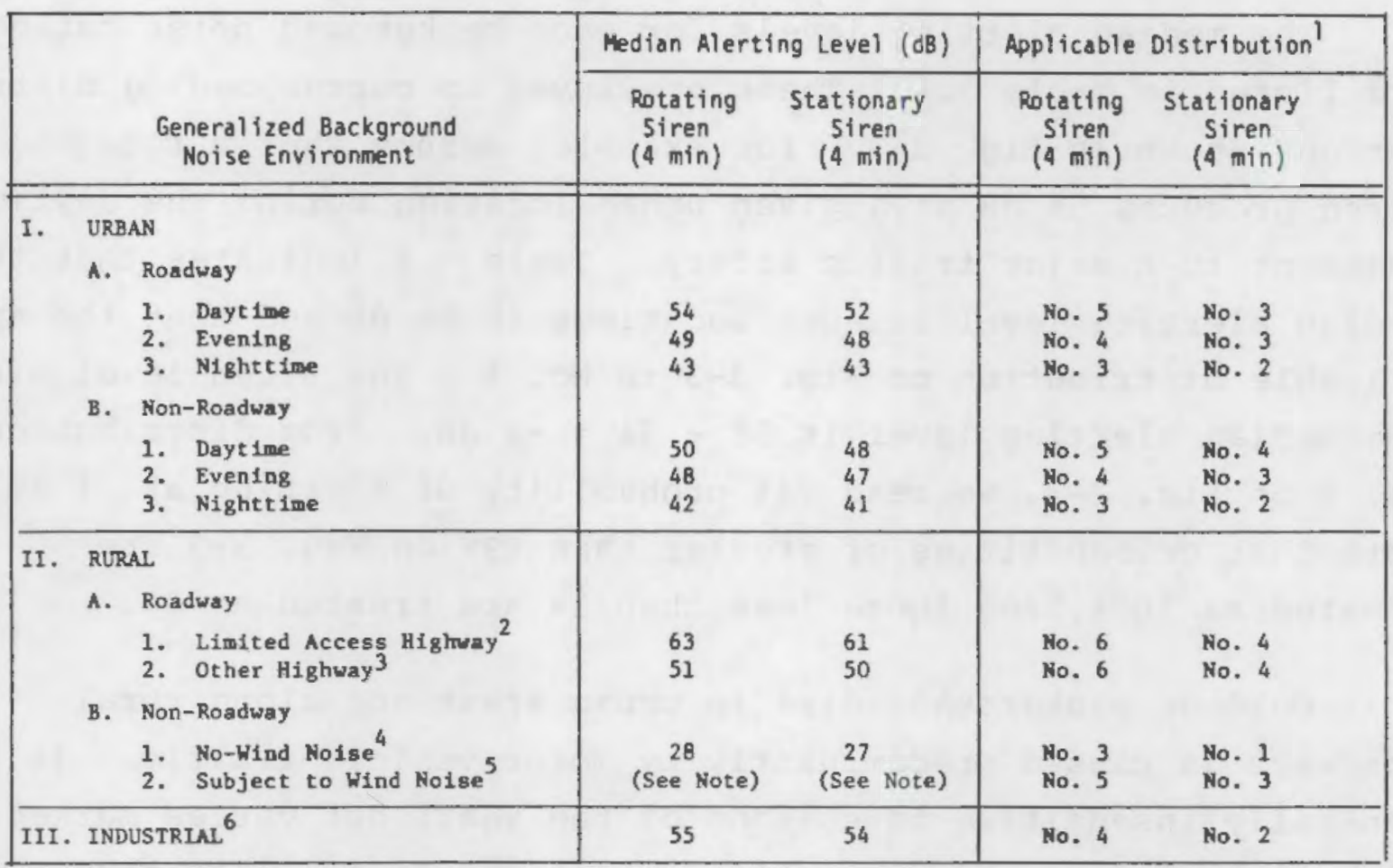

NOTES:

1. See Fig. 3-3.

2. Alerting levels apply for sites within $500 \mathrm{ft}$, with view angle $(\theta)$ of $180^{\circ}$ to highway; beyond $500 \mathrm{ft}$, levels should be reduced by $10 \log _{10}(\mathrm{D} / 500)$, where $\mathrm{D}=\mathrm{dist}$. from highway in $\mathrm{ft}$; for view angles less than $180^{\circ}$, levels should be further reduced by $10 \log 10(180 / \theta)$.

3. Alerting levels apply for sites within $1600 \mathrm{ft}$, with view angle $(\theta)$ of $180^{\circ}$ to highway; beyond 1600 $\mathrm{ft}$, levels should be reduced by $10 \log _{10}(\mathrm{D} / 1600)$, where $\mathrm{D}=\mathrm{d}$ ist. from highway in $\mathrm{ft}$; for view angles less than $180^{\circ}$, levels should be further reduced by $10 \log _{10}(180 / \theta)$.

4. Hind speed < 1 mph.

5. Median Alcrting Level (with wind) = Median Alerting Level (no vind) $+15 \log _{10}(\mathrm{~s})+1 \mathrm{~dB}$, where $S$ - average wind speed in mph.

6. Alerting levels apply at $1000 \mathrm{ft}$ from source; for other distances adjust levels by $20 \log _{10}(1000 /$ distance). 


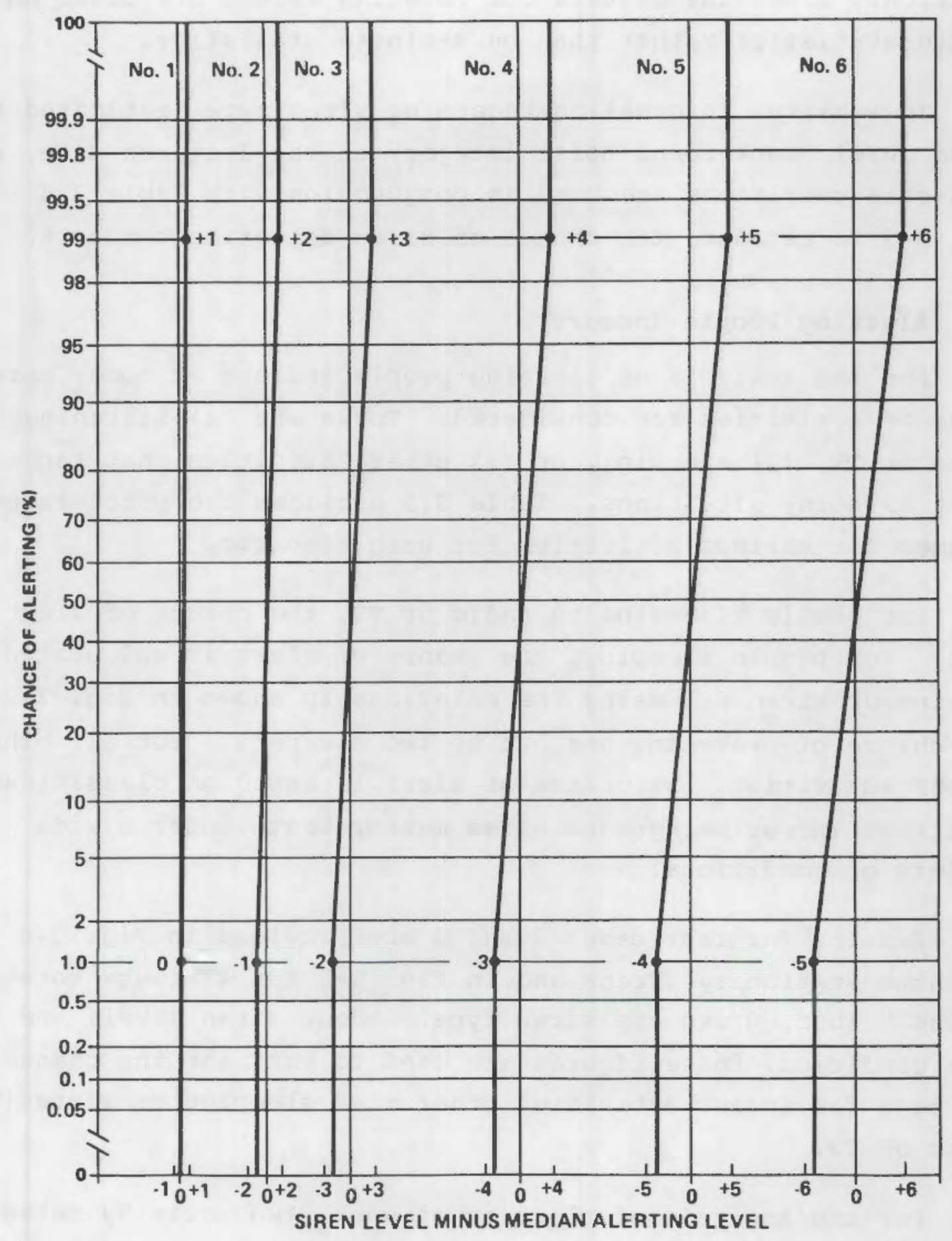

FIG. 3-3. DISTRIBUTIONS FOR DETECTION BY PEOPLE OUT OF DOORS. 
location. Thus, the results for rotating sirens are based on 1minute statistics rather than on 4 -minute statistics.

In summary, information regarding siren type, estimated siren sound level, background noise category at the listener site, and test-case conditions are used in conjunction with Table 3.4 and Fig. 3-3 to estimate the chance of siren detection outdoors.

\subsection{Alerting People Indoors}

For the analysis of alerting people indoors at home, three types of activities are considered. These are (1) listening to radio or IV, (2) sleeping, or (3) other activities that range from quiet to noisy situations. Table 3.5 provides the percentages assumed for various activities for each scenario.

For people listening to radio or TV, the chance of alert is 1008. For people sleeping, the chance of alert is calculated from the indoor siren SEL using the relationship shown in Fig. 3-2 for the chance of awakening one out of two sleepers. For all other indoor activities, the chance of alert is based on classifications of actual indoor background noise measurements under a wide variety of conditions.

Results for test cases 1 and 3 are provided in Fig. 3-4 for 4-minute stationary sirens and in Fig. 3-5 for 4-minute rotating sirens. Thus, given the siren type, indoor siren level, and test case condition, these figures are used to estimate the chance of alerting for indoor activities other than sleeping or listening to radio or $\mathrm{TV}$.

For the analysis of alerting at work, two activity categories are considered: (1) commercial/institutional, and (2) industrial environments. For the TMI analysis, it was assumed that 758 of the working population are in commercial establishments while the 

TABLE 3.5. ASSUMED ACTIVITIES AND BACKGROUND NOISE ENVIRONMENTS
FOR PEOPLE INDOORS.

\begin{tabular}{|c|c|c|c|c|c|c|c|c|}
\hline \multirow{3}{*}{\multicolumn{2}{|c|}{ Scenario }} & \multicolumn{7}{|c|}{ Percentages of People Engaged in Various Activities Indoors (x) } \\
\hline & & \multirow[b]{2}{*}{$\begin{array}{l}\text { At Place } \\
\text { of Business }\end{array}$} & \multirow[b]{2}{*}{$\begin{array}{l}\text { Listening to } \\
\text { TV/Radio }\end{array}$} & \multirow[b]{2}{*}{ Sleeping } & \multicolumn{4}{|c|}{ Indoor Noise Environment } \\
\hline & & & & & $\begin{array}{l}\text { Obviously } \\
\text { Noisy'1 }\end{array}$ & $\begin{array}{c}\text { Busy and } \\
\text { Active }^{2}\end{array}$ & Isolated ${ }^{3}$ & $\begin{array}{c}\text { poviously } \\
\text { Quiet }\end{array}$ \\
\hline 1. & $\begin{array}{l}\text { Warm Summer Weekday } \\
\text { Afternoon (clear to } \\
\text { partly cloudy) }\end{array}$ & 41 & 27 & 5 & -- & 8 & 5 & 14 \\
\hline 2. & $\begin{array}{l}\text { Sumuer Weekday N1ght } \\
\text { (clear to partly } \\
\text { cloudy) }\end{array}$ & 4 & -- & 96 & -- & -- & -- & -- \\
\hline 3. & $\begin{array}{l}\text { Winter Weekday During } \\
\text { Evening Conmuting } \\
\text { Hours (cold and } \\
\text { overcast) }\end{array}$ & -- & 20 & $\sim$ & 5 & 50 & 20 & 5 \\
\hline 4. & $\begin{array}{l}\text { Hinter N1ght During } \\
\text { Snowfall }\end{array}$ & 5 & -- & 95 & -- & - & -- & -- \\
\hline
\end{tabular}

NOTES :

1. Vacuum cleaning, dishwasher, shower, vent fan on, etc.

2. Dinner conversation, kitchen work, playing music, children ot play, etc.

3. Noise-producing activity in adjacent room, ooft background music, etc.

4. Reading, atudy, eating alone. 
remaining 258 are in industrial locations. For commercial locations, the chance of alert is based on the statistics of background noise measured in a typical office environment, using Fig. 3-6. For industrial locations, it has been assumed that 1008 of the people are likely to be alerted by some means of communication other than sirens.

\subsection{Alerting People in Motor Vehicles}

The analysis for the alerting of motorists is based on the assumption of an average siren signal strength and spacing throughout the EPZ. The probability that a motorist will pass within the alert range of a siren during its 4-minute operation is estimated as follows:

$$
C=\frac{2 R+d}{L} \times 100 \text { (not to exceed } 1008 \text { ) }
$$

where $C$ is the chance of alert $(q), R$ is the maximum alert distance ( $f t), d$ is distance traveled in 4 minutes ( $f t$ ), and $L$ is the average siren spacing $(\mathrm{ft})$. Separate analyses were carried out for urban and rural areas of the TMI EPZ.

The average urban siren produces a sound level of $125 \mathrm{~dB}$ at $100 \mathrm{ft}$, and the average rural siren produces a sound level of 123 $\mathrm{dB}$ at $100 \mathrm{ft}$. Alerting ability was evaluated by using the results of a study for the Society of Automotive Engineers (SAE) [6]. Siren alerting levels for speeds of $55 \mathrm{mph}$ and $30 \mathrm{mph}$ with windows shut or open were first determined from the SAE study results. The average siren source levels for rural and urban areas were 


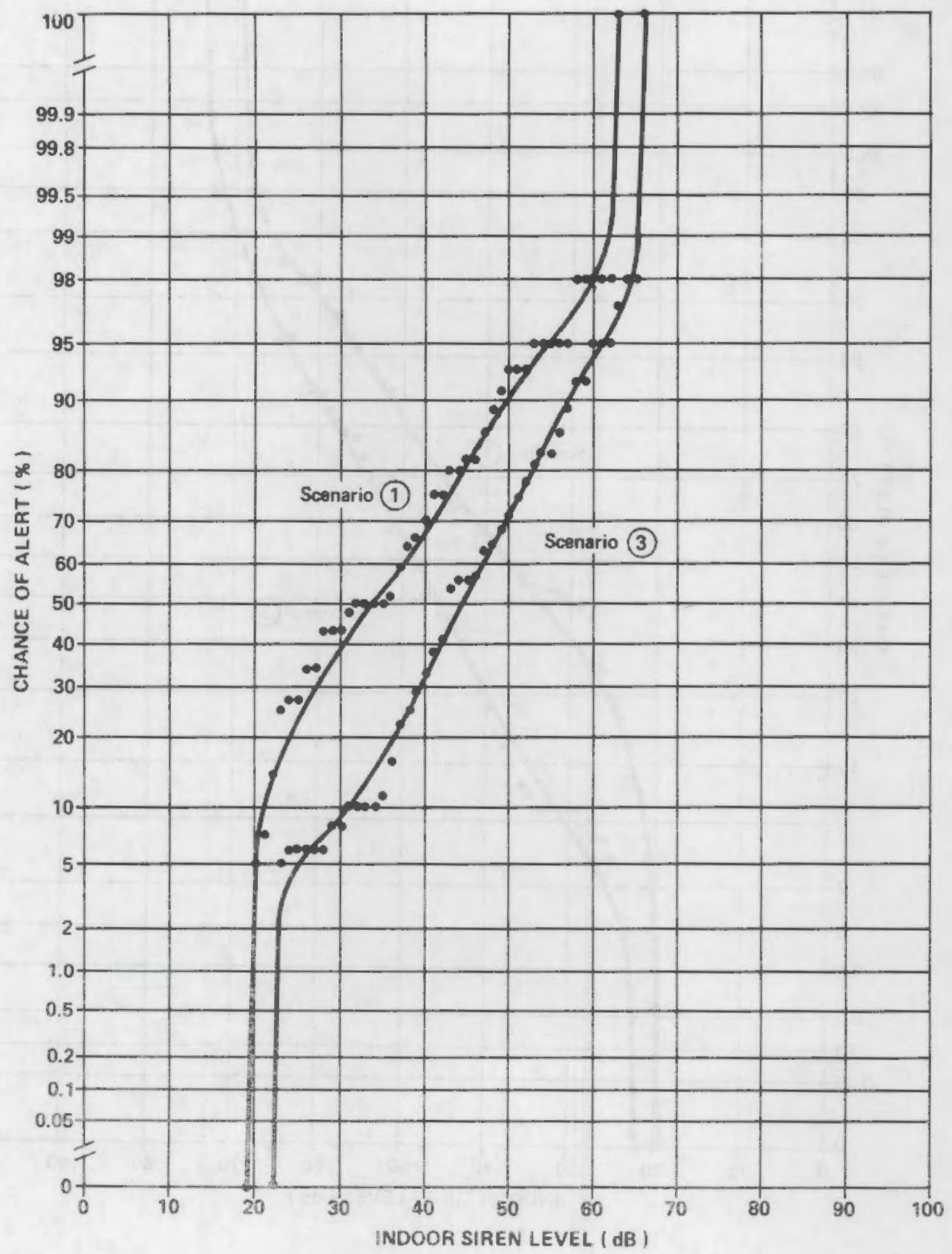

PIG. 3-4. CHANCE OF ALERT FOR PEOPLE INDOORS AT ROHE (4-HINUTE STATIONARY SIREN). 


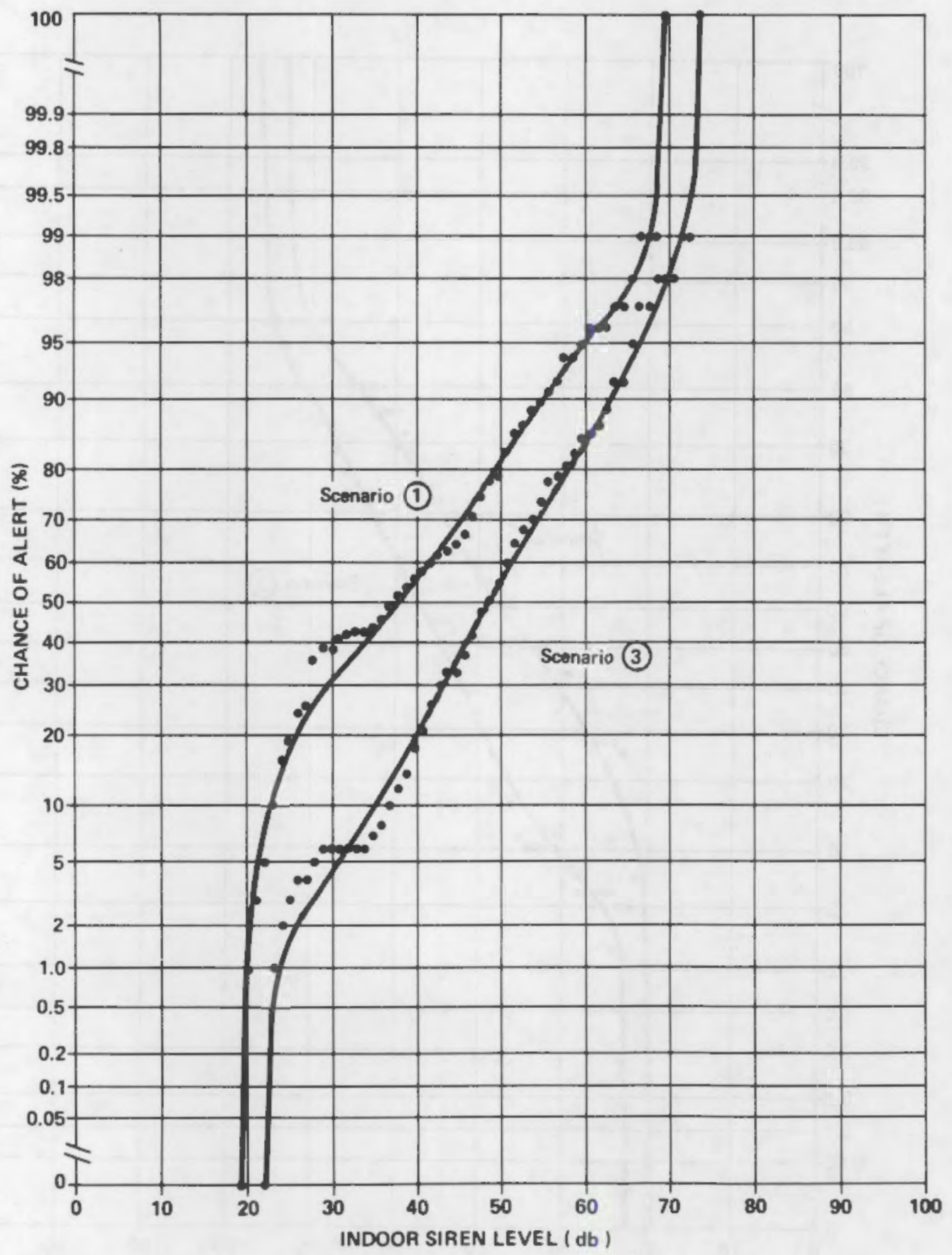

PIG. 3-5. CHANCE OF ALERT FOR PEOPLE INDOORS AT HOME (4-MINUTE ROTATING SIREN). 


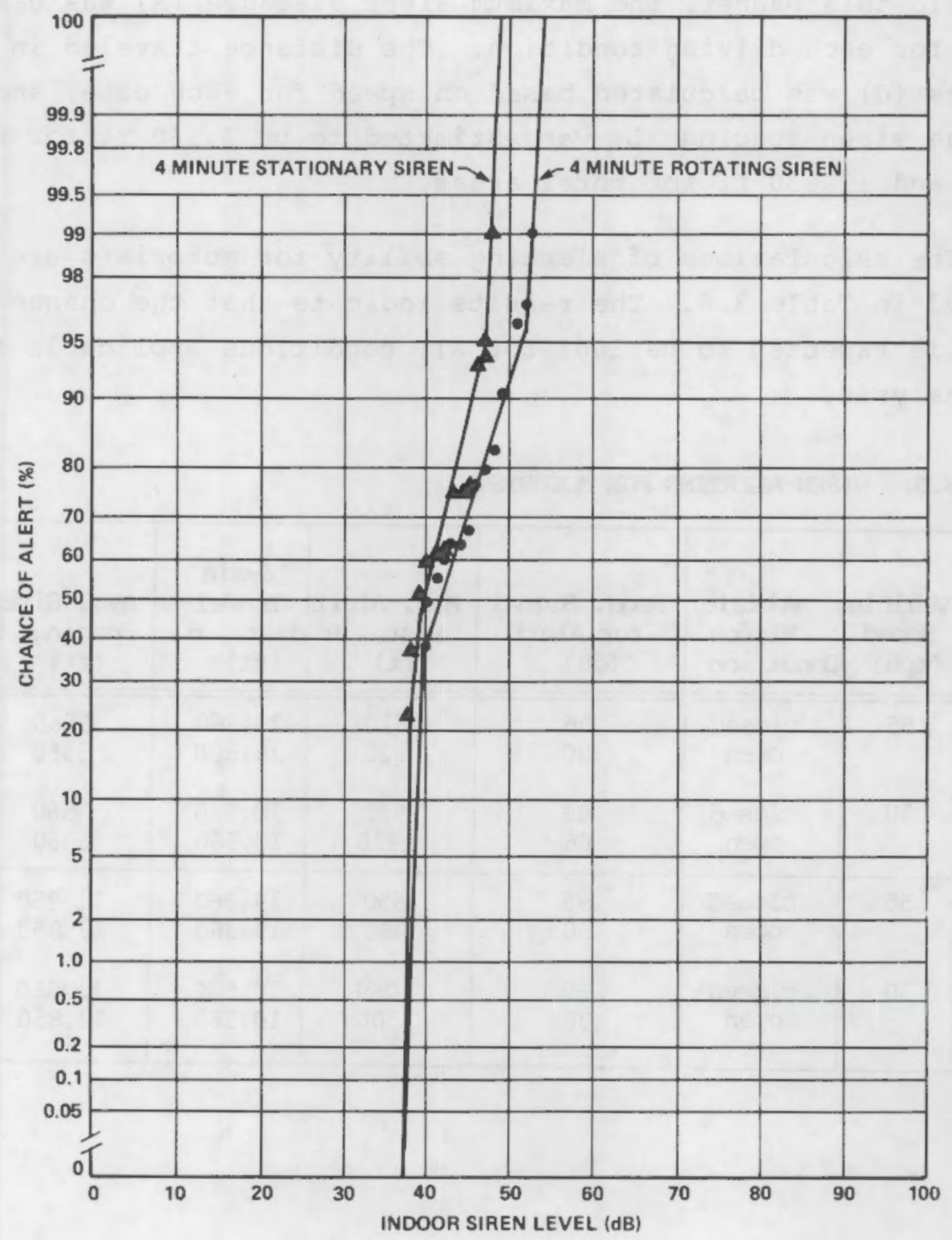

FIG. 3-6. CHANCE OF ALERT FOR PEOPLE INDOORS AT WORK IN COMMERCIAL/INSTITUTIONAL ESTABLISHMENTS. 
then reduced to alerting levels in accordance with the propagation models from current NRC guidelines (i.e., $10 \mathrm{~dB} /$ double distance) [7]. In this manner, the maximum alert distance ( $R$ ) was calculated for each driving condition. The distance traveled in 4 minutes (d) was calculated based on speed for each case, and the average siren spacing (L) was estimated to be 5,560 ft for urban areas and $11,850 \mathrm{ft}$ for rural areas.

The calculations of alerting ability for motorists are summarized in Table 3.6. The results indicate that the chance of alert is expected to be $100 \%$ for all conditions applicable to the TMI analysis.

TABLE 3.6. SIREN ALERTING FOR MOTORISTS.

\begin{tabular}{|c|c|c|c|c|c|c|c|}
\hline Area & $\begin{array}{l}\text { Vehicle } \\
\text { Speed } \\
\text { (mph) }\end{array}$ & $\begin{array}{r}\text { Vehicle } \\
\text { Window } \\
\text { Condition }\end{array}$ & $\begin{array}{l}\text { Reqd. Signal } \\
\text { for Alert } \\
\text { (dB) }\end{array}$ & $\begin{array}{l}\text { Max. Alert } \\
\text { Dist., R } \\
\text { (ft) }\end{array}$ & $\begin{array}{l}\text { 4-min } \\
\text { Travel } \\
\text { dist. , d } \\
\text { (ft) }\end{array}$ & $\begin{array}{l}\text { Avg. Siren } \\
\text { Spacing, L } \\
\text { (ft) }\end{array}$ & $\begin{array}{l}\text { Chance } \\
\text { of Alert } \\
(8)\end{array}$ \\
\hline \multirow{2}{*}{ URBAN } & 55 & $\begin{array}{l}\text { closed } \\
\text { open }\end{array}$ & $\begin{array}{l}96 \\
90\end{array}$ & $\begin{array}{l}610 \\
920\end{array}$ & $\begin{array}{l}19,360 \\
19,360\end{array}$ & $\begin{array}{l}5560 \\
5560\end{array}$ & $\begin{array}{l}100 \\
100\end{array}$ \\
\hline & 30 & $\begin{array}{l}\text { closed } \\
\text { open }\end{array}$ & $\begin{array}{l}89 \\
86\end{array}$ & $\begin{array}{r}980 \\
1210\end{array}$ & $\begin{array}{l}10,560 \\
10,560\end{array}$ & $\begin{array}{l}5560 \\
5560\end{array}$ & $\begin{array}{l}100 \\
100\end{array}$ \\
\hline \multirow{2}{*}{ RURAL } & 55 & $\begin{array}{l}\text { closed } \\
\text { open }\end{array}$ & $\begin{array}{l}96 \\
90\end{array}$ & $\begin{array}{l}650 \\
980\end{array}$ & $\begin{array}{l}19,360 \\
19,360\end{array}$ & $\begin{array}{l}11,850 \\
11,850\end{array}$ & $\begin{array}{l}100 \\
100\end{array}$ \\
\hline & 30 & $\begin{array}{l}\text { closed } \\
\text { open }\end{array}$ & $\begin{array}{l}89 \\
86\end{array}$ & $\begin{array}{l}1060 \\
1300\end{array}$ & $\begin{array}{l}10,560 \\
10,560\end{array}$ & $\begin{array}{l}11,850 \\
11,850\end{array}$ & $\begin{array}{l}100 \\
100\end{array}$ \\
\hline
\end{tabular}




\section{EVALUATION OF THE PROMPT ALERTING SYSTEH FOR THE INDIAN POINT NUCLEAR POAER STATION}

This section summarizes the evaluation of the siren alerting system for the Indian Point Nuclear Power Station. The procedure that was used consists of a detailed analysis of siren alerting capability at each of 50 randomly chosen listener locations, under four different "sample scenario" conditions. The random selection process for listener sites is described in Appendix $J$ and the four test cases (sample scenarios) are included in Appendix $K$. The analysis is based on existing and proposed siren locations as of 25 August 1981. Maps which show the siren locations are provided in Appendix L.

The results of the evaluation for Indian point are summarized in Table 4.1 and indicate that the chance of alert is estimated to vary between $57 \%$ and 958 depending on the sample scenario under consideration. The remainder of this report describes the procedure used to arrive at this conclusion. Input and output data for the analysis are included in Appendix $M$.

\subsection{Estimating Siren Sound Levels out of Doors at Listener Sites}

The first step in the procedure is to determine the siren in the vicinity of each selected listener site that is expected to produce the highest sound level at that site for each sample scenario. This choice is not always obvious, because the sound level caused by a particular siren at a given listener site depends not only on the sound output of the siren and its distance from the listener, but also on shielding and atmospheric effects (particularly wind direction). Therefore, it is generally necessary to evaluate several sirens in the vicinity of each listener site in order to determine the dominant one. As a general rule, the closest, highest-rated, nonshielded sirens are selected for evaluation at each site. Furthermore, sirens should be chosen 
TABLE 4.1. SUMMARY OF INDIAN POINT SIREN SYSTEM EVALUATION RESULTS.

\begin{tabular}{|c|c|c|c|c|}
\hline \multirow{2}{*}{\multicolumn{2}{|c|}{ Scenario }} & \multicolumn{3}{|c|}{ Chance of Alert } \\
\hline & & \multirow{2}{*}{$\begin{array}{l}\text { Urban } \\
(\%)\end{array}$} & \multirow{2}{*}{$\underset{(\%)}{\text { Rural }}$} & \multirow{2}{*}{$\begin{array}{c}\text { Population- } \\
\text { Weighted Average } \\
(\%)\end{array}$} \\
\hline No. & Description & & & \\
\hline 1 & $\begin{array}{l}\text { Warm Summer Weekday After- } \\
\text { noon (clear to partly cloudy) }\end{array}$ & 98 & 93 & 95 \\
\hline 2 & $\begin{array}{l}\text { Sumer Weekday N1ght } \\
\text { (clear to partly cloudy) }\end{array}$ & 80 & 70 & 74 \\
\hline 3 & $\begin{array}{l}\text { Wincer Weekday Evening } \\
\text { (cold and overcast) }\end{array}$ & 91 & 78 & 83 \\
\hline 4 & $\begin{array}{l}\text { Winter Night } \\
\text { (during snowfall) }\end{array}$ & 63 & 53 & 57 \\
\hline
\end{tabular}

* Based on a total urban population of 110,928 and a total rural population of 146,454 . 
such that they are distributed north, south, east, anc west of the site (or in any other four mutually perpendicular directions) where possible to account for different wind directions. For the Indian Point analysis, four or five sirens were evaluated at each of the 50 listener sites.

The next step in the procedure is to establish the outdoor sound level produced by the selected sirens at each listener location. This is accomplished by applying adjustments to the rated sound level of the siren as follows:

$$
L(\text { listener })=L(\text { siren })-A_{d}-A_{S}-A_{a i r}-A_{a t m} \text {, }
$$

where $\mathrm{L}(\mathrm{listener)}$ is the outdoor siren sound pressure level at the listener site $(A B), L(s i r e n)$ is the rated sound pressure level of the siren at $100 \mathrm{ft}(\mathrm{dB}), \mathrm{A}_{d}$ is the distance attenuation $(d B), A_{S}$ is the shielding attenuation $(d B), A_{a i r}$ is the air absorption $(A B)$, and $A a t m$ is the atmospheric attenuation caused by wind and temperature gradients $(\mathrm{dB})$.

The rated sound pressure level for all of the Indian Point sirens was taken to be $125 \mathrm{~dB}$ at a distance of $100 \mathrm{ft}$, based upon the siren manufacturer's rating; all sirens are rotating type units.

The first two adjustments (for distance and shielding) are the same for all four test cases and are based on information obtained from USGS maps. Distance attenuation beyond $100 \mathrm{ft}$ is calculated by assuming sound propagation from an acoustic point source with a reduction of $6 \mathrm{~dB}$ per distance doubled. It is calculated as follows:

$$
A_{d}=20 \log _{10}\left(\frac{d}{100}\right) \text {, }
$$

where $d$ is the siren-to-listener distance ( $f t$ ). 
Shielding attenuation $\left(A_{S}\right)$ is estimated using the following formula for the attenuation of a rigid straight barrier for sound incident from a point source [2]:

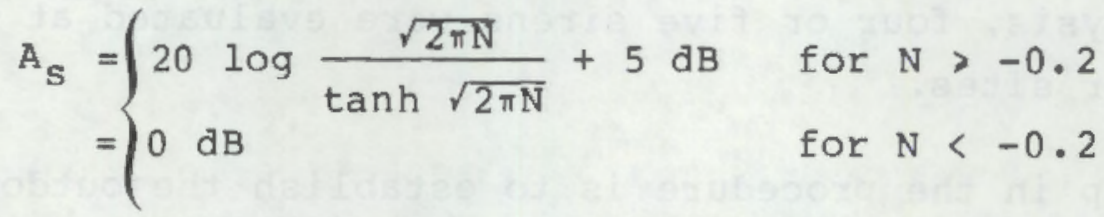

$\mathrm{N}$ is the Fresnel number (dimensionless):

$$
N=\frac{2}{\lambda}(A+B-d)
$$

Where $\lambda$ = wavelength of sound, ft (1.79 ft for $630-\mathrm{Hz}$ siren tone)

$\mathrm{d}=$ straight-line distance between source and receiver, $\mathrm{ft}$

$\mathrm{A}+\mathrm{B}=$ shortest path length of wave travel over the barrier between source and receiver, ft.

$+\operatorname{sign}=$ receiver in the shadow zone (i.e., barrier obstructs line-of-sight)

- sign = receiver in the bright zone (i.e., barrier doesn't obstruct line-of-sight)

When $\mathrm{N}$ is negative, the above equation for $\mathrm{A}_{\mathbf{S}}$ is evaluated by replacing $\mathrm{N}$ with $|\mathrm{N}|$, and by replacing tanh with $\tan$.

Shielding attenuation is limited to a maximum of $24 \mathrm{~dB}$ based upon a large body of experimental data. For the Indian point analysis, sirens are assumed to be at a height of $52 \mathrm{ft}$ above terrain level, listener sites are assumed to be at a height of 5 ft above terrain level, and barrier heights are obtained from ground contour information on USGS maps.

The adjustments for air absorption and atmospheric effects depend on the meteorological conditions for the particular scenario. The assumed conditions for the Indian point site are 
provided in Table 4.2 for the four test cases, based on local weather information.* In terms of air absorption, these conditions indicate the following attenuation rates based upon temperature and relative humidity [3].

$\begin{array}{cc}\text { Scenario } & \text { Aair }_{\text {a }}(\mathrm{dB} \text { per } 1000 \mathrm{ft} \text { ) } \\ 1 & 0.85 \\ 2 & 0.81 \\ 3 & 0.49 \\ 4 & 0.46\end{array}$

The adjustment for atmospheric gradient effects $\left(A_{a t m}\right)$ is based on siren-to-listener azimuth with respect to wind direction and on wind and temperature gradient characteristics. Table 4.3 summarizes the calculation procedure for determining $A_{a t m}$ for each scenario at the Indian point site. A more detailed description of the estimation procedure for $A_{a t m}$ can be found in Appendix D.

Application of the above calculations yields the estimated outdoor sound pressure level for various sirens at each sample listener site, for each of the four scenarios. For the balance of the analysis, only the highest siren level at each listener site is used.

\subsection{Estimating Indoor Sound Levels of Sirens}

The result of the above calculations is a single outdoor siren sound pressure level at each of the 50 sample listener locations for each of the four test cases. Corresponding indoor

* Final Facility Description and Safety Analysis Report for Indian Point No. 3 Nuclear Power Plant, Section 2.6 (1973). 
TABLE 4.2. METEOROLOGICAL CONDITIONS FOR THE FOUR SAMPLE SCENARIOS USED TO EVALUATE THE INDIAN POINT SIREN SYSTEM.

\begin{tabular}{|c|c|c|c|c|}
\hline $\begin{array}{c}\text { Scenario } \\
\text { No. }\end{array}$ & Wind Conditions* & $\begin{array}{c}\text { Temperature } \\
\text { Gradient }\end{array}$ & $\begin{array}{l}\text { Relative } \\
\text { Humidity } \\
(\%)\end{array}$ & $\begin{array}{c}\text { Temperature } \\
\left(\mathrm{O}^{\mathrm{F}}\right)\end{array}$ \\
\hline 1 & $\begin{array}{l}10 \text { mph from the SSE; from } \\
\text { the south in the river } \\
\text { valley }\end{array}$ & $\begin{array}{l}-1.00 \mathrm{~F} / 100 \mathrm{ft} \\
\text { Class A }\end{array}$ & 65 & 80 \\
\hline 2 & $\begin{array}{l}6 \text { mph from the NNE; from } \\
\text { the north in the river } \\
\text { valley }\end{array}$ & $\begin{array}{l}+0.5^{\circ} \mathrm{F} / 100 \mathrm{ft} \\
\mathrm{Class} \mathrm{E}\end{array}$ & 80 & 70 \\
\hline 3 & $10 \mathrm{mph}$ from the northwest & $\begin{array}{l}-0.5^{\circ} \mathrm{F} / 100 \mathrm{ft} \\
\text { C1ass D }\end{array}$ & 70 & 30 \\
\hline 4 & 15 mph from the southeast & $\begin{array}{l}-0.5^{\circ} \mathrm{F} / 100 \mathrm{ft} \\
\text { Class D }\end{array}$ & 90 & 30 \\
\hline
\end{tabular}

*At 100 ft above ground level. 
TABLE 4.3. CALCULATION OF ATMOSPHERIC ATTENUATION, Aatm * CAUSED BY WIND AND TEMPERATURE GRADIENTS (SEE APPENDIX D FOR DETAILS).

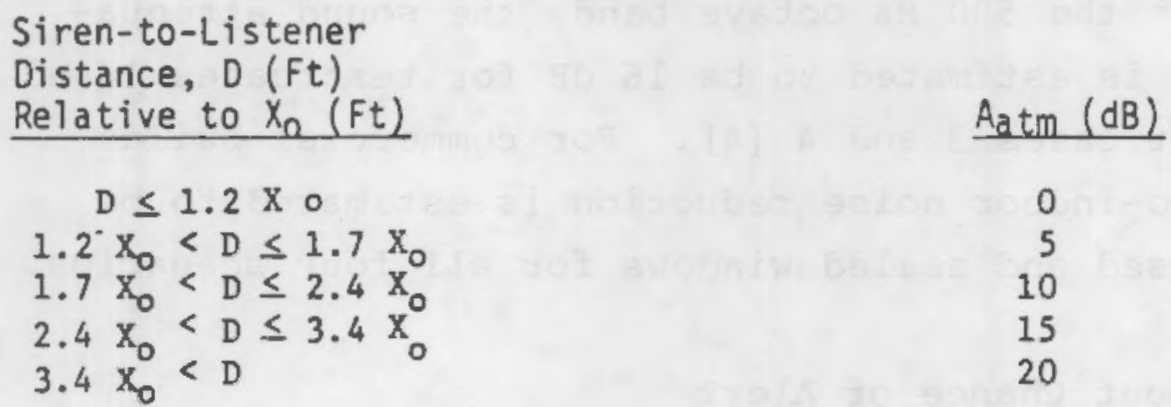

10

15

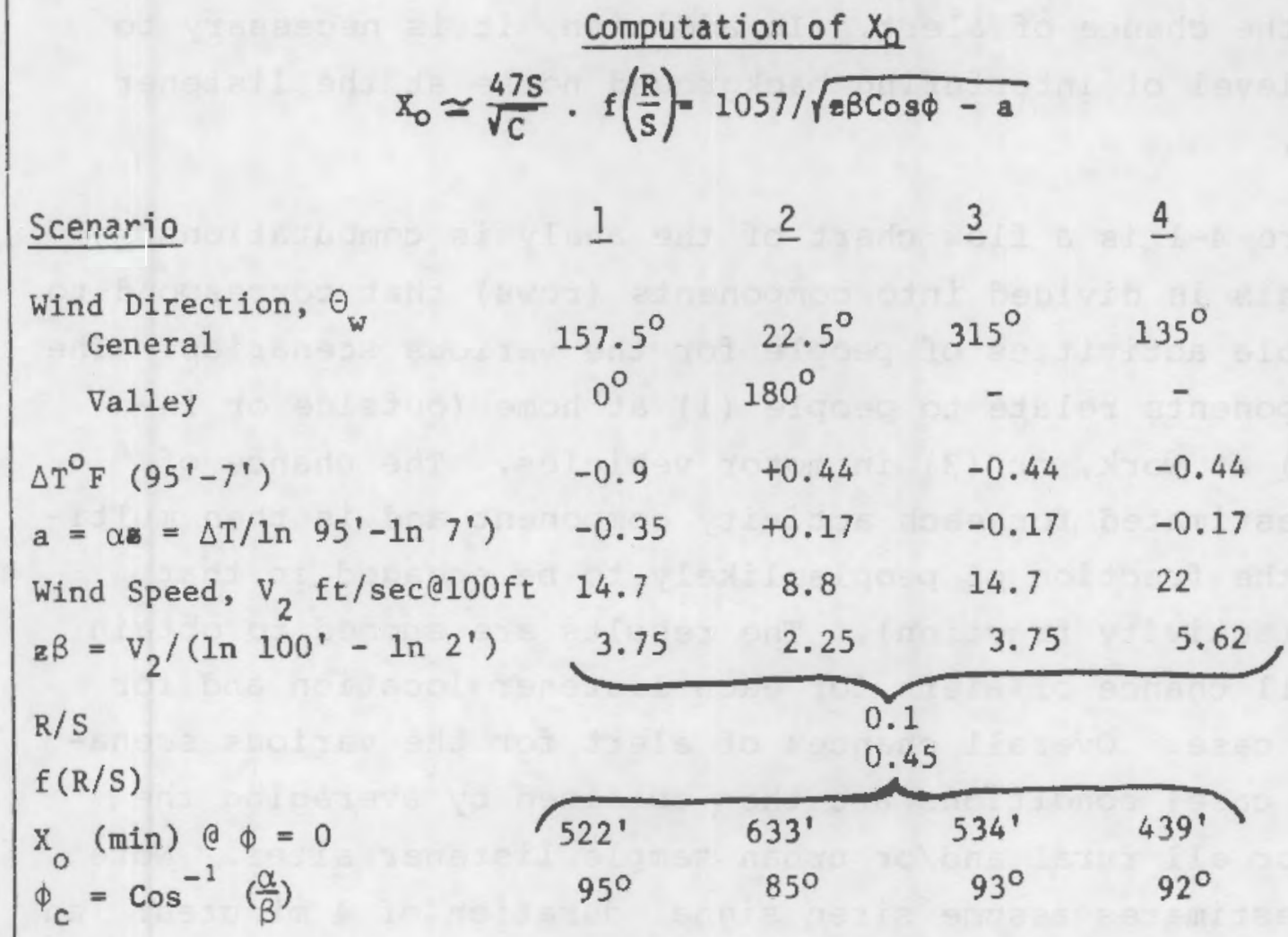


levels are then obtained by subtracting typical values for commercial or residential building sound attenuation. For test cases 1 and 2 (summer), residential windows were assumed to be partly open; for test cases 3 and 4 (winter) residential windows were assumed to be closed (with storm windows). For the frequency region within the $500 \mathrm{~Hz}$ octave band, the sound attenuation into buildings is estimated to be $16 \mathrm{~dB}$ for test cases 1 and 2 and $31 \mathrm{~dB}$ for test cases 3 and 4 [4]. For commercial buildings, the outdoor-to-indoor noise reduction is estimated to be $31 \mathrm{~dB}$, assuming closed and sealed windows for all four scenarios.

\subsection{Assumptions about Chance of Alert}

The outdoor and indoor siren levels calculated by the above procedure provide some of the information required for the analysis of the chance of alert. In addition, it is necessary to know the level of interfering background noise at the listener locations.

Figure 4-1 is a flow chart of the analysis computations. The analysis is divided into components (rows) that correspond to the possible activities of people for the various scenarios. The major components relate to people (1) at home coutside or inside), (2) at work, or (3) in motor vehicles. The chance of alert is estimated for each activity component and is then multiplied by the fraction of people likely to be engaged in that activity (activity fraction). The results are summed to obtain the overall chance of alert for each listener location and for each test case. Overall chances of alert for the various scenario (test case) conditions are then obtained by averaging the chances for all rural and/or urban sample listener sites. Note that all estimates assume siren signal duration of 4 minutes: an 

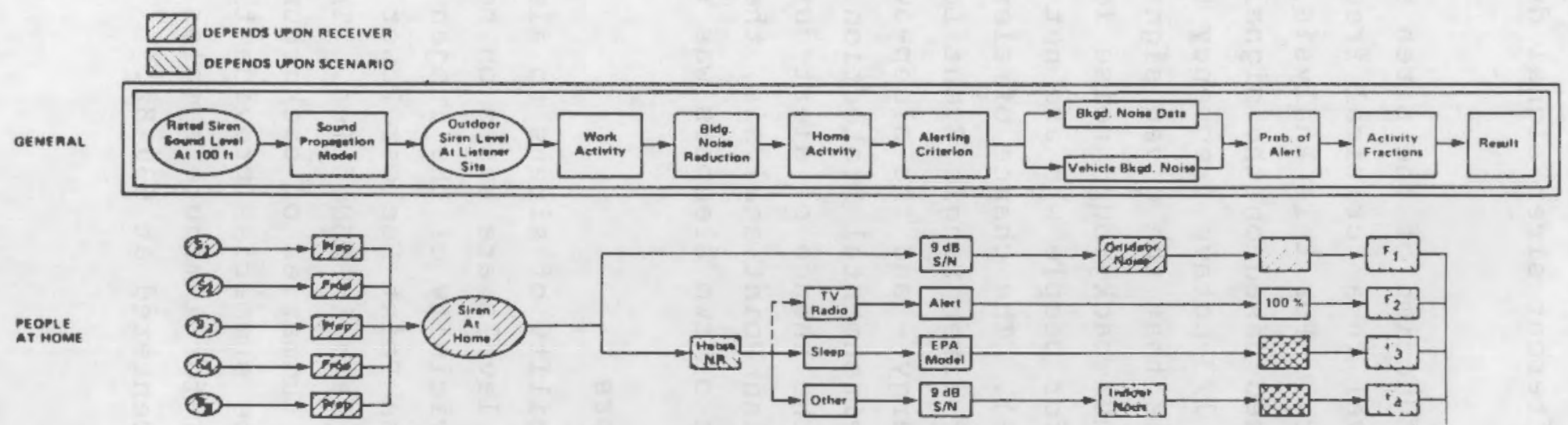

קEoplé

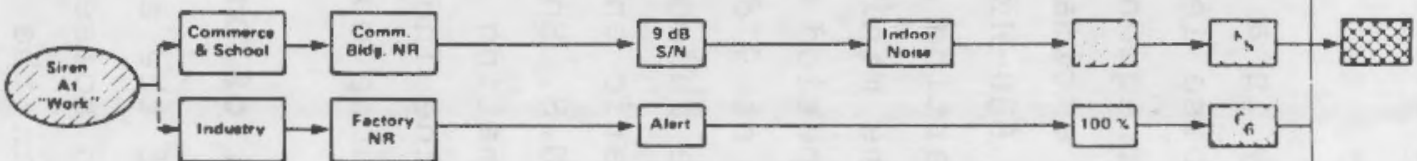

eEores

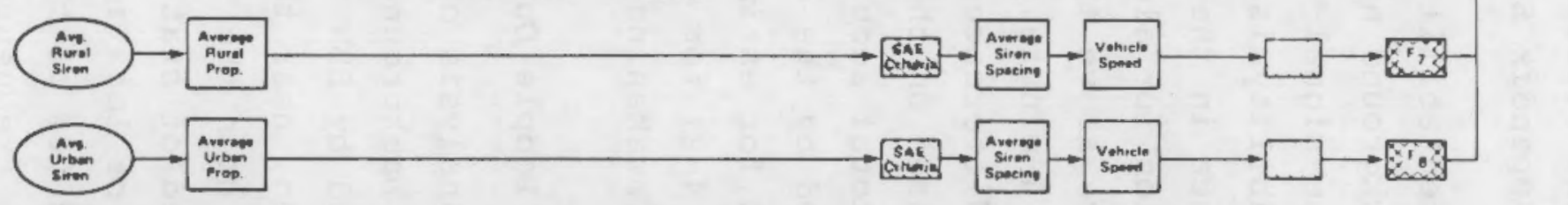

FIG. 4-1. FLOW OF COMPUTATIONS. 
average of the " 3 to 5 minutes" called for in Appendix 3 of NUREG-0654. The effects of different siren signal durations are discussed in Appendix E.

Siren detectability is a function of the siren signal level and of the background noise level in a "critical frequency band" centered at the signal frequency. For this analysis, outdoor and indoor detectability is estimated based on the signal-to-noise $(\mathrm{S} / \mathrm{N})$ difference in the $630-\mathrm{Hz} 1 / 3$-octave frequency band. The chosen criterion for alerting is that the given signal level must be $9 \mathrm{~dB}$ or more above the minimum background noise level at any time during a 4-minute period for people who are not sleeping (i.e., a $S / N$ difference of $9 \mathrm{~dB}$ ). The chance of alert while sleeping is based on the indoor siren single Event Level (SEL) a measure of total acoustic energy - and the sleep-awakening model developed by the U.S. Environmental Protection Agency [5]. The graph used for estimating the chance of alert during sleep is shown in Fig. 4-2; for the Indian point analysis, the curve for the chance of awakening one out of two sleepers was used.

\subsection{Alerting People Out of Doors}

For the analysis of the ability of sirens to alert people out of doors, background noise levels are based on noise measurements conducted by BBN in the vicinity of the Trojan Nuclear Plant in Oregon, near the Indian Point Nuclear Power Station in New York, and upon the body of data in BBN files. The data typically consisted of statistical summaries of background noise at various types of locations. The summaries provide the $\mathrm{L}_{90}$ (sound level exceeded 908 of the time) for 1 -minute samples of data in the 1/3-octave frequency band centered at $630 \mathrm{~Hz}$.*

\footnotetext{
*The $\mathrm{L}_{90}$ was used as a conservative estimate of the minimum sound level.
} 


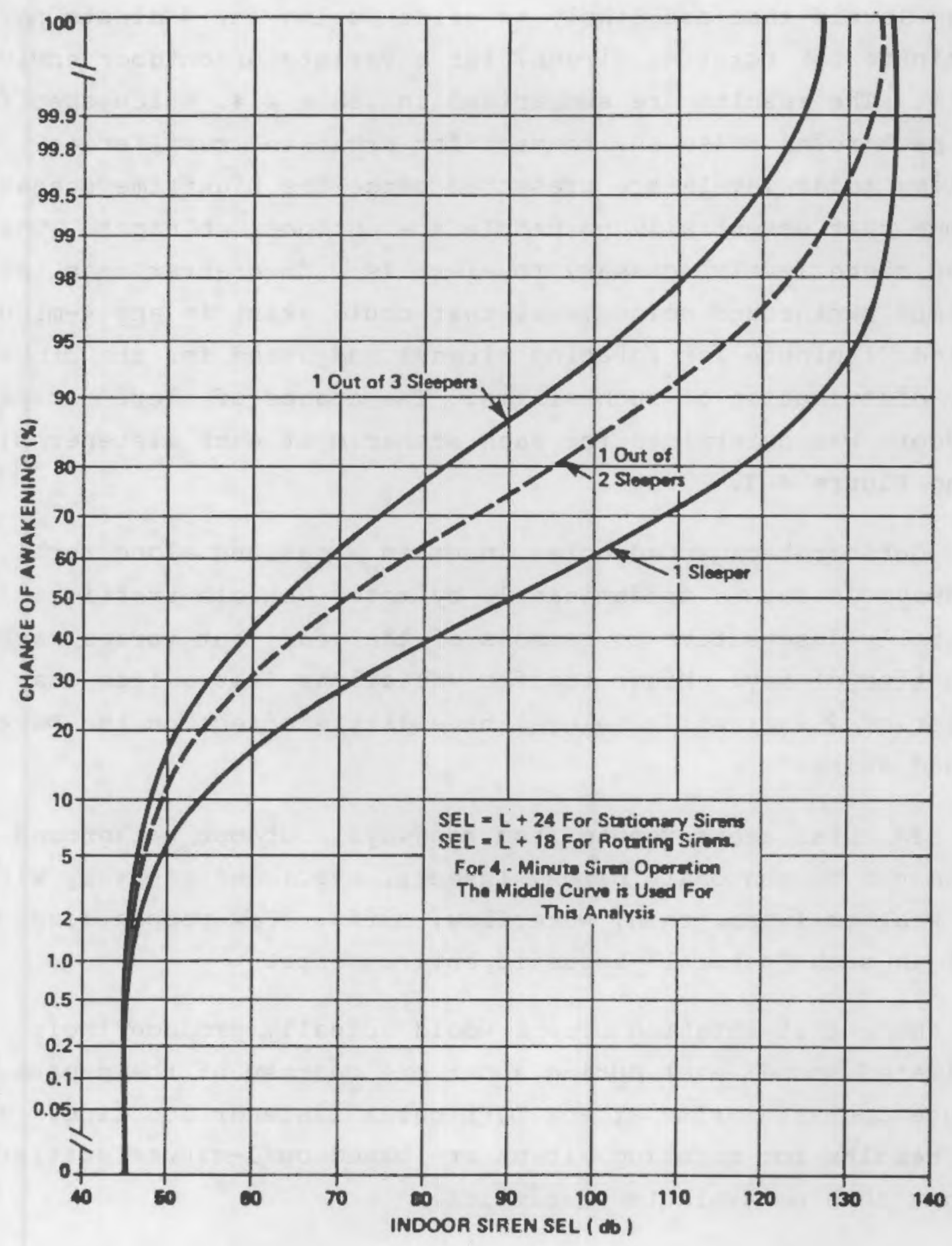

FIG. 4-2. CHANCE OF ALERT FOR AMARENING PEOPLE ASLEEP. 
These data were used to estimate the range of background noise levels that are likely to exist during any 4-minute period (1 minute for rotating sirens) for a variety of outdoor environments. The results are summarized in Table 4.4, which specifies the background noise environment for urban and rural areas. Only daytime noise levels are presented since the nighttime scenarios assume that essentially no people are outdoors at night. The siren sound level necessary to alert is $9 \mathrm{~dB}$ greater than the minimum background noise level that could exist in any 4-minute period (1 minute for rotating sirens), adjusted for the probability distribution of such minima. The chance of alert for people outdoors was determined for each scenario at each listener site using Figure 4-3.

Outdoor background noise in urban areas and along rural roadways is caused predominantly by motor vehicle traffic. It is generally insensitive to seasons of the year, but varies markedly with time of day. Minor traffic variations (i.e., less than a factor of 2 in traffic volume) have little effect on the background noise.

In rural areas remote from roadways, outdoor background noise can be seasonal (birds, insects, etc.) and can vary with the weather (wind, rain, waterflow, surf). Few people live or work in such "natural" acoustic environments.

Note that rotating sirens would actually produce their estimated sound level during about one quarter of the presumed 4minute operating time at any particular listener location. Thus, the results for rotating sirens are based on 1 -minute statistics rather than on 4-minute statistics. 
TABLE 4.4. MINIMUM BACKGROUND NOISE LEVELS FOR GENERALIZED CATEGORIES OF OUTDOOR ENVIRONMENTS (SEE FIG. 4-3 FOR DISTRIBUTIONS).

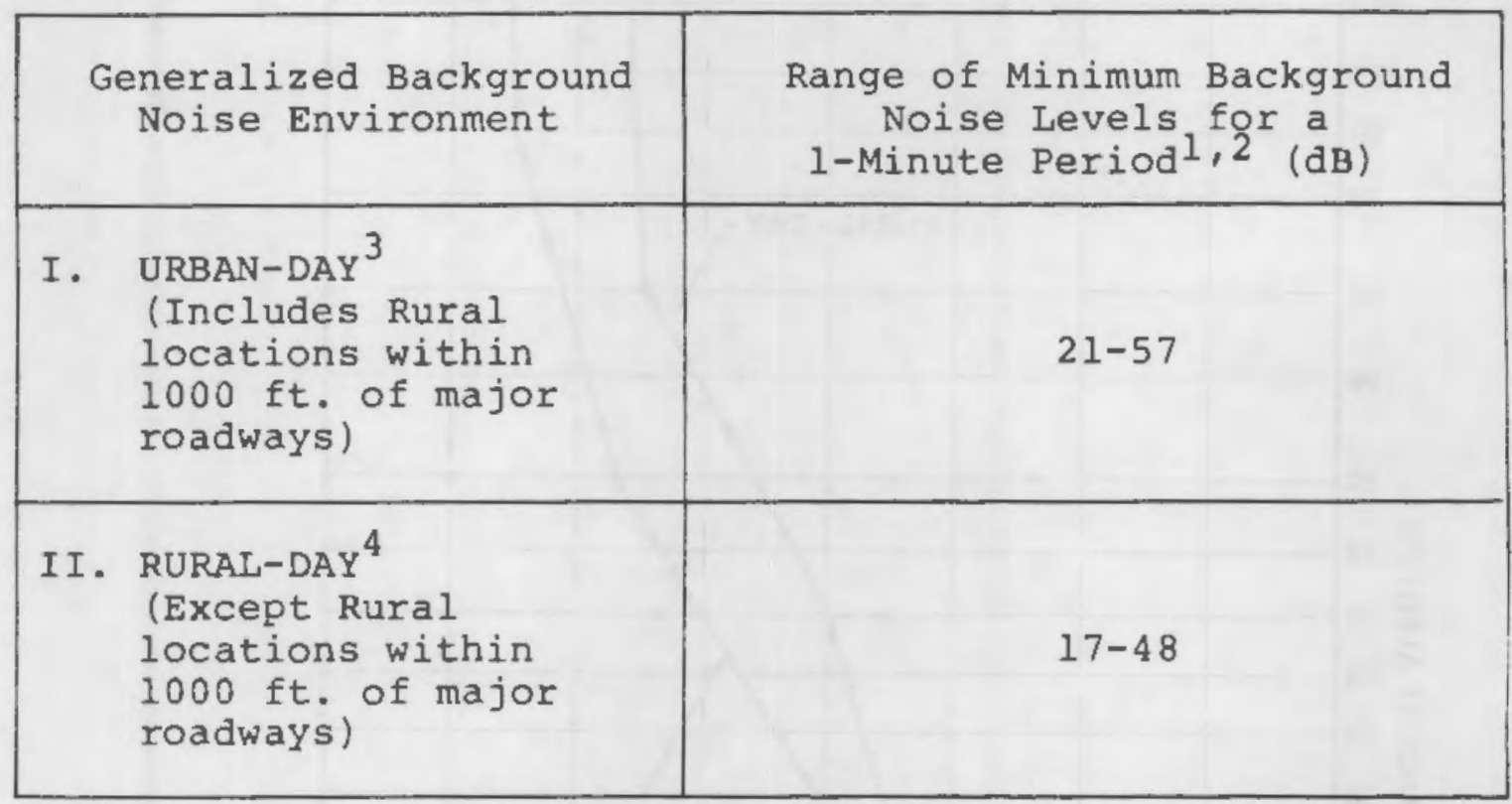

\section{NOTES:}

1. Refers to the range of the minimum ( $\left.\mathrm{L}_{90}\right)$ sound pressure levels in the $630 \mathrm{~Hz}$ one-third octave band during the specified time period.

2. Applicable for analysis of rotating sirens operated for 4 minutes.

3. Urban locations are defined as the pink "building exclusion" areas of topographic maps, or as those communities with a population density exceeding 2000 people per square mile. Major roadways are defined as roadways with more than one lane in each direction.

4. Rural locations are taken to be all sites not classified as urban (above). 


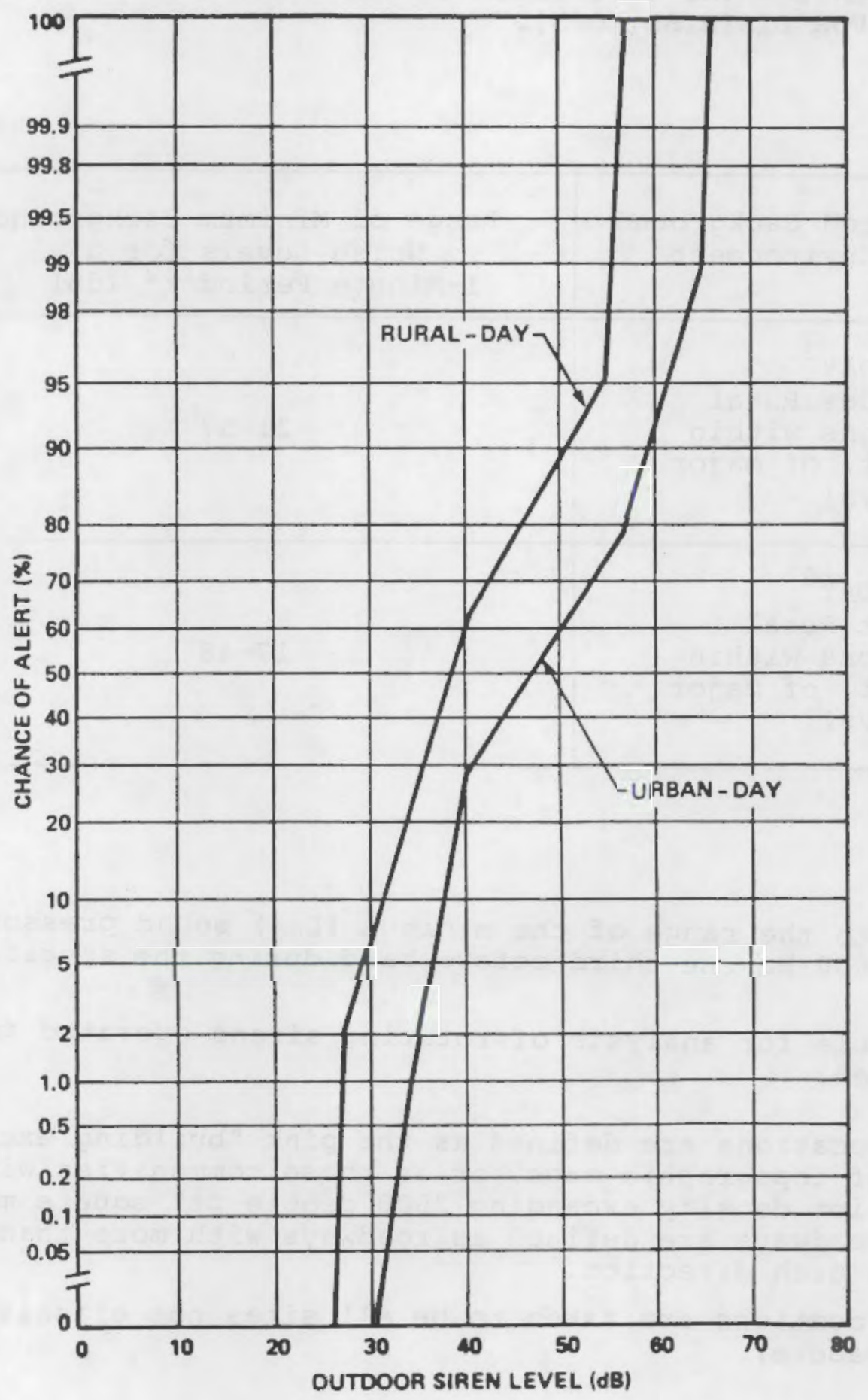

PIG. 4-3. CHANCE OF ALERT FOR PEOPLE INDOORS (4-MINUTE ROTATING SIREN). 


\subsection{Alerting People Indoors}

For the analysis of alerting people indoors at home, three types of activities are considered. These are (1) listening to radio or TV, (2) sleeping, or (3) other activities that range from quiet to noisy situations. Table 4.5 provides the percentages assumed for various activities for each scenario.

For people listening to radio or $T V$, the chance of alert is 1008. For people sleeping, the chance of alert is calculated from the indoor siren SEL using the relationship shown in Fig. 4-2 for the chance of awakening one out of two sleepers. For all other indoor activities, the chance of alert is based on classifications of actual indoor background noise measurements under a wide variety of conditions.

Results for test cases 1 and 3 are provided in Fig. 4-4 for 4-minute rotating sirens. Thus, given the indoor siren level and test case condition, this figure was used to estimate the chance of alerting for indoor activities other than sleeping or listening to radio or TV.

For the analysis of alerting at work, two activity categories are considered: (1) commercial/institutional, and (2) industrial environments. For the Indian Point analysis, it was assumed that $75 \%$ of the working population are in commercial establishments while the remaining $25 \%$ are in industrial locations. For commercial locations, the chance of alert is based on the statistics of background noise measured in a typical office environment, using Fig. 4-5. For industrial locations, it has been assumed that 1008 of the people are likely to be alerted by some means of communication other than sirens. 
TABLE 4.5. ASSUMED ACTIVITIES AND BACRGROUND NOISE ENVIRONMENTS FOR PEOPLE INDOORS.

\begin{tabular}{|c|c|c|c|c|c|c|c|c|}
\hline \multirow{3}{*}{\multicolumn{2}{|c|}{ Scenario }} & \multicolumn{7}{|c|}{ Percentages of People Engaged in Various Activities Indoors (z) } \\
\hline & & \multirow[b]{2}{*}{$\begin{array}{l}\text { At Place } \\
\text { of Business }\end{array}$} & \multirow[b]{2}{*}{$\begin{array}{l}\text { Listening to } \\
\text { TV/Radio }\end{array}$} & \multirow[b]{2}{*}{ Sleeping } & \multicolumn{4}{|c|}{ Indoor Noise Environment } \\
\hline & & & & & $\begin{array}{l}\text { Obviously } \\
\text { Noisy' }\end{array}$ & $\begin{array}{r}\text { Busy and } \\
\text { Active }\end{array}$ & Isolated ${ }^{3}$ & $\begin{array}{l}\text { poviously } \\
\text { Quiet" }\end{array}$ \\
\hline & $\begin{array}{l}\text { Warm Sumer Heekday } \\
\text { Af cernoon (clear to } \\
\text { partly cloudy) }\end{array}$ & 41 & 27 & 5 & -- & 8 & 5 & 14 \\
\hline & $\begin{array}{l}\text { Summer Weekday N1ght } \\
\text { (clear to partly } \\
\text { cloudy) }\end{array}$ & 4 & -- & 96 & -- & -- & -- & -- \\
\hline 3. & $\begin{array}{l}\text { Winter Weekday During } \\
\text { Evening Commuting } \\
\text { Hours (cold and } \\
\text { overcagt) }\end{array}$ & -- & 20 & - & 5 & 50 & 20 & 5 \\
\hline 4. & $\begin{array}{l}\text { Winter N1ght During } \\
\text { Snowfall }\end{array}$ & $s$ & -- & 95 & $\cdots$ & - & -- & -- \\
\hline
\end{tabular}

NOTES :

1. Vacuum cleaning, dishwasher, shower, vent fan on, etc.

2. Dinner conversation, kitchen work, playing music, chlldren at play, etc.

3. No1se-producing activity in adjacent room, soft background music, etc.

4. Reading, atudy, eating alone. 


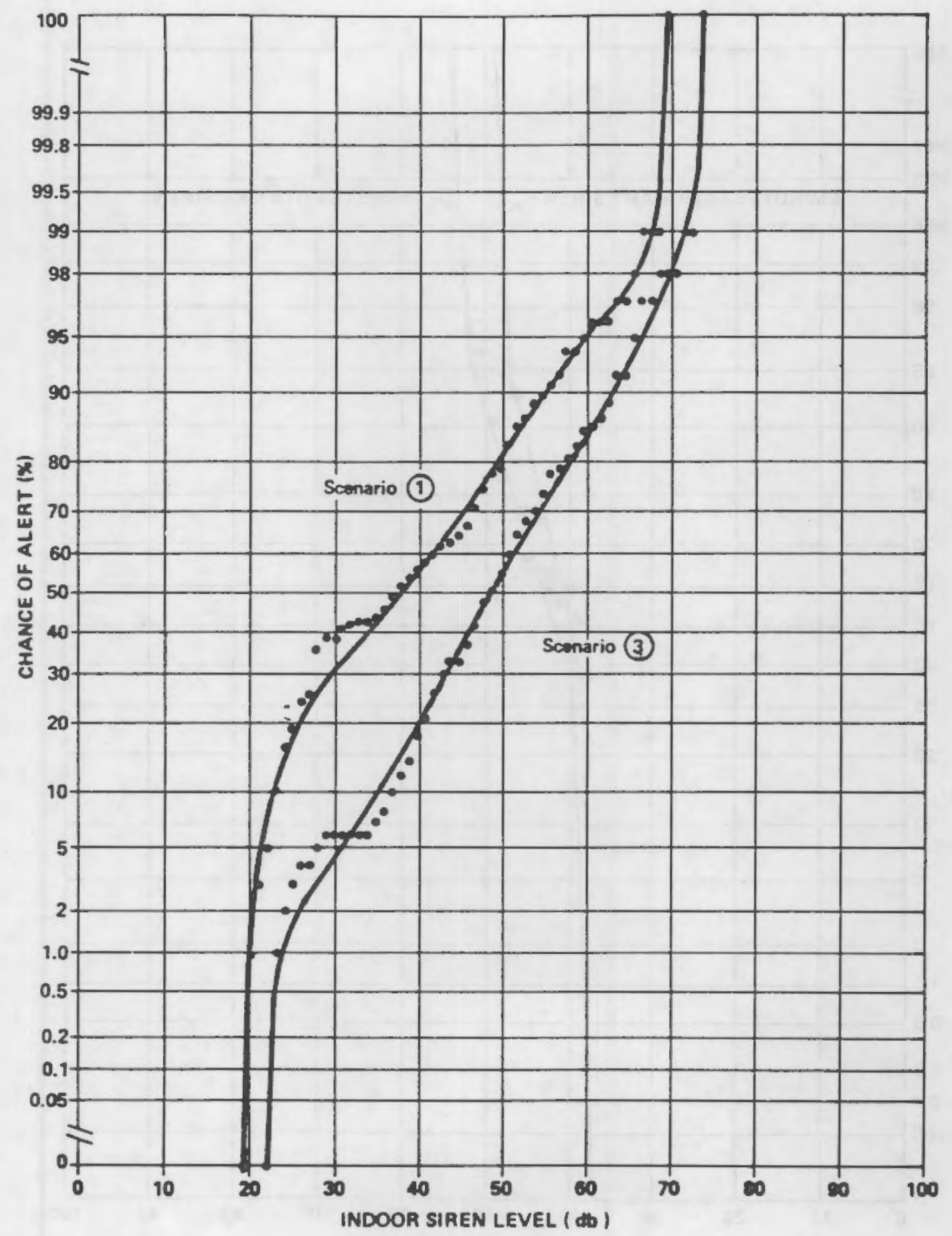

FIG. 4-4. CHANCE OF ALERT FOR PEOPLE INDOORS AT HOME (4-MINUTE ROTATING SIREN). 


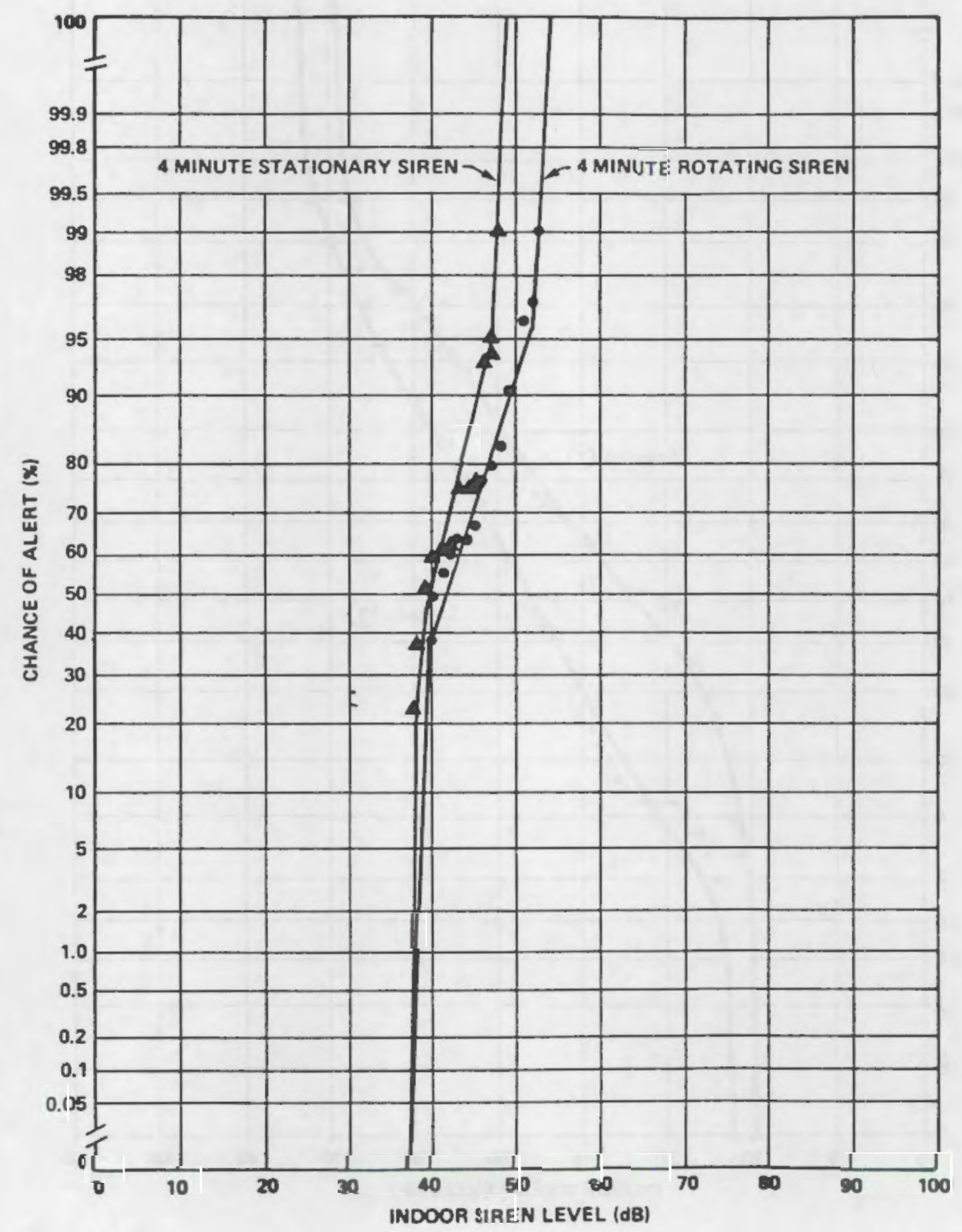

PIG. 4-5. CHANCE OF ALERT FOR PEOPLE INDOORS AT WORK IN COMMERCIAL/INSTITUTIONAL ESTABLISHMENTS. 


\subsection{Alerting People in Motor Vehicles}

The analysis for the alerting of motorists is based on the assumption of an average siren signal strength and spacing throughout the EPZ. The chance that a motorist will pass within the alert range of a siren during its 4-minute operation is estimated as follows:

$$
\left.C=\frac{2 R+d}{L} \times 100 \text { (not to exceed } 1008\right)
$$

where $C$ is the chance of alert ( 8$), R$ is the maximum alert distance ( $\mathrm{ft}$ ), d is distance traveled in 4 minutes ( $\mathrm{ft}$ ), and $\mathrm{L}$ is the average siren spacing ( $f t$ ). Separate analyses were carried out for urban and rural areas of the Indian Point EPZ.

The average urban or rural siren produces a sound level of $125 \mathrm{~dB}$ at $100 \mathrm{ft}$. Alerting ability was evaluating by using the results of a study for the Society of Automotive Engineers (SAE). [6]. Siren alerting levels for speeds of $55 \mathrm{mph}$ and $30 \mathrm{mph}$ with windows shut or open were first determined from the SAE study results. The average siren source levels for rural and urban areas were then reduced to alerting levels in accordance with the propagation models from current NRC guidelines (i.e., $10 \mathrm{~dB}$ ) double distance) [7]. In this manner, the maximum alert distance (R) was calculated for each driving condition. The distance traveled in 4 minutes (d) was calculated based on speed for each case, and the average siren spacing (L) was estimated to be 4,890 $\mathrm{ft}$ for urban areas and $12,530 \mathrm{ft}$ for rural areas.

The calculations of alerting ability for motorists are summarized in Table 4.6. The results indicate that the chance of alert is expected to be $100 \%$ for all conditions applicable to the Indian point analysis. 
TABLE 4.6. SIREN ALERTING FOR MOTORISTS.

\begin{tabular}{|c|c|c|c|c|c|c|c|}
\hline Area & $\begin{array}{l}\text { Vehicle } \\
\text { Speed } \\
\text { (mph) }\end{array}$ & $\begin{array}{l}\text { Vehicle } \\
\text { Window } \\
\text { Condition }\end{array}$ & $\begin{array}{l}\text { Reqd. Signal } \\
\text { for Alert } \\
\text { (dB) }\end{array}$ & $\begin{array}{l}\text { Max. Alert } \\
\text { Dist. R } \\
\text { (ft) }\end{array}$ & $\begin{array}{c}\text { 4-min } \\
\text { Travel Dist., d } \\
\text { (ft) }\end{array}$ & $\begin{array}{l}\text { Avg. Siren } \\
\text { Spacing L } \\
(\mathrm{ft})\end{array}$ & $\begin{array}{r}\text { Chance } \\
\text { of Alert } \\
(\%)\end{array}$ \\
\hline URBAN & 30 & $\begin{array}{l}\text { Closed } \\
\text { Open }\end{array}$ & $\begin{array}{l}89 \\
86\end{array}$ & $\begin{array}{r}980 \\
1,210\end{array}$ & $\begin{array}{l}10,560 \\
10,560\end{array}$ & $\begin{array}{l}4,890 \\
4,890\end{array}$ & $\begin{array}{l}100 \\
100\end{array}$ \\
\hline RURAL & 55 & $\begin{array}{l}\text { Closed } \\
\text { Open }\end{array}$ & $\begin{array}{l}96 \\
90\end{array}$ & $\begin{array}{l}650 \\
980\end{array}$ & $\begin{array}{l}19,360 \\
19,360\end{array}$ & $\begin{array}{l}12,530 \\
12,530\end{array}$ & $\begin{array}{l}100 \\
100\end{array}$ \\
\hline
\end{tabular}




\section{EVALIJATION OF THE PROMPT ALERTING SYSTEM FOR THE ZION NUCLEAR PONER STATION}

This section summarizes the evaluation of the siren alerting system for the zion Nuclear power station. The procedure that was used consists of a detailed analysis of siren alerting capability at each of 50 randomly chosen listener locations, under four different "sample scenario" conditions. The random selection process for 1 istener sites is described in Appendix $\mathrm{N}$ and the four test cases (sample scenarios) are included in Appendix o. The analysis is based on existing and proposed siren locations as of 15 October 1981. Maps which show the siren locations are provided in Appendix $P$.

The results of the evaluation for zion are summarized in Table 5.1 and indicate that the chance of alert is estimated to vary between $58 \%$ and 978 depending on the sample scenario under consideration. The remainder of this report describes the procedure used to arrive at this conclusion. Input and output data for the analyses are included in Appendix $Q$.

\subsection{Estimating Siren Sound Levels out of Doors at Listener Sites}

The first step in the procedure is to determine the siren in the vicinity of each selected listener site that is expected to produce the highest sound level at that site for each sample scenario. This choice is not always obvious, because the sound level caused by a particular siren at a given listener site depends not only on the sound output of the siren and its distance from the 1 istener, but also on shielding and atmospheric effects (particularly wind direction). Therefore, it is generally necessary to evaluate several sirens in the vicinity of each listener site in order to determine the dominant one. As a general rule, the closest, highest-rated, nonshielded sirens are selected for evaluation at each site. Furthermore, sirens should be chosen 
TABLE 5.1. SUMMARY OF ZION SIREN SYSTEM EVALUATION RESULTS.

\begin{tabular}{|c|c|c|c|c|}
\hline & & & Chance & of Alert \\
\hline & Scenario & & & Population- \\
\hline No. & Description & $(\%)$ & $(\%)$ & $(\%)$ \\
\hline 1 & $\begin{array}{l}\text { Warm Summer Weekday After- } \\
\text { noon (clear to partly cloudy) }\end{array}$ & 97 & 96 & 97 \\
\hline 2 & $\begin{array}{l}\text { Summer Weekday Night } \\
\text { (clear to partly cloudy) }\end{array}$ & 81 & 74 & 80 \\
\hline 3 & $\begin{array}{l}\text { Winter Weekday Evening } \\
\text { (cold, overcast, light } \\
\text { precipitation) }\end{array}$ & 90 & 85 & 89 \\
\hline 4 & $\begin{array}{l}\text { Winter Night } \\
\text { (windy) }\end{array}$ & 59 & 51 & 58 \\
\hline
\end{tabular}

* Based on a total urban population of 268,629 and a total rural population of 33,201 . 
such that they are distributed north, south, east, and west of the site (or in any other four mutually perpendicular directions) where possible to account for different wind directions. For the zion analysis, four or five sirens were evaluated at 46 of the 50 listener sites. Only two or three sirens were considered at the remaining four sites; these sites were located at the fringe of siren coverage such that sirens were not present in all directions.

The next step in the procedure is to establish the outdoor sound level produced by the selected sirens at each listener location. This is accomplished by applying adjustments to the rated sound level of the siren as follows:

$$
L(1 \text { istener })=L(\text { siren })-A_{d}-A_{S}-A_{a i r}-A_{a t m} \text {, }
$$

where $L$ (listener) is the outdoor siren sound pressure level at the listener site $(d B), L(s i r e n)$ is the rated sound pressure level of the siren at $100 \mathrm{ft}(\mathrm{dB}), A_{d}$ is the distance attenuation $(d B), A_{S}$ is the shielding attenuation $(d B), A_{a i r}$ is the air absorption $(\mathrm{dB})$, and $A_{a t m}$ is the atmospheric attenuation caused by wind and temperature gradients (dB).

The rated sound pressure levels for all the proposed $\mathrm{zion}$ sirens were obtained based on information provided by Commonwealth Edison, and are as follows:

- $\mathrm{ACA}$ Dual-Tone Rotating Sirens $=123 \mathrm{dBC}$ a $100 \mathrm{ft}$

- $\mathrm{ACA}$ Single-Tone Rotating Sirens $=126 \mathrm{dBC}$ @ $100 \mathrm{ft}$

- Whelen Electronic Rotating Sirens = $124 \mathrm{dBC}$ e $100 \mathrm{ft}$

- ACA Stationary Sirens $=115 \mathrm{dBC}$ e $100 \mathrm{ft}$

The rated sound pressure levels for existing sirens to be employed in the $\mathrm{zion}$ system were taken to be $125 \mathrm{dBC}$ for rotating 
units and $115 \mathrm{dBC}$ or $100 \mathrm{dBC}$ for stationary units, all at a distance of $100 \mathrm{ft}$.

The first two adjustments (for distance and shielding) are the same for all four test cases and are based on information obtained from USGS maps. Distance attenuation beyond $100 \mathrm{ft}$ is calculated by assuming sound propagation from an acoustic point source with a reduction of $6 \mathrm{~dB}$ per distance doubled. It is calculated as follows:

$$
A_{d}=20 \log _{10}\left(\frac{d}{100}\right),
$$

where $d$ is the siren-to-listener distance ( $f t$ ).

Shielding attenuation $\left(A_{S}\right)$ is estimated using the following formula for the attenuation of a rigid straight barrier for sound incident from a point source [2]:

$$
\begin{aligned}
& A_{S}= \begin{cases}20 \log \frac{\sqrt{2 \pi N}}{\tanh \sqrt{2 \pi N}}+5 d B & \text { for } N>-0.2 \\
0 & \text { for } N<-0.2\end{cases} \\
& N \text { is the Fresnel number (dimensionless): } \\
& \quad N= \pm \frac{2}{\lambda}(A+B-d)
\end{aligned}
$$

where $\lambda=$ wavelength of sound, ft ( $1.79 \mathrm{ft}$ for $630-\mathrm{Hz}$ siren tone)

$\mathrm{d}=$ straight-line distance between source and receiver, ft

$\mathrm{A}+\mathrm{B}=$ shortest path length of wave travel over the barrier between source and receiver, ft

+ sign = receiver in the shadow zone (i.e., barrier obstructs line-of-sight)

- sign = receiver in the bright zone (i.e., barrier doesn't obstruct line-of-sight) 
When $\mathrm{N}$ is negative, the above equation for $\mathrm{A}_{\mathrm{S}}$ is evaluated by replacing $\mathrm{N}$ with $|\mathrm{N}|$, and by replacing tanh with tan.

Shielding attenuation is 1 imited to a maximum of $24 \mathrm{~dB}$ based upon a large body of experimental data. For the zion analysis, sirens are assumed to be at a height of 25-60 ft above terrain level, listener sites are assumed to be at a height of $5 \mathrm{ft}$ above terrain level, and barrier heights are obtained from ground contour information on USGS maps.

The adjustments for air absorption and atmospheric effects depend on the meteorological conditions for the particular scenario. The assumed conditions for the zion site are provided in Table 5.2 for the four test cases, based on local weather information.* In terms of air absorption, these conditions indicate the following attenuation rates based upon temperature and relative humidity $[2,3]$ :

$\begin{array}{cc}\text { Scenario } & \text { Aair (dB per } 1000 \mathrm{ft} \text { ) } \\ 1 & 0.85 \\ 2 & 0.85 \\ 3 & 1.0 \\ 4 & 2.0\end{array}$

The adjustment for atmospheric gradient effects (Aatm) is based on siren-to-listener azimuth with respect to wind direction and on wind and temperature gradient characteristics. Table 5.3 summarizes the calculation procedure for determining $A_{a t m}$ for each scenario at the zion site. A more detailed description of the estimation procedure for $A_{a t m}$ can be found in Appendix D.

*Commonwealth Edison, Zion Nuclear Power Station Weather Data Records. 
TABLE 5.2. METEROLOGICAL CONDITIONS FOR THE FOUR SAMPLE SCENARIOS USED TO EVALUATE THE ZION SIREN SYSTEM.

\begin{tabular}{|c|c|c|c|c|}
\hline $\begin{array}{c}\text { Scenario } \\
\text { No. }\end{array}$ & Wind Conditions* & $\begin{array}{c}\text { Temperature } \\
\text { Gradient }\end{array}$ & $\begin{array}{c}\text { Relative } \\
\text { Humidity } \\
(\%)\end{array}$ & $\begin{array}{c}\text { Temperature } \\
\text { (OF) }\end{array}$ \\
\hline 1 & $11 \mathrm{mph}$ from the southeast & $-1.3^{\circ} \mathrm{F} / 90 \mathrm{ft}$ & 60 & 71 \\
\hline 2 & $12 \mathrm{mph}$ from the WNW & $+1.1^{\circ} \mathrm{F} / 90$ ft & 60 & 70 \\
\hline 3 & $11 \mathrm{mph}$ from the NNW & $-0.70^{\circ} \mathrm{F} / 90$ ft & 95 & 17 \\
\hline
\end{tabular}

*At $125 \mathrm{ft}$ above ground level. 
table 5.3. CALCUlation of atmospheric attenuation, Aatm' CAUSED BY WIND AND TEMPERATURE GRADIENTS (SEE APPENDIX D FOR DETAILS).

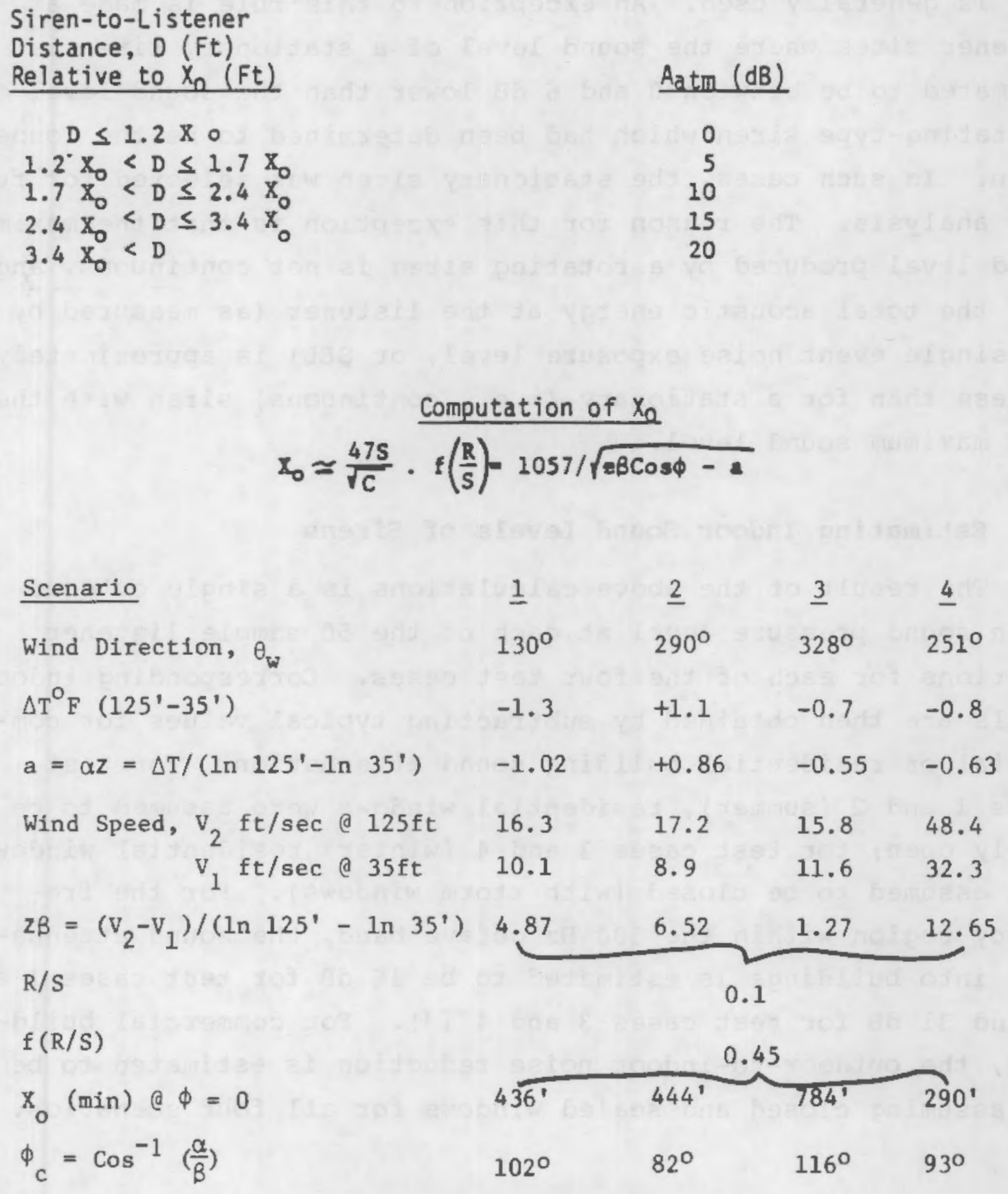


Application of the above calculations yields the estimated outdoor sound pressure level for various sirens at each sample listener site, for each of the four scenarios. For the balance of the analysis, only the highest siren level at each listener site is generally used. An exception to this rule is made at listener sites where the sound level of a stationary siren is estimated to be between 0 and $6 \mathrm{~dB}$ lower than the sound level of a rotating-type siren which had been determined to be the loudest siren. In such cases, the stationary siren was selected for further analysis. The reason for this exception is that the maximum sound level produced by a rotating siren is not continuous, and thus the total acoustic energy at the listener (as measured by the single event noise exposure level, or SEL) is approximately 6 dB less than for a stationary (i.e., continuous) siren with the same maximum sound level.

\subsection{Estimating Indoor Sound Levels of Sirens}

The result of the above calculations is a single outdoor siren sound pressure level at each of the 50 sample listener locations for each of the four test cases. Corresponding indoor levels are then obtained by subtracting typical values for commercial or residential building sound attenuation. For test cases 1 and 2 (summer), residential windows were assumed to be partly open; for test cases 3 and 4 (winter) residential windows were assumed to be closed (with storm windows). For the frequency region within the $500 \mathrm{~Hz}$ octave band, the sound attenuation into buildings is estimated to be $16 \mathrm{~dB}$ for test cases 1 and 2, and $31 \mathrm{~dB}$ for test cases 3 and 4 [4]. For commercial buildings, the outdoor-to-indoor noise reduction is estimated to be 31 dB, assuming closed and sealed windows for all four scenarios. 


\subsection{Assumptions about Chance of Alert}

The outdoor and indoor siren levels calculated by the above procedure provide some of the information required for the analysis of the chance of alert. In addition, it is necessary to know the level of interfering background noise at the listener locations.

Figure $5-1$ is a flow chart of the analysis computations. The analysis is divided into components (rows) that correspond to the possible activities of people for the various scenarios. The major components relate to people (1) at home (outside or inside), (2) at work, or (3) in motor vehicles. The chance of alert is estimated for each activity component and is then multiplied by the fraction of people likely to be engaged in that activity (activity fraction). The results are summed to obtain the overall chance of alert for each listener location and for each test case. Overall chances of alert for the various scenario (test case) conditions are then obtained by averaging the chances for all rural and/or urban sample listener sites. Note that all estimates assume siren signal duration of 4 minutes: an average of the " 3 to 5 minutes" called for in Appendix 3 of NUREG-0654. The effects of different siren signal durations are discussed in Appendix E.

Siren detectability is a function of the siren signal level and of the background noise level in a "critical frequency band" centered at the signal frequency. For this analysis, outdoor and indoor detectability is estimated based on the signal-to-noise $(\mathrm{S} / \mathrm{N})$ difference in the $630-\mathrm{Hz} 1 / 3$-octave frequency band. The chosen criterion for alerting is that the given signal level must be $9 \mathrm{~dB}$ or more above the minimum background noise level at any 


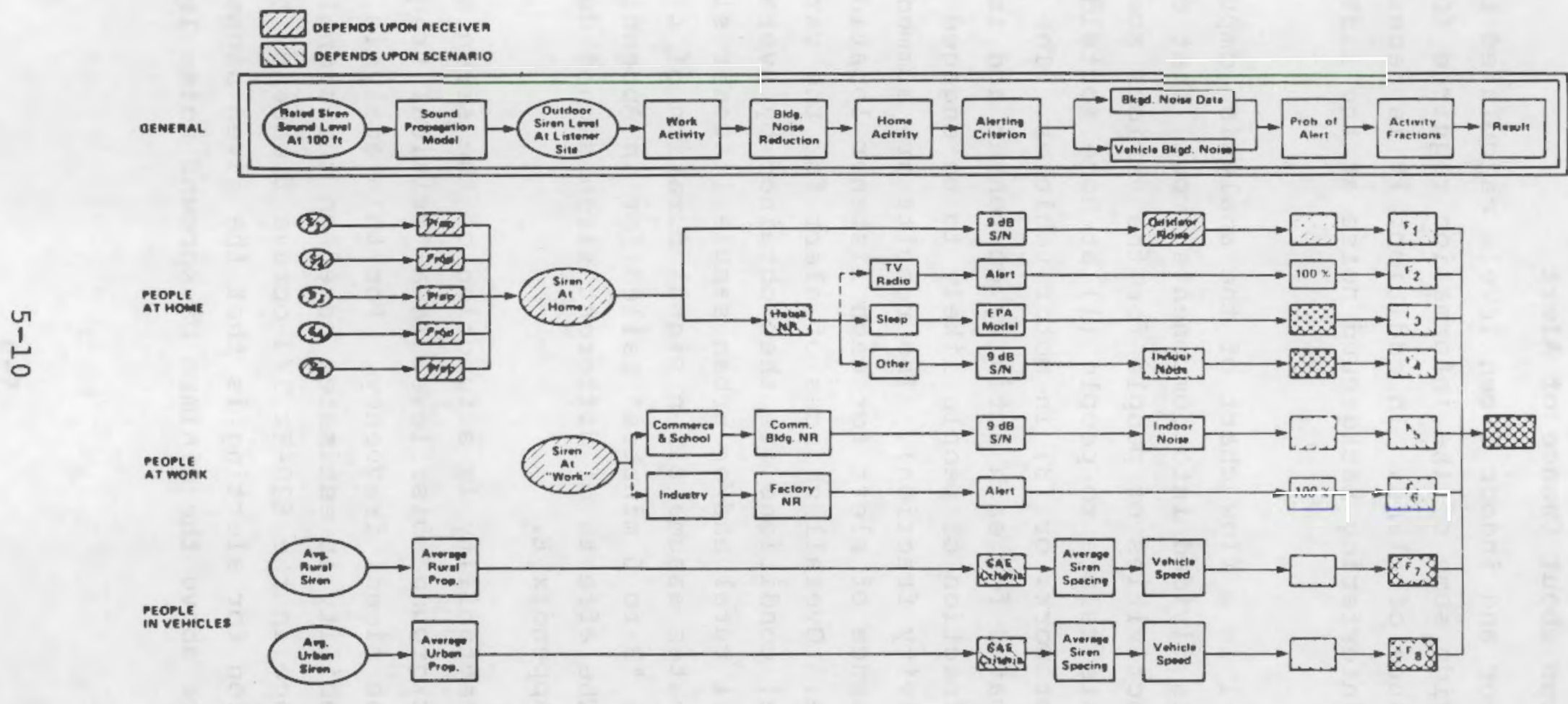

FIG. 5-1. FLOW OF COMPUTATIONS. 
time during a 4-minute period for people who are not sleeping (i.e., a $\mathrm{S} / \mathrm{N}$ difference of $9 \mathrm{~dB}$ ). The chance of alert while sleeping is based on the indoor siren single Event Level (SEL) a measure of total acoustic energy - and the sleep-awakening model developed by the U.S. Environmental Protection Agency [5]. The graph used for estimating the chance of alert during sleep is shown in Fig. 5-2; for the zion analysis, the curve for the chance of awakening one out of two sleepers was used.

\subsection{Alerting People out of Doors}

For the analysis of the ability of sirens to alert people out of doors, background noise levels are based on noise measurements conducted by BBN in the vicinity of the Trojan Nuclear Plant in Oregon, near the zion Nuclear Power station in New York, and upon the body of data in BBN files. The data typically consisted of statistical summaries of background noise at various types of locations. The summaries provide the $\mathrm{L}_{90}$ (sound level exceeded $90 \%$ of the time) for 1 -minute samples of data in the 1/3-octave frequency band centered at $630 \mathrm{~Hz}$. * These data were used to estimate the range of background noise levels that are likely to exist during any 4-minute period ( 1 minute for rotating sirens) for a variety of outdoor environments. The results are summarized in Table 5.4, which specifies the background noise environment for urban and rural areas. Only daytime noise levels are presented since the nighttime scenarios assume that essentially no people are outdoors at night.

The siren sound level necessary to alert is $9 \mathrm{~dB}$ greater than the minimum background noise level that could exist in any

* The $L_{90}$ was used as a conservative estimate of the minimum sound
level. 


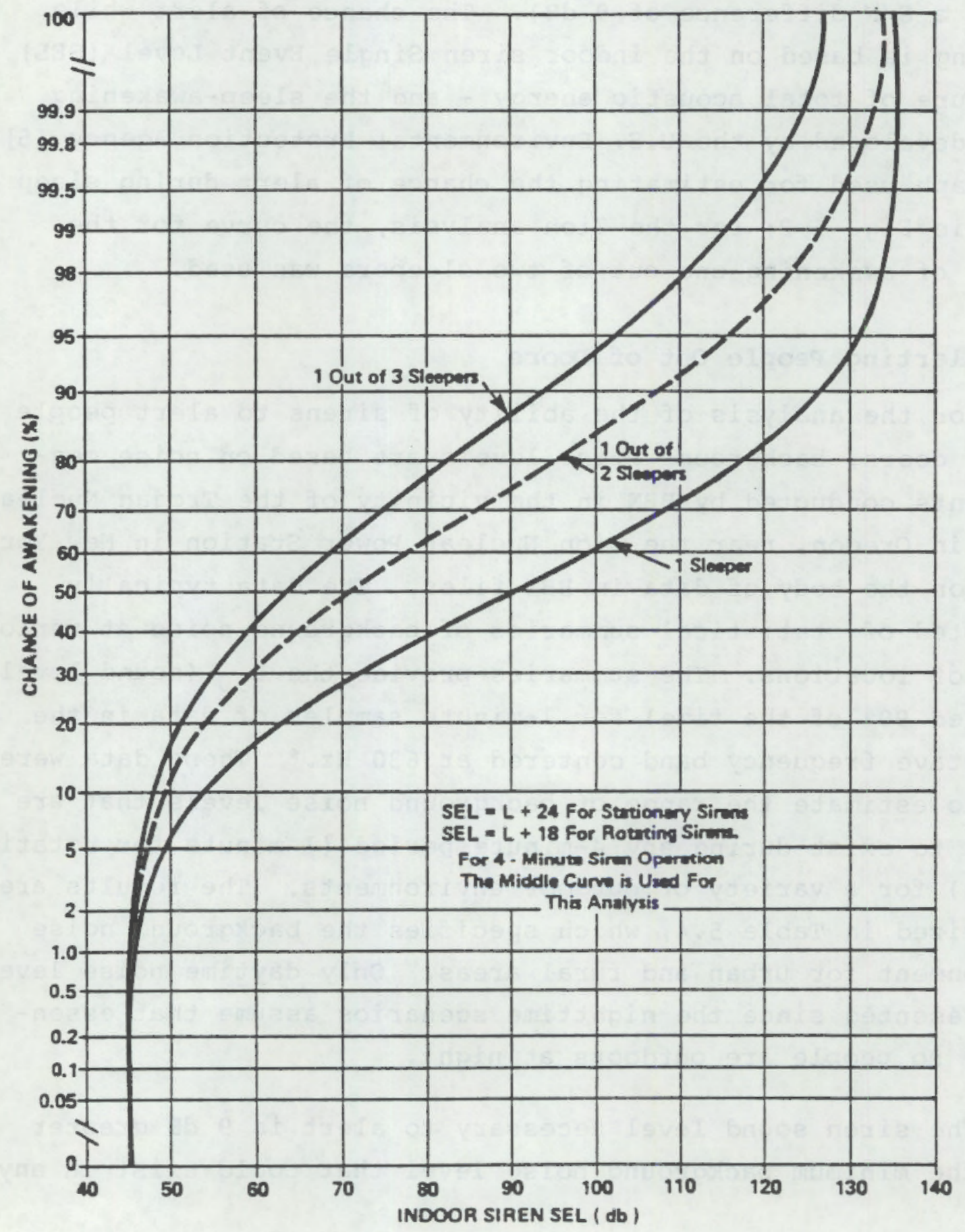

FIG. 5-2. CHANCE OF ALERT FOR ANARENING PEOPLE ASLEEP. 
TABLE 5.4. MINIMUM BACKGROUND NOISE LEVELS FOR GENERALIZED CATEGORIES OF OUTDOOR ENVIRONMENTS (SEE FIGS. 5-3 AND 5-4 FOR DISTRIBUTIONS).

\begin{tabular}{|c|c|c|}
\hline $\begin{array}{l}\text { Generalized Background } \\
\text { Noise Environment }\end{array}$ & $\begin{array}{r}\text { Range of } M \\
\text { Noise }\end{array}$ & $\begin{array}{l}\text { imum Background } \\
\text { evels }{ }^{(\mathrm{dB})}\end{array}$ \\
\hline & 1-Minute Period ${ }^{2}$ & 4-Minute Period ${ }^{3}$ \\
\hline $\begin{array}{l}\text { I. URBAN-DAY } \\
\text { (Includes Rural } \\
\text { locations within } \\
\text { looo ft. of major } \\
\text { roadways) }\end{array}$ & $21-57$ & $21-57$ \\
\hline $\begin{array}{l}\text { II. } \text { RURAL-DAY } \\
\text { (Except Rural } \\
\text { locations within } \\
1000 \text { ft. of major } \\
\text { roadways) }\end{array}$ & $17-48$ & $17-47$ \\
\hline
\end{tabular}

NOTES:

1. Refers to the range of the minimum ( $\left.\mathrm{L}_{90}\right)$ sound pressure levels in the $630 \mathrm{~Hz}$ one-third octave band during the specified time period.

2. Applicable for analysis of rotating sirens operated for 4 minutes.

3. Applicable for analysis of stationary sirens operated for 4 minutes.

4. Urban locations are defined as the pink "building exclusion" areas of topographic maps, or as those communities with a population density exceeding 2000 people per square mile. Major roadways are defined as roadways with more than one lane in each direction.

5. Rural locations are taken to be all sites not classified as urban (above). 
4-minute period ( 1 minute for rotating sirens), adjusted for the probability distribution of such minima. The chance of alert for people outdoors was determined for each scenario at each listener site using Figs. 5-3 and 5-4.

Outdoor background noise in urban areas and along rural roadways is caused predominantly by motor vehicle traffic. It is generally insensitive to seasons of the year, but varies markedly with time of day. Minor traffic variations (i.e., less than a factor of 2 in traffic volume) have little effect on the background noise.

In rural areas remote from roadways, outdoor background noise can be seasonal (birds, insects, etc.) and can vary with the weather (wind, rain, waterflow, surf). However, few people live or work in such "natural" acoustic environments.

Note that results are given separately for stationary sirens and rotating sirens. This is because rotating sirens would actually produce their estimated sound level during about one quarter of the presumed 4-minute operating time at any particular listener location. Thus, the results for rotating sirens are based on 1-minute statistics rather than on 4-minute statistics.

In summary, information regarding siren type, estimated siren sound level, background noise category at the listener site, and test-case conditions were used in conjunction with Figs. 5-3 and 5-4 to estimate the chance of siren detection outdoors at the zion Site. 


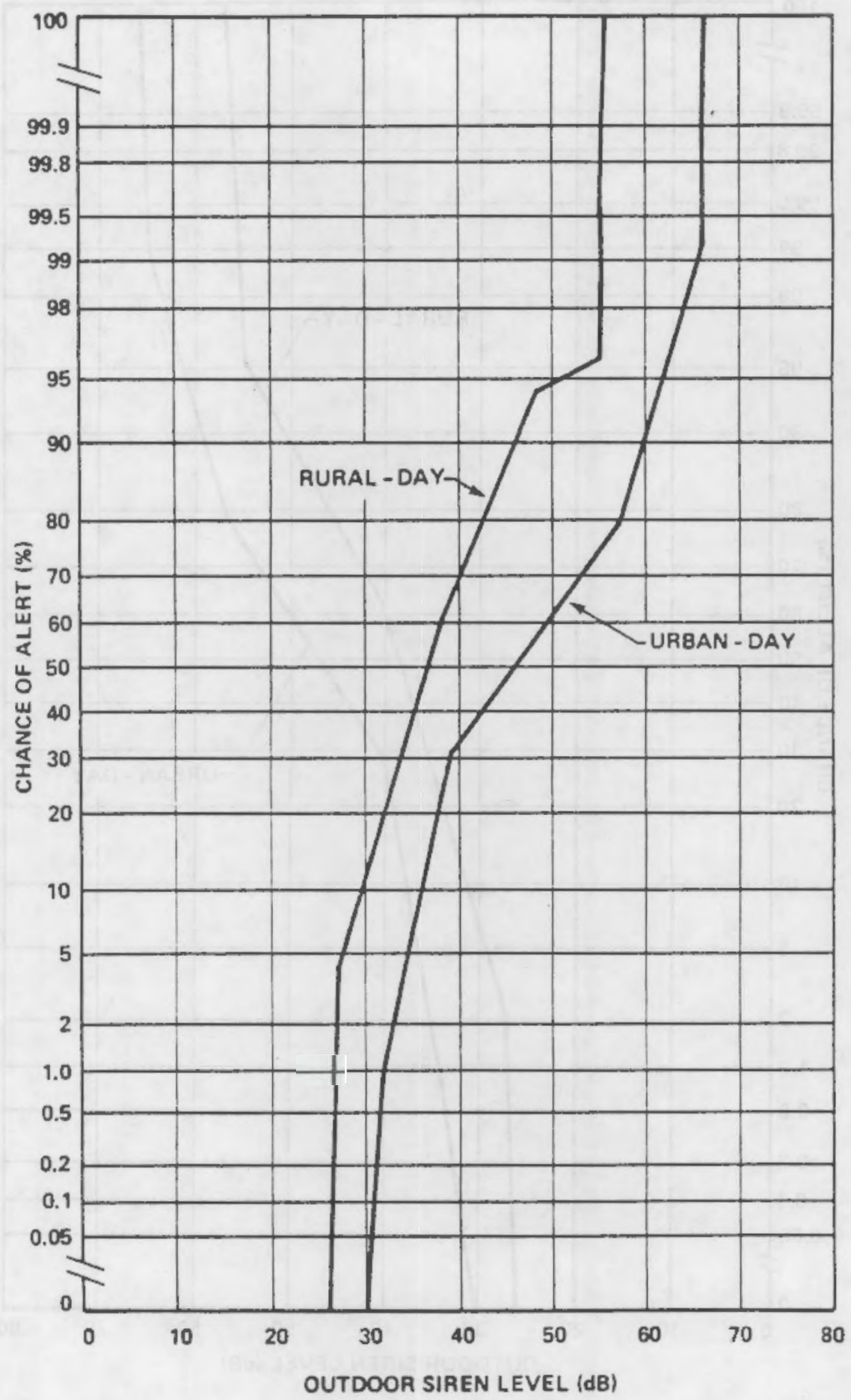

PIG. 5-3. CHANCE OP ALERT FOR PEOPLE OUTDOORS (4-MINUTE STATIONARY SIREN). 


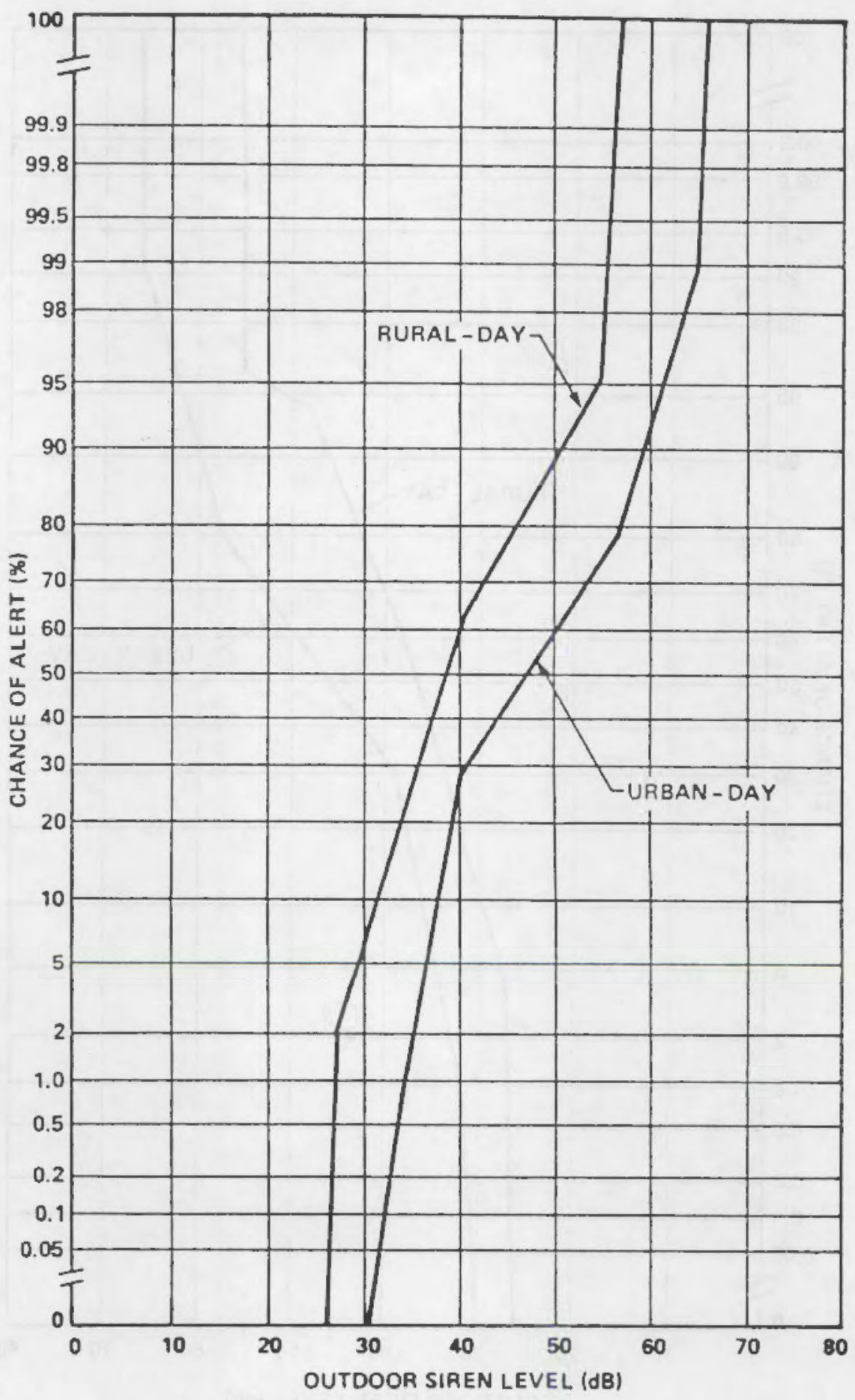

FIG. 5-4. CHANCE OF ALERT FOR PEOPLE OUTDOORS (4-MINUTE ROTATING SIREN). 


\subsection{Alerting People Indoors}

For the analysis of alerting people indoors at home, three types of activities are considered. These are (1) listening to radio or $T V$, (2) sleeping, or (3) other activities that range from quiet to noisy situations. Table 5.5 provides the percentages assumed for various activities for each scenario.

For people listening to radio or $T V$, the chance of alert is 1008. For people sleeping, the chance of alert is calculated from the indoor siren SEL using the relationship shown in Fig. 5-2 for the chance of awakening one out of two sleepers. For all other indoor activities, the chance of alert is based on generalized categories of actual indoor background noise measurements under a wide variety of conditions. The ranges of minimum background noise levels for these categories are listed in Table 5.6.

Results for test cases 1 and 3 are provided in Fig. 5-5 for 4-minute stationary sirens and in Fig. 5-6 for 4-minute rotating sirens. Thus, given the siren type, indoor siren level and test case condition, these figures were used to estimate the chance of alerting for indoor activities other than sleeping or 1 istening to radio or $\mathrm{TV}$.

For the analysis of alerting at work, two activity categories are considered: (1) commercial/institutional, and (2) industrial environments. For the zion analysis, it was assumed that 758 of the working population are in commercial establishments while the remaining 258 are in industrial locations. For commercial locations, the chance of alert is based on the statistics of background noise measured in a typical office environment, using Figure 5-7. For industrial locations, it has been assumed that 100 of of the people are likely to be alerted by some means of communication other than sirens. 
TABLE 5.5. ASSUMED ACTIVITIES AND BACKGROUND NOISE ENVIRONMENTS FOR PEOPLE INDOORS.

\begin{tabular}{|c|c|c|c|c|c|c|c|c|}
\hline \multirow{3}{*}{\multicolumn{2}{|c|}{ Scenario }} & \multicolumn{7}{|c|}{ Percentages of People Engaged in Various Activities Indoors (z) } \\
\hline & & \multirow[b]{2}{*}{$\begin{array}{l}\text { At Place } \\
\text { of Business }\end{array}$} & \multirow[b]{2}{*}{$\begin{array}{l}\text { Listening to } \\
\text { TV/Radio }\end{array}$} & \multirow[b]{2}{*}{ Sleeping } & \multicolumn{4}{|c|}{ Indoor Noise Environment } \\
\hline & & & & & $\begin{array}{c}\text { Obviously } \\
\text { Moisy' }\end{array}$ & $\begin{array}{l}\text { Busy and } \\
\text { Active }\end{array}$ & Isolated & $\begin{array}{l}\text { Poviously } \\
\text { Quiet" }\end{array}$ \\
\hline & $\begin{array}{l}\text { Warn Summer Heekday } \\
\text { Afternoon (clear to } \\
\text { partly cloudy) }\end{array}$ & 41 & 27 & s & -- & 8 & 5 & 14 \\
\hline & $\begin{array}{l}\text { Summer Heekday Night } \\
\text { (clear to partly } \\
\text { cloudy) }\end{array}$ & 4 & $\cdots$ & 96 & -- & $\cdots$ & -- & -- \\
\hline 3. & $\begin{array}{l}\text { Winter Heekday During } \\
\text { Evening Commuting } \\
\text { llours (cold and } \\
\text { overcast) }\end{array}$ & -- & 20 & -- & 5 & so & 20 & 5 \\
\hline & $\begin{array}{l}\text { Winter Night During } \\
\text { Snowfall }\end{array}$ & 5 & -- & 95 & -- & -- & -- & -- \\
\hline
\end{tabular}

NOTES :

1. Vacuum cleaning, dishwasher, shower, vent fan on, etc.

2. Dinner conversation, kitchen work, playing mulic, children at play, etc.

3. Molee-producing activity in adjacent room, soft background music, etc.

4. Resing, study, eating elone. 
TABLE 5.6. MINIMUH BACKGROUND NOISE LEVELS FOR GENERALIZED CATEGORIES OF INDOOR ACTIVITIES/ENVIRONMENTS.

\begin{tabular}{|c|c|c|}
\hline \multirow[t]{2}{*}{$\begin{array}{l}\text { Generalized } \\
\text { Activity/Environment }\end{array}$} & \multicolumn{2}{|c|}{$\begin{array}{l}\text { Range of Minimum Background } \\
\text { Noise Levels in } \mathrm{dB}^{\mathrm{S}}\end{array}$} \\
\hline & 1-Min. Period ${ }^{2}$ & 4-Min. Period ${ }^{3}$ \\
\hline $\begin{array}{l}\text { At home, obviously noisy } \\
\text { (i.e., vacuum cleaning, } \\
\text { dishwasher, shower, } \\
\text { vent fan on }\end{array}$ & $41-76$ & $41-73$ \\
\hline $\begin{array}{l}\text { At home, busy and active } \\
\text { ( } i, e \text {, dinner conver- } \\
\text { sation, kitchen work, } \\
\text { playing music, children } \\
\text { at play) }\end{array}$ & $21-64$ & $21-54$ \\
\hline $\begin{array}{l}\text { At home, isolated } \\
\text { (i.e., noise-producing } \\
\text { activity in adjacent } \\
\text { room, soft background } \\
\text { music) }\end{array}$ & $23-49$ & $23-38$ \\
\hline $\begin{array}{l}\text { At home, obviously quiet } \\
\text { (i.e., reading, study, } \\
\text { eating alone) }\end{array}$ & $11-39$ & $11-28$ \\
\hline $\begin{array}{l}\text { At work, office and } \\
\text { commercial }\end{array}$ & $28-49$ & $28-45$ \\
\hline
\end{tabular}

NOTES:

1. Refers to the range of the minimum $\left(\mathrm{L}_{90}\right)$ sound pressure levels in the $630 \mathrm{~Hz}$ one-third octave-band.

2. Applicable for analysis of rotating sirens operated for 4minutes.

3. Applicable for analysis of stationary sirens operated for 4minutes.

4. To simplify the procedure, these are combined into a single indoor range on the basis of the activity fractions in rable 5.5 . 


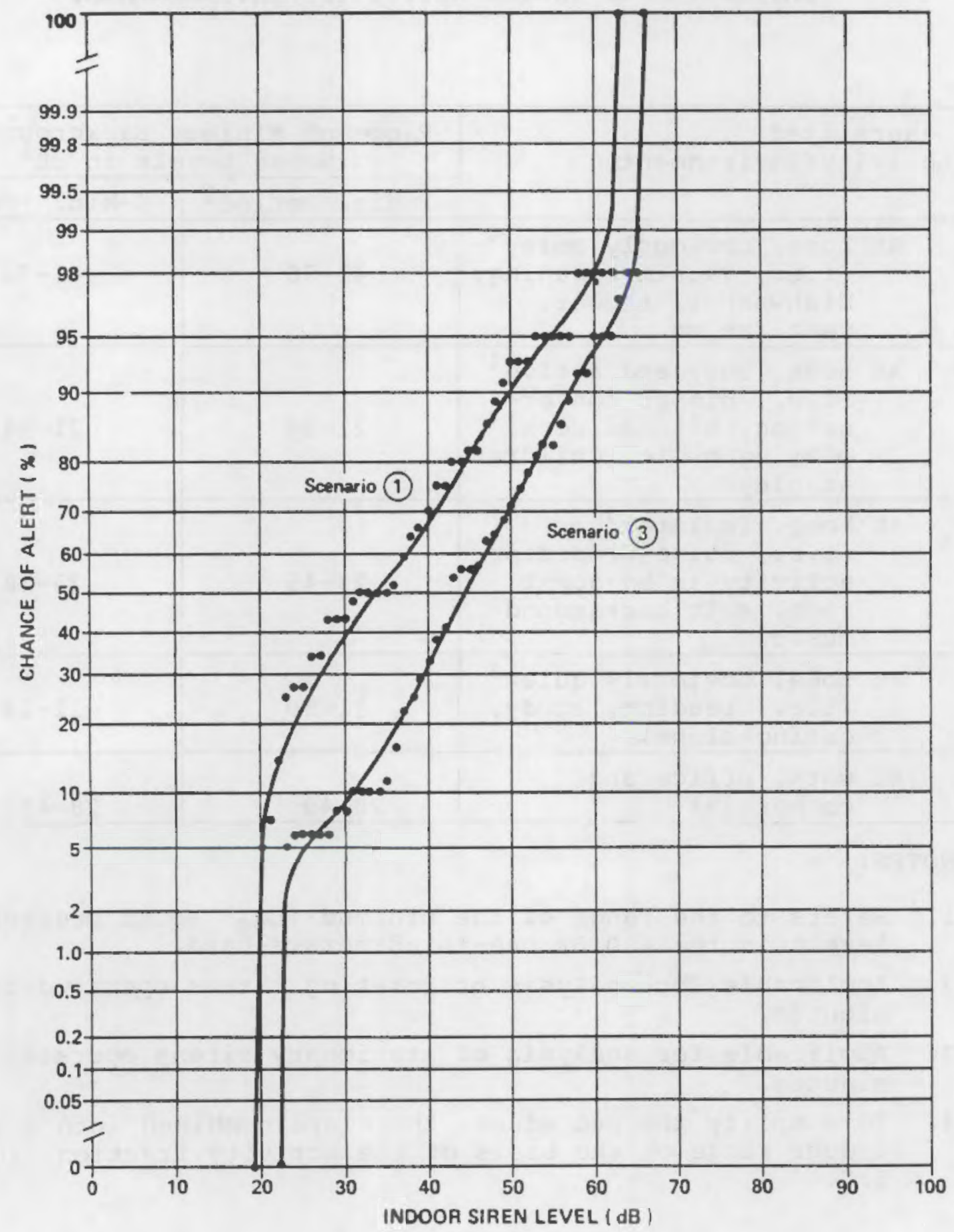

PIG. 5-5. CHANCE OF ALERT FOR PEOPLE INDOORS AT HOME (4-MINUTE STATIONARY SIREN). 


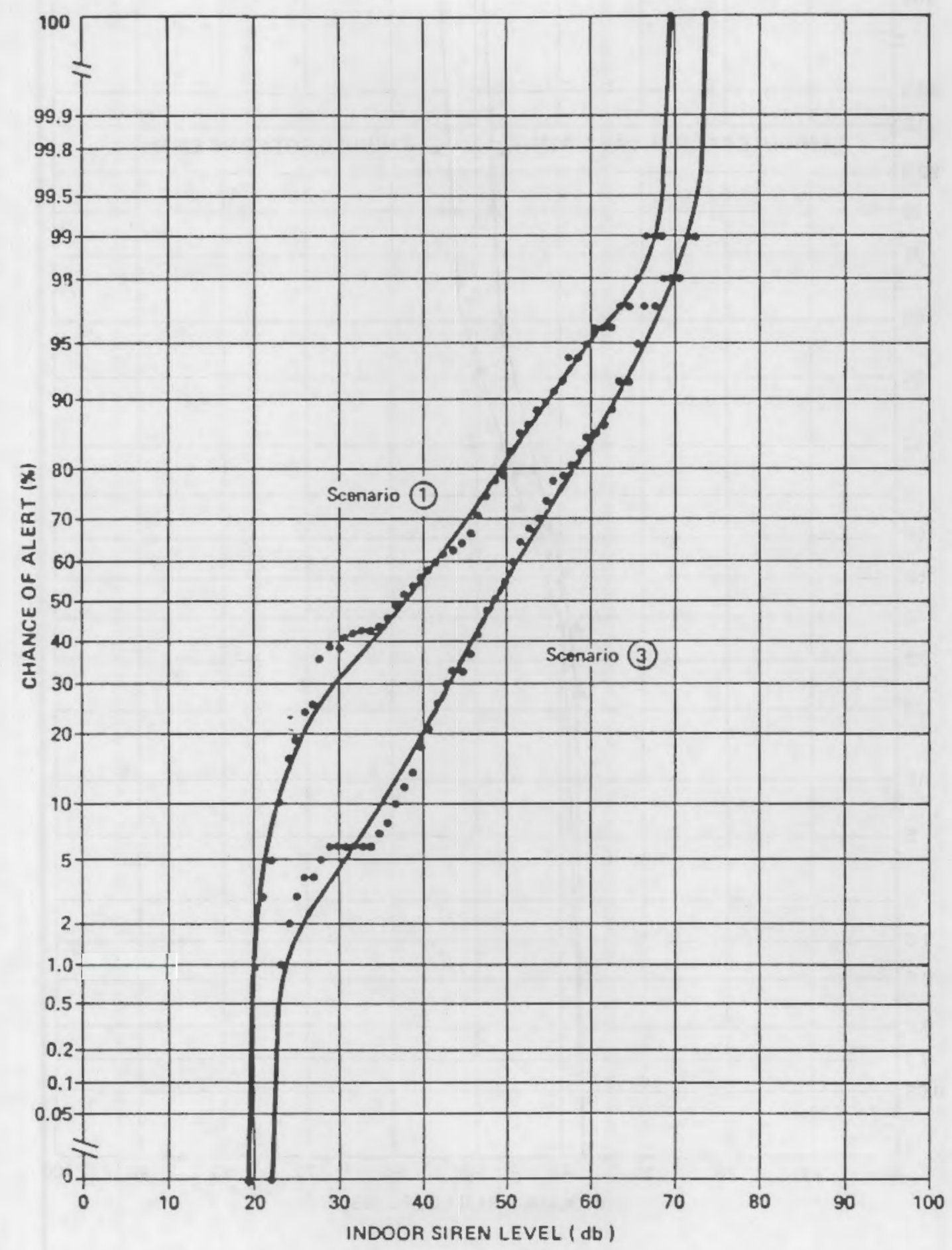

Fig. 5-6. CHANCE OF ALERT FOR PEOPLE INDOORS AT HOME (4-MINUTE ROTATING SIREN). 


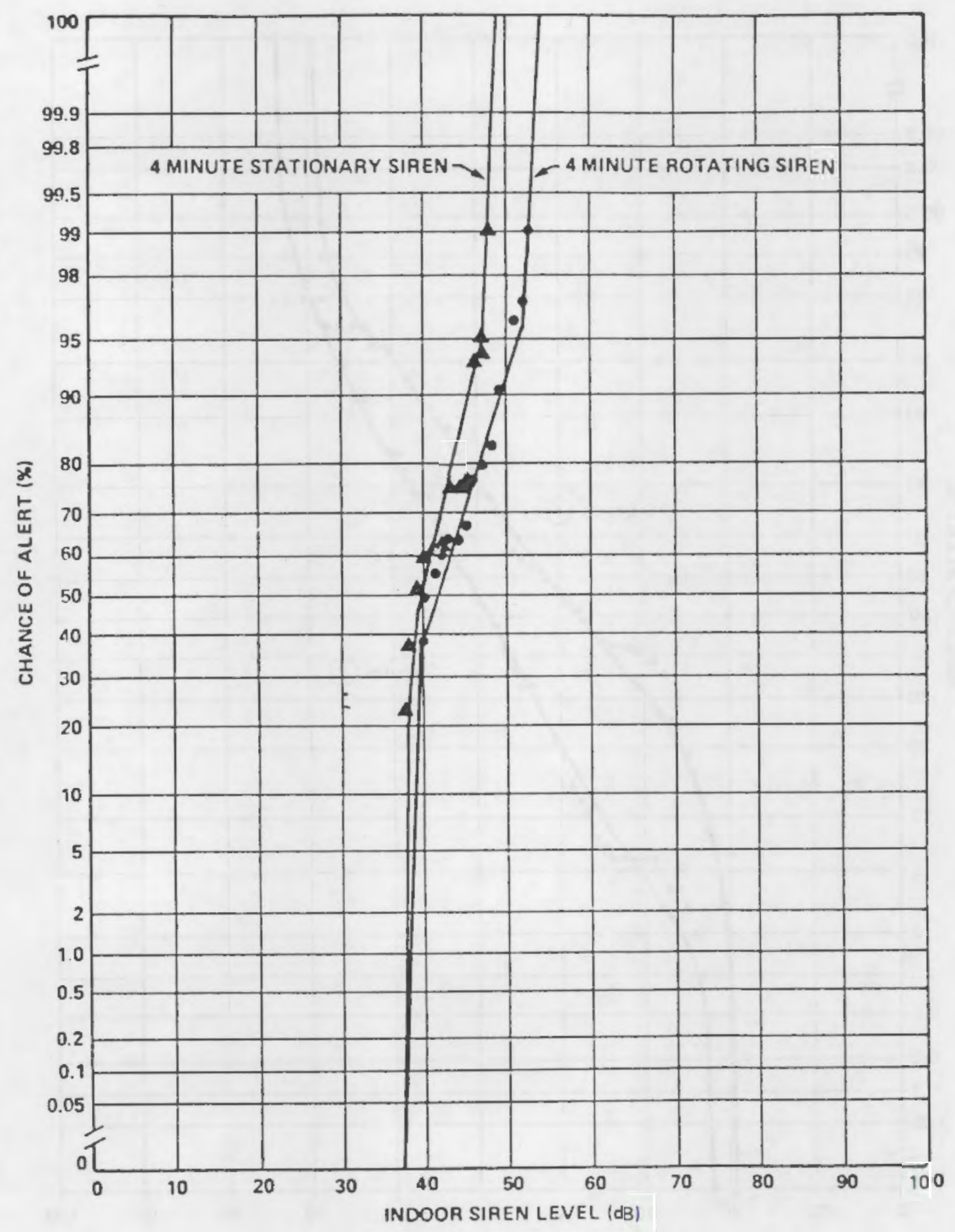

FIG. 5.7 CHANCE OF ALERT FOR PEOPLE INDOORS AT WORR IN COMMERCIAL/INSTITUTIONAL ESTABLISHMENTS. 


\subsection{Alerting People in Motor Vehicles}

The analysis for the alerting of motorists is based on the assumption of an average siren signal strength and spacing throughout the EPZ. The chance that a motorist will pass within the alert range of a siren during its 4 -minute operation is estimated as follows:

$$
C=\frac{2 R+d}{L} \times 100 \text { (not to exceed 1008) }
$$

where $C$ is the chance of alert ( 8$), R$ is the maximum alert distance ( $f t), d$ is distance traveled in 4 minutes ( $f t$ ), and $L$ is the average siren spacing $(f t)$. Separate analyses were carried out for urban and rural areas of the Zion EPZ.

The average urban siren produces a sound level of $123 \mathrm{~dB}$ at $100 \mathrm{ft}$ and the average rural siren produces a sound level of 124 $\mathrm{dB}$ at $100 \mathrm{ft}$. Alerting ability was evaluating by using the results of a study for the Society of Automotive Engineers (SAE) [6]. Siren alerting levels for speeds of $55 \mathrm{mph}$ and $30 \mathrm{mph}$ with windows shut or open were first determined from the SAE study results. The average siren source levels for rural and urban areas were then reduced to alerting levels in accordance with the propagation models from current NRC guidelines (i.e., $10 \mathrm{~dB} /$ double distance) [7]. In this manner, the maximum alert distance (R) was calculated for each driving condition. The distance traveled in 4 minutes (d) was calculated based on speed for each case, and the average siren spacing (L) was estimated to be 5,045 $\mathrm{ft}$ for urban areas and $19,240 \mathrm{ft}$ for rural areas.

The calculations of alerting ability for motorists are summarized in Table 5.7. The results indicate that the chance of alert is expected to be 1008 for all conditions applicable to the zion analysis. 
TABLE 5.7. SIREN ALERTING FOR HOTORISTS.

\begin{tabular}{|c|c|c|c|c|c|c|c|}
\hline Area & $\begin{array}{c}\text { Vehicle } \\
\text { Speed } \\
\text { (mph) }\end{array}$ & $\begin{array}{l}\text { Vehicle } \\
\text { Window } \\
\text { Condition }\end{array}$ & $\begin{array}{l}\text { Reqd. Signal } \\
\text { for Alert } \\
\text { (dB) }\end{array}$ & $\begin{array}{l}\text { Max. Alert } \\
\text { Dist. R } \\
\text { (ft) }\end{array}$ & $\begin{array}{c}\text { 4-min } \\
\text { Travel Dist.. d } \\
\text { (ft) }\end{array}$ & $\begin{array}{l}\text { Avg. Siren } \\
\text { Spacing } L \\
\text { (ft) }\end{array}$ & $\begin{array}{r}\text { Chance } \\
\text { of Alert } \\
(z)\end{array}$ \\
\hline URBAN & 30 & $\begin{array}{l}\text { Closed } \\
\text { Open }\end{array}$ & $\begin{array}{l}89 \\
86\end{array}$ & $\begin{array}{l}1,000 \\
1,200\end{array}$ & $\begin{array}{l}10,560 \\
10,560\end{array}$ & $\begin{array}{l}5,045 \\
5,045\end{array}$ & $\begin{array}{l}100 \\
100\end{array}$ \\
\hline RURAL & 55 & $\begin{array}{l}\text { Closed } \\
\text { Open }\end{array}$ & $\begin{array}{l}96 \\
90\end{array}$ & $\begin{array}{r}700 \\
1,000\end{array}$ & $\begin{array}{l}19,360 \\
19,360\end{array}$ & $\begin{array}{l}19,240 \\
19,240\end{array}$ & $\begin{array}{l}100 \\
100\end{array}$ \\
\hline
\end{tabular}




\section{REFERENCES}

1. Keast, D.N., Towers, D.A., and Anderson, G.S., "Procedure for Analyzing the Effectiveness of Siren Systems for Alerting the Public," BBN Report No. 4774 (February, 1982), (Published by the U.S. Nuclear Regulatory Commission as NUREG/CR-2654.)

2. L.L. Beranek, ed., "Noise and Vibration Control," McGrawHill Book Company (1971).

3. C.M. Harris, ed., "Hardbook of Noise Control," Chapter 3, McGraw-Hill Book Company (1979).

4. D.A. Driscoll, J.P. Dulin, Jr., and D.N. Keast, "Attenuation of Northern Dwellings to a Linear Source of Noise." Presented at the 95 th Meeting of the Acoustical Society of America, Providence, R.I. (May 1978).

5. U.S. Environmental Protection Agency, "National Roadway Noise Exposure Mode1," Draft Report (1980).

6. R.C. Potter et al., "Effectiveness of Audible Warning Devices on Emergency Vehicles," U.S. Department of Transportation, Report DOT-TSC-OST-77-38, washington, DC (August 1977).

7. "Criteria for Preparation and Evaluation of Radiological Emergency Response Plans and Preparedness in Support of Nuclear Power Plants," Nuclear Regulatory Commission, NUREG0654, Revision 1, Appendix 3, Part C.3.e, Washington, DC (November 1980). (The Federal Emergency Management Agency also publishes this document as FEMA-REP-1.) 


\section{APPENDIX A: POPULATED-WEIGHTED RANDOM SELECTION OF LISTENING POINTS AT THE TROJAN SITE}

The objective of the listener-site-selection process is to 1dentify 50 randomly selected residential locations within the 10-mile EPZ surrounding the Trojan Nuclear Plant. It was arbitrar1ly decided that 40 sites were to be 1 rural areas (population density below 2000 persons/sq mi) and 10 sites were to be in urban areas (population density above 2000 persons/sq mi). of the rural sites, 20 were to lie within 5 miles of the plant and 20 were to lie between 5 to 10 miles from the plant. These ground rules were established based on site-specific information.

The various steps used in the site selection procedure are described below:

1. The boundaries of urban and rural areas were defined on a set of USGS topographical maps cover1ng the EPZ. Those regions denoted by USGS as "bullding omission areas" on the maps (plnk shading) were assumed to be urban (w1th uniform population density), and all other areas were assumed rural. The urban areas included only the communities of Longview and Kelso.

2. A population distribution drawing (see Fig. A-1) consisting of a 10-mile-radius circle divided into annular sectors defined by interior circles and rad11 was superimposed on the U.S.G.S. maps. Population distribution information consisted of the number of people within each annular sector. These data were used to population-welght the random selection process for rural sites as described in step 3 below. 
TROJAN NUCLEAR PLANT
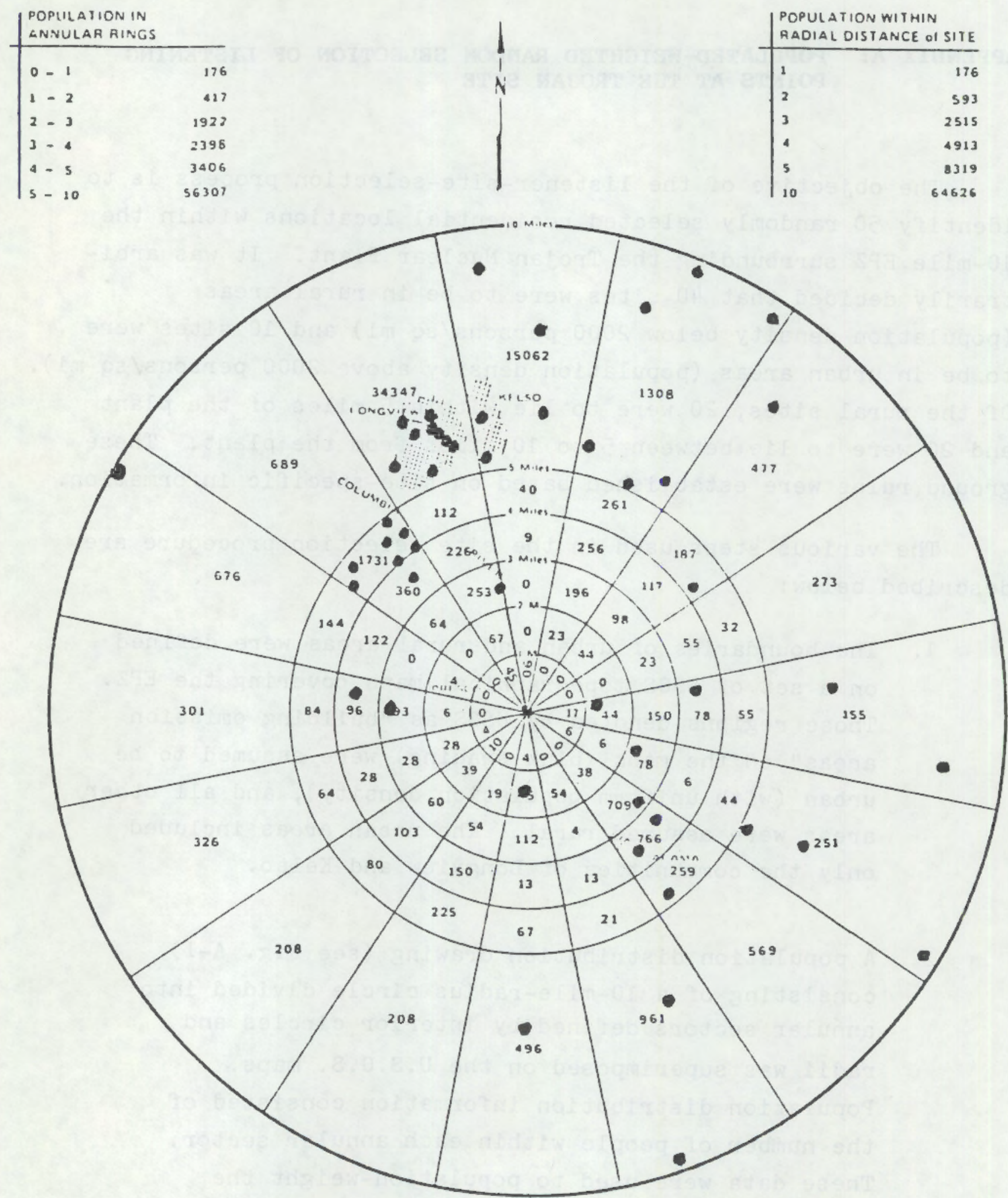

PIG. A-1. 1980 PROJECTED POPULATION DISTRIBUTION WITHIN 10 MILES AND RANDOMLY SELECTED LISTENER SITES (APPROXIMATE). 
3. Each annular sector was first assigned a number. A range of numbers was then assigned to each sector according to the population in that sector. For example, Sector no. 1, due north of the s1te, had a population of 90 and thus was assigned numbers 1 through 90. Sectors 2 through 4 (moving clockwise) had zero population and were therefore not assigned any numbers. Sector 5 had a population of 17 and was assigned numbers 91 through 107. This process was continued until each number between 1 and 18,600 (the total estimated rural population) was assigned to a particular sector. A random number generator (available, for example, on a Texas Instruments Model TI-59 hand calculator) was then used to select 20 numbers at random between 1 and 8,293 (representing sectors within 5 miles of the plant) and 20 numbers at random between 8,294 and 18,600 (representing sectors between 5 and 10 miles from the plant). Each number selected represented one site (to be chosen later) within the sector assigned to that number. Thus, sectors with larger populations would have a greater probability of including chosen listener sites.

4. Having determined the sector location for each rural listener site, the next step in the procedure involved selecting the actual location of each site within 1ts respective sector. This was accomplished by first overlaying a rectangular coordinate grid on each sector of interest on the USGS map. The grid was composed of boxes with dimensions of 
approximately $1000 \mathrm{ft} \mathrm{sq}$, and each box was assigned an $X$ and $a \mathrm{Y}$ coordinate according to 1ts location on the grid. The grid was positioned so that the $X$ axis was oriented in the east-west direction and the $Y$ axis was oriented in the north-south direction, and so that all parts of the sector of interest were covered by a positive $(X, Y)$ coordinate pair box. A random number generator was then used to select random pairs of numbers within the $X$ and $Y$ ranges including the sector of interest. Each $X, Y$ pair was used to locate a particular $1000 \mathrm{ft} s q$ box on the USGS map. If no residences were ins1de the square area or If the area fell outside of the sector of interest, the coordinate pair was disregarded and another pair was chosen at random. This process was continued until a square area including one or more residential structures was found in the sector of interest. The listener site was then chosen to be any residence within the randomiy selected square area. In this manner, the sample of 40 rural l1stener sites was selected.

5. The selection procedure for urban sites was similar to that for rural sites, except that each distinct urban area was treated as a sector and population was assumed to be uniformly distributed throughout each urban sector. Thus, random number pairs were used to select square areas on the grid, and a listener site was chosen anywhere in that area provided that the site fell within the urban sector of interest. In th1s manner, the sample of 10 urban listener s1tes was selected. 
The above procedure resulted in a random sample of 50 listener locations, distributed throughout the EPZ as shown roughly on Fig. A-1. 

APPENDIX B: TEST CASES (SAMPLE SCENARIOS) FOR THE TROJAN SITE

1. Warm summer weekend day, weather clear to partly cloudy

People: $70 \%$ out of doors $20 \%$ indoors $10 \%$ in motor vehicles (windows open)

Buizdings: Windows open

Wind: $\quad 10 \mathrm{mph}$ - from the north throughout the region

upslope in the canyon

Temperature Gradient: $-2^{\circ} \mathrm{C} / 100 \mathrm{~m}$; Class A Relative Humidity: $\quad 50 \%$

2. Summer weekday night, weather clear to partly cloudy

People: $95 \%$ indoors, sleeping

$4 \%$ indoors, at work

1\% In motor vehicles (windows closed)

Buizdings: Windows open

Wind: from the north on ridges and plateaus

east and west of the site

$5 \mathrm{mph}$ - from the south in the river valley

downslope in the canyons

Temperature Gradient: $\quad+1.5^{\circ} \mathrm{C} / 100 \mathrm{~m}$; Class $\mathrm{E}$

Relative Humidity: $\quad 90 \%$

3. Winter weekday during evening commuting hours

Cool, damp, and overcast

People: $70 \%$ indoors

25\% in motor vehicles (windows closed)

$5 \%$ out of doors

Buildings: Wlndows closed 
Wind: $\quad 3 \mathrm{mph}$ - from the south calm in the canyons

Temperature Gradient: $+1^{\circ} \mathrm{C} / 100 \mathrm{~m}$; Class $\mathrm{E}$ Relative Humidity: $\quad 80 \%$

4. Winter night during rainstorm

People: $95 \%$ indoors, sleeping

$4 \%$ indoors, at work

$1 \%$ in motor vehicles (windows closed)

Buildings: Windows closed

Wind: $\quad 15 \mathrm{mph}$ - irom the south

$5 \mathrm{mph}$ - downslope in the canyons

Temperature Gradient: $\quad+1^{\circ} \mathrm{C} / 100 \mathrm{~m}$; Class $\mathrm{E}$ Relative Humidity: $\quad 90 \%$

Sources: EIR, Amendment 1, March 1973, F1g. 2.3.4, Tables 2.3.3 and 2.3.13. Site-specific wind velocity profile inversion at Trojan has not been considered. 


\section{APPENDIX C: SIREN LOCATIONS FOR THE TROJAN EPZ}

This appendix provides siren locations for the Trojan EPZ on a set of maps $(1-6)$. A siren location map index is provided which shows the relationship of individual maps to the Trojan EPZ.

Table C. 1 provides information on the type and rating for each siren, as well as a guide for locating the sirens on the maps. 


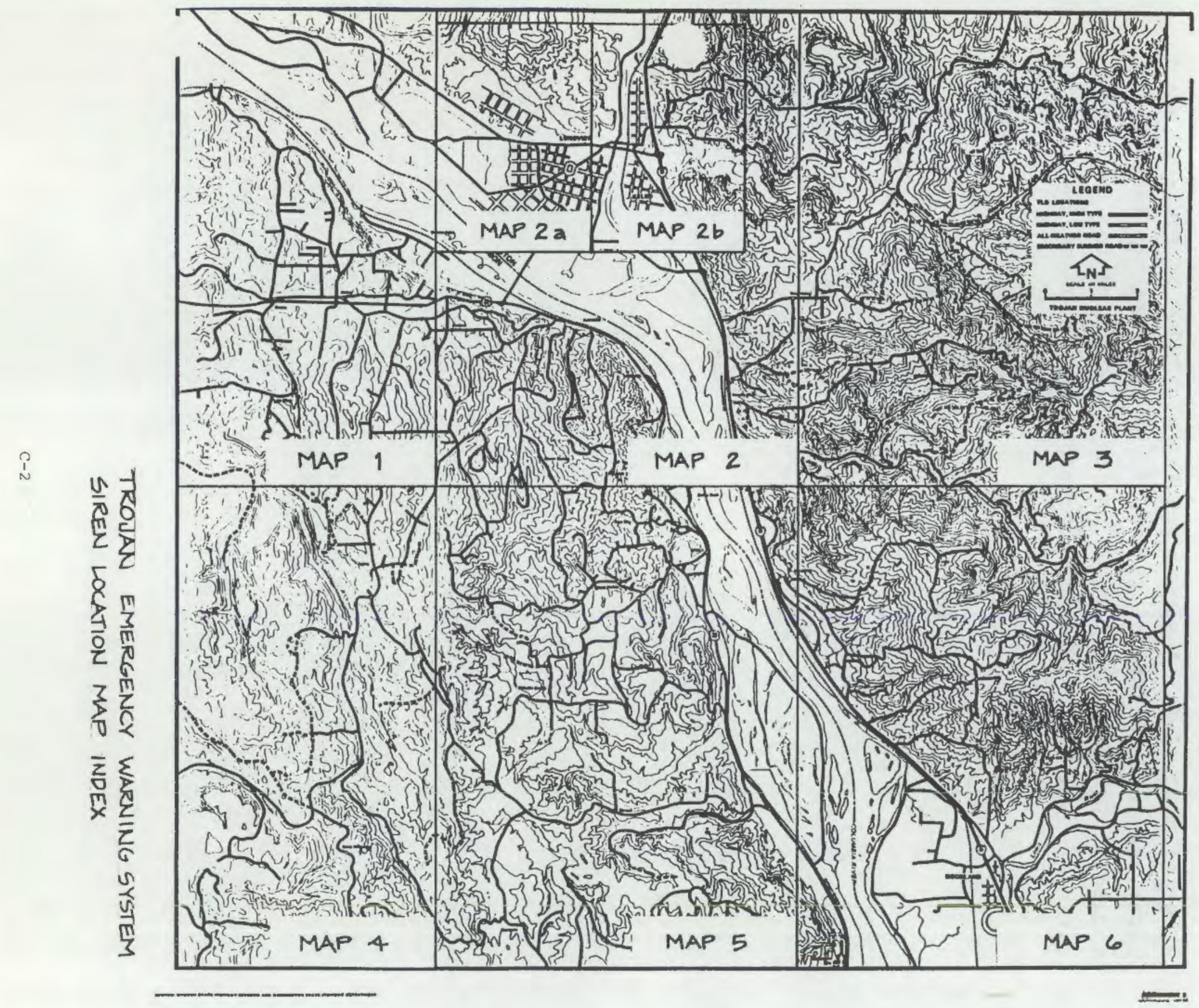




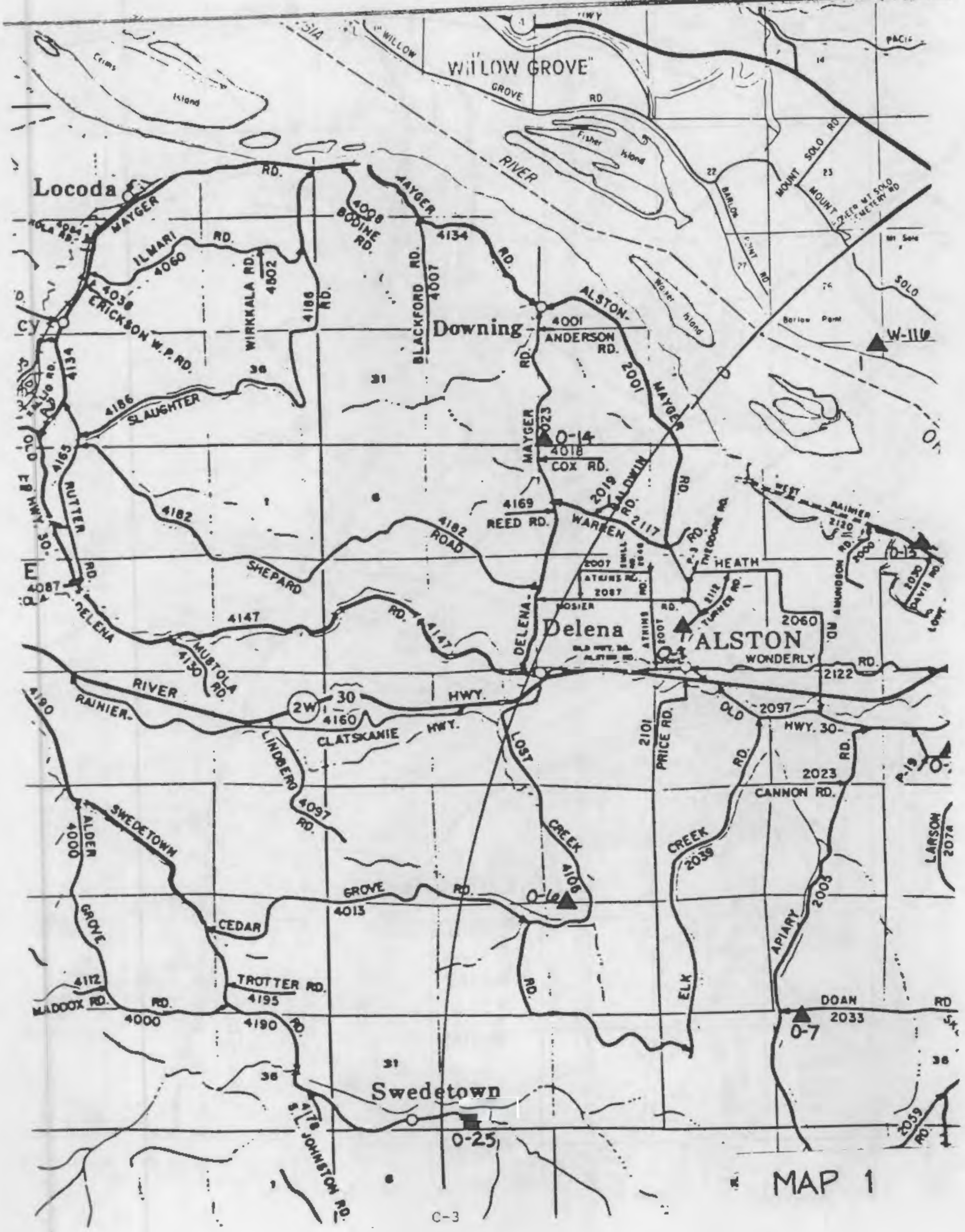




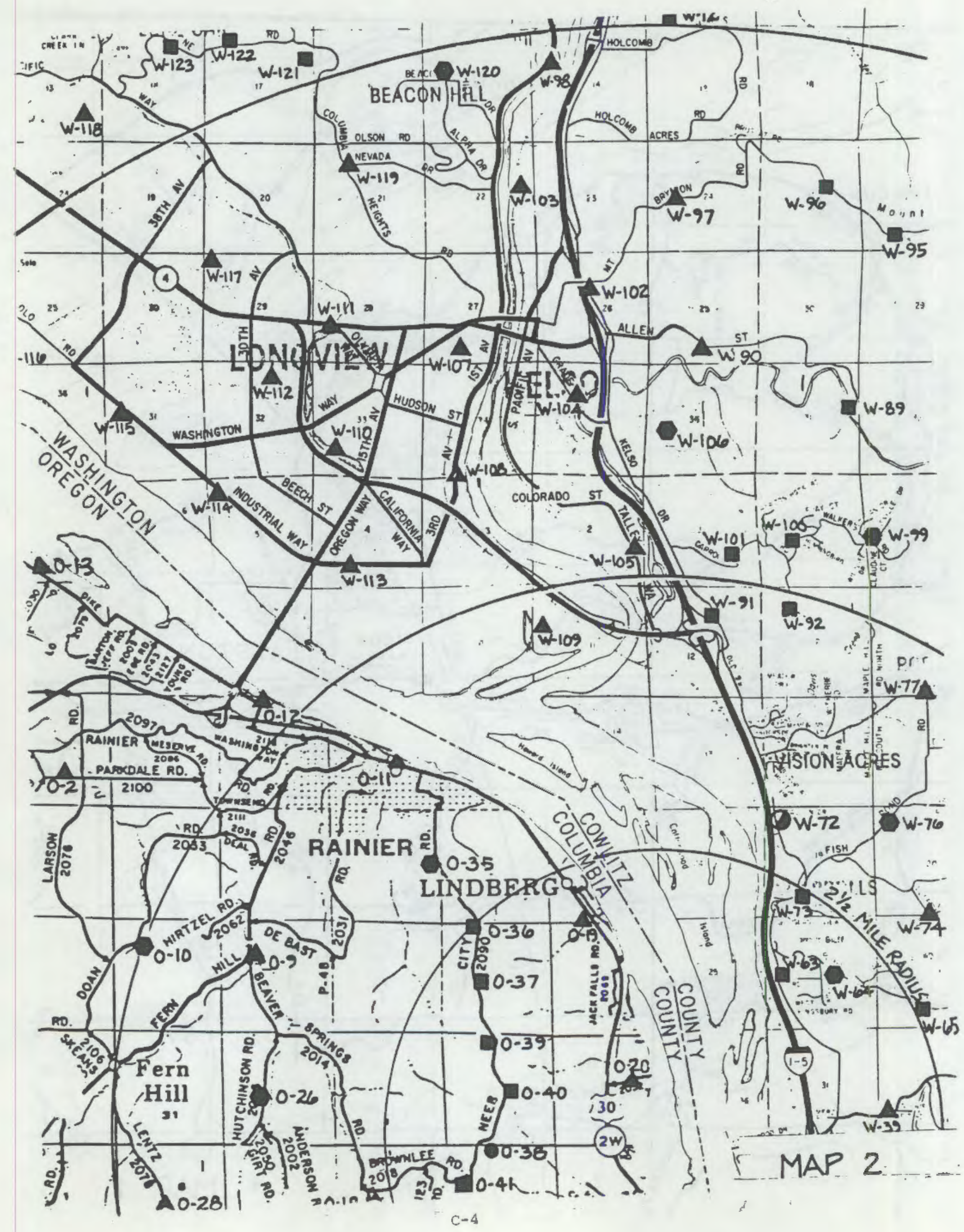




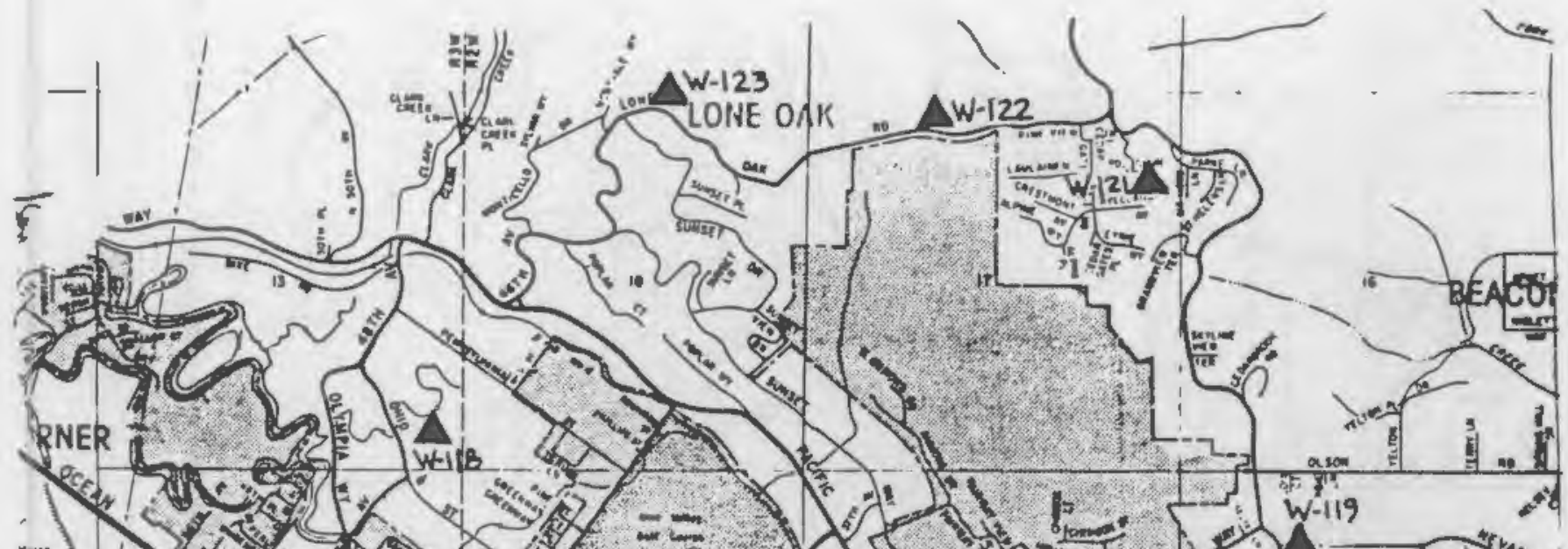

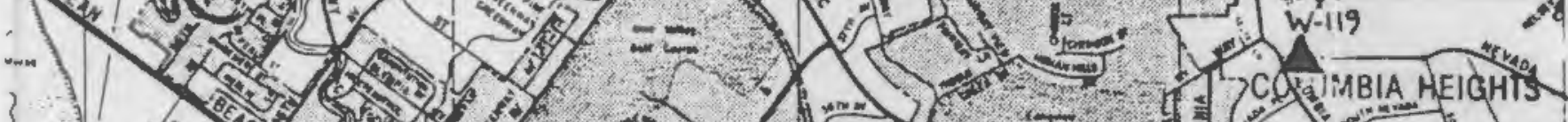

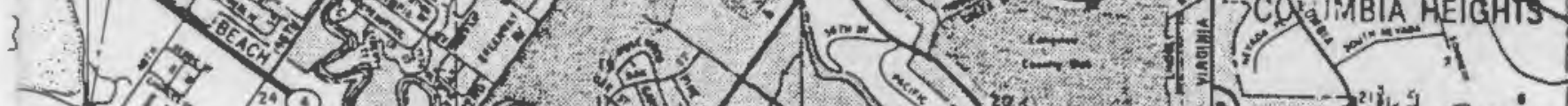

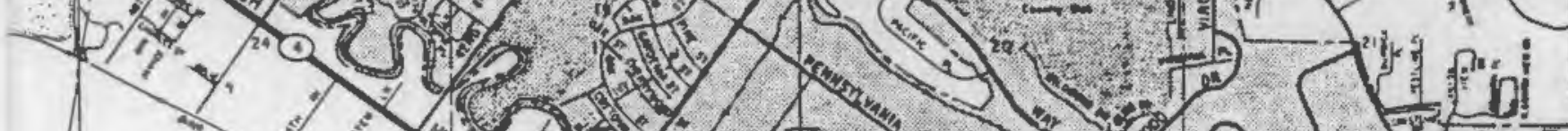

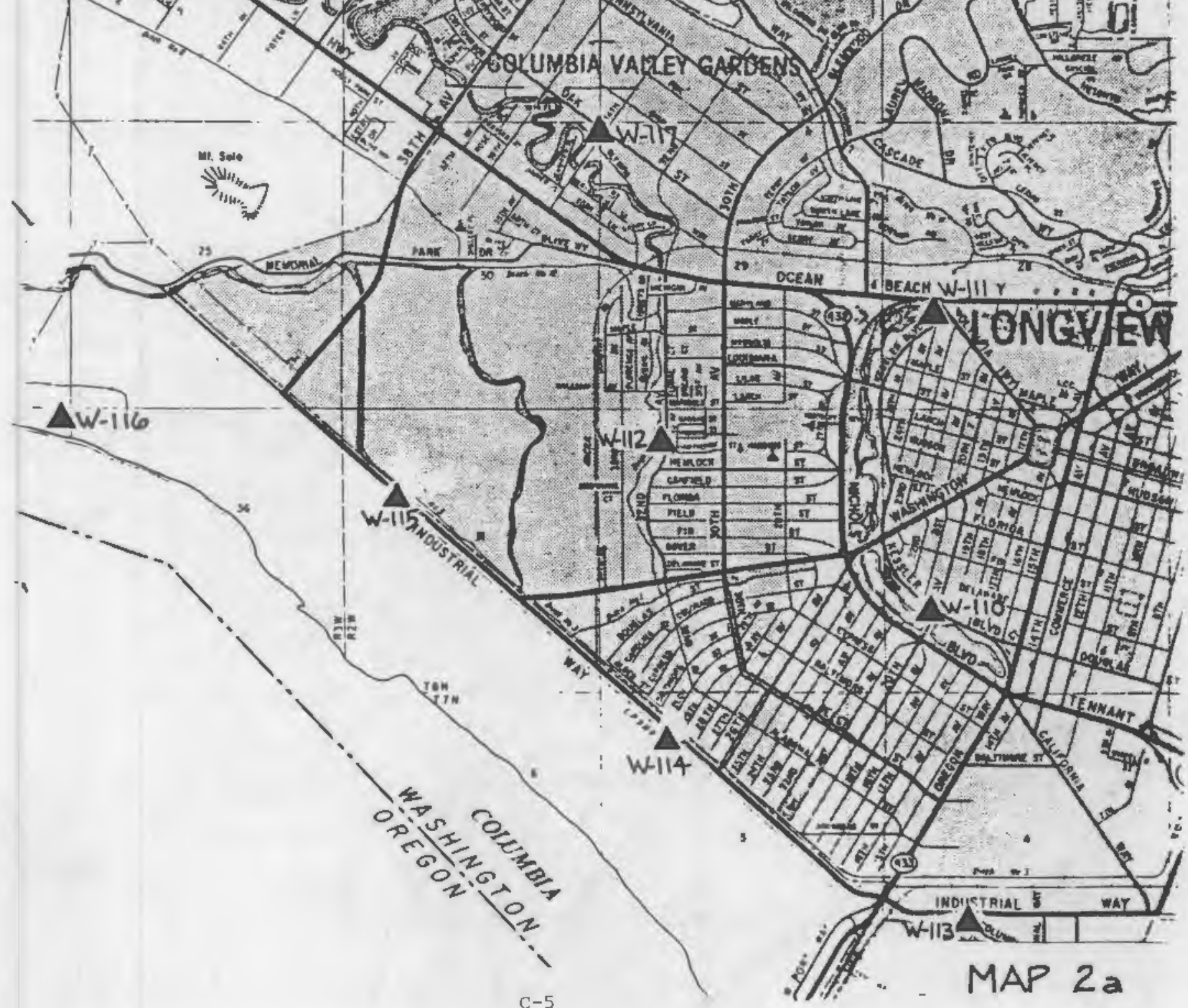




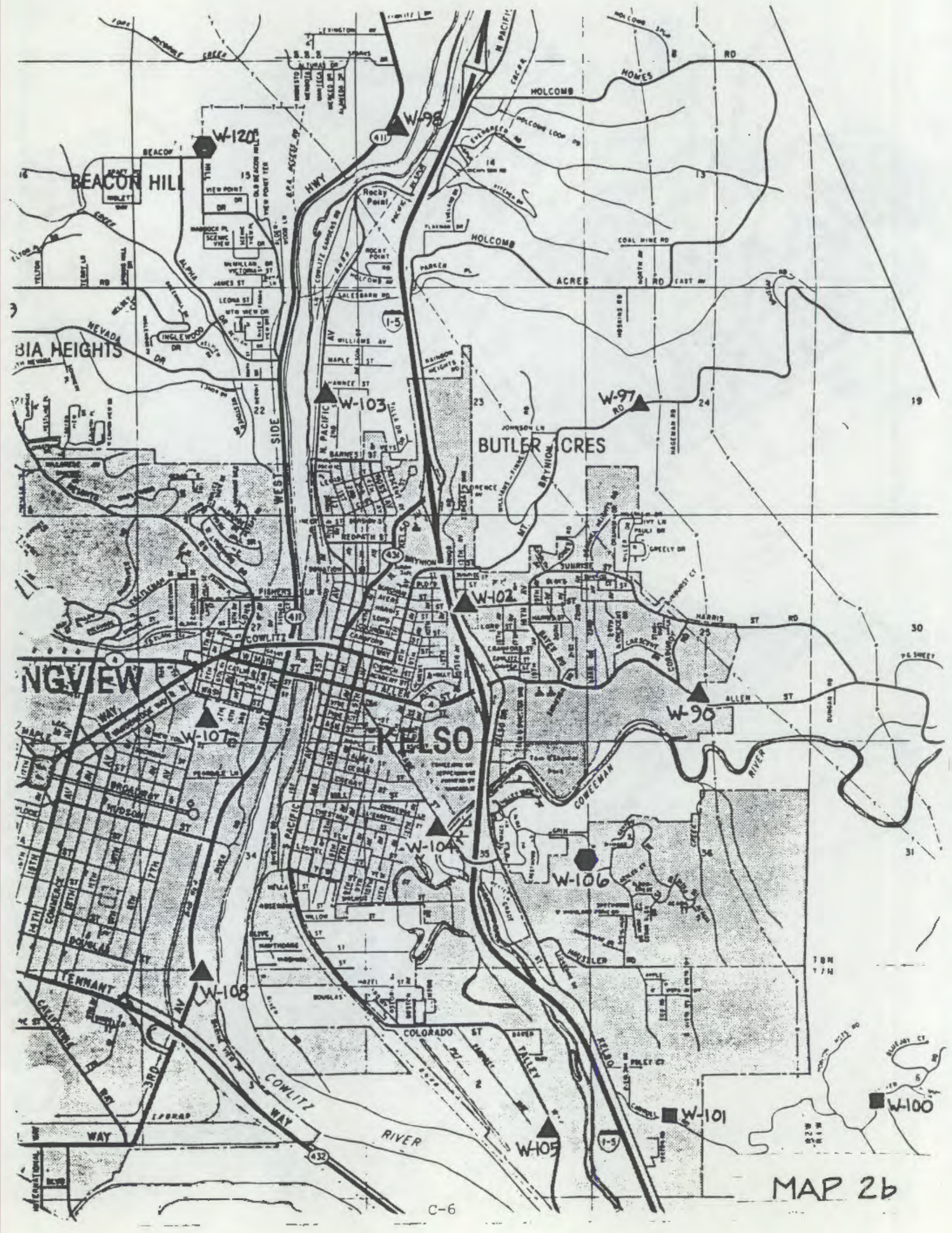




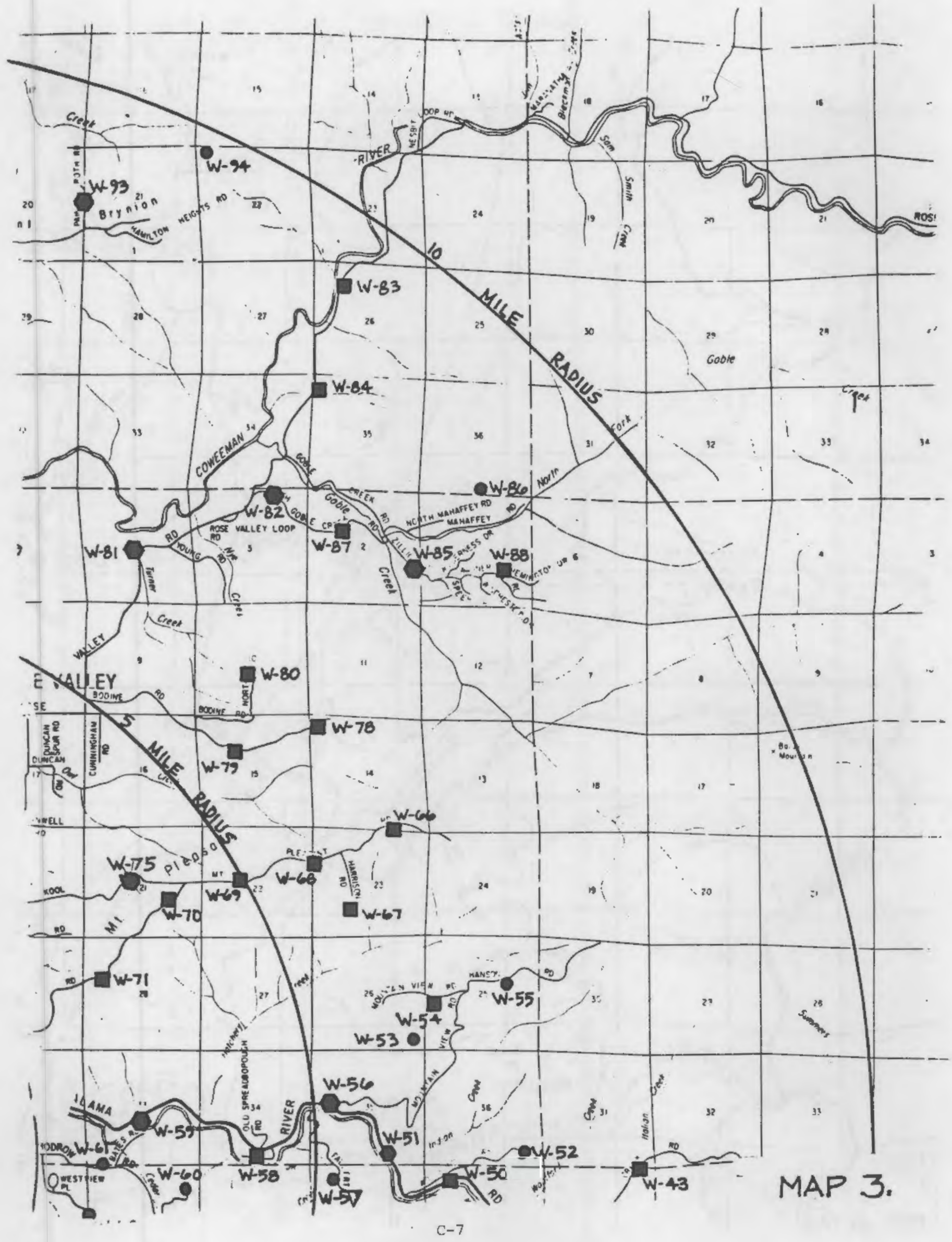




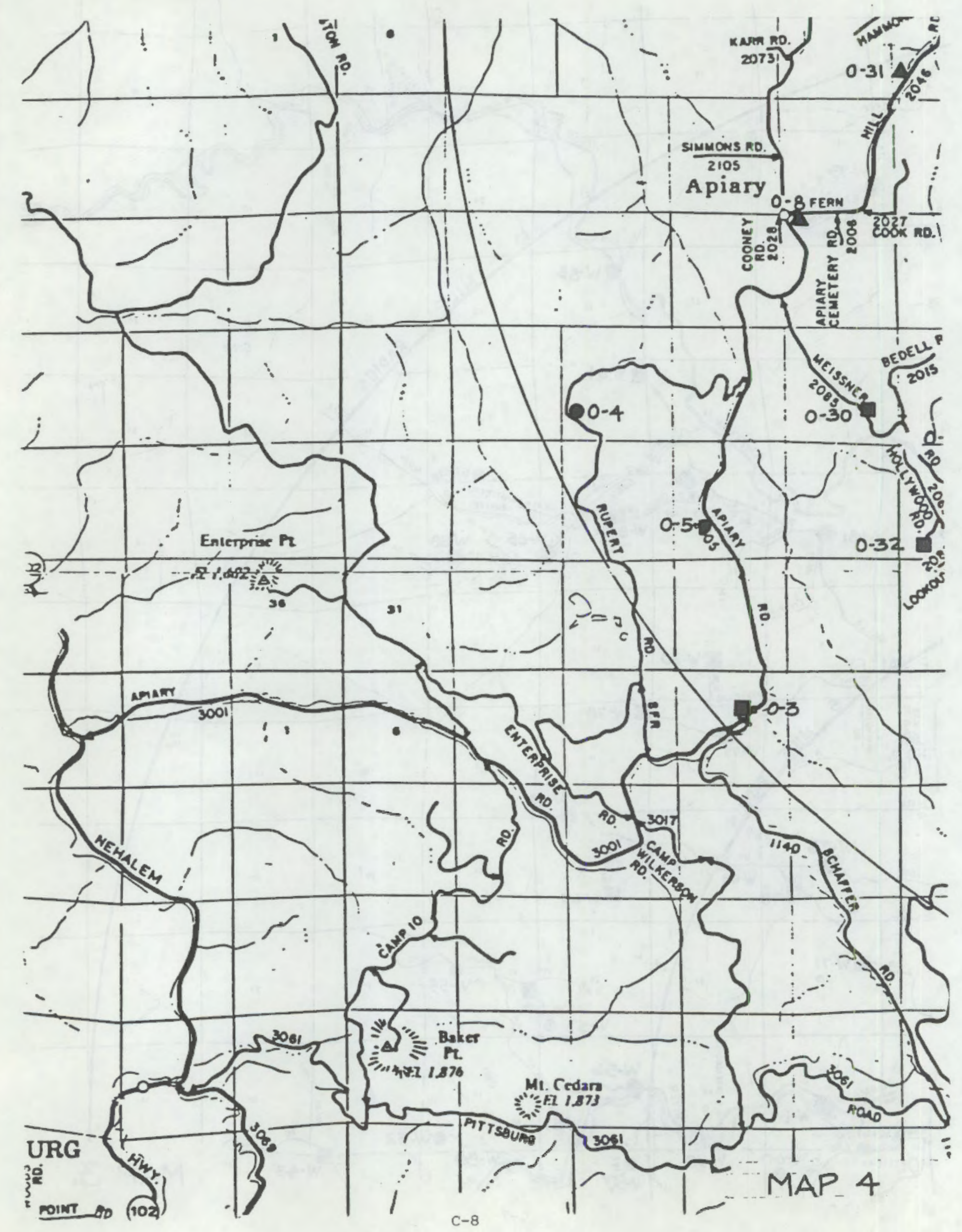




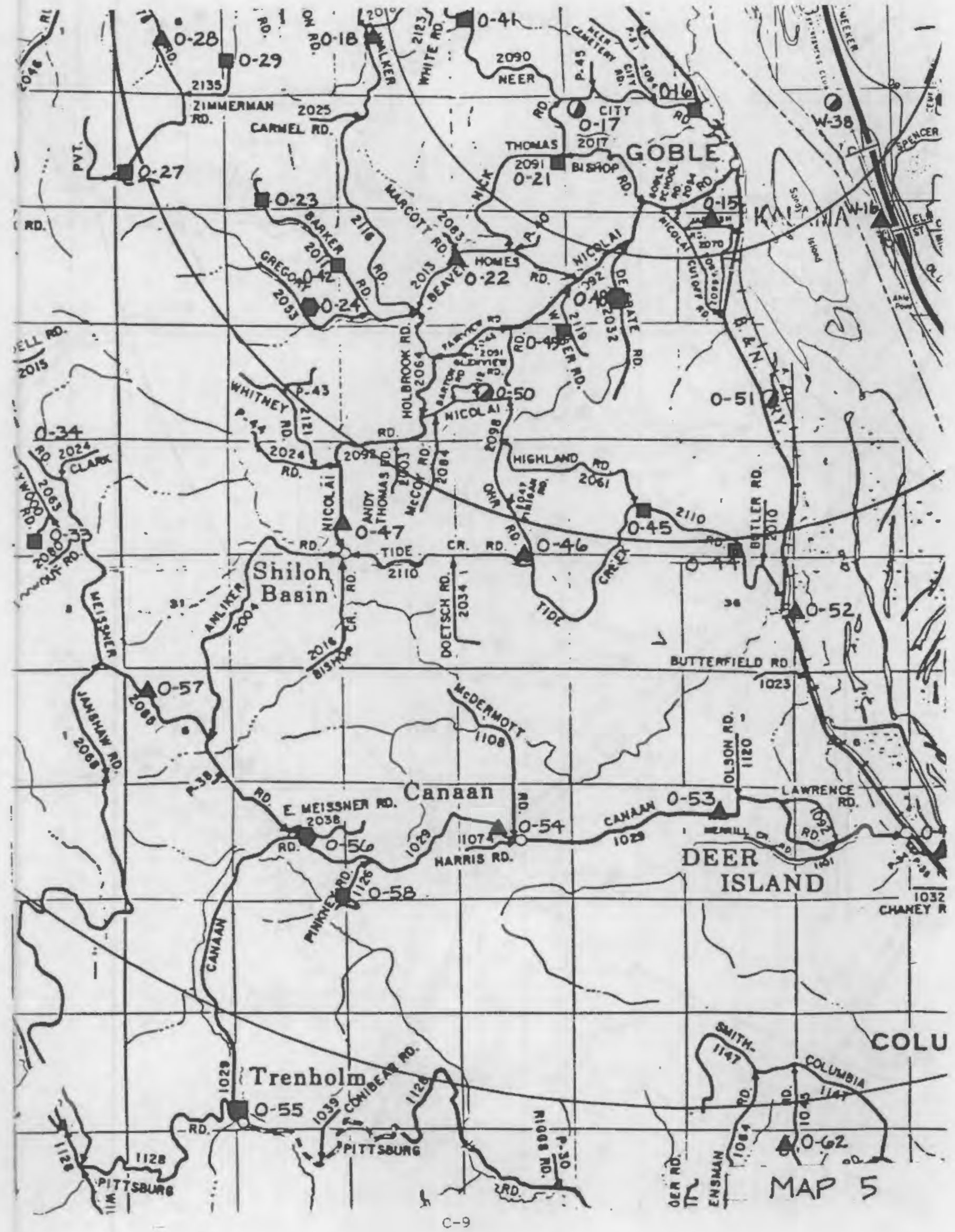




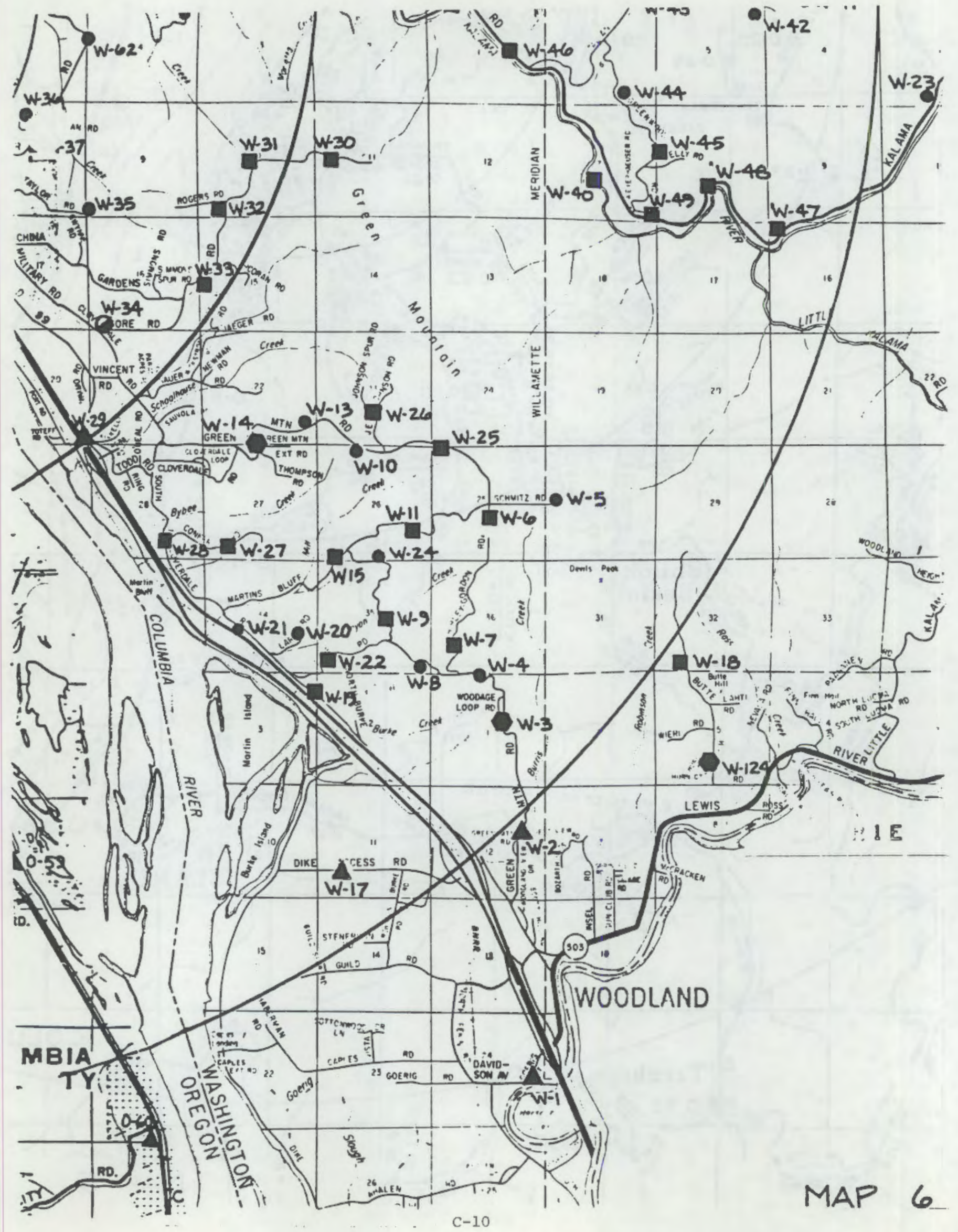


TABLE C.1. TROJAN SIREN INFORMATION.

siren №.

$0-1$

$0-2$

$0-3$

$0-4$

$0-5$

$0-6$

$0-7$

$0-8$

$0-9$

$0-10$

$0-11$

$0-12$

$0-13$

$0-14$

$0-15$

$0-16$

$0-17$

$0-18$

$0-19$

$0-20$

$0-21$

$0-22$

$0-23$

$0-24$

$0-25$

$0-26$

$0-27$

$0-28$

$0-29$

$0-30$

$0-31$

$0-32$

$0-33$

$0-34$

$0-35$

$0-36$

$0-37$

$0-38$

$0-39$

$0-40$

$0-41$

$0-42$
Location

(Map No.)

1

2

4

4

4

1

4

2

2

2

2

1

1

5

5

5

5

2

2

5

5

5

5

1

2

5

5

5

4

4

4

5

5

2

2

2

2

2

2

5
Rated SPL

(dB $100 \mathrm{ft}$ ) Type*

125

125

102

86

86

125

125

125

125

107

125

125

125

125

125

102

115

125

125

125

102

125

102

107

102

107

102

125

102

102

125

102

86

115

107

102

102

86

102

102

102

102
R

R

S

$S$

S

R

R

R

R

S

R

R

R

R

R

S

S

R

R

R

$\mathrm{S}$

R

S

S

S

S

S

R

$\mathrm{S}$

S

R

$\mathrm{S}$

S

S

S

S

S

S

$\mathrm{S}$

S

S

S

*Rotating (R) or Stationary (S) 
TABLE C. 1. TROJAN SIREN INFORMATION (Cont.). Location Rated SPL

Siren No.

(Map No.)

(dB e $100 \mathrm{ft}$ )

Type*

$0-43$

5

$0-44$

125

102

102

$0-45$

5

$0-46$

125

125

$0-47$

107

$0-48$

102

115

115

$0-50$

125

125

125

102

107

125

102

125

125

102

125

125

125

102

W2

พ3

W4

W5

พ6

พ7

พ8

W9

W10

W1 1

พ1 2

W13

86

86

102

102

86

102

86

102

102

R

S

$S$

R

R

$\mathrm{S}$

S

$\mathrm{S}$

$S$

R

R

R

$S$

S

R

S

R

R

S

R

R

R

S

S

S

S

S

S

$\mathrm{S}$

S

S

86

107

102

125

125

102

102

86

86

S

S

$S$

$S$

R

R

S

S

S

S

ॠRotating (R) or Stationary (S) 
TABLE C.1. TROJAN SIREN INFORMATION (CONt).

Siren No.

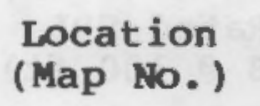

Rated SPL

(dB $100 \mathrm{ft}) \quad$ Type*

พ 22

$6 \quad 102$

พ23

พ24

พ 25

W26

W27

พ28

W29

พ30

W31

พ32

W33

W34

W35

พ36

พ37

W38

พ39

W40

W41

W4 2

W43

W44

W45

W4 6

W4 7

W48

W4 9

W50

พ51

พ5 2

W5 3

W5 4

W5 5

พ56

W57

W58

พ59

W60

W61

W62

6

6

6

6

6

6

6

6

6

6

6

6

6

6

5

2

6

6

6

3

6

6

6

6

6

6

3

3

3

3

3

3

3

3

3

3

3

3

6
102
102

86

102

102

102

102

125

102

102

102

102

115

86

86

102

115

125

102

86

86

102

86

102

102

102

102

102

102

107

86

86

102

86

107

86

102

107

86

86

86
S

S

S

$\mathrm{S}$

S

$S$

S

R

S

$\mathrm{S}$

S

$S$

S

S

S

S

S

R

S

S

S

S

S

S

S

S

S

S

S

S

S

$\mathrm{S}$

S

S

S

S

S

S

S

S

S

*Rotating (R) or Stationary (S) 
TABLE C.1. TROJAN SIREN INFORMATION (Cont.)

\begin{tabular}{|c|c|c|c|}
\hline Siren No. & $\begin{array}{l}\text { Location } \\
\text { (Map No.) }\end{array}$ & $\begin{array}{c}\text { Rated SPL } \\
(\mathrm{dB} \quad 100 \mathrm{ft})\end{array}$ & Type* \\
\hline W63 & 2 & 102 & $\mathrm{~s}$ \\
\hline W64 & 2 & 107 & $\mathrm{~s}$ \\
\hline W65 & 2 & 102 & $\mathrm{~s}$ \\
\hline W66 & 3 & 102 & $\mathrm{~S}$ \\
\hline W67 & 3 & 102 & $\mathrm{~S}$ \\
\hline W68 & 3 & 102 & $\mathrm{~S}$ \\
\hline W69 & 3 & 102 & $\mathrm{~S}$ \\
\hline W70 & 3 & 102 & $\mathrm{~S}$ \\
\hline W71 & 3 & 102 & $S$ \\
\hline w7 2 & 2 & 115 & $\mathrm{~S}$ \\
\hline พ73 & 2 & 102 & $\mathrm{~S}$ \\
\hline W7 4 & 3 & 102 & $\mathrm{~S}$ \\
\hline W75 & 3 & 107 & $\mathrm{~S}$ \\
\hline พ76 & 2 & 107 & $\mathrm{~s}$ \\
\hline W77 & 2 & 125 & $\mathrm{R}$ \\
\hline W78 & 3 & 102 & $\mathrm{~s}$ \\
\hline W79 & 3 & 102 & S \\
\hline พ80 & 3 & 102 & S \\
\hline พ81 & 3 & 107 & $\mathrm{~S}$ \\
\hline พ8 2 & 3 & 107 & $\mathrm{~s}$ \\
\hline W83 & 3 & 102 & $\mathrm{~s}$ \\
\hline พ8 4 & 3 & 102 & $\mathrm{~s}$ \\
\hline W8 5 & 3 & 107 & $\mathrm{~s}$ \\
\hline พ8 6 & 3 & 86 & $\mathrm{~s}$ \\
\hline W87 & 3 & 102 & $\mathrm{~s}$ \\
\hline W8 8 & 3 & 102 & $\mathrm{~S}$ \\
\hline พ89 9 & 2 & 102 & $\mathrm{~s}$ \\
\hline พ90 0 & 2 & 125 & $\mathrm{R}$ \\
\hline W91 & 2 & 102 & S \\
\hline พ9 2 & 2 & 102 & $\mathrm{~S}$ \\
\hline W9 3 & 3 & 107 & s \\
\hline W94 & 3 & 86 & $\mathrm{~S}$ \\
\hline W9 5 & 2 & 102 & S \\
\hline พ96 & 2 & 102 & $\mathrm{~s}$ \\
\hline พ97 & $2 b$ & 125 & $\mathrm{R}$ \\
\hline W98 & $2 b$ & 125 & $\mathrm{R}$ \\
\hline พ99 & 2 & 115 & $\mathrm{~s}$ \\
\hline W100 & $2 b$ & 102 & $\mathrm{~s}$ \\
\hline W101 & $2 b$ & 102 & $\mathbf{s}$ \\
\hline W102 & $2 \mathrm{~b}$ & 125 & $\mathrm{R}$ \\
\hline W103 & $2 b$ & 125 & R \\
\hline
\end{tabular}

* Rotating (R) or Stationary (S) 


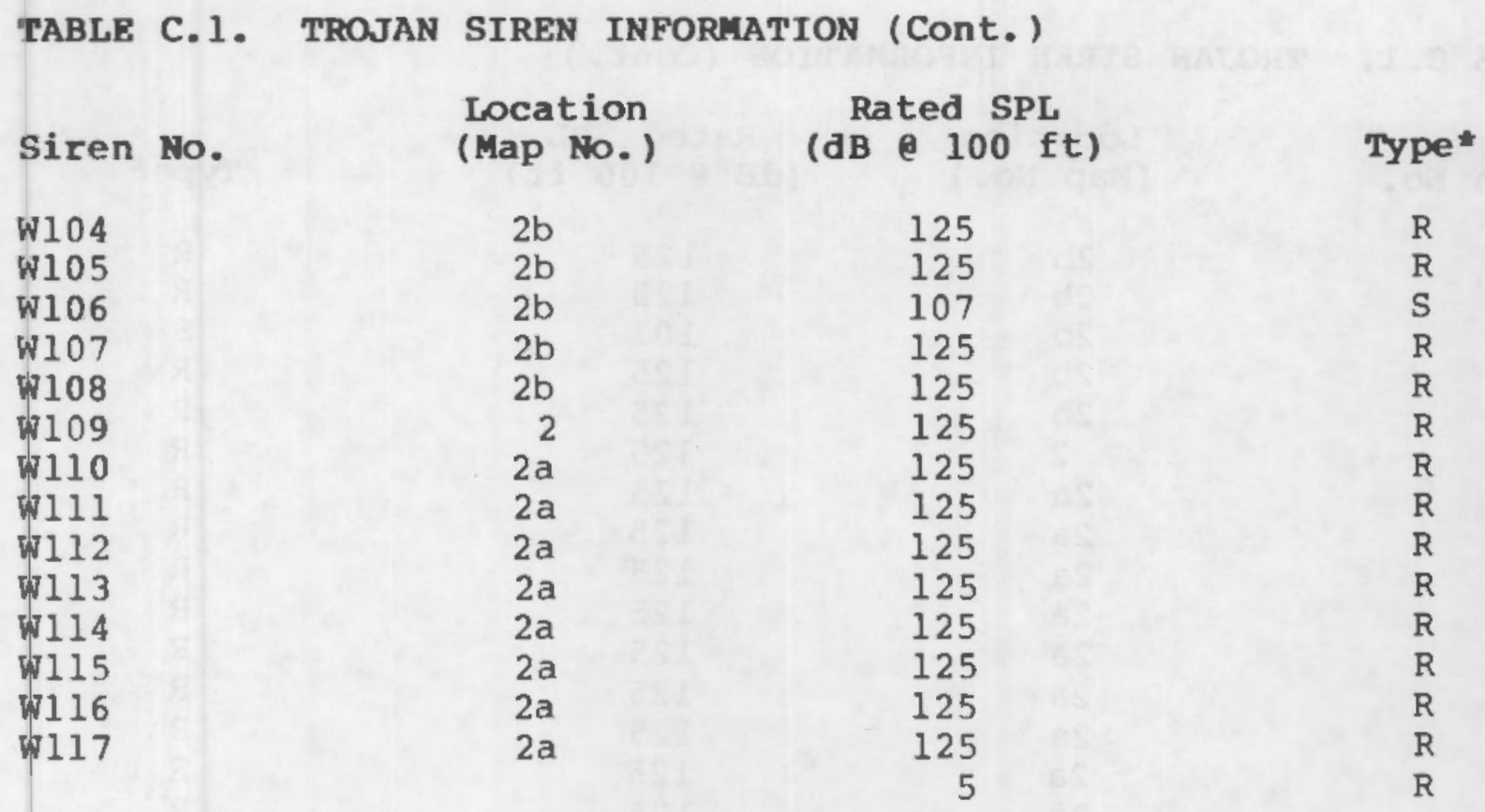


TABLE C.1. TROJAN SIREN INFORMATION (Cont.)

\begin{tabular}{|c|c|c|c|}
\hline Siren No. & $\begin{array}{l}\text { Location } \\
\text { (Map No.) }\end{array}$ & $\begin{array}{l}\text { Rated SPL } \\
(\mathrm{dB} \text { e } 100 \mathrm{ft})\end{array}$ & Type* \\
\hline W104 & $2 b$ & 125 & $\mathrm{R}$ \\
\hline W105 & $2 b$ & 125 & $\mathrm{R}$ \\
\hline W106 & $2 b$ & 107 & \\
\hline W107 & $2 \mathrm{~b}$ & 125 & $\mathrm{R}$ \\
\hline W108 & $2 b$ & 125 & $\mathrm{R}$ \\
\hline W109 & 2 & 125 & $\mathrm{R}$ \\
\hline W1 10 & $2 a$ & 125 & $\mathrm{R}$ \\
\hline W111 & $2 a$ & 125 & $R$ \\
\hline W112 & $2 a$ & 125 & $\mathrm{R}$ \\
\hline W113 & $2 a$ & 125 & $\mathrm{R}$ \\
\hline W114 & $2 a$ & 125 & $\mathrm{R}$ \\
\hline W115 & $2 a$ & 125 & $\mathrm{R}$ \\
\hline W116 & $2 a$ & 125 & R \\
\hline W117 & $2 a$ & 125 & $\mathrm{R}$ \\
\hline W118 & $2 a$ & 125 & $\mathrm{R}$ \\
\hline W119 & $2 a$ & 125 & $\mathrm{R}$ \\
\hline W120 & $2 b$ & 107 & S \\
\hline W121 & $2 a$ & 102 & $\mathrm{~S}$ \\
\hline W122 & $2 a$ & 102 & S \\
\hline W1 23 & $2 a$ & 102 & $S$ \\
\hline W1 24 & 6 & 107 & $S$ \\
\hline
\end{tabular}

${ }^{*}$ Rotating (R) or Stationary (S) 


\section{APPENDIX D: ESTIMATION OF A ATM}

The speed of sound in air increases with the square root of the absolute temperature. When the atmosphere is in motion, the speed of sound is the vector sum of its speed in still air and the wind speed. The temperature and wind in the atmosphere near the ground are almost never uniform. Hence, atmospheric nonuniformity produces gradients of the speed of sound, and thus refraction (bending) of sound wave paths. Near the ground, this refraction can have a major effect on the apparent attenuation of sound propagated through the atmosphere.

For the purpose of this procedure we have assumed a horizontally stratified atmosphere in which temperature and wind speed vary only with the logarithm of height above the ground. During the daytime, temperature normally decreases with height (lapse), so that sound waves from a source near the ground are refracted upwards. In the absence of wind, an "acoustic shadow" forms around the source (Fig. D-la) into which no direct sound waves can penetrate. Marked attenuations are observed at receiving points well into the shadow zone - it is just as if a solid barrier had been built around the source. At night a temperature increase with height is common near the ground (inversion) and our "barrier" disappears as in Fig. D-lb.

Near the ground, wind speed almost always increases with height. Because the speed of sound is the vector sum of its speed in still air and the wind vector, a shadow zone can form upwind of the source, but is suppressed downwind (Fig. D-1c).

The combined effects of wind and temperature are usually such as to create acoustic shadows upwind of a source, but not downwind. Only under rare circumstances will a temperature lapse be sufficient to overpower wind effects and create a shadow 
PATHS OF

SOUND WAVES

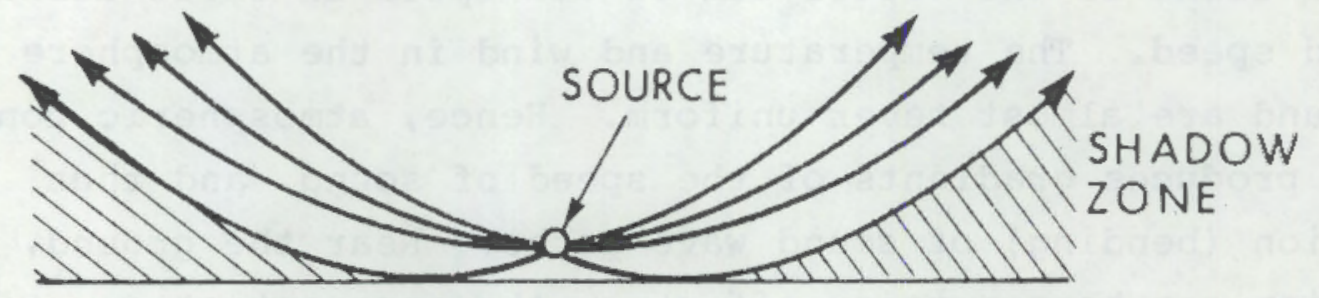

a. TEMPERATURE DECREASING WITH HEIGHT

Typical Daytime

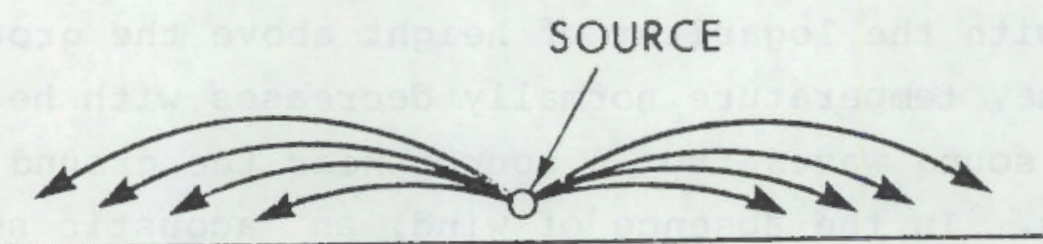

b. TEMPERATURE INCREASING WITH HEIGHT

Typical Nighttime

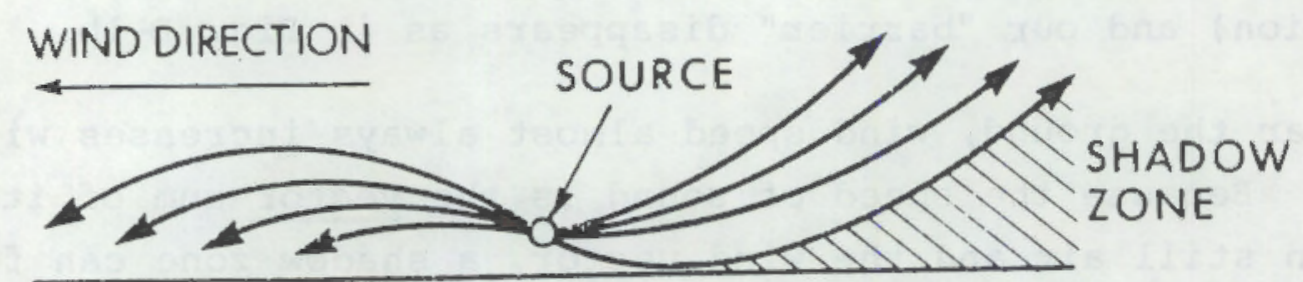

c. WIND SPEED INCREASING WITH HEIGHT ABOVE THE GROUND

FIG. D-1. SRETCHES ILLUSTRATING THE EFFECTS OF VERTICAL TEMPERATURE AND WIND GRADIENTS IN FORMING ACOUSTIC SHADOW ZONES. 
surrounding a source. It is less rare, but still uncommon for a surface inversion to be sufficiently strong to entirely overcome an upwind shadow.

The general situation is illustrated in plan view on Fig. D-2. A shadow boundary, symmetrical about the wind vector, can exist in the upwind direction from a sound source when the vertical wind gradient effect predominates over any effect caused by a temperature inversion. It is likely that no shadow will exist downwind from the source, for the wind gradient will usually overcome the effect of any temperature lapse. Along a radius at an angle $\Phi_{c}$ from the wind vector, the shadow boundary (theoretically) approaches an infinite distance from the source.

In the "upwind" sector of Fig. D-2, the sound wave paths are generally concave upwards, as on the right side of Fig. D-lc. In the "downwind" sector, they are generally concave downwards, as on the left side of Fig. D-lc. In the "crosswind" direction, the sound wave paths are approximately straight lines from the source to the receiver.

For the purposes of this propagation model, we have assumed that temperature in the atmosphere, $T$, is horizontally uniform and varies with the logarithm of height above the ground, z.*

$\mathrm{T} \simeq \mathrm{a} \operatorname{lnz}$

$$
T=\frac{T_{2}-T_{1}}{\operatorname{lnh} h_{2}-\operatorname{lnh}}=\frac{\Delta T}{\operatorname{lnh} 2-\operatorname{lnh} 1}
$$

and

$$
\frac{\partial T}{\partial z}=a z^{-1}
$$

*This approximation is generally valid close to the ground except during strong surface-based temperature inversions $[1,2]$. 


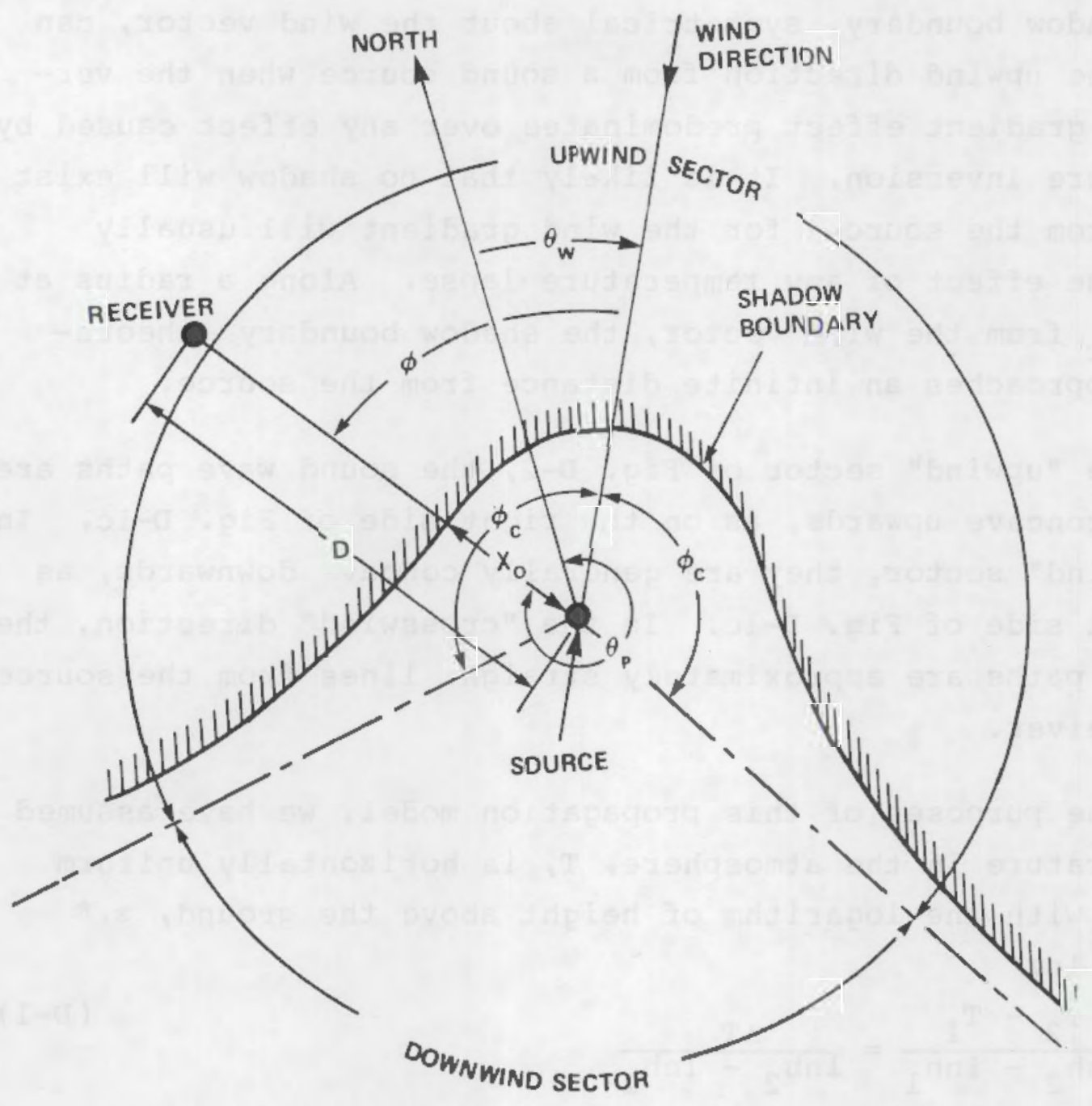

FIG. D-2. PLAN VIEW OF SOUND PROPAGATION SECTORS, WITH PARAMETERS USED TO DESCRIBE THEM (see text). 
The speed of sound, c, varies directly with the square root of the absolute temperature

$$
c=c_{0}\left[\frac{T_{0}+a\left(\ln z-\ln z_{0}\right)}{T_{0}}\right]^{\frac{1}{2}} \simeq c_{0}\left[1+\frac{a\left(\ln z-\ln z_{0}\right)}{2 T_{0}}\right]
$$

where $c_{o}$ is the speed of sound at some reference temperature, $T_{O}$, observed at a reference height of $z_{0}$. Thus, the vertical gradient of the speed of sound due to temperature, $\alpha$, is:

$$
\frac{\partial c}{\partial z} \equiv \alpha=\frac{C_{0}}{2 T_{0}} a z^{-1} \simeq 1.086 \mathrm{az}^{-1} \sec ^{-1} \text { in English units }(D-2)
$$

Note that $\alpha$ can be positive (inversion) or negative (lapse).

Likewise, we assume that the vertical profile of wind speed, $\beta$, varies only with the logarithm of height, $z$, so that:*

$$
B \equiv\left[\frac{v_{2}-v_{1}}{\operatorname{lnh} h_{2}-\operatorname{lnh} h_{1}}\right] z^{-1}
$$

where $v_{2}$ is the speed of height $h_{2}$ and $v_{1}$ is the speed of height at $h_{1}$. Note that $\beta$ is always assumed to be positive.

The combined gradient of the speed of sound, $C$, resulting from both the temperature and wind gradients is thus

*This is a shakier simplification than that for the temperature profile [1], and normally holds only for near-neutral conditions [3]. The actual shape of the wind profile is a function of surface roughness, and of vertical momentum transfer due to thermal instability. 


$$
C=z(\beta \cos \phi-\alpha)
$$

where $\phi$ is the angle between the direction from which the wind is coming and the sound path (Fig. D-2).

Each sound path can be classified as "upwind", or "downwind" for a given sample of meteorological data, on the basis of the following steps.

a. If $\alpha$ is positive and greater than $B(\alpha>B$; so that $C$ would be negative for all values of $\phi$ ), then no shadow zone can exist and all paths are classified as "downwind". This is the strong-inversion, low-wind condition.

b. If $a$ is negative and numerically larger than $\beta$ (i.e., $|-\alpha|>B$, so that $C$ would be positive for all values of $\phi)$, then the shadow zone completely surrounds the source and all paths are classified as "upwind". This is the strong-lapse, lowwind condition.

c. If $|\alpha|<\beta$, then the "critical angle", $\phi_{c}$ " (where temperature, and wind effects cancel) is calculated by setting $C=0$ in Eq. $D-4$

$$
\begin{aligned}
& c=z\left(\beta \cos \phi_{C}-\alpha\right)=0 \\
& \phi_{C}=\cos ^{-1} \frac{\alpha}{\beta}
\end{aligned}
$$

where $0 \leq \phi_{c} \leq 180^{\circ}$

It is now necessary to do some coordinate transformations of the azimuthal data, entered relative to true North, to bearings relative to the direction from which the wind blows. Refer to Fig. D-2. The wind-sound angle, $\phi$, is: 


$$
\begin{aligned}
& \phi=\left|\theta_{\mathrm{p}}-\theta_{\mathrm{w}}\right|, \text { or if }\left|\theta_{\mathrm{p}}-\theta_{\mathrm{w}}\right|>180^{\circ}: \\
& \phi=360-\left|\theta_{\mathrm{p}}-\theta_{\mathrm{w}}\right|
\end{aligned}
$$

Examine the difference $\phi_{C}-\phi:$

If $\phi<\phi_{\mathrm{C}}$ then the path is a "upwind" path.

If $\phi>\phi_{C}$ then the path is a "downwind" path.

It is clear that this simplified model does not take into consideration some common effects, such as changes of wind direction with height and location and upper level inversions, which can lead to significant sound propagation to distances quite remote from a source.

\section{Computing the Distance to the Shadow-zone Boundary, $x$}

Nyborg and Mintzer (4) have derived an expression for the distance, $x_{0}$ (See Fig. D-2), from a sound source to the boundary of its shadow zone at the height of the receiver, $R, f t$ above local ground, and in the presence of a vertical sound velocity gradient which varies with the logarithm of height. Their work has been adapted for this procedure in the following form:

$$
\begin{aligned}
x_{0} & =s \sqrt{\frac{2 c_{0}}{C}} \cdot f\left(\frac{R}{S}\right) \text { feet } \\
\simeq & \frac{47 S}{\sqrt{C}} \cdot f\left(\frac{R}{S}\right) \text { in English units }
\end{aligned}
$$

where $S$ is the effective source height in feet above local

ground, and the function $f\left(\frac{R}{S}\right)$ is obtained from Table D.1. The distance $x_{0}$ is in feet and is assumed to be frequencyindependent. 

TABLE D. 1. $f\left(\frac{R}{S}\right)$ vs $\frac{R}{S}$ for computing $x_{0}$ in $E q .(E-7)$.
(after Hyborg and Mintzer [4]).

\begin{tabular}{|l|l|}
\hline$R / S$ & $f(R / S)$ \\
\hline$\leq 0.05$ & 0.4 \\
0.1 & 0.45 \\
0.2 & 0.55 \\
0.3 & 0.6 \\
0.4 & 0.7 \\
0.5 & 0.75 \\
0.7 & 0.85 \\
0.9 & 1.0 \\
1 & 1.05 \\
1.5 & 1.25 \\
2 & 1.5 \\
3 & 1.9 \\
4 & 2.3 \\
5 & 2.65 \\
6 & 3.0 \\
7 & 3.3 \\
8 & 3.65 \\
9 & 3.95 \\
10 & 4.2 \\
10 & Set $\mathrm{X}_{0}>\mathrm{D}$ \\
\hline & \\
\hline
\end{tabular}

Interpolation is permitted, and for manual computations a graph of $f(R / S)$ vs. $R / S$ is most useful. 
TABLE D. 2. ATTENUATION WITHIN TAE SHADON zONE, Aatm'
VS SIREN-TO-LISTENER DISTANCE, D, FT.

\begin{tabular}{|c|c|}
\hline & $\leq 1.2 \mathrm{x}_{\mathrm{o}}$ \\
$1.2 \mathrm{x}_{\mathrm{o}}<\mathrm{D} \leq 1.7 \mathrm{x}_{\mathrm{o}}$ & $0 \mathrm{~dB}$ \\
$1.7 \mathrm{x}_{\mathrm{O}}<\mathrm{D} \leq 2.4 \mathrm{x}_{\mathrm{o}}$ & 10 \\
$2.4 \mathrm{x}_{\mathrm{O}}<\mathrm{D} \leq 3.4 \mathrm{x}_{\mathrm{o}}$ & 15 \\
$\mathrm{D}>3.4 \mathrm{x}_{\mathrm{O}}$ & 20 \\
\hline
\end{tabular}

\section{Attenuation within the Shadow zone, $A_{y}$}

Theoretically, the attenuation within a shadow zone can be arbitrarily large for large distances beyond the shadow boundary. In practice, more than 25-30 dB is rarely observed because the loss of sound energy from the direct waves is partially replaced by the energy of indirect waves scattered from turbulence, ground surface roughness, etc.

In this procedure, we have used representative values derived from the experimental work of Parkin and Scholes $[6,7\}$ and Weiner and Keast [8]. The recommended values (Table 2 of the main text) have an upper 1 imit of $20 \mathrm{~dB}$. Attenuation because of a shadow zone has occasionally been observed to decrease somewhat at extreme distances relative to closer-in distances. The conservative values in Table D. 2 allow for this possibility. 


\section{REFERENCES \\ TO APPENDIX D}

1. Keast, D.N. and F.M. Wiener, "An Empirical Method for

Estimating wind Profiles over Open, Level Ground", Trans. Am. Geophys. Union 39, (5), pp. 858-864, October 1958.

2. Sutton, O.G., Micrometeorology, McGraw-Hill Book Co., London, sect. 6.4, p. 206, 1953.

3. Ibid, Sect. 7.2 , p. 232 et seq.

4. Nyborg, W.L. and D. Mintzer, "Review of Sound Propagation in the Lower Atmosphere", WADC Technical Report 54-602, Sect. 1.5.5, p.50 et seq., May 1955.

5. Ibid, Fig. 16, p. 54 .

6. Parkin, P.H. and W.E. Scholes, "The Horizontal Propagation of Sound from a Jet Engine Close to the Ground, at Radlett", J. Sound and Vibration, 1, pp. 1-15, 1964.

7. Parkin, P.H. and W.E. Scholes, "The Horizontal Propagation of Sound from a Jet Engine Close to the Ground, at Hatfield", J. Sound and Vibration, 2 (4), pp. 353-374, 1965 .

8. Wiener, F.M. and D.N. Keast, "Experimental Study of the Propagation of Sound Over Ground",J. Acoust. Soc. Am.' 31 $724-733,1959$. 


\section{APPENDIX E: DEPENDENCE OF ALERT UPON SIREN DURATION}

In the main body of this report, the chances of alert are predicted for a four-minute period of siren operation (here called siren duration). In this appendix, predictions are generalized for longer and shorter siren durations. This appendix will allow readers to convert four-minute results to results for other siren durations.

This appendix begins with an overview of the relationship between siren level and siren duration, and how this relationship affects the chances of alert. It continues with development of the mathematics of this relationship, and then summarizes results for the reader's use.

\section{E. 1 Overview}

Table E.l is a typical "chance-of-alert" table for a particular background-noise environment. Siren durations are listed across the top, and siren levels down the left side. Within the table are the chances of alert -- from 100 down to zero percent. In the main body of this report, results are based upon the fourminute columns of tables such as this one.* Variations within the table are related to fluctuating background noise in the Iistener's environment. **

*And upon the one-minute columns for rotating sirens.

** Precision within Table E.l degrades for longer siren durations (to the right) and for lower siren levels (to the bottom). For longer siren durations, precision suffers from the limited amount of total data that underlie the table. These data in clude 250 minutes of background noise, which is only about eight times the longest siren duration. For lower siren levels, precision suffers from the very small percentage of time that these low siren levels will alert the listener. Although the amount of data is large compared to the siren durations, the background noise is rarely low enough to contribute to the statistics at these low siren levels. For longer siren durations and lower siren levels combined, the precision is particularly bad. 
TABLE E.1. TYPICAL CHANCE-OF-ALERT TABLE FOR A PARTICULAR BACKGROUND-NOISE ENVIRONMENT.

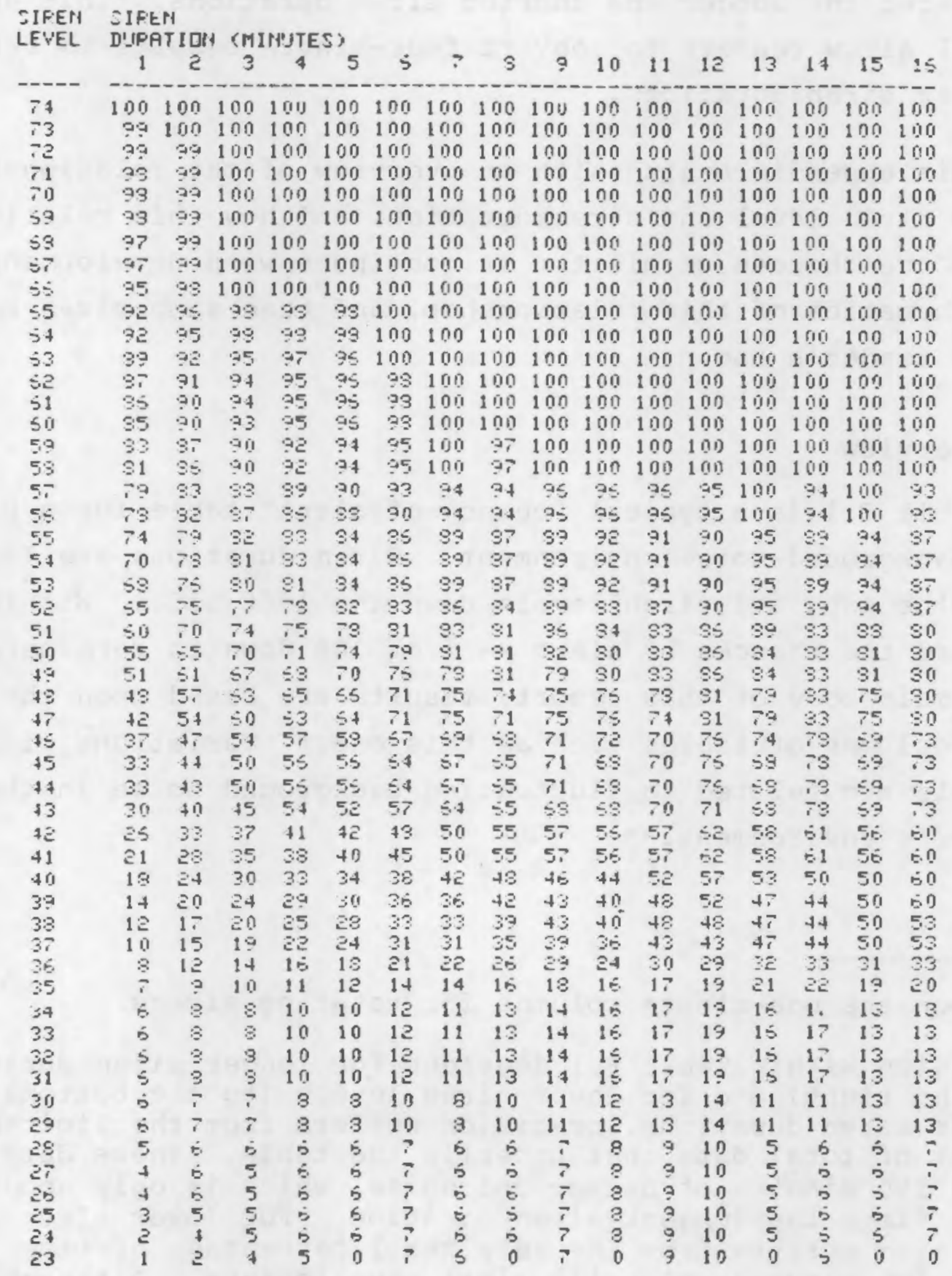


In this table, the chance of alert is 100 percent when the siren level is much higher than the background noise could ever be at the listener. When the siren level is $74 \mathrm{~dB}$, for example, the siren will definitely alert the listener even for siren durations as short as one minute.

The chance of alert is zero percent when the siren level is low, say $20 \mathrm{~dB}$ or less, no matter how long the siren sounds. The background noise is always sufficient to mask (acoustically cover up) such low siren levels.

For siren signals of intermediate levels, the chance of alert falls between 100 and zero percent, in the detailed manner shown. These intermediate details follow from the fluctuations of the background noise, from minute to minute.

For these intermediate siren levels, the chance of alert increases with siren duration as indicated in the table. For a siren level of $50 \mathrm{~dB}$, for example, the chance of alert is 71 percent if the siren is sounded for four minutes. If this duration is doubled to eight minutes, the chance of alert increases to 81 percent.

How can this increase with duration be understood mathematically? If such understanding results in a particular mathematical pattern, then this pattern can be used to convert four-minute results to results for other siren durations. The search for this mathematical pattern is the subject of the next section.

\section{E. 2 Development of the Mathematics}

The search for patterns within tables of numbers is necessarily an exploratory matter. First, some underlying mathematics must be postulated, and then a numerical pattern must be sought with this mathematics as guidance. Once a preliminary pattern is 
discovered, it must be simplified to be of use, and then must be generalized for other similar tables. Ideally, the pattern will emerge as a simple equation, with a small number of adjustable constants.

The steps involved in developing such a pattern are:

- preparation

- underlying mathematics and its simplification

- exploratory graphs, guided by the mathematics

- simplification and generalization to all other tables.

These steps are discussed next.

\section{E.2.1 Preparation}

Figure E-l shows typical background noise as it fluctuates over a one-minute period. The fluctuations are generally large, as shown here. In this background noise, a listener will be alerted by a siren whenever it is 9 decibels or more above the background noise level.* The figure shows a siren that produces a steady $49 \mathrm{~dB}$ at the 1 istener. A dashed line 9 dB below the siren level denotes the alerting threshold. During the shaded time intervals below this threshold, the siren will alert the listener.

*Throughout this appendix, background noise includes the noise in a 1/3-octave frequency band centered at $630 \mathrm{~Hz}$, a typical siren operating frequency. Dictated by the physiology of the ear, only this 1/3-octave band is available to mask, or cover up, the pure-tone signal of typical sirens. Siren levels are usually measured as overall sound levels, though the same values would be measured using only a $1 / 3$-octave frequency band filter. 


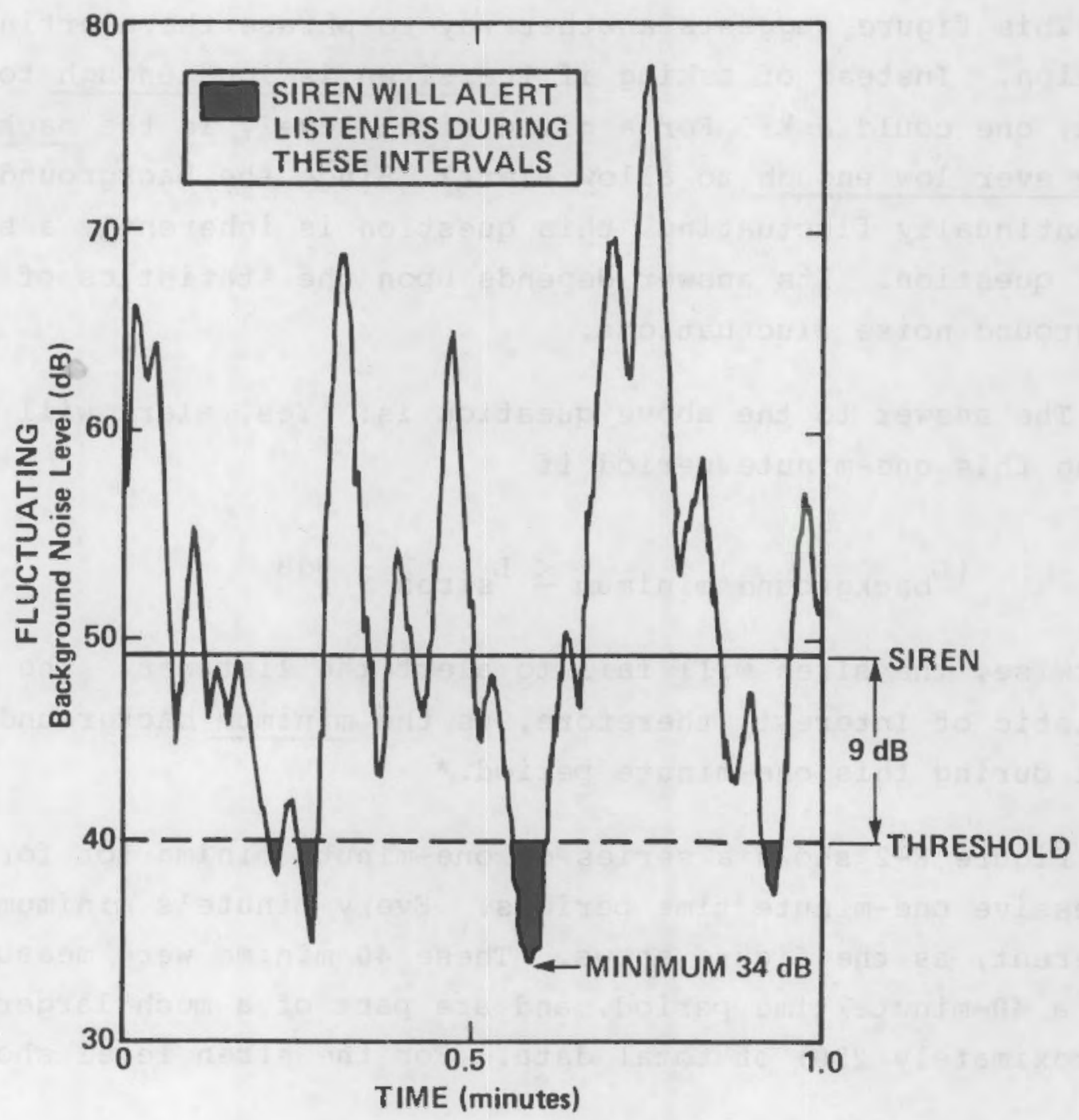

FIG. E-1. BACKGROUND NOISE LEVEL AS A FUNCTION OF TIME. 
This siren level has succeeded in alerting the listener during its one-minute duration. However, a siren level some 7 decibels lower would not alert because the background noise would always be above its lowered threshold line of $33 \mathrm{~dB}$.

This figure suggests another way to phrase the alerting question. Instead of asking if the siren is loud enough to cause alert, one could ask: For a given siren level, is the background noise ever low enough to allow alert? Since the background noise is continually fluctuating, this question is inherently a statistical question. Its answer depends upon the statistics of the background noise fluctuations.

The answer to the above question is: Yes, alert will occur during this one-minute period if

$$
\left(L_{\text {background }}\right)_{\text {minimum }} \leq L_{\text {siren }}-9 d B
$$

Otherwise, the siren will fail to alert the listener. The only statistic of interest, therefore, is the minimum background noise level during this one-minute period.*

Figure E-2 shows a series of one-minute minima for forty successive one-minute time periods. Every minute's minimum is different, as the figure shows. These 40 minima were measured over a 40-minute time period, and are part of a much larger set (approximately 250) of total data. For the siren level shown, 35

\footnotetext{
* Our analysis for this study actually utilized the 90 -percentile background noise level, rather than the minimum level. The 90percentile noise level is the level exceeded 90 percent of the time; the remaining 10 percent of the noise falls below this level. Use of the 90-percentile noise level adds a measure of conservatism to the results, since it requires slightly higher siren levels before alert is predicted.
} 


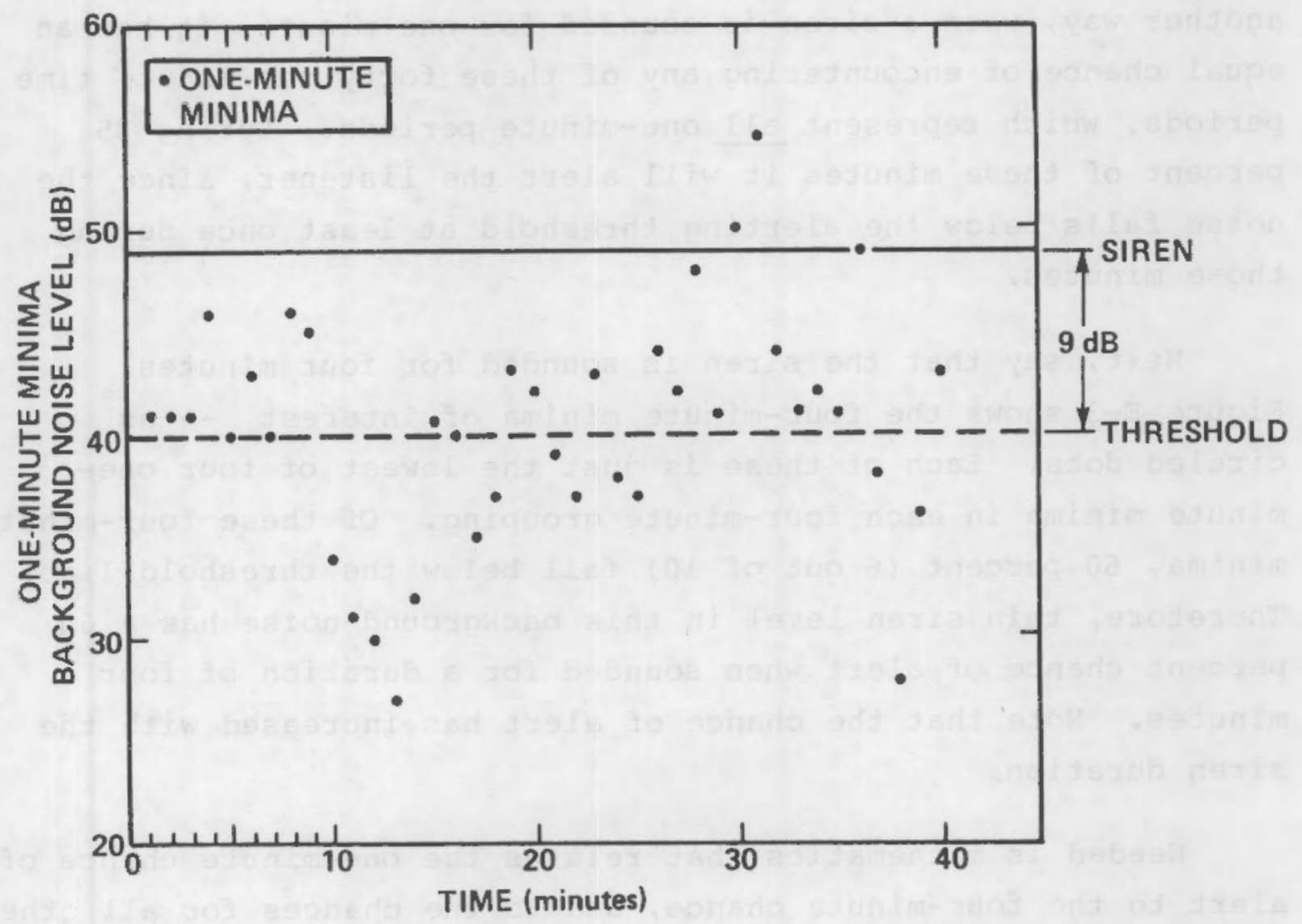

FIG. E-2. MINIMUM BACKGROUND NOISE LEVELS OBSERVED IN ONE-MINUTE INTERVALS FOR A 40-MINUTE TIME PERIOD. 
percent of the minima ( 14 out of 40 ) fall below the threshold line. Therefore, this siren level in this background noise has a 35 percent chance of alert -- when sounded for a duration of one minute.

This plot applies only to sirens sounded for one minute, since the background-noise minima are one-minute minima. Stated another way, when a siren is sounded for one minute, it has an equal chance of encountering any of these forty one-minute time periods, which represent all one-minute periods. During 35 percent of these minutes it will alert the listener, since the noise falls below the alerting threshold at least once during those minutes.

Next, say that the siren is sounded for four minutes. Figure E-3 shows the four-minute minima of interest -- as circled dots. Each of these is just the lowest of four oneminute minima in each four-minute grouping. Of these four-minute minima, 60 percent ( 6 out of 10 ) fall below the threshold line. Therefore, this siren level in this background noise has a 60 percent chance of alert when sounded for a duration of four minutes. Note that the chance of alert has increased with the siren duration.

Needed is mathematics that relates the one-minute chance of alert to the four-minute chance, and to the chances for all other siren durations as well. This mathematics is based upon probabilities P, rather than upon "chances." A 35 percent chance of alert is equivalent to a probability $P$ of 0.35 . Moreover, this mathematics is based upon the probability of failure to alert, rather than success in alerting. 


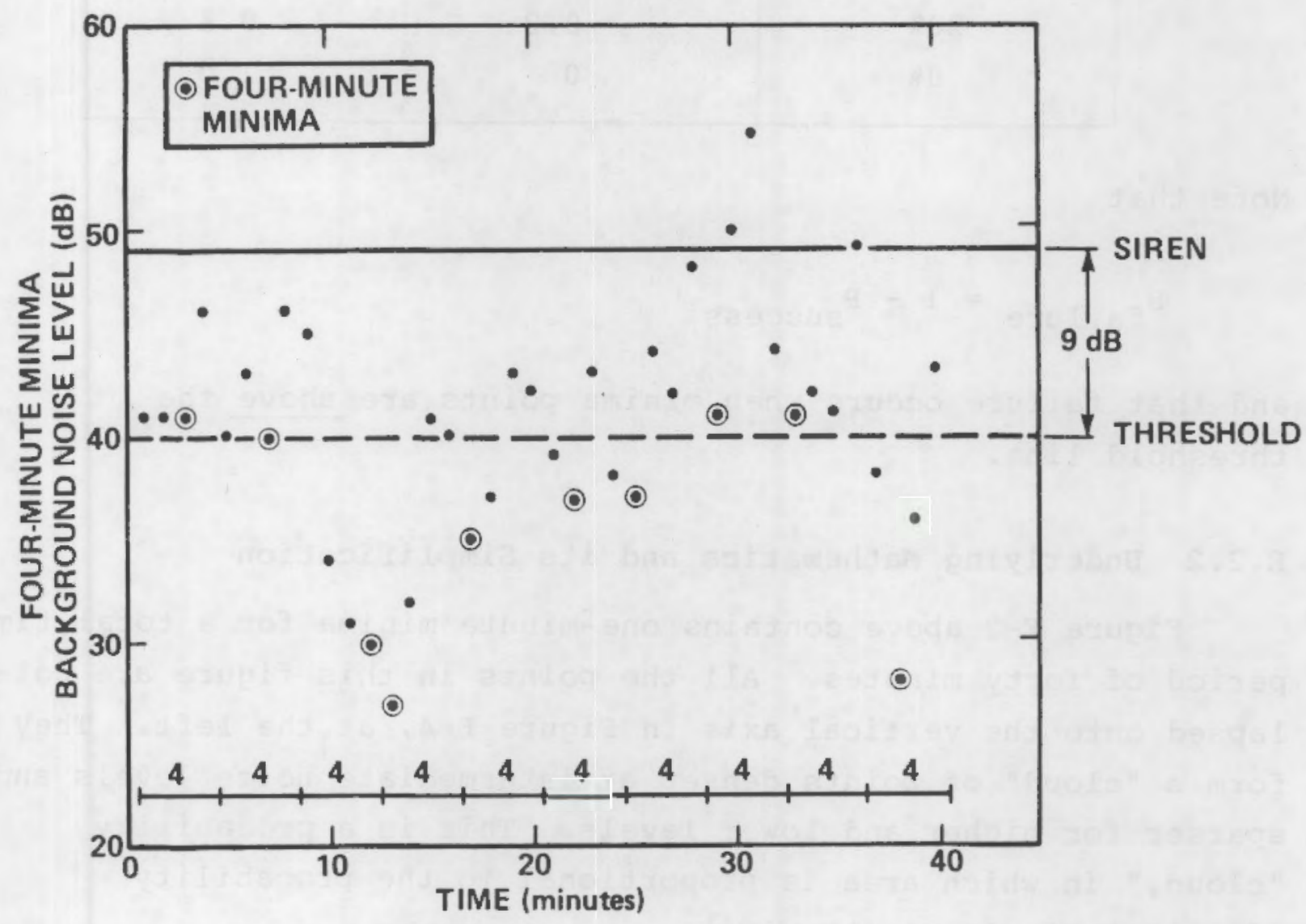

FIG. E-3. MINIMUM NOISE LEVELS OBSERVED IN FOUR-MINUTE INTERVALS FOR A 40-MINUTE TIHE PERIOD (from Fig. E-2).

$$
\text { E-9 }
$$




\begin{tabular}{|c|c|c|}
\hline \multirow{2}{*}{$\begin{array}{c}\text { Chance of } \\
\text { Success }\end{array}$} & \multicolumn{2}{|c|}{ Probability } \\
\cline { 2 - 3 } & of Success & of Failure \\
\hline & & \\
8008 & 1.0 & 0 \\
608 & 0.8 & 0.2 \\
408 & 0.6 & 0.4 \\
208 & 0.4 & 0.6 \\
08 & 0.2 & 0.8 \\
\hline
\end{tabular}

Note that

$$
\mathrm{P}_{\text {failure }}=1-\mathrm{P}_{\text {success }}
$$

and that failure occurs when minima points are above the threshold line.

\section{E.2.2 Underlying Mathematics and its Simplification}

Figure E-2 above contains one-minute minima for a total time period of forty minutes. All the points in this figure are collapsed onto the vertical axis in Figure E-4, at the left. They form a "cloud" of points denser at intermediate noise levels and sparser for higher and lower levels. This is a probability "cloud," in which area is proportional to the probability (density) of one-minute minima.

For any one-minute period, the probability of failure is proportional to the "cloud" area above the threshold line. This upper area, divided by the total cloud area, is the probability that the background noise will exceed the threshold level throughout any one-minute period -- that is, the probability that 


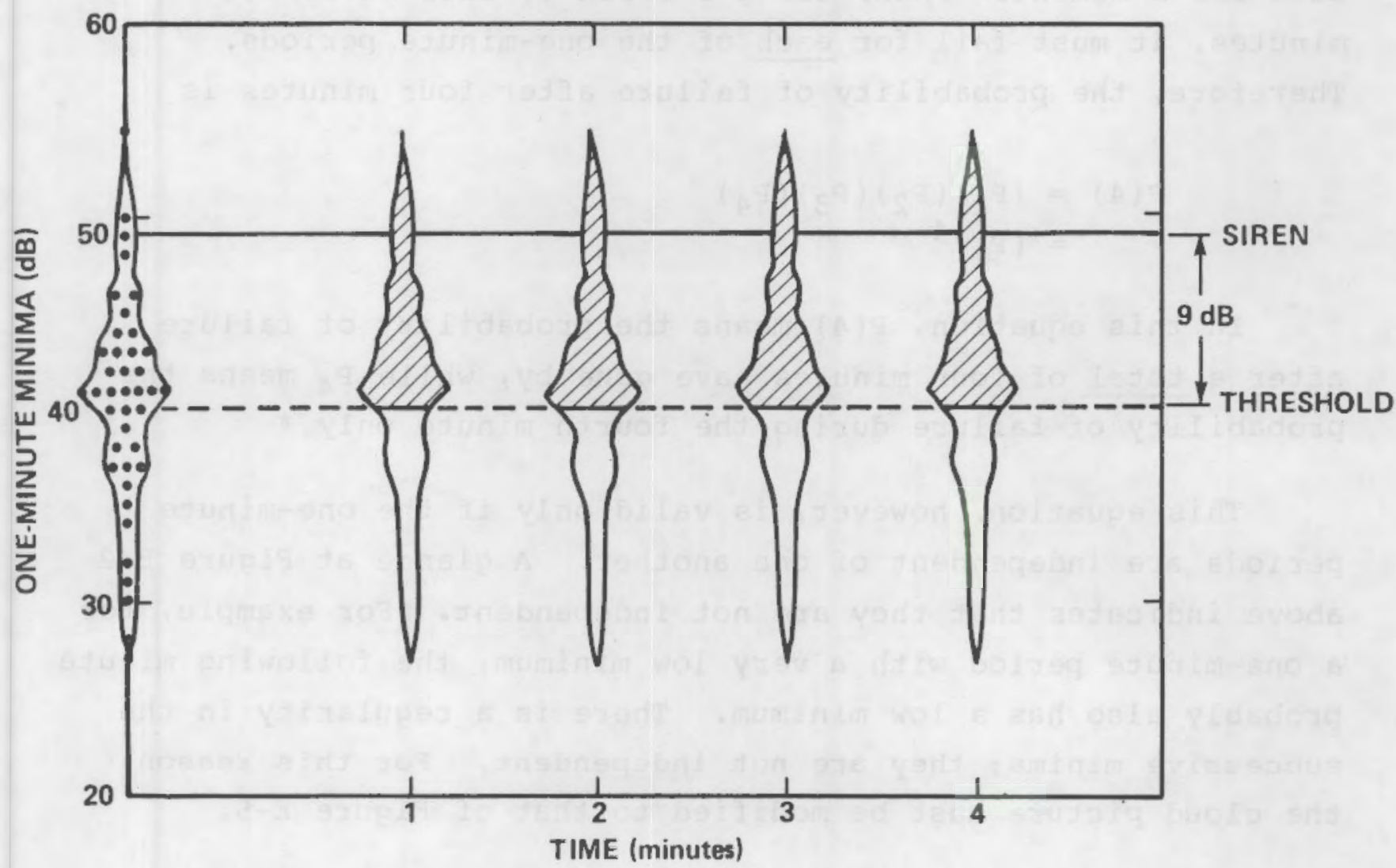

FIG. E-4. PROBABILITY "CLOUDS" FOR ONE-MINUTE BACKGROUND NOISE IN SUCCESSIVE MINUTES, ASSUMING EACH MINUTE IS STATISTICALLY INDEPENDENT OF ALL OTHER MINUTES. 
the siren will fail to alert the listener. This one-minute probability of failure is $(1-0.35)=0.65$ for the example shown.

To the right in the figure, this cloud is duplicated at each of four successive minutes. If we assume these four minutes to be independent of one another, this probability cloud would apply equally to all of them, as shown. Let us assume this to be the case for a moment. Then, for the siren to fail after four minutes, it must fail for each of the one-minute periods. Therefore, the probability of failure after four minutes is

$$
\begin{aligned}
P(4) & =\left(P_{1}\right)\left(P_{2}\right)\left(P_{3}\right)\left(P_{4}\right) \\
& =\left(P_{1}\right)^{4}
\end{aligned}
$$

In this equation, $P(4)$ means the probability of failure after a total of four minutes have gone by, while $\mathrm{P}_{4}$ means the probability of failure during the fourth minute only. *

This equation, however, is valid only if the one-minute periods are independent of one another. A glance at Figure E-2 above indicates that they are not independent. For example, for a one-minute period with a very low minimum, the following minute probably also has a low minimum. There is a regularity in the successive minima; they are not independent. For this reason, the cloud picture must be modified to that of Figure E-5.

In Figure E-5, the first minute's cloud is unchanged from that of Figure E-4. However, the second minute's cloud represents the conditional probability of: "failure during minute

*If we had worked with probabilities of success, combining four minutes into one equation would be far more complicated. That is why we choose to work with failure instead. As the very last step, we shall convert from failure back to success. 


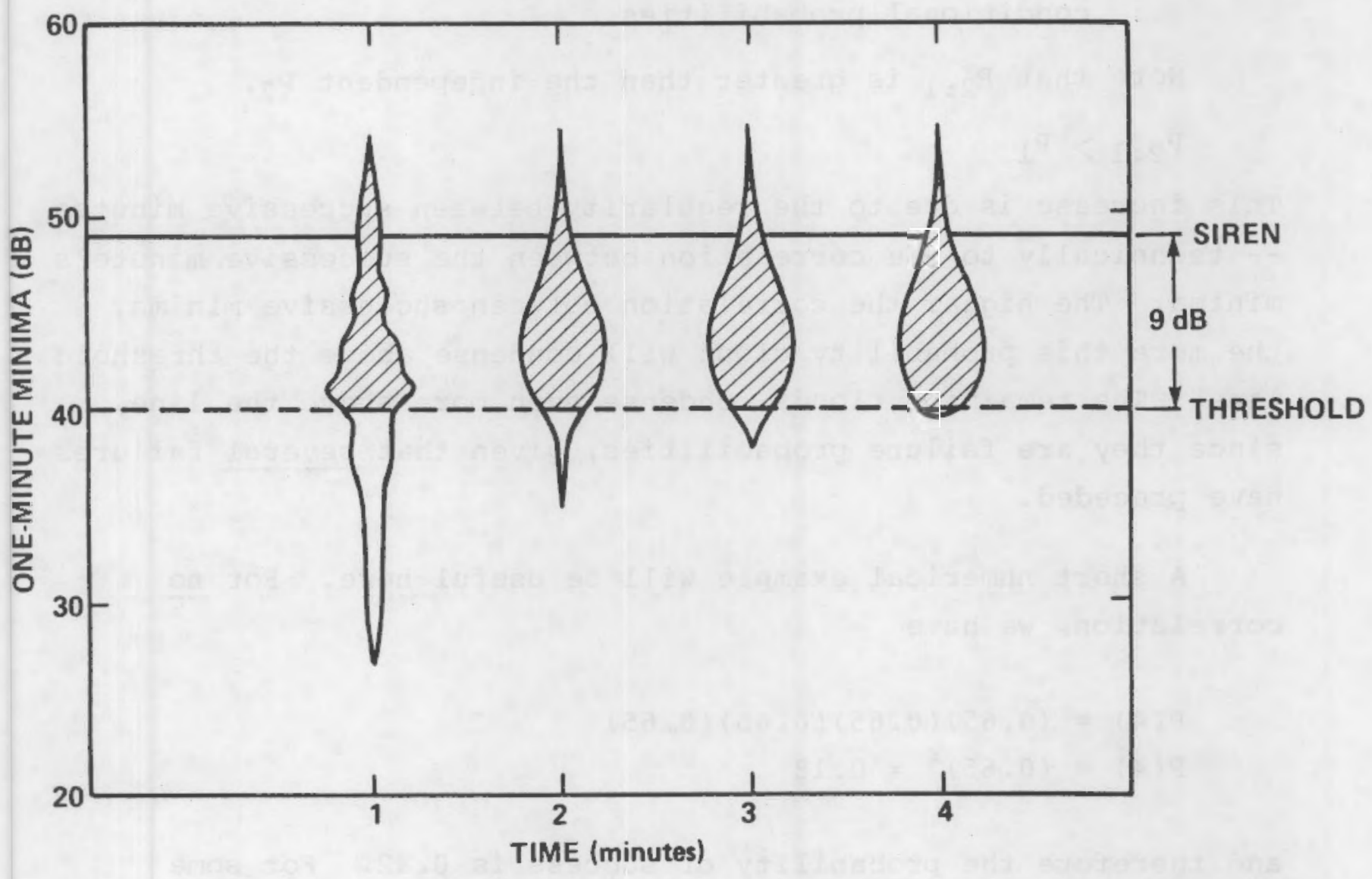

FIG. E-5. PROBABILITY "CLOUDS" FOR ONE-MINUTE BACKGROUND NOISE MINIMA IN SUCCESSIVE HINUTES, ASSUMING MINIMA IN SUCCESSTVE MINUTES ARE NOT INDEPENDENT. 
two, given that failure occurred during minute one." In other words, the cloud at minute two represents the probability that the second minute's minimum will be above the threshold, given that the first minute's was also above the threshold. Mathematically, we write $P_{2: 1}$ for this conditional probability. Then

$$
\begin{aligned}
P(4) & =\left(P_{1}\right)\left(P_{3}: 1: 2\right)\left(P_{4}: 1,2,3\right) \\
& \text { conditional probabilities }
\end{aligned}
$$

Note that $P_{2: 1}$ is greater than the independent $P_{2}$.

$$
\mathrm{P}_{2: 1}>\mathrm{P}_{1}
$$

This increase is due to the regularity between successive minutes -- technically to the correlation between the successive minute's minima. The higher the correlation between successive minima, the more this probability cloud will condense above the threshold line. The remaining clouds condense even more above the line, since they are failure probabilities, given that several failures have preceded.

A short numerical example will be useful here. For no correlation, we have

$$
\begin{aligned}
& P(4)=(0.65)(0.65)(0.65)(0.65) \\
& P(4)=(0.65)^{4} \simeq 0.18
\end{aligned}
$$

and therefore the probability of success is 0.82 . For some correlation, we have

$$
\begin{aligned}
& P(4)=(0.65)(0.8)(0.85)(0.9) \\
& P(4) \simeq 0.40
\end{aligned}
$$


for a probability of success of 0.60 . And for full correlation we have

$$
\begin{aligned}
& P(4)=(0.65)(1.0)(1.0)(1.0) \\
& P(4)=0.65
\end{aligned}
$$

for a probability of success of 0.35 .

In general,

$$
\begin{aligned}
P(n) & =\left(P_{1}\right)\left(P_{2: 1}\right)\left(P_{3: 1,2}\right) \ldots\left(P_{n: 1,2,3, \ldots, n-1}\right) \\
& =\left(P_{1}\right)^{n} \text { for no correlation } \\
& =P_{1} \text { for full correlation. }
\end{aligned}
$$

The upper half of Figure E-6 illustrates graphically how the probability of failure thus decreases with increasing time -that is, with increasing siren duration. The probability of success therefore increases with siren duration, as shown in the bottom half of the figure. (This figure is an example only, not a general result.)

Note for large correlation between successive minima, there is not as much benefit in sounding the siren longer. If the siren fails to alert during the first minute, it will most likely fail to alert thereafter, because the first minute is nearly identical to all subsequent minutes.

This underlying mathematics resides in Eq. E-1 above. In Eq. E-1, the notation $P_{n}: 1,2,3, \ldots, n-1$ reminds us that $P_{n}$ is a conditional probability, which assumes the siren failed during 

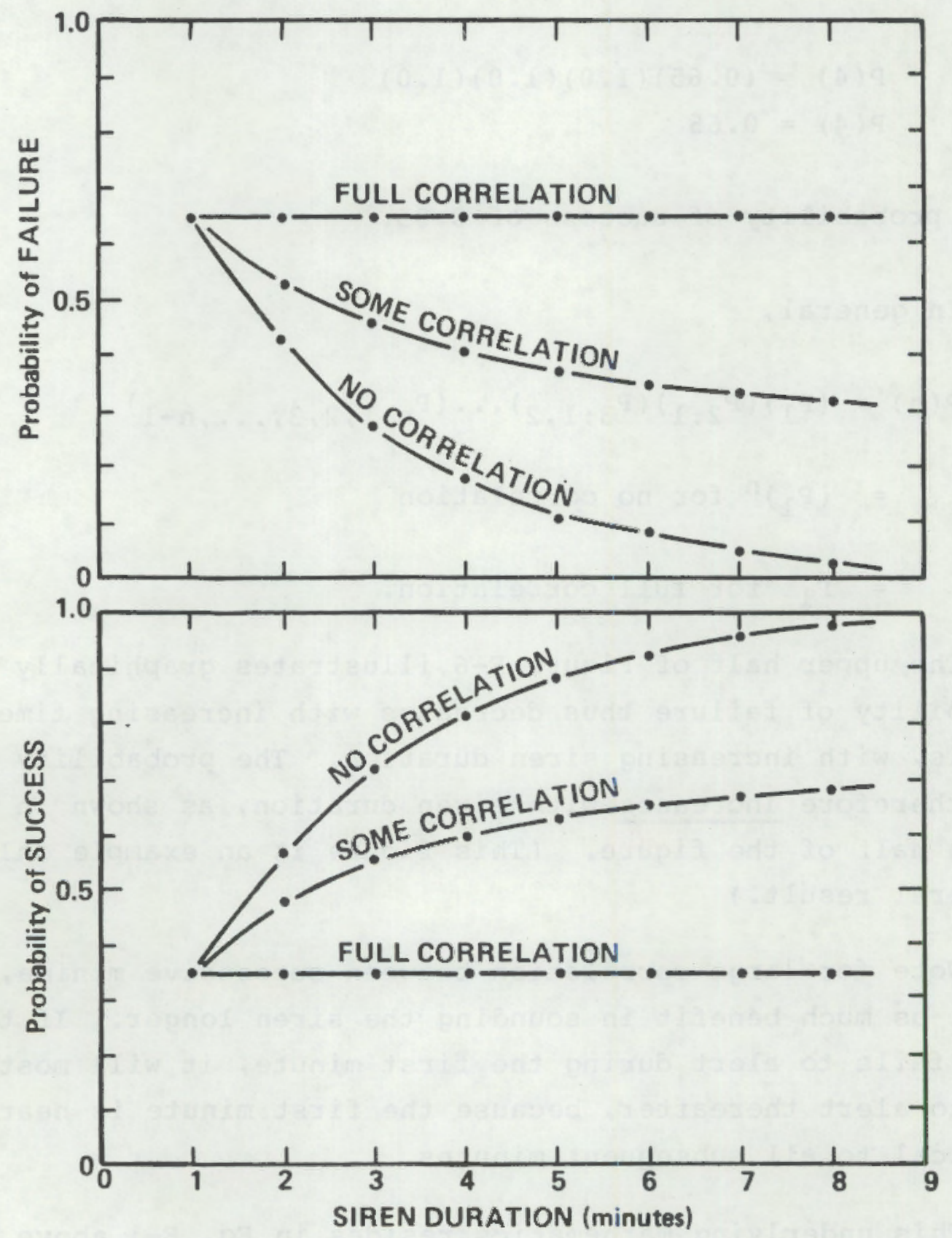

PIG. E-6. GRAPHIC ILLUSTRATION OF SIREN ALERTING PROBABILITIES VS. SIREN DURATION, FOR VARIOUS AMOUNTS OF CORRELATION BETWEEN BACKGROUND NOISE MINIMA IN SUCCESSIVE MINUTES (Example only). 
all previous minutes. We next simplify, so that this $P_{n}$ assumes failure only during the immediately preceding minute. Mathematically,

$$
P_{n: 1,2,3, \ldots, n-1}=P_{n: n-1}
$$

Let

$$
P_{n: n-1}=\mathrm{CP}_{1}
$$

where $C$ contains all the conditional aspects of the probability. The term $P_{1}$ is the unconditional probability for the first minute. Then

$$
\begin{aligned}
& P(n)=\left(P_{1}\right)\left(C P_{1}\right)\left(C P_{1}\right) \ldots\left(C P_{1}\right) \\
& P(n)=P_{1}{ }^{n} C^{n-1}
\end{aligned}
$$

Note that for no correlation,

$$
C=1
$$

and therefore

$$
P(n)=P_{1} n
$$

as before. For full correlation,

$$
c=\frac{1}{P_{1}}
$$

to make

$$
\begin{aligned}
P(n) & =P_{1}^{n}\left(\frac{1}{P_{1}}\right)^{n-1} \\
& =P_{1}
\end{aligned}
$$


as before.

Eq. E-2 is the desired simplification. In the following section, we graph measured background data, to explore the nature of $C$, for correlations typically present in measured background noise data.

\section{E.2.3 Exploratory Graphs, Guided by the Mathematics}

To explore for C graphically, we first take the logarithm of Eq. E-2.

$$
\begin{aligned}
& P(n)=P_{1}{ }^{n} C^{n-1} \\
& \log P(n)=n \log P_{1}+(n-1) \log C \\
& \log P(n)=-\log C+n\left[\log C P_{1}\right]
\end{aligned}
$$

If $\log P(n)$ is then plotted against $n$, the resulting straight line should have a vertical intercept of $-\log C$ and a slope of $\log \mathrm{CP}_{1}$. After some curve-smoothing on linear paper, on Fig. E-7 we logarithmically plot part of the data in Table E.l above. Each line is for a different representative siren level, labelled (1) through (5).

of course, the linear curve-smoothing helped line up the points shown here. Even so, the regression fit to straight lines for each siren level is very good. Note however, that the vertical intercepts and the slopes vary from curve to curve. Therefore, C must vary with siren level.

We then set each intercept equal to - $\log C$ and each slope equal to $\log \mathrm{CP}_{1}$, and solve for $\mathrm{C}$ and $\mathrm{P}_{1}$-- separately for each straight line. 


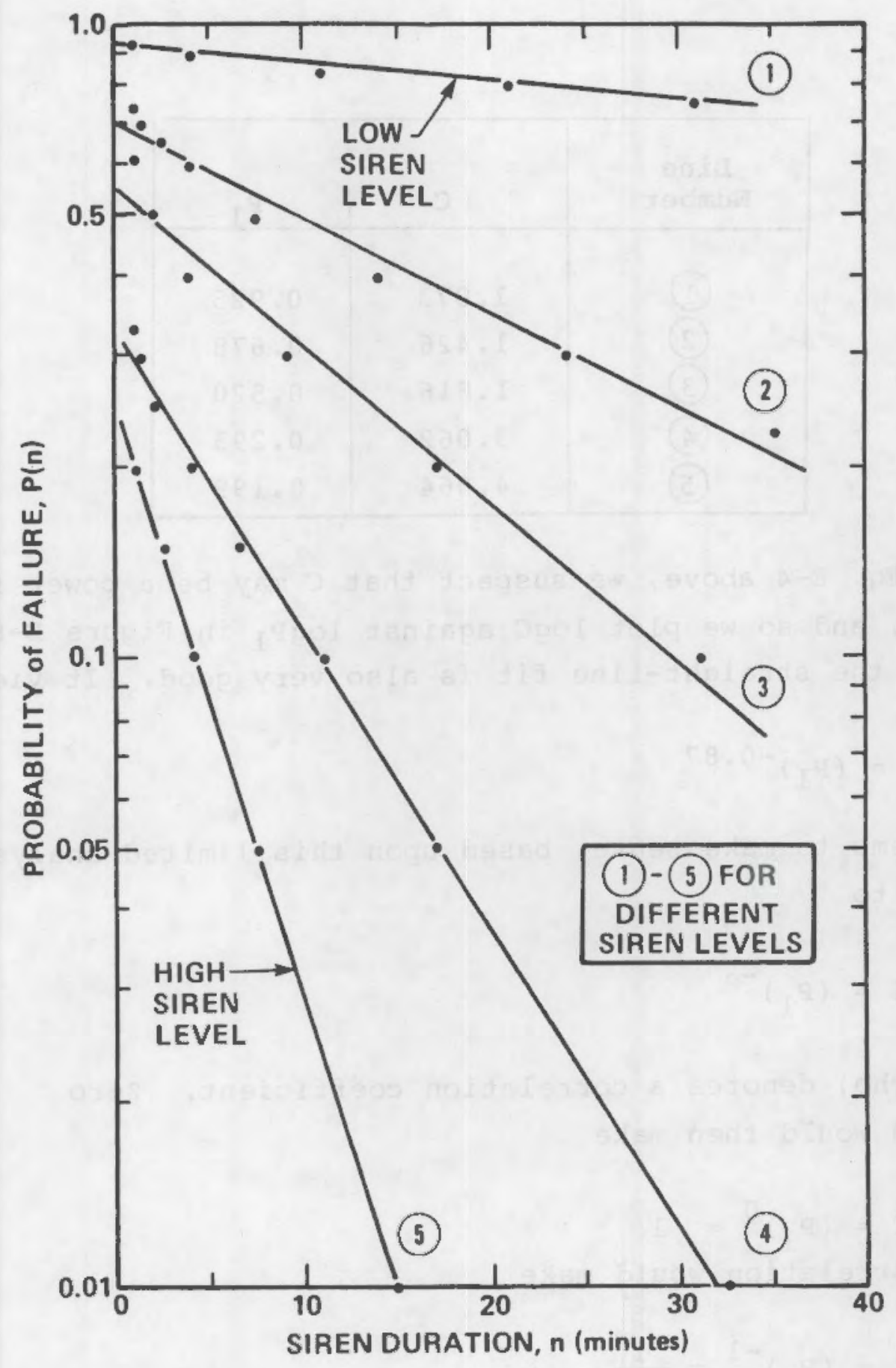

FIG. E-7. LOGARITHM OF THE PROBABILITY OF SIREN FAILURE-TO-ALERT VS. SIREN DURATION FOR FIVE DIFFERENT SIREN LEVELS, DERIVED FROI THE DATA IN TABLE E.I. 


\begin{tabular}{|c|c|c|}
\hline $\begin{array}{c}\text { Line } \\
\text { Number }\end{array}$ & $\mathbf{C}$ & $\mathbf{p}_{\mathbf{1}}$ \\
\hline (1) & 1.073 & 0.925 \\
(2) & 1.426 & 0.678 \\
(3) & 1.816 & 0.520 \\
(4) & 3.062 & 0.293 \\
(5) & 4.064 & 0.199 \\
\hline
\end{tabular}

From Eq. E-4 above, we suspect that $C$ may be a power function of $\mathrm{P}_{1}$, and so we plot $\log \mathrm{C}$ against $\log \mathrm{P}_{1}$ in Figure $\mathrm{E}-8$. On this plot, the straight-line fit is also very good. It yields:

$$
C=\left(\mathbf{P}_{1}\right)^{-0.87}
$$

It seems to make sense, based upon this limited analysis, to generalize to

$$
C=\left(P_{1}\right)^{-\rho}
$$

where $p$ (rho) denotes a correlation coefficient. Zero correlation would then make

$$
C=\left(P_{1}\right)^{0}=1
$$

and full correlation would make

$$
C=\left(P_{1}\right)^{-1}=\frac{1}{P_{1}}
$$

These agree with Eqs. E-3 and E-4 above. 


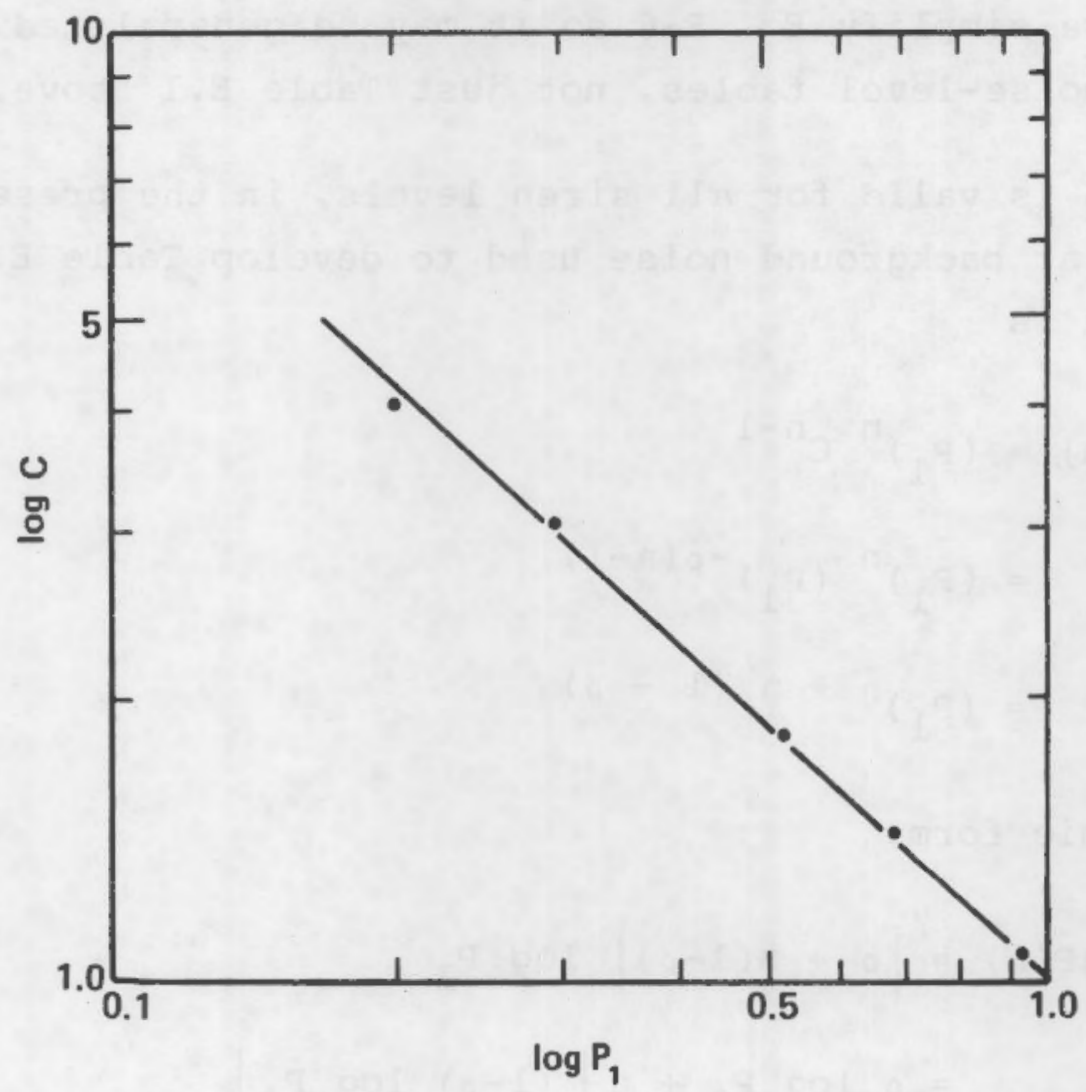

FIG. E-8. PLOT OF VALUES OF CUMULATIVE CONDITIONAL PROBABILITIES (LOG C) VS. PROBABILITY OF FAILURE IN THE PIRST MINUTE (LOG $\mathbf{P}_{1}$ ), DERIVED FROM PIG. E-7. 
In summary then, the time-pattern within Table E.l can be written as

$$
P(n)=\left(P_{1}\right)^{n-0.87(n-1)}=\left(P_{1}\right) 0.87+0.13 n \quad(E-6)
$$

The two constants in the exponent sum to 1.00 , and depend upon correlation within the background noise, from minute to minute. Moreover, Eq. E-6 depends upon the siren level through $\mathrm{P}_{1}$, which varies with siren level.

Next, we simplify Eq. E-6 so it may be generalized to a wide variety of noise-level tables, not just Table E.1 above.

Eq. E-6 is valid for all siren levels, in the presence of the particular background noise used to develop Table E.I. Its general form is

$$
\begin{aligned}
P(n) & =\left(P_{1}\right)^{n} c^{n-1} \\
& =\left(P_{1}\right)^{n}\left(P_{1}\right)^{-\rho(n-1)} \\
& =\left(P_{1}\right)^{\rho+n}(1-\rho)
\end{aligned}
$$

In logarithmic form,

$$
\begin{aligned}
\log P(n) & =[\rho+n(1-\rho)] \log P_{1} \\
& =\rho \log P_{1}+n\left[(1-\rho) \log P_{1}\right]
\end{aligned}
$$

With $\log P(n)$ plotted against $n$, this is the equation of a straight line with vertical intercept $\rho \log P_{1}$ and slope $(1-p) \log P_{1}$. 
A normal regression $f$ it would solve for the two variables $\rho$ and $P_{1}$, separately for each of the siren levels (as shown in Figure E-7, for instance). However, there is a relationship above that implies $\rho$ to be a constant, independent of the siren level. Therefore, we wish to collapse all curves, for all siren levels, to a single curve. For this purpose, we manipulate Eq. $\mathrm{E}-8$ as follows :

$$
\begin{aligned}
& \log P(n)=[\rho+n(1-\rho)] \log P_{1} \\
& \begin{aligned}
\log P(n) & =\rho+n(1-\rho) \\
\log P_{1} & =1+(n-1)(1-\rho)
\end{aligned}
\end{aligned}
$$

Hence, plotting $\left(\log P(n) / \log P_{1}\right)$ against $(n-1)$ yields a straight 1 ine of intercept 1 and slope (1- $\rho)$, independent of siren level. In other words, each curve in Figure E-7 has been normalized to its value of $\mathrm{P}_{1}$, and all curves have been collapsed into one.

We will have need below for a similar equation, but normalized to the probability at four minutes, rather than at one minute. We develop this next.

In the graphs above, letter $n$ was interpreted as progressing in one-minute steps $(n=1,2,3$ equals $t=1,2,3)$. However, nothing in the mathematics requires this interpretation. Any time interval could be taken as the basic interval $n$ above. In particular, the basic time interval could be taken as four minutes. Then four-minute minima $(n=1)$ would combine into eight-minute minima $(n=2)$, and so forth. The result would be Eq. E-9 above, but with

$$
\mathrm{n}=4 \mathrm{t} \text { (in minutes) }
$$

and

$$
\left.P_{1}=P_{(n=1)}=P_{(t=4} \text { minutes }\right)
$$


Figure E-9 schematically compares these one-minute and fourminute normalizations. * For the one-minute normalization on top: $n=t$, and therefore $n-1=t-1$, as shown on the first horizontal axis. Plotted horizontally is the range

$$
\begin{aligned}
& 0 \leq t-1 \leq 3 \\
& 1 \leq t \leq 4
\end{aligned}
$$

The small plotted points represent the tabulated values for these four minutes, collapsed into one line by the $\mathrm{P}_{1}$ normalization. The line is fit by linear regression and has slope (1-p).

This upper portion of Figure E-9 is for rotating sirens. As explained in the main text, rotating sirens are less effective in alerting the public, since they produce their maximum siren level for only a portion of their duration. For this reason, fourminute results for rotating sirens are derived from the oneminute background-noise statistics. In the figure, the third horizontal scale shows the corresponding siren durations for rotating sirens. The normalization is therefore to a four-minute siren duration, and the graph extends up to a maximum of 16 minutes.

* Note that the lines in Figure E-9 rise rather than fall to the right, as does Figure E-7, for this reason: In Figure $E-7$, the actual logarithms on the vertical axis are negative, since the $P(n)$ 's are less than unity. Therefore, this vertical axis actually decreases, from zero at the top to minus-two at the bottom. For increasing $n$, then, the curves take on increasingly large negative values (for example: $-1,-1.5,-2$ ). Figure E-9 is normalized by $\log \mathrm{P}_{1}$, however, which is also negative, and which turns these increasingly negative values into increasingly positive values. Therefore, the lines rise in Figure E-9. 

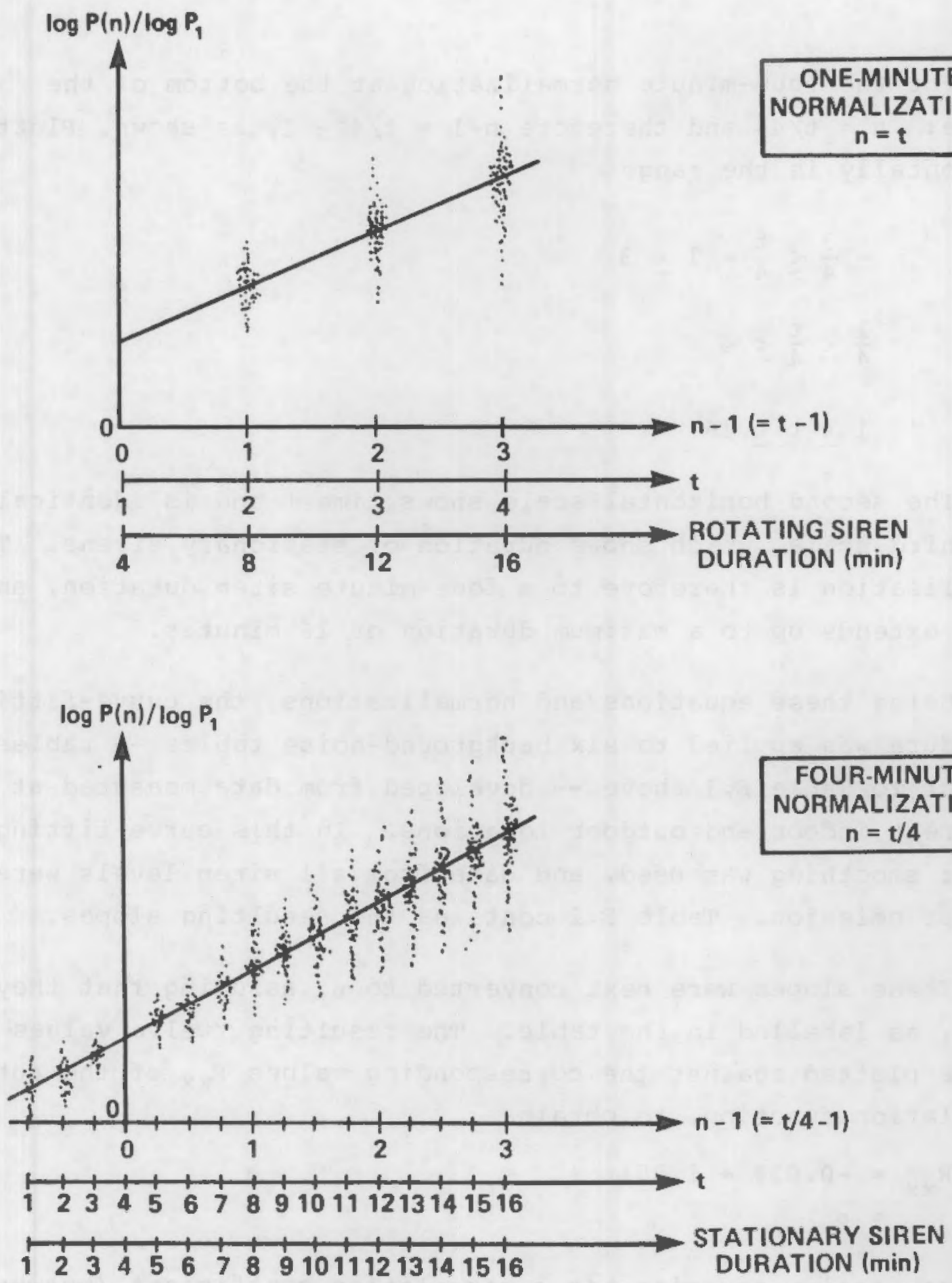

FIG. 8-9. SRETCH OF ONE-MINUTE AND FOUR-MINUTE NORMALIZATIONS TO SHOW RELATIONSHIP BETWEEN VARIABLE N AND SIREN DURATIONS. 
For the four-minute normalization at the bottom of the figure: $n=t / 4$, and therefore $n-1=t / 4-1$, as shown. Plotted horizontally is the range

$$
\begin{aligned}
& -\frac{3}{4} \leq \frac{t}{4}-1 \leq 3 \\
& \frac{1}{4} \leq \frac{t}{4} \leq 4 \\
& 1 \leq t \leq 16
\end{aligned}
$$

The second horizontal scale shows time $t$ and is identical to the third scale, which shows duration of stationary sirens. The normalization is therefore to a four-minute siren duration, and the graph extends up to a maximum duration of 16 minutes.

Using these equations and normalizations, the curve-fitting procedure was applied to six background-noise tables -- tables similar to Table E.l above -- developed from data measured at 74 different indoor and outdoor locations. In this curve-fitting, no linear smoothing was used, and data from all siren levels were used without omission. Table E. 2 contains the resulting slopes.

These slopes were next converted to $\rho$, assuming that they equal $(1-p)$, as labelled in the table. The resulting twelve values of $p$ were plotted against the corresponding values $R_{x x}$ of the auto correlation function, to obtain

$$
\begin{aligned}
R_{x x} & =-0.034+1.051 \rho \\
& \simeq \rho
\end{aligned}
$$

This regression equation has a correlation coefficient (between values of $\rho$ and $r_{x x}$ ) of 0.85 , which is satisfactorily high. 
In the next section, we collect these results into a form of use to the reader.

\section{E. 3 Summary of Results}

Figure E-10 contains the results of the analysis above. This figure is used as follows:

- Convert the four-minute "chance of alert" to a probability of failure-to-alert" :

$P=1-($ Chance of alert) $/ 100$

- Raise this value to the exponent determined from Figure E10, for the particular siren duration of interest.

$P=\left(P_{4-m i n}\right)$ Exponent

- Convert this "probability of failure-to-alert" back to a "chance of alert":

Chance of alert $=100(1-\mathrm{P})$

TABLE E.2. SLOPES RESULTING FROM SIREN LEVEL DATA.

\begin{tabular}{|c|c|c|c|}
\hline \multirow{2}{*}{$\begin{array}{l}\text { Listener } \\
\text { Location }\end{array}$} & \multirow[t]{2}{*}{ Subclass } & \multicolumn{2}{|c|}{ Resulting slopes $(1-\rho)$} \\
\hline & & $\begin{array}{c}\text { Stationary } \\
\text { Sirens }\end{array}$ & $\begin{array}{l}\text { Rotating } \\
\text { Sirens }\end{array}$ \\
\hline \multirow[t]{2}{*}{ Indoors } & Scenario 1 & 0.217 & 0.142 \\
\hline & Scenario 3 & 0.274 & 0.254 \\
\hline \multirow[t]{4}{*}{ Outdoors } & Rural, day & 0.164 & 0.177 \\
\hline & Urban, day & 0.065 & 0.103 \\
\hline & Rural, eve/night & 0.150 & 0.075 \\
\hline & Urban, eve/night & 0.046 & 0.039 \\
\hline
\end{tabular}



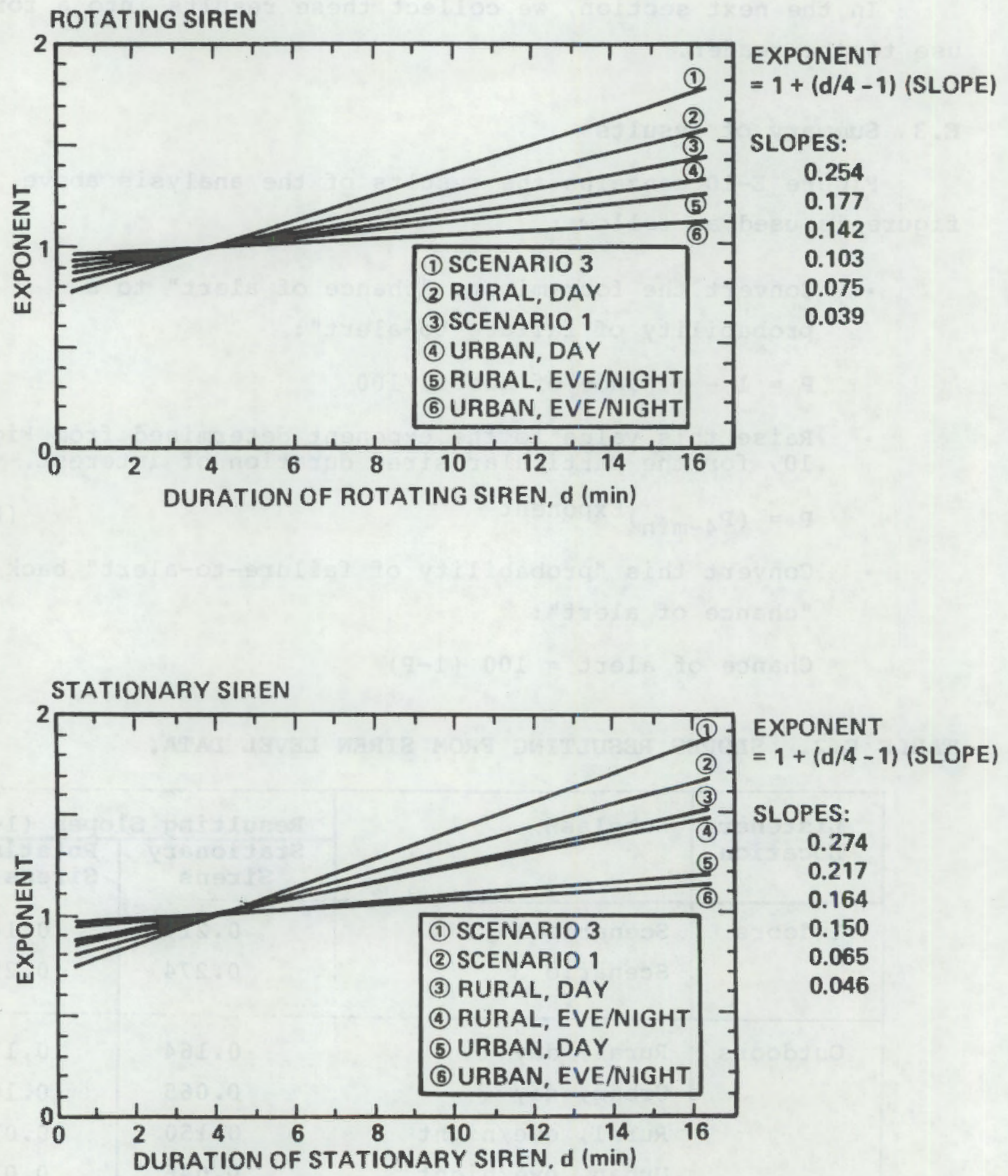

FIG. E-10. GRAPH OF EXPONENT FOR USE IN EQ. E-10. 


\section{APPENDIX F. RANDOM SELECTION OF POPULATION-WEIGHTED LISTENING POINTS AT THE THREE MILE ISLAND SITE}

The objective of the listener-site-selection process was to identify 50 randomly selected residential locations within the 10- mile EPZ surrounding the TMI Nuclear Plant. No arbitrary decision was made as to how many of the points would lie in urban or rural areas or within certain distances of the plant.

The various steps used in the site selection procedure are described below:

1. A population-distribution map (see Fig. F-l), consisting of a 10-mile-radius circle divided into annular sectors defined by interior circles and radii, was superimposed on the U.S.G.S. maps. Population distribution information consisted of the number of people within each annular sector. These data were used in order to population-weight the random selection process described below.

2. Each annular sector was first assigned a designator, such as a letter. A range of numbers was then assigned to each sector according to the population in that sector. For example, Sector A, just north of the site, has a population of 19 and thus was assigned numbers 1 through 19. Sector B (moving clockwise) has a population of 55 and was assigned numbers from 20 to 74. Sector $C$ has a population of 42 and was assigned numbers 75 through 116 . This process was continued until each number between 1 and 166,295 (the total estimated population) was assigned to a particular sector. A ran- 
dom number generator (available on a Texas Instruments Model TI-59 hand calculator, for example) was then used to select 50 numbers at random between 1 and 166,295 . Each number selected represented one site (to be chosen later) within the sector containing that number. Thus, sectors with larger populations had a greater possibility of including chosen listener sites.

3. Having determined the sector locations for each listener site, the next step in the procedure involved selecting the actual location of each site within the respective sector. This was accomplished by first overlaying a rectangular coordinate grid on each sector of interest on the topographic map. The grid was composed of boxes with dimensions of approximately 1000 feet square, and each box was assigned an $X$ and a $Y$ coordinate according to its location on the grid. The grid was positioned such that the $\mathrm{x}$-axis was oriented in the east-west direction and the $\mathrm{Y}$-axis was oriented in the north-south direction, and such that all parts of the sector of interest were covered by a positive $(X, Y)$ coordinate pair box. A random number generator was then used to select random pairs of numbers within the $\mathrm{X}$ and $\mathrm{Y}$ ranges covering the sector of interest. Each $X, Y$ pair was used to locate a particular 1000 feet square box on the map. If there were no residences inside the square or if the square fell outside of the sector of interest, that coordinate pair was disregarded and another pair was chosen at random. This process was continued until a square area including one or more residential structures was found in the sector of 
interest. The listener site was then chosen to be any residence within the randomly selected square area.

For urban sites in the pink "building-extension" area of the topographic map a residential building was always assumed to exist, and was selected at the center of the pink area in the 1000 feet square box.

The above procedure resulted in a random sample of 50 listener locations, distributed throughout the EPZ as shown roughly on Fig. F-1. 


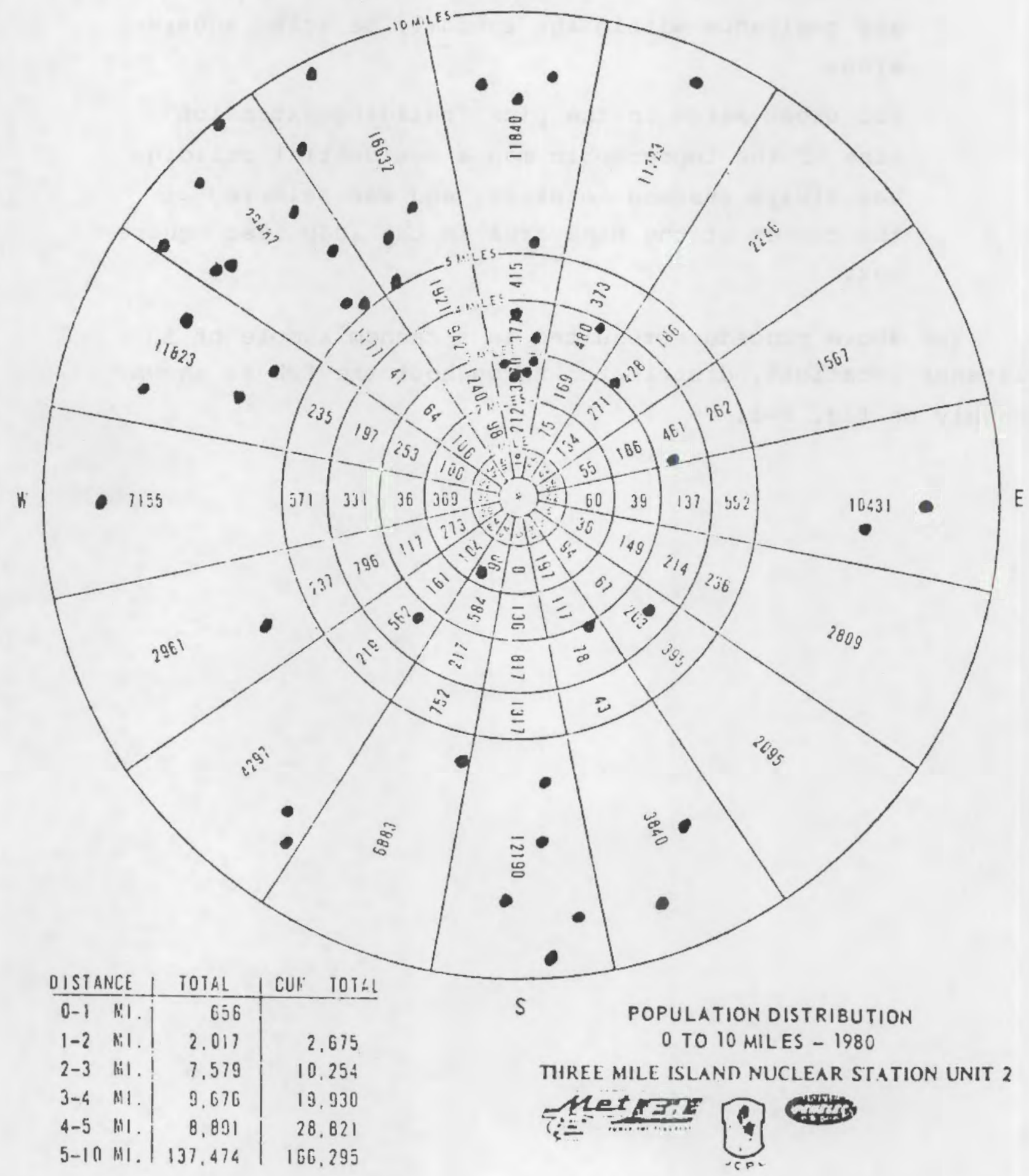

"EXCLISIOLI RAOIUS

FIG. F-1. RANDONLY SELECTED LISTENER SITES AT THREE MILE ISLAND. 


\section{APPENDIX G: TEST CASES (SAMPLE SCENARIOS) FOR THE THREE MILE ISLAND SITE}

1. Warm Summer Weekday Afternoon: Weather clear to partly cloudy.

People: $30 \%$ indoors, at work

$40 \%$ indoors, at home

$20 \%$ outdoors

$6 \%$ in motor vehicles (windows open)

$4 \%$ asleep

Buildings: Windows open (homes)

Windows closed (workplace)

Wind: (100 ft) $5 \mathrm{mph}$ from East

Temperature Gradient: $\quad-1.0^{\circ} \mathrm{F} / 100 \mathrm{ft}$. , Pasquill stability Class A

Relative Humidity: $65 \%$

2. Summer Weekday Night: Weather clear to partly cloudy.

People: $95 \%$ 1ndoors, sleeping

$4 \%$ indoors, at work

$1 \%$ in motor vehicles (windows closed)

Buildings: Windows open (homes)

Windows closed (workplace)

Wind (100 ft ): Northwest, $5 \mathrm{mph}$

Temperature Gradient: $+0.5^{\circ} \mathrm{F} / 100 \mathrm{ft}$.

Stability Class E

Relative humidity: $80 \%$

3. Winter Weekday Dur1ng Evening Community Hours: Cold, overcast

People: $70 \%$ indoors

$25 \%$ in motor vehicles (windows closed)

$5 \%$ outdoors

Buildings: Windows closed, storm windows closed 
3. Continued

Wind $(100 \mathrm{ft})$ : Southeast at $3 \mathrm{mph}$

Temperature Gradient: $\quad-0.5^{\circ} \mathrm{F} / 100 \mathrm{ft}$.

Stability Class D

Relative Hunidity: $70 \%$

4. Winter Night During Snowfall.

People: $95 \%$ indoors, sleeping

$5 \%$ indoors, at work

Building: Windows closed, storm windows closed

Wind $(100 \mathrm{ft}$.$) : West at 15 \mathrm{mph}$

Temperature Gradient: $\quad-0.5^{\circ} \mathrm{F} / 100 \mathrm{ft}$ Stability Class D

Relative Humidity: $\quad 90 \%$ 
APPENDIX H: SIREN LOCATIONS FOR THE TMI EPZ

This appendix provides siren information for the TMI EPZ. Siren locations are indicated on Fig. H-1 (see foldout). Table H.l provides information on the type and rating for each siren.

TABLE H.1. TMI SIREN INFORMATION.

County/Siren Designation

Cumberland $\mathrm{Cl}$

Cumberland $\mathrm{C} 2$

Cumberland C3

Dauphin Dl

Dauphin D2

Dauphin D3

Dauphin D4

Dauphin D5

Dauphin D6

Dauphin D7

Dauphin D8

Dauphin D9

Dauphin D10

Dauphin Dll

Dauphin D12

Dauphin D13

Dauphin D14

Dauphin D15

Dauphin D16

Dauph in D17

Dauphin D18

Dauphin D19

Dauphin D20
Type*

R

S

$\mathrm{S}$

$\mathrm{S}$

$\mathrm{S}$

$\mathrm{R}$

$\mathrm{S}$

S

$\mathrm{S}$

S

$\mathrm{R}$

S

S

S

$\mathrm{S}$

$\mathrm{s}$

$\mathrm{s}$

$S$

R

R

S

$\mathrm{S}$

S
Rated SPL (dB a $100 \mathrm{ft}$ )

124

122

122

122

122

124

122

122

122

122

124

122

122

122

122

122

122

122

124

124

122

122

122

*Rotating (R) or Stationary (S) 
TABLE H.1. TMI SIREN INFORMATION (Cont.)

\begin{tabular}{|c|c|c|}
\hline County/Siren Designation & Type* & $\begin{array}{c}\text { Rated SPL } \\
(\mathrm{dB} \in 100 \mathrm{ft})\end{array}$ \\
\hline Dauphin D22 & E & 124 \\
\hline Dauphin D23 & s & 122 \\
\hline Dauphin D24 & $\mathbf{R}$ & 124 \\
\hline Dauphin D25 & R & 124 \\
\hline Dauphin D26 & $\mathbf{R}$ & 124 \\
\hline Dauphin D27 & $\mathrm{R}$ & 124 \\
\hline Dauphin D28 & s & 122 \\
\hline Dauphin D29 & R & 124 \\
\hline Dauph in D30 & s & 122 \\
\hline Lancaster LAI & $\mathbf{R}$ & 124 \\
\hline Lancaster LA2 & $\mathbf{R}$ & 124 \\
\hline Lancaster $\mathrm{LA} 3$ & $\mathrm{R}$ & 124 \\
\hline Lancaster LA4 & $\mathrm{R}$ & 124 \\
\hline Lancaster LA5 & $\mathrm{R}$ & 124 \\
\hline Lancaster LA6 & R & 124 \\
\hline Lancaster LA7 & $\mathrm{s}$ & 122 \\
\hline Lancaster LA8 & $s$ & 122 \\
\hline Lancaster LA9 & $\mathbf{R}$ & 124 \\
\hline Lancaster LAlO & $\mathrm{s}$ & 122 \\
\hline Lancaster LAII & $\mathrm{R}$ & 124 \\
\hline Lancaster LAI2 & s & 122 \\
\hline Lancaster LA13 & $\mathrm{R}$ & 124 \\
\hline Lancaster LAl4 & s & 122 \\
\hline Lebanon LEl & s & 122 \\
\hline Lebanon LE2 & $s$ & 122 \\
\hline York Y1 & $\mathrm{s}$ & 122 \\
\hline York Y2 & $\mathrm{R}$ & 124 \\
\hline
\end{tabular}

*Rotating (R) or Stationary (S) 
TABLE H.1. THI SIREN INFORMATION (Cont.)

\section{County/Siren Designation}

York Y3

York $\mathrm{Y} 4$

York Y5

York Y6

York $\mathrm{Y} 7$

York $\mathrm{Y} 8$

York Y9

York Yl0

York Yll

York Y12

York Y13

York Y14

York Y15

York Y16

York Y17

York Y18

York Y19

York Y20

York Y21

York Y22

York Y 23

York Y24

York Y 25

York Y26

York Y 27

York Y28

York Y 29

York Y30
Type*

$\mathrm{S}$

$\mathrm{S}$

S

R

$S$

R

S

$\mathrm{S}$

R

R

$S$

$S$

R

$S$

S

$\mathrm{S}$

S

$\mathrm{S}$

R

$S$

S

R

$S$

S

R

$\mathrm{S}$

$\mathrm{S}$

R
Rated SPL (dB $100 \mathrm{ft}$ )

122

122

122

124

122

124

122

122

124

124

122

122

124

122

122

122

122

122

124

122

122

124

122

122

124

122

122

124

*Rotating (R) or Stationary (S) 
TABLE H.1. TMI SIREN INFORHATION (Cont.)

County/Siren Designation

York Y31

York Y32

York Y33
Type*

R

S

S
Rated SPL

(dB $100 \mathrm{ft}$ )

124

122

122

*Rotating (R) or Stationary (S) 


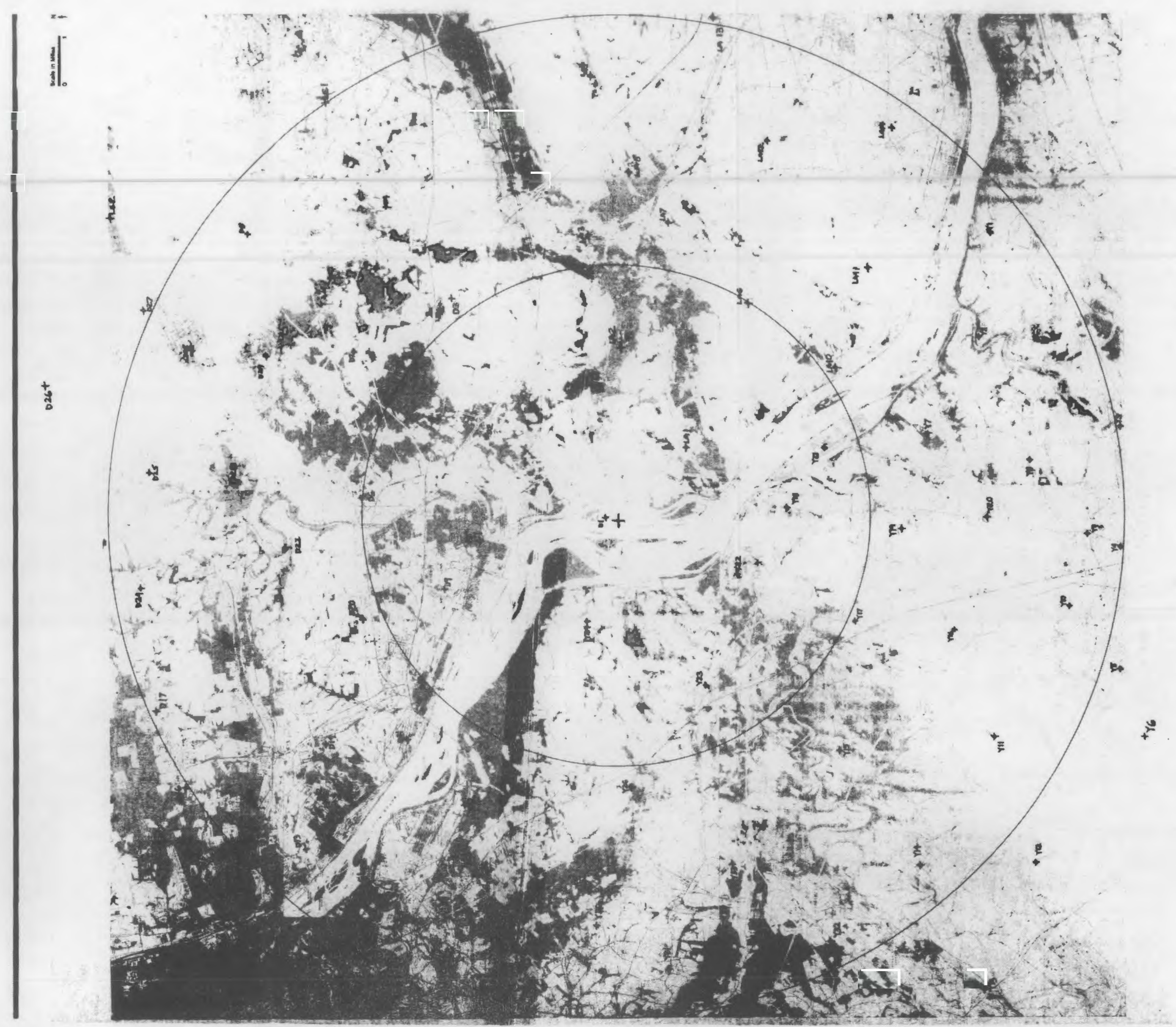

FIG. H-1. TMI SIREN LOCATION MAP. 

APPENDIX I: ANALYSIS INPUT/OUTPUT DATA FOR THREE MILE ISLAND

This appendix provides 1 istings of computer file input and output data for the TMI analysis. Explanation of the terminology used for each listing is provided below.

\section{TABLE I.1. TMI-SIRENS}

This file contains input data for each of the TMI sirens as follows:

- Siren No. number assigned to each siren for use by computer program

- Siren Name first letter indicates whether the siren is rotating or stationary type ( $R$ or $S)$; the remainder consists of the actual TMI siren designation, beginning with county letter abbreviation and ending with a number.

- $x, y, z$ these are the physical coordinates for the siren location; the $x$-axis is oriented eastwest, the $y$-axis is oriented north-south, and the $z$-axis is oriented vertically. The $x$ and $y$ coordinates are in units of $\mathrm{km}$, referenced to the grid shown on the Feb. 1981 NRC Emergency Planning Map for TMI (the plant center is located approximately at $x=353, y=$ 4446). The $z$ coordinates are in units of feet.

- SPLE100FT these numbers indicate the rated sound pressure level for each siren at a distance of 100 $f t$, in $d B$. 


\section{TABLE I.2. TMI-LISTENERS}

This file contains input data for each of the randomly selected listener locations as follows:

- Site No.

- Site Name

- $x, y, z$ number assigned to each site for use by computer prograin

designator for listener site; the first letter indicates whether site is urban or rural ( $U$ or R) .

these are the physical coordinates for the siren location; the $\mathrm{x}$-axis is oriented eastwest, the $y$-axis is oriented north-south, and the $z$-axis is oriented vertically. The $x$ and $y$ coordinates are in units of $\mathrm{km}$, referenced to the grid shown on the Feb. 1981 NRC Emergency Planning Map for TMI (the plant center is located approximately at $x=353, y=$ 4446). The $z$ coordinates are in units of feet.

- odLR the outdoor median alerting level for a 4-min. rotating siren (see Table 3.4 and Fig. 3-3 of text). An entry is given for each of the four scenarios.

- ovCR

the outdoor alert distribution for a 4-min. rotating siren (see Table 3.4 and Fig. 3-3 of text). An entry is given for each of the four scenarios.

- OVLS the outdoor median alerting level for a 4-min. stationary siren (see Table 3.4 and Fig. 3-3 of text). An entry is given for each of the four scenarios. 
- ovCS

The outdoor alert distribution for a 4-min. stationary siren (see Table 3.4 and Fig. 3-3 of text). An entry is given for each of the four scenarios.

\section{TABLE I.3. TMI-SCENARIO}

This file contains input for each of the four sample scenarios as follows:

- Scenario No. number assigned to each scenario (see App. G.)

- AMCL molecular absorption, in $\mathrm{dB} / \mathrm{P} 000 \mathrm{ft}$

- WIND wind direction in degrees $\left(0^{\circ}=\right.$ wind from north, etc.)

- NRES

residential building outdoor-to-indoor noise reduction, in $\mathrm{dB}$

- NCRM

commercial building outdoor-to-indoor noise reduction, in $d B$

- $\mathrm{F} 1-\mathrm{F} 10$ activity fractions

fraction of people outdoors

F2

fraction of people indoors, at home, listening to radio or $\mathrm{TV}$

F3 fraction of people indoors, at home, sleeping

F 4 fraction of people indoors, at home, neither sleeping nor listening to radio or TV

F5 fraction of people indoors, at work, in commercial establishments

F6

fraction of people indoors, at work, in industrial locations 
fraction of people in vehicies in rural areas at $55 \mathrm{mph}$

F8 fraction of people in vehicles in rural areas at $30 \mathrm{mph}$

F9 fraction of people in vehicles in urban areas at $55 \mathrm{mph}$

Fl0 fraction of people in vehicles in urban areas at $30 \mathrm{mph}$

- INP

indoor alert probability curve (see Figs. 3-4 and $3-5$ of text)

- PU55

probability of alert for motorists in urban areas at $55 \mathrm{mph}$

- PU30

probability of alert for motorists in urban areas at $30 \mathrm{mph}$

- PR55

probability of alert for motorists in rural areas at $55 \mathrm{mph}$

- $\quad$ PR30

probability of alert for motorists in rural areas at $30 \mathrm{mph}$

- MUL vertical profile of wind speed, $B z$, in $\mathrm{ft} / \mathrm{sec} / \ln \mathrm{ft}$.

- $A D D$ vertical profile of air temperature, $a$, in ${ }^{\circ} \mathrm{F} / \mathrm{In} \mathrm{ft}$.

\section{TABLE I.4. LISTENEROUTPUT}

This listing provides the number, name, and outdoor sound pressure level (LOUT, in $d B$ ) for the "dominant" siren at each sample listener location, for each of the four sample scenarios. The results are listed in numerical order for scenarios one through four for each listener site. 


\section{TABLE I.5. PROBS}

This listing provides the final results for the analysis. Information is listed in numerical order for scenarios one through four for each listener site. This information consists of alert probabilities Pl through PlO corresponding to activity fractions FI through $F 10$, as well as the total probability of alert (PT) for each sample scenario at each sample listener site.

A summary is provided at the end of the listing showing the rural and urban populations followed by the total rural probability of alert (PTRUR), the total urban probability of alert for the EPZ (PTALL). The total probability values are listed in numerical order for sample scenarios one through four. 
TABLE I. 1.

TMI-SIRENS

\begin{tabular}{|c|c|c|c|c|c|c|}
\hline SIRENA & SIREM & NAME & $x$ & $\gamma$ & $z$ & SPLQ100 \\
\hline 1 & $R \quad C 1$ & & 341.650 & 4454.200 & 360.000 & 124 \\
\hline Z & $S \mathrm{CE}$ & & 338.950 & 4455.600 & 450.000 & 122 \\
\hline 3 & $5 \mathrm{C} 3$ & & 340.550 & 4452.950 & 450.000 & 122 \\
\hline 4 & S II & & 353.200 & 4446.600 & 350.000 & 122 \\
\hline 5 & s $\mathrm{ne}$ & & 355.950 & 4450.150 & 590.000 & 122 \\
\hline 6 & R. D3 & & 360.300 & 4451.300 & 510.000 & 124 \\
\hline 7 & $5 \mathrm{D} 4$ & & 363.300 & 4453.250 & 520.000 & $1 \overline{2}$ \\
\hline 8 & 505 & & 352.500 & 4450.500 & 370.000 & 122 \\
\hline 9 & S 16 & & 354.000 & 4454.250 & 470.000 & 122 \\
\hline 10 & 517 & & 358.700 & 4454.400 & 640.000 & 122 \\
\hline 11 & R IS & & $36 e .550$ & 4457.700 & 480.000 & 124 \\
\hline 12 & S 19 & & 351.000 & 4451.650 & 390.000 & 122 \\
\hline 13 & 5 III0 & & 347.700 & 4452.250 & 360.000 & 122 \\
\hline 14 & 5011 & & 346.150 & 4452.900 & 390.000 & 122 \\
\hline 15 & S: I1] & & 344.200 & 4455.550 & 550.000 & $12 \mathrm{e}$ \\
\hline 16 & 5113 & & 342.750 & 4456.200 & 430.000 & $1 \hat{\mathrm{Ee}}$ \\
\hline 17 & $S \mathrm{D} 14$ & & 344.150 & 4457.800 & 425.000 & 122 \\
\hline 18 & $3 \lcm{015}$ & & 342.400 & 4459.300 & 600.000 & 122 \\
\hline 19 & R 116 & & 344.750 & 4460.050 & 550.000 & 124 \\
\hline 20 & $\mathrm{R} 1117$ & & 346.900 & 4460.550 & 540.000 & 124 \\
\hline 21 & 51118 & & 346.600 & 4458.150 & 470.000 & 122 \\
\hline $2 \mathrm{z}$ & 519 & & 346.100 & 4455.450 & 570.000 & 122 \\
\hline 23 & $\leq$ İं̄ & & 350.100 & 4454.300 & 490.000 & $12 \overline{2}$ \\
\hline 24 & F nę & & 352.350 & 4456.650 & 350.000 & 124 \\
\hline 25 & s ne3 & & 354.600 & 4458.350 & 450.000 & $1 \mathrm{Cg}$ \\
\hline 26 & F $D 24$ & & 351.150 & 4461.300 & 530.000 & 124 \\
\hline 27 & R nes & & 354.900 & 4461.000 & 510.000 & 124 \\
\hline 28 & R 1126 & & 357.700 & 4464.650 & 450.000 & 124 \\
\hline 29 & $3 \quad 027$ & & 360.100 & 4461.100 & 430.000 & 122 \\
\hline 30 & S пе8 & & 358.750 & 4459.600 & 450.000 & $1 \mathrm{eg}$ \\
\hline 31 & R Iİ9 & & 358.600 & 4457.250 & 750.000 & 124 \\
\hline 32 & 51030 & & 349.200 & 4458.450 & 530.000 & 122 \\
\hline 33 & R LA1 & & 355.500 & 4443.950 & 570.000 & 124 \\
\hline 34 & F. LAE & & 358.650 & 4446.000 & 570.000 & 124 \\
\hline 35 & R LA3 & & 362.300 & 4446.950 & 590.000 & 124 \\
\hline 36 & F: LA4 & & 363.650 & 4449.250 & 490.000 & 124 \\
\hline 37 & F LA5 & & 367.550 & 4450.750 & 530.000 & 124 \\
\hline 38 & R. LAE. & & 360.000 & 4441.800 & 510.000 & 124 \\
\hline 39 & $\Xi L A \vec{r}$ & & 362.700 & 4444.350 & 460.000 & 122 \\
\hline 40 & $S L A B$ & & 364.300 & 4445.650 & 530.000 & 122 \\
\hline 41 & R LA9 & & 367.400 & 4446.800 & 590.000 & 124 \\
\hline 42 & $S$ LA10 & & 357.900 & 4439.050 & 350.000 & 122 \\
\hline 43 & R LA11 & & 361.100 & 4438.000 & 450.000 & 124 \\
\hline 44 & S LA1E & & 365.250 & 4441.150 & 450.000 & 122 \\
\hline 45 & R. LA13 & & 369.400 & 4442.850 & 450.000 & 124 \\
\hline 46 & 5 LF14 & & 365.700 & 4437.200 & 450.000 & 122 \\
\hline 47 & S LE1 & & 366.700 & 4455.100 & 560.000 & 122 \\
\hline 48 & 5 LEZ & & 363.150 & 4462.050 & 500.000 & 122 \\
\hline 49 & $S Y 1$ & & $36 \overline{.} \cdot 250$ & 4434.150 & 730.000 & 122 \\
\hline 50 & R YZ & & 358.800 & 4434.550 & 370.000 & 124 \\
\hline
\end{tabular}


TABLE I.1. (Cont.)

$\begin{array}{llllll}51 & S Y 3 & 355.900 & 4430.100 & 550.000 & 122 \\ 52 & S Y 4 & 352.050 & 4430.100 & 470.000 & 122 \\ 53 & S Y 5 & 348.100 & 4430.250 & 530.000 & 122 \\ 54 & R Y 6 & 346.000 & 4429.600 & 490.000 & 124 \\ 55 & S Y 7 & 355.800 & 4436.250 & 520.000 & 122 \\ 56 & R Y 8 & 354.950 & 4433.000 & 690.000 & 124 \\ 57 & S Y 9 & 352.450 & 4431.250 & 460.000 & 122 \\ 58 & S Y 10 & 350.150 & 4431.850 & 490.000 & 122 \\ 59 & R Y 11 & 346.000 & 4434.300 & 530.000 & 124 \\ 60 & R Y 12 & 341.950 & 4433.050 & 670.000 & 124 \\ 61 & S Y 13 & 337.850 & 4434.700 & 570.000 & 122 \\ 62 & S Y 14 & 341.850 & 4436.700 & 600.000 & 122 \\ 63 & R Y 15 & 345.600 & 4439.200 & 630.000 & 124 \\ 64 & S Y 16 & 349.450 & 4435.500 & 390.000 & 122 \\ 65 & S Y 17 & 349.750 & 4438.600 & 470.000 & 122 \\ 66 & S Y 18 & 353.450 & 4440.700 & 510.000 & 122 \\ 67 & S Y 19 & 352.800 & 4437.100 & 500.000 & 122 \\ 68 & S Y 20 & 353.100 & 4434.400 & 530.000 & 122 \\ 69 & R Y 21 & 355.350 & 4439.500 & 330.000 & 124 \\ 70 & S Y 22 & 351.300 & 4442.250 & 520.000 & 122 \\ 71 & S Y 23 & 347.750 & 4443.500 & 670.000 & 122 \\ 72 & R Y 24 & 349.900 & 4447.200 & 490.000 & 124 \\ 73 & S Y 25 & 347.000 & 4449.350 & 770.000 & 122 \\ 74 & S Y 26 & 344.600 & 4445.850 & 510.000 & 122 \\ 75 & R Y 27 & 344.100 & 4451.150 & 370.000 & 124 \\ 76 & S Y 28 & 342.000 & 4450.350 & 920.000 & 122 \\ 77 & S Y 29 & 338.750 & 4451.950 & 570.000 & 122 \\ 78 & R Y 30 & 340.100 & 4447.000 & 620.000 & 124 \\ 79 & R Y 31 & 338.650 & 4444.750 & 540.000 & 124 \\ 80 & S Y 32 & 339.500 & 4439.550 & 675.000 & 122 \\ 81 & S Y 33 & 342.050 & 4442.700 & 530.000 & 122\end{array}$


TABLE I. 2.

IHI-LISTENEKS

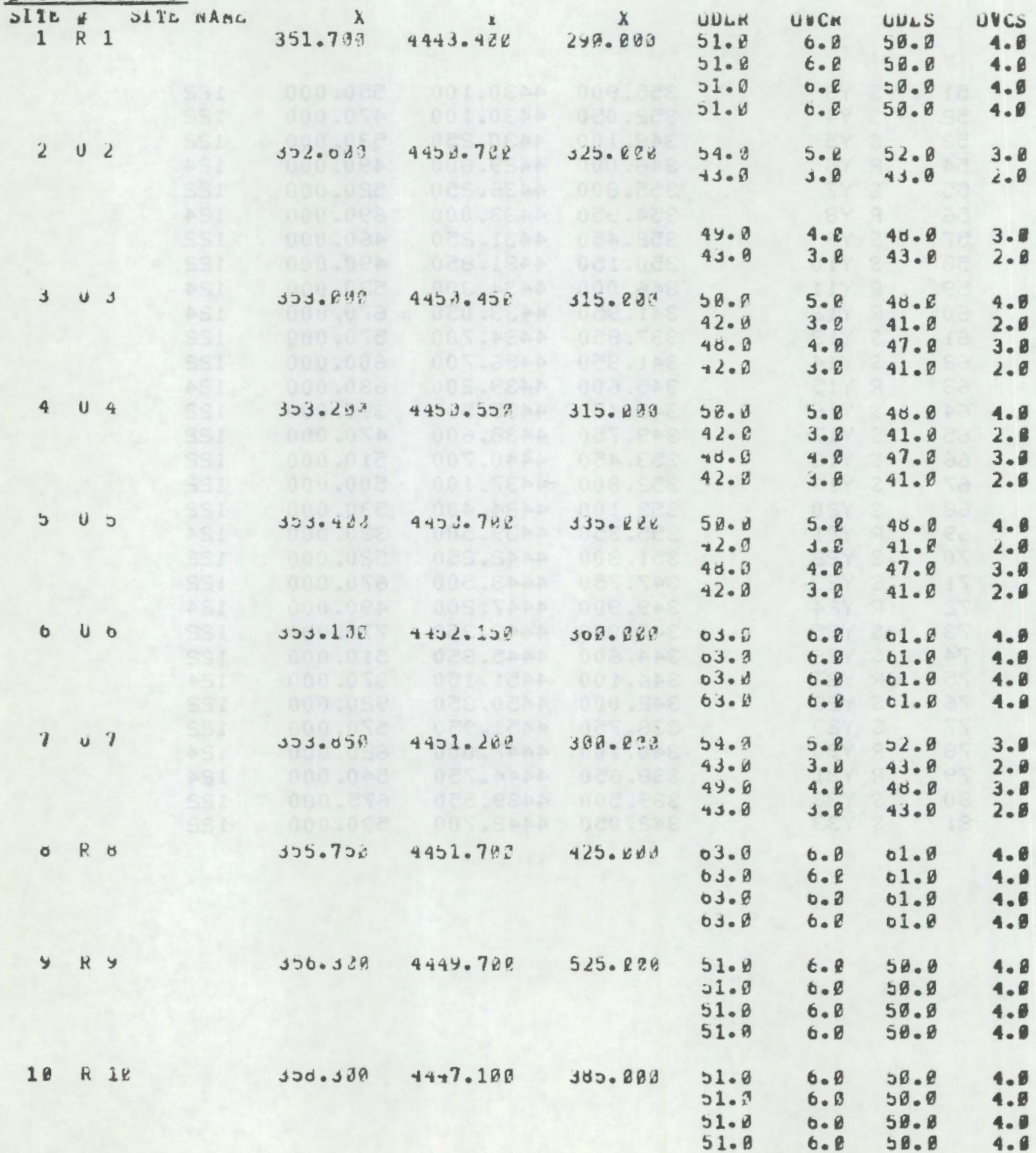


TABLE 1.2. (Cont.)

\begin{tabular}{|c|c|c|c|c|c|c|c|c|c|}
\hline 11 & K 1 & 11 & 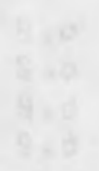 & $557.70 ?$ & 4442.520 & 385.290 & $\begin{array}{l}34.0 \\
54.0 \\
36.8 \\
47.0\end{array}$ & $\begin{array}{l}5.8 \\
5.8 \\
5.8 \\
5.8\end{array}$ & $\begin{array}{l}38.0 \\
38.0 \\
35.0 \\
46.0\end{array}$ \\
\hline 2 & $\mathrm{R}$ & 12 & 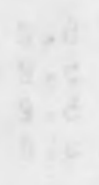 & 305.056 & 4441.050 & 305.003 & $\begin{array}{l}51.0 \\
51.0 \\
51.0 \\
51.0\end{array}$ & $\begin{array}{l}0.0 \\
0.18 \\
0.0 \\
6.0\end{array}$ & $\begin{array}{l}50.0 \\
58.0 \\
50.0 \\
50.0\end{array}$ \\
\hline 13 & $k$ & 13 & $\begin{array}{l}3=4 \\
2=0 \\
6=0 \\
5-4\end{array}$ & $3+y .05 B$ & 4442.242 & 485.282 & $\begin{array}{l}34.0 \\
3 y .8 \\
30.8 \\
47.8\end{array}$ & $\begin{array}{l}5.8 \\
5.8 \\
5.8 \\
5.2\end{array}$ & $\begin{array}{l}38.8 \\
30.0 \\
35.0 \\
46.0\end{array}$ \\
\hline & K & 14 & 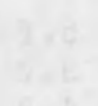 & $3350+30$ & $7131.30:$ & 300.83 & $\begin{array}{l}50.0 \\
50.3\end{array}$ & $\begin{array}{l}0.8 \\
0.1\end{array}$ & $\begin{array}{l}24.8 \\
54.8\end{array}$ \\
\hline & & 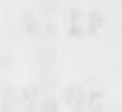 & 3.5 & $6 x^{3}=$ & & & $\begin{array}{l}50.0 \\
30.0\end{array}$ & $\begin{array}{l}0.8 \\
0.8\end{array}$ & $\begin{array}{l}54.8 \\
34.0\end{array}$ \\
\hline 15 & P. : & 10 & 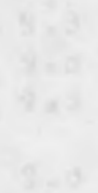 & $102.10 x$ & $4+03$. ena & 568.088 & $\begin{array}{l}34.0 \\
34.0 \\
36.0 \\
47.0\end{array}$ & $\begin{array}{l}5.8 \\
5.8 \\
5.8 \\
5.8\end{array}$ & $\begin{array}{l}30.0 \\
30.0 \\
13.0 \\
40.0\end{array}$ \\
\hline 10 & $\mathrm{R}$ & 10 & $4+2$ & 3 د2. die & 4454.750 & $405 \cdot R E R$ & $\begin{array}{l}3 y .10 \\
3 y .3 \\
30.0 \\
47.0\end{array}$ & $\begin{array}{l}5.8 \\
5.8 \\
5.8 \\
5.8\end{array}$ & $\begin{array}{l}38.0 \\
10.0 \\
35.1 \\
40.0\end{array}$ \\
\hline 17 & R & 27 & 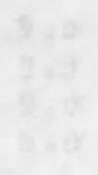 & 503.033 & ++00.100 & 120.800 & $\begin{array}{l}3 y .6 \\
34.0 \\
36.0 \\
47.8\end{array}$ & $\begin{array}{l}5.8 \\
5.8 \\
5.0 \\
5.8\end{array}$ & $\begin{array}{l}30.8 \\
30.8 \\
35.9 \\
46.8\end{array}$ \\
\hline 10 & $u$ & 10 & $\sqrt{3}+4$ & $35+.45 \Omega$ & 4400.282 & 440.820 & $\begin{array}{l}55.8 \\
42.0 \\
48.8 \\
42.0\end{array}$ & $\begin{array}{l}5.8 \\
3.8 \\
4.8 \\
3.8\end{array}$ & $\begin{array}{l}48.0 \\
41.0 \\
47.0 \\
41.0\end{array}$ \\
\hline $1 y$ & u : & 14 & a & 304.358 & 4444.750 & 485.985 & $\begin{array}{l}58.0 \\
42.0 \\
40.8 \\
42.0\end{array}$ & $\begin{array}{l}5.0 \\
3.0 \\
4.0 \\
3.0\end{array}$ & $\begin{array}{l}48.0 \\
41.0 \\
47.8 \\
41.0\end{array}$ \\
\hline $2 b$ & k & 26 & 7 & $500.30 \theta$ & $4444 . Y Q R$ & $49 \% .828$ & $\begin{array}{l}34.0 \\
34.8 \\
30.8 \\
47.8\end{array}$ & $\begin{array}{l}5.8 \\
3.8 \\
5.8 \\
5.8\end{array}$ & $\begin{array}{l}38.0 \\
38.0 \\
35.0 \\
40.9\end{array}$ \\
\hline
\end{tabular}


TABLE I.2. (Cont.)

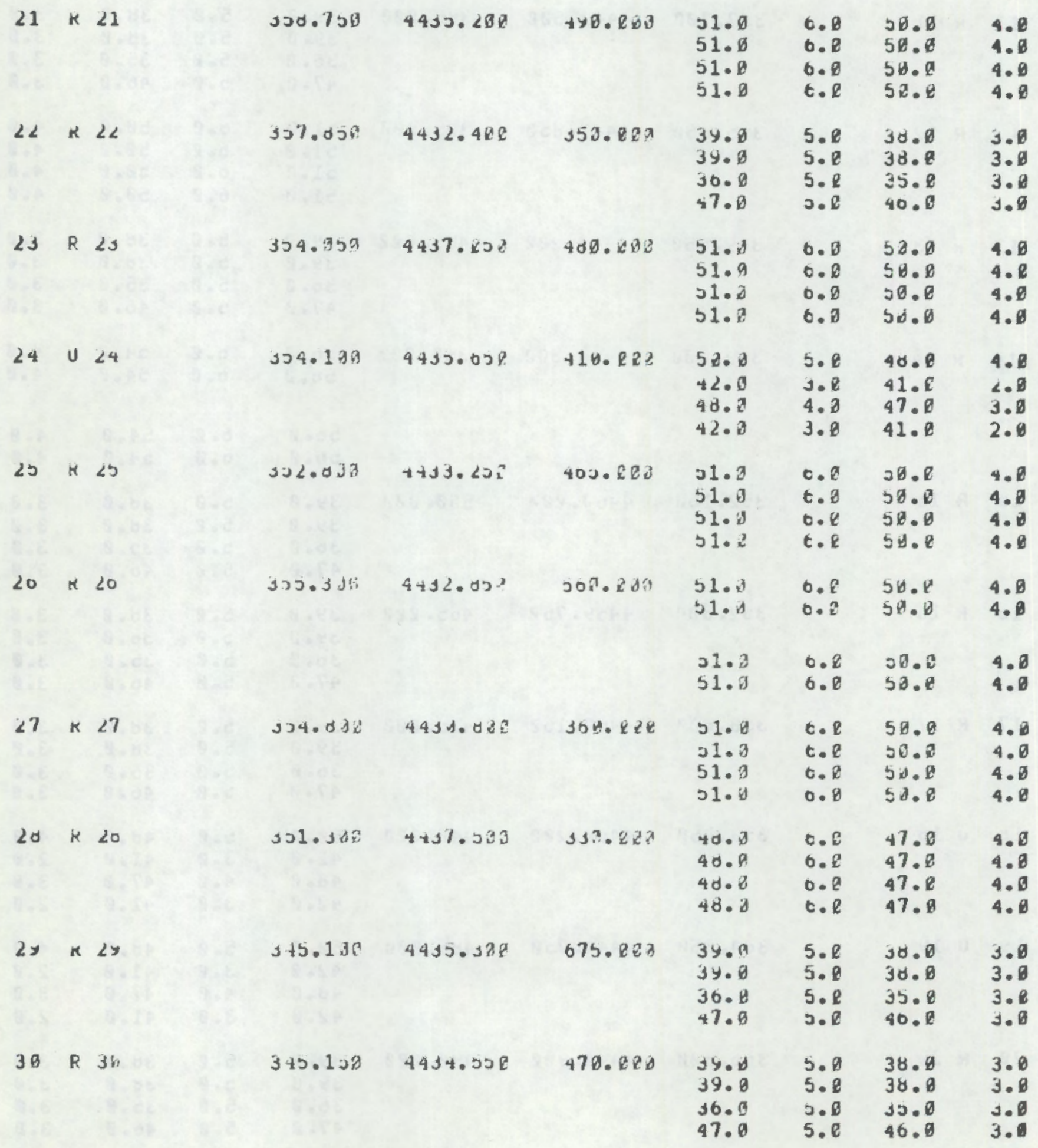


TABLE I.2. (Cont.)

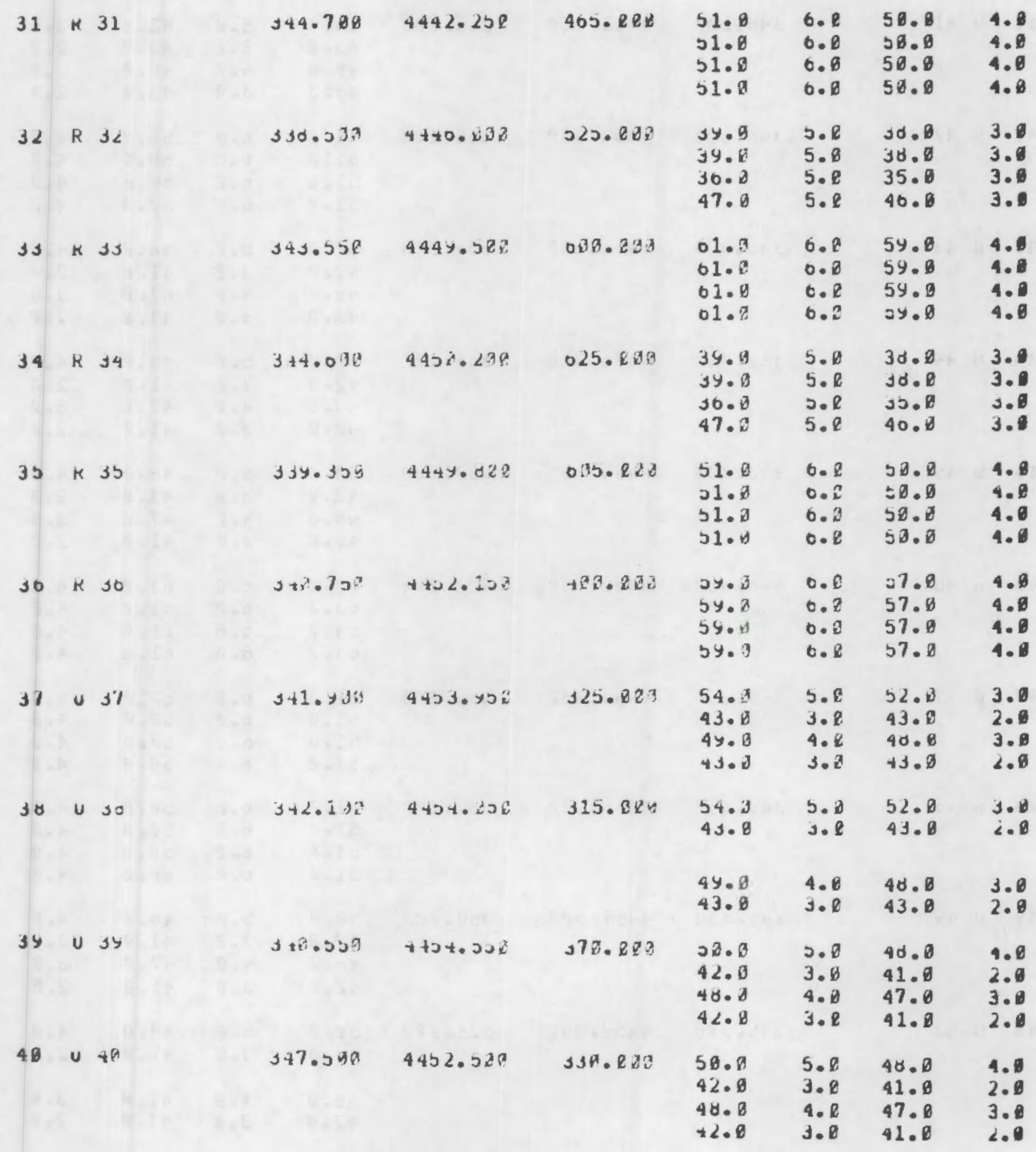


TABLE I.2. (Cont.)

\begin{tabular}{|c|c|c|c|c|c|c|c|c|c|c|}
\hline 41 & 04 & 41 & 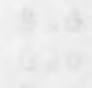 & 340.100 & 4 45.52. & 505.000 & $\begin{array}{l}54.6 \\
43.6\end{array}$ & $\begin{array}{l}5.0 \\
3.0\end{array}$ & $\begin{array}{l}52.6 \\
43.0\end{array}$ & $\begin{array}{l}3.0 \\
2.0\end{array}$ \\
\hline (3.1. & & $9+4 x^{2}$ & 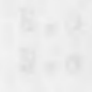 & & & & $\begin{array}{l}49.18 \\
43.2\end{array}$ & $\begin{array}{l}4.8 \\
3.8\end{array}$ & $\begin{array}{l}40.0 \\
43.0\end{array}$ & $\begin{array}{l}3.0 \\
2.0\end{array}$ \\
\hline 42 & K 4 & 42 & 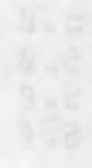 & 340.018 & 4454.150 & 465.828 & $\begin{array}{l}51.0 \\
51.0 \\
51.0 \\
51.9\end{array}$ & $\begin{array}{l}0.0 \\
0.1 \\
0.0 \\
0.0\end{array}$ & $\begin{array}{l}50.0 \\
50.0 \\
50.0 \\
50.0\end{array}$ & $\begin{array}{l}4.8 \\
4.8 \\
4.8 \\
4.8\end{array}$ \\
\hline 43 & $\boldsymbol{u}<$ & 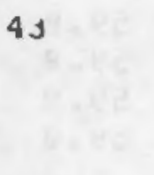 & 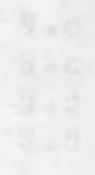 & $3+3.300$ & $4+00.080$ & 500.825 & $\begin{array}{l}30.0 \\
42.0 \\
40.0 \\
42.0\end{array}$ & $\begin{array}{l}3.8 \\
3.8 \\
4.8 \\
3.8\end{array}$ & $\begin{array}{l}40.0 \\
41.0 \\
47.0 \\
41.0\end{array}$ & $\begin{array}{l}4.0 \\
2.0 \\
3.0 \\
2.0\end{array}$ \\
\hline 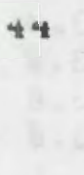 & $u$. & +4 & 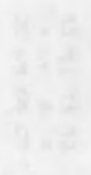 & 342.62 & $4+50.720$ & 305.280 & $\begin{array}{l}50.0 \\
42.0 \\
40.0 \\
+2.9\end{array}$ & $\begin{array}{l}5.8 \\
3.8 \\
4.8 \\
3.2\end{array}$ & $\begin{array}{l}4.10 \\
41.0 \\
47.6 \\
41.0\end{array}$ & $\begin{array}{l}4.8 \\
2.8 \\
3.8 \\
2.8\end{array}$ \\
\hline 45 & $0<$ & 45 & 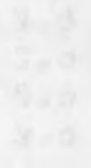 & $3+5.2 \mathrm{~J} 2$ & $4453.05 \%$ & 400.243 & $\begin{array}{l}50.0 \\
42.0 \\
48.3 \\
42.0\end{array}$ & $\begin{array}{l}5.8 \\
3.8 \\
4.2 \\
3.8\end{array}$ & $\begin{array}{l}48.0 \\
41.0 \\
47.0 \\
41.0\end{array}$ & $\begin{array}{l}4.8 \\
2.0 \\
3.0 \\
2.0\end{array}$ \\
\hline 40 & $k$. & 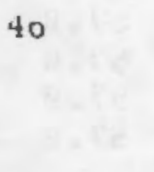 & 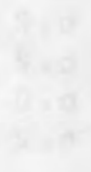 & $3+0.00 .1$ & 44 כ & $423 . R E E$ & $\begin{array}{l}0.1 .8 \\
01.2 \\
03.3 \\
03.0\end{array}$ & $\begin{array}{l}6.8 \\
0.0 \\
0.0 \\
0.0\end{array}$ & $\begin{array}{l}01.0 \\
01.9 \\
01.0 \\
01.0\end{array}$ & $\begin{array}{l}4.8 \\
4.8 \\
4.8 \\
4.8\end{array}$ \\
\hline$x^{2}=$ & $\mathrm{R}$ & 47 & 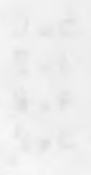 & $3+0.250$ & $x+0+0120$ & .30 .203 & $\begin{array}{l}51.8 \\
51.8 \\
51.0 \\
51.0\end{array}$ & $\begin{array}{l}0.8 \\
6.18 \\
6.0 \\
6.8\end{array}$ & $\begin{array}{l}50.8 \\
50.0 \\
50.9 \\
50.9\end{array}$ & $\begin{array}{l}4.8 \\
4.8 \\
4.8 \\
4.8\end{array}$ \\
\hline 40 & $\kappa$ & to & & $34>.35 ?$ & $4455.6 x^{3} ?$ & bos. $29 a$ & $\begin{array}{l}31 . x \\
51.8 \\
31.8 \\
51.8\end{array}$ & $\begin{array}{l}0.8 \\
0.8 \\
6.8 \\
0.8\end{array}$ & $\begin{array}{l}50.0 \\
50.0 \\
50.0 \\
50.0\end{array}$ & $\begin{array}{l}4.0 \\
4.0 \\
4.0 \\
4.0\end{array}$ \\
\hline $4 y$ & $u<$ & 4y & & 345.350 & $4+57 . y 40$ & Jat. Q2: & $\begin{array}{l}50.0 \\
42.0 \\
40.0 \\
42.8\end{array}$ & $\begin{array}{l}5.8 \\
3.8 \\
4.8 \\
3.8\end{array}$ & $\begin{array}{l}48.0 \\
41.0 \\
47.0 \\
41.0\end{array}$ & $\begin{array}{l}4.0 \\
2.0 \\
3.0 \\
2.0\end{array}$ \\
\hline 50 & $u:$ & 53 & & 345.486 & $4+00.302$ & $5 \angle 0.820$ & $\begin{array}{l}58.8 \\
+2.8\end{array}$ & $\begin{array}{l}5.6 \\
3.0\end{array}$ & $\begin{array}{l}48.0 \\
41.6\end{array}$ & $\begin{array}{l}4.0 \\
2.8\end{array}$ \\
\hline 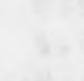 & & & & & & & $\begin{array}{l}48.0 \\
42.0\end{array}$ & $\begin{array}{l}4.8 \\
3.8\end{array}$ & $\begin{array}{l}47.0 \\
41.0\end{array}$ & $\begin{array}{l}3.0 \\
2.0\end{array}$ \\
\hline
\end{tabular}


TABLE I. 3.

TALSCENHEIU

\begin{tabular}{|c|c|c|c|c|c|c|c|c|c|c|c|c|c|c|}
\hline & & & & & & & & & & & & & & \\
\hline 1 & & प्र & & & & & & & & & & & & \\
\hline 2 & & & 11 & & & & & & & & & & D & \\
\hline s & & & d) & & & & & & & & & & 0 & \\
\hline 4 & 09 & $7 x$ & 31 & & & 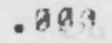 & $5 x^{2}$ & g & 243 & 110 & .000 & $D D C$ & 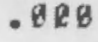 & \\
\hline
\end{tabular}

\begin{tabular}{|c|c|c|c|c|c|c|}
\hline$r$ & זטכ & pos? & כבאזי & 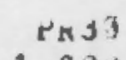 & MUL & ALL \\
\hline 1 & 1. 093 & 1.936 & $2.3 x_{0}$ & $1.2 \times 0$ & 1.078 & 1 \\
\hline 1 & 1.430 & 1. & & 1. & $\delta 7 x$ & $-i$ \\
\hline 3 & $1.30 ?$ & 1.6 & 1.3 & 1. & 1.220 & 0.40 \\
\hline 1 & 1. 84,3 & 1.032 & 1.338 & 1.209 & 0.029 & 4.40 \\
\hline
\end{tabular}


TABLE I.4. LISTENEKUUTPUT

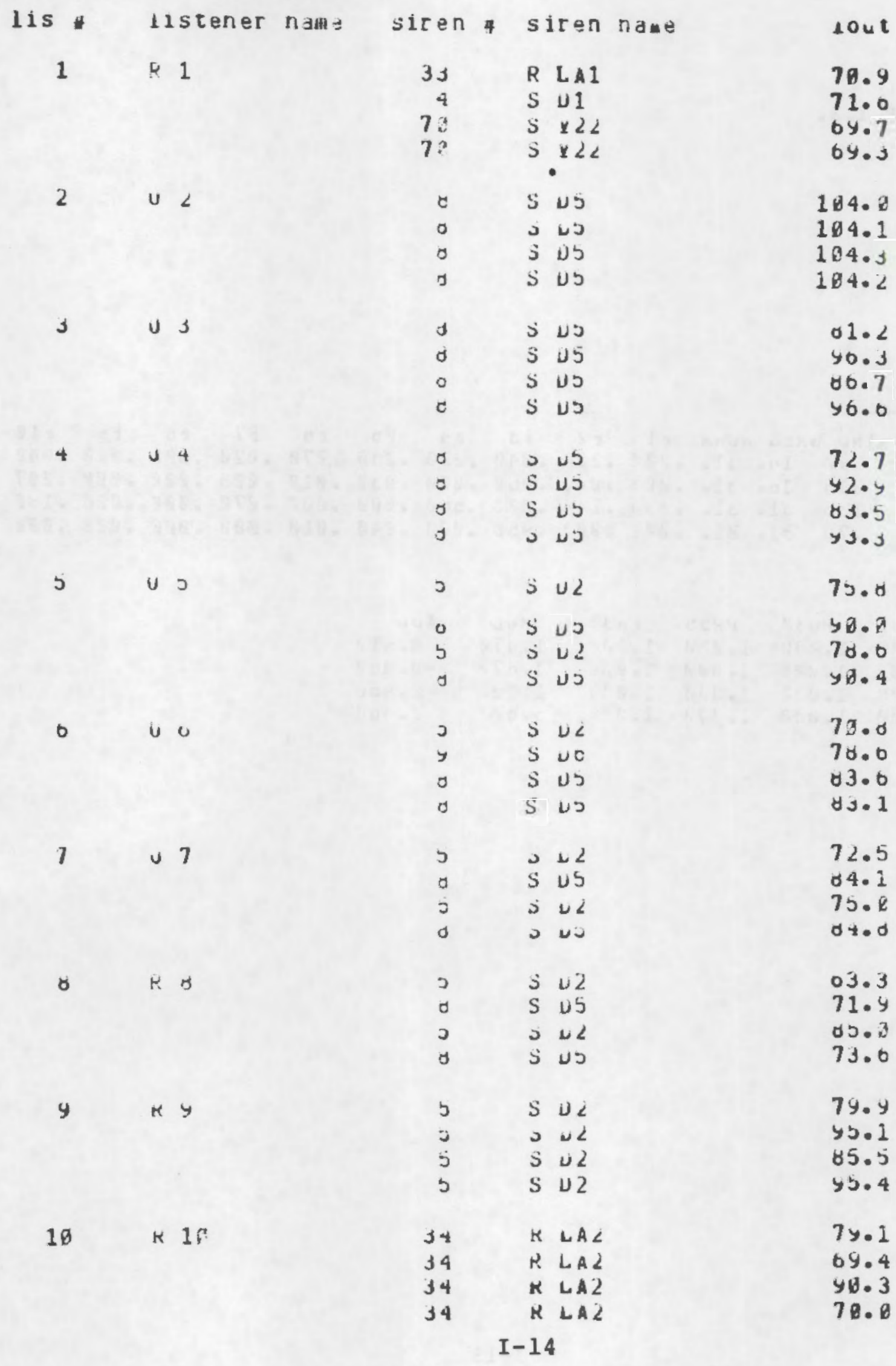


TABLE I.4. (Cont.)

11

$+11$

30

33

* LAO

05.7

30

$K$ LA 1

09.1

6.8. 3

Is

$K L A O$

78.1

12

R 12

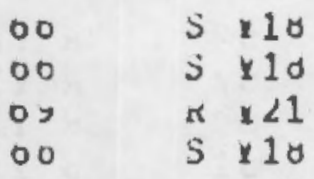

20.0

77.3

d1. $y$

78.0

$13 \times 11$

$\begin{array}{ll}72 & 5 \times 22 \\ 70 & 5122 \\ 70 & 5 \times 22 \\ 71 & 5 \times 22\end{array}$

62.0

01.2

84.3

$03 . y$

14 1 工

S 10

y s no

y S vo

y s 46

y.t.s

64.5

Y5. 3

74.0

$10 \times 10$

$\angle 7 \quad \therefore \quad 4 \angle 0$

20

K $\cup 24$

27

a 425

$\angle 0$

$x \sim 24$

10 r. 10

$20 \leq 23$

27

$x<<0$

$<0$

ए 423

20

Q 424

75.y

वह. 3

74.1

01.1

77.9

79.6

o.

74.5

$17 \div 17$

20

S U⿺J

74.5

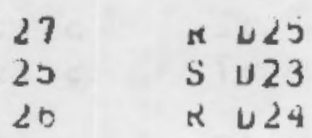

75.4

01.7

71.4

10010

$2 y \quad 2427$

32 के i 20

13 क ज व

$3 ?>L 20$

67.0

$>0.0$

80.7

>ㄹ. 4

Iy 0 1y

40 S LAO

$4 \ell$ S LAO

+2 D $\triangle A O$

42 ILAJ

75.6

90.2

70.8

Y.. 7

$20 \quad \div \quad 21$

41 KLA9

+2 工 LAO

44 S LAI2

43

$S$ LAO

68.2

04.0

01.4

05.7 
TABLE I.4. (Cont.)

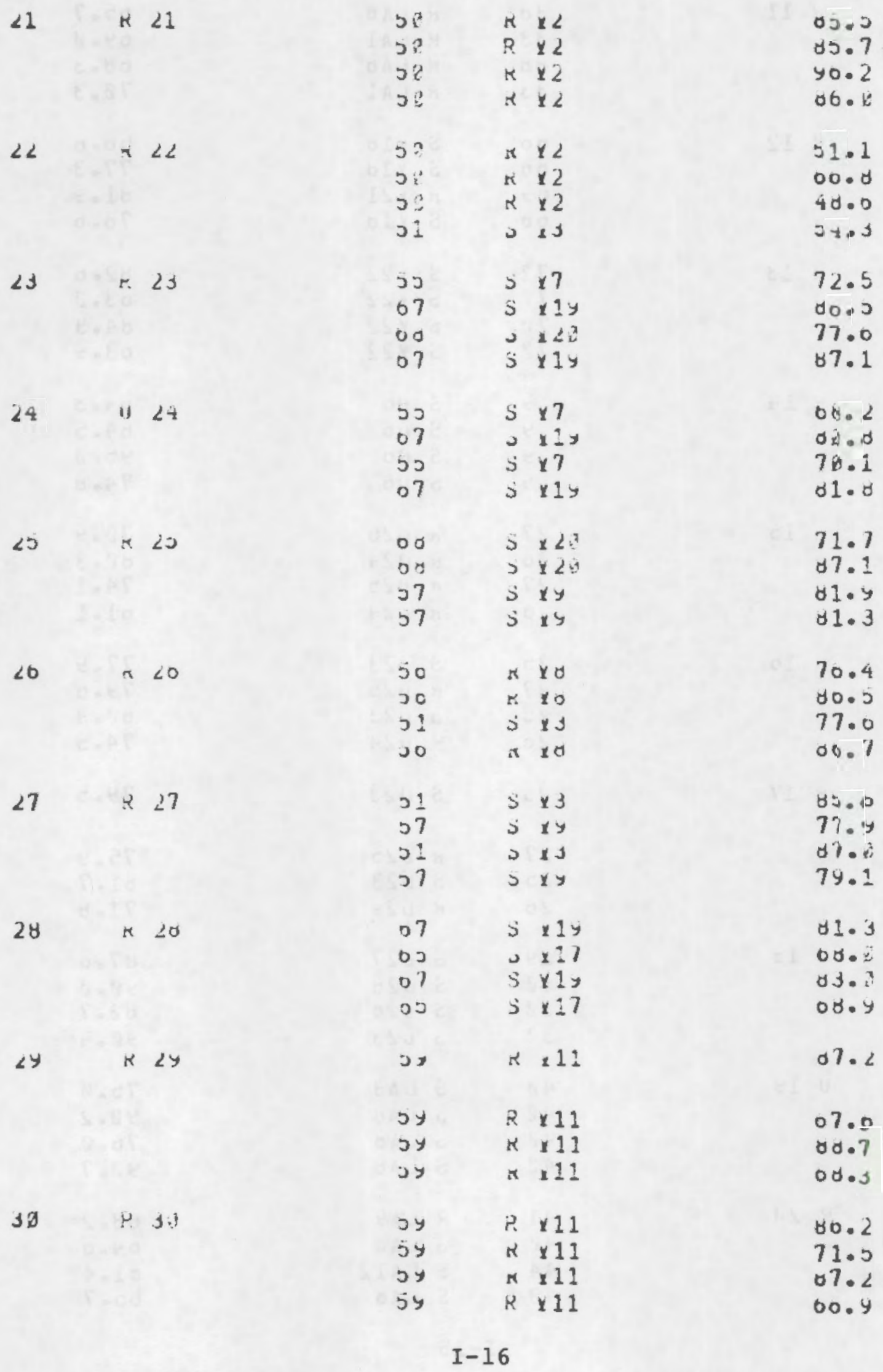


TABLE I.4. (Cont.)

\begin{tabular}{|c|c|c|c|c|c|}
\hline 31 & $r$ & 31 & $\begin{array}{l}71 \\
01 \\
71 \\
01\end{array}$ & $\begin{array}{ll}5 & x<3 \\
j & x 33 \\
s & x 23 \\
s & x 33\end{array}$ & $\begin{array}{l}50.0 \\
01.0 \\
55.4 \\
02.0\end{array}$ \\
\hline 32 & $k$ & $J L$ & $\begin{array}{l}70 \\
70 \\
7 y \\
70\end{array}$ & $\begin{array}{lll}k & y & 38 \\
5 & y & 138 \\
k & x 31\end{array}$ & $\begin{array}{l}02.7 \\
63.3 \\
77.4 \\
04.2\end{array}$ \\
\hline 35 & $n$ & 31 & $\begin{array}{l}75 \\
70 \\
74 \\
70\end{array}$ & $\begin{array}{l}3 \times 25 \\
S \quad \times 20 \\
3 \times 20 \\
3 \times 120\end{array}$ & $\begin{array}{l}05.4 \\
02.1 \\
73.2 \\
03.7\end{array}$ \\
\hline 54 & $\nu$ & 14 & $\begin{array}{l}75 \\
75 \\
70 \\
75\end{array}$ & $\begin{array}{ll}P & \times 27 \\
\times & 127 \\
\kappa & 127 \\
? & \times 27\end{array}$ & $\begin{array}{l}04.7 \\
05.1 \\
03.4 \\
85.0\end{array}$ \\
\hline 35 & $x$ & 15 & $\begin{array}{l}70 \\
17 \\
70 \\
77\end{array}$ & $\begin{array}{ll}S & 120 \\
D & 1<y \\
S & 120 \\
S & x 2 y\end{array}$ & $\begin{array}{l}51.2 \\
03.7 \\
54.1 \\
00.0\end{array}$ \\
\hline 50 & 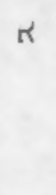 & so & $\begin{array}{l}3 \\
j \\
3 \\
j\end{array}$ & $\begin{array}{ll}S & i s \\
s & c s \\
s & c s \\
S & \text { cs }\end{array}$ & $\begin{array}{l}70.0 \\
41.2 \\
70.4 \\
41.0\end{array}$ \\
\hline ד'7 & $v$ & 37 & $\begin{array}{l}1 \\
1 \\
1 \\
1\end{array}$ & 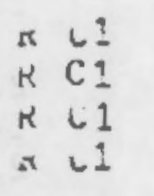 & $\begin{array}{r}30.7 \\
101.0 \\
47.1 \\
102.1\end{array}$ \\
\hline 10 & $u$ & is & $\begin{array}{l}1 \\
1 \\
1 \\
1\end{array}$ & 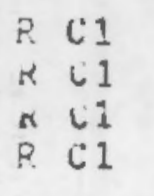 & $\begin{array}{l}01.0 \\
y 0 . y \\
0 y .0 \\
y y .2\end{array}$ \\
\hline Jy & $u$ & Jy & $\begin{array}{l}1 \\
\vdots \\
\vdots \\
2\end{array}$ & $\begin{array}{lll}\kappa & c & 1 \\
j & c 2 \\
p & c & 1 \\
s & C & 2\end{array}$ & $\begin{array}{l}8 y .1 \\
70.2 \\
\text { Ye. } \\
79.1\end{array}$ \\
\hline 40 & $u$ & 4 เท & $\begin{array}{l}13 \\
15 \\
13 \\
13\end{array}$ & $\begin{array}{ll}S & 412 \\
S & 112 \\
S & 412 \\
S & 412\end{array}$ & $\begin{array}{r}100.0 \\
100.7 \\
101.0 \\
y 9.4\end{array}$ \\
\hline
\end{tabular}


TABLE I.4. (Cont.)

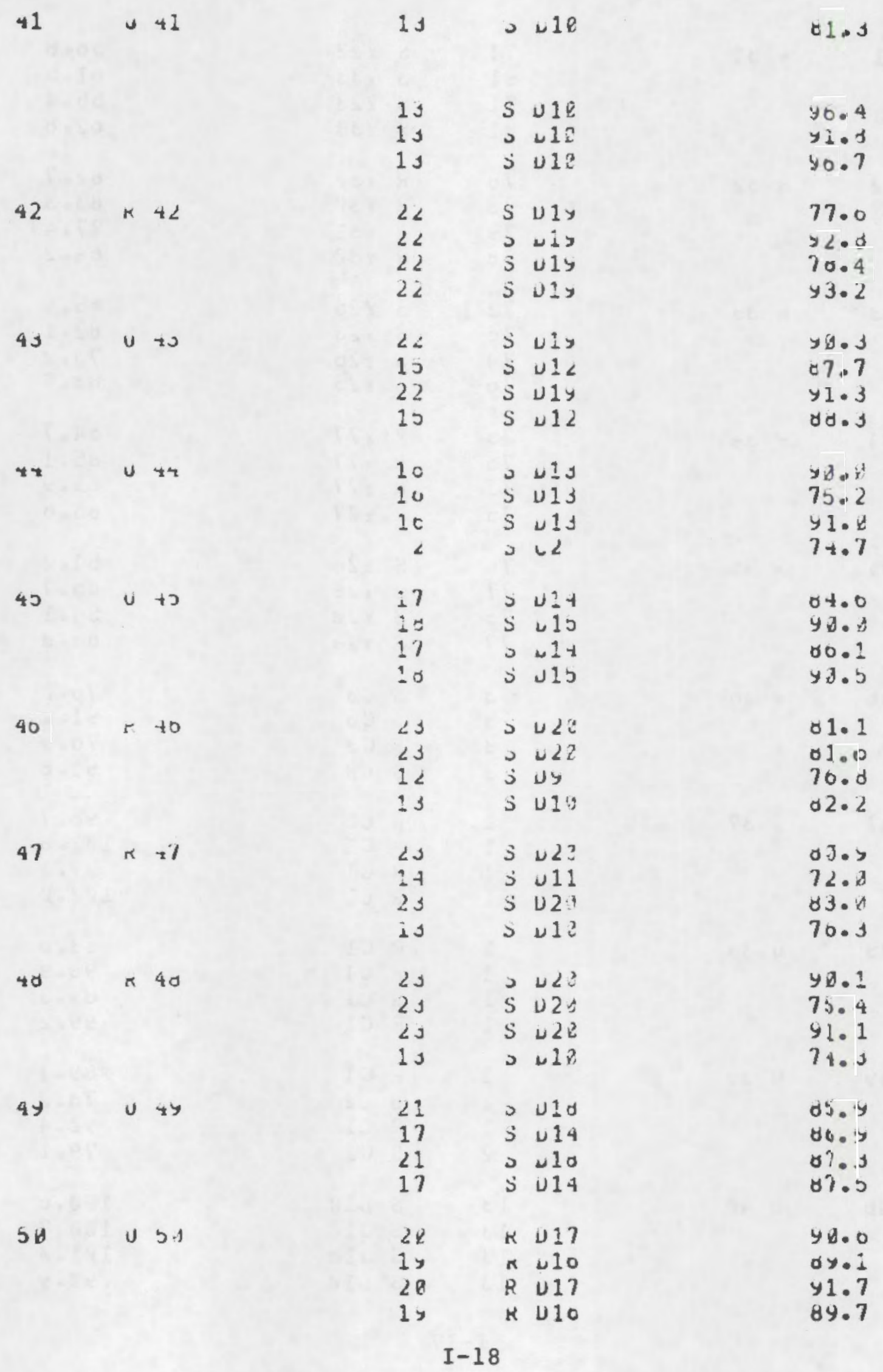


TABLE I.5. PROBS

\begin{tabular}{|c|c|c|c|c|c|c|c|c|c|c|}
\hline p 1 & $p<$ & p3 & p4 & ps & po & p $?$ & po & y & p1o & $p t$ \\
\hline & 1 & & & & & & & & & \\
\hline 1. 000 & 1.360 & $x \cdot 5<3$ & f. y 1 & 3. 3 > & 1.002 & 1. 822 & $1 . X 2 D$ & 1.300 & 1.200 & $\varepsilon, d$ \\
\hline 1.000 & 1.003 & $\$ .010$ & 4.457 & 8.572 & I. $2 \mathrm{BL}$ & 1.228 & 1. $\triangle 28$ & 1.800 & 1.003 & \\
\hline $1.0 B 0$ & 1.391 & 14.121 & 9.272 & d. 400 & $1 . \triangle P Q$ & $1 \cdot E<2$ & 1.082 & 1. $8 R Q$ & 1. $\operatorname{le} \bar{Z}$ & a \\
\hline 1.100 & $\begin{array}{l}1 . \text { या } \\
\text { r }\end{array}$ & $3 \cdot 3+3$ & a.05t & $3.37+$ & 1. & $1.08 d$ & 1.322 & 1.800 & 1.000 & $\theta$. \\
\hline
\end{tabular}

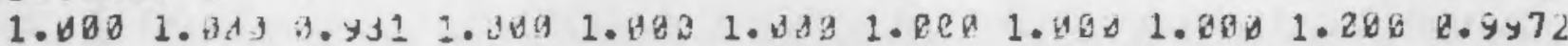

1.0001 .3939 .431 1. $1001.32 \times 1.0921 .2801 .3281 .2901 .0000 .4940$

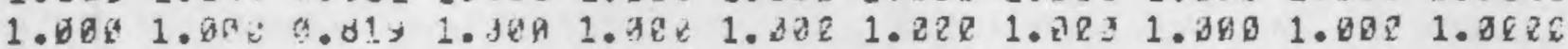

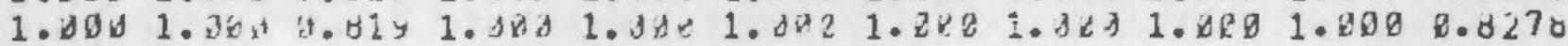

listener 3

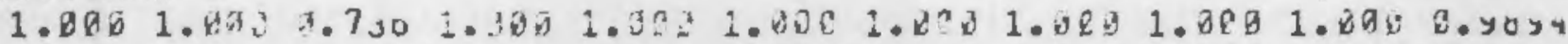

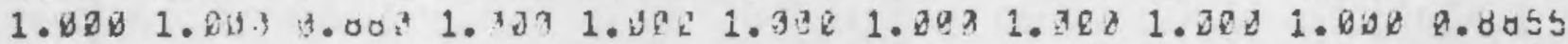

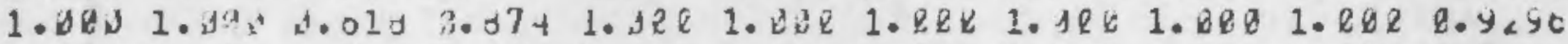

1.000 1. listener 4

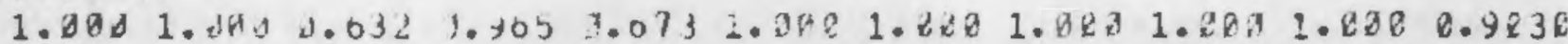

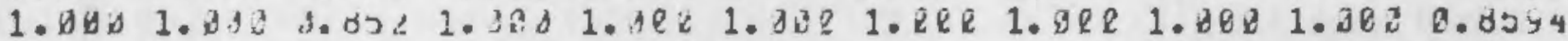

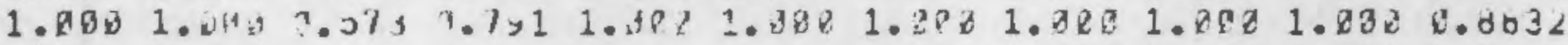

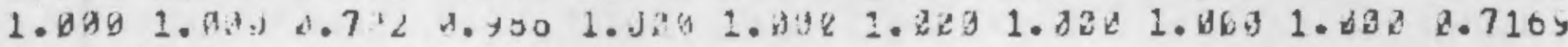

listener 5

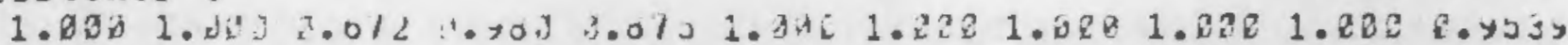

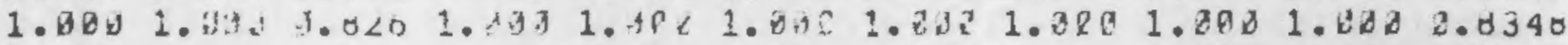

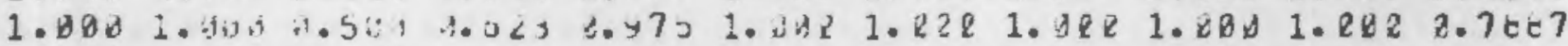

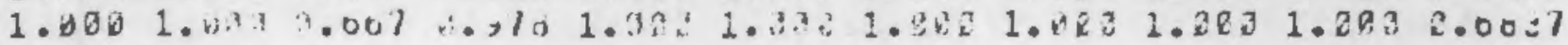

listener 0

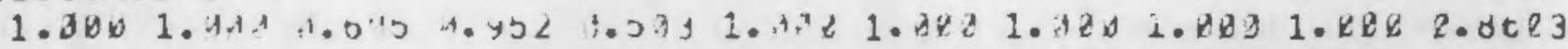

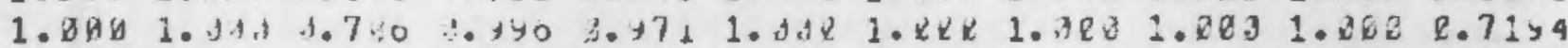

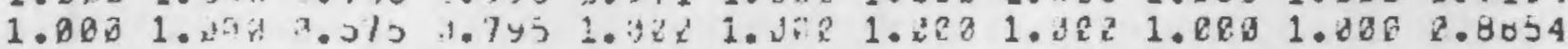

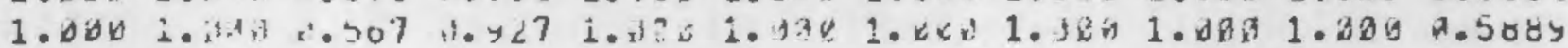
listent?

$1.0201 .402 j .0 \angle 0$.

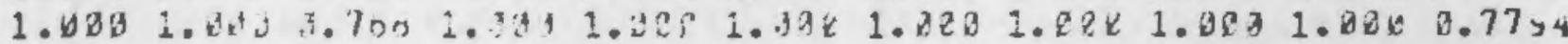

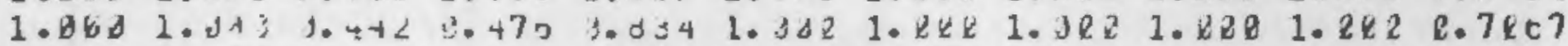

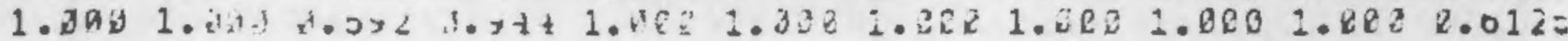

IIstener o

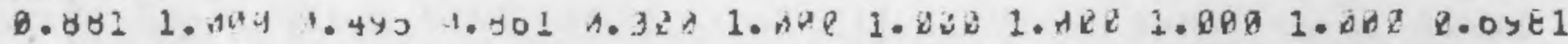

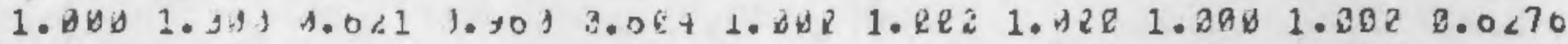

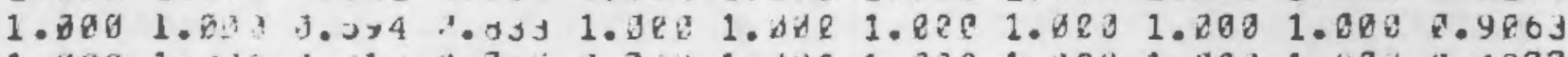

$1.0001 .9030 .41 \times 1.7051 .7+21.0081 .8281 .3221 .0201 .0009 .4377$

listener y

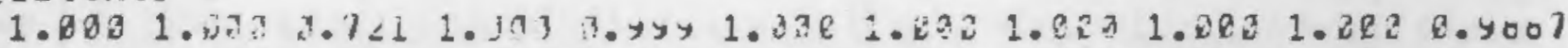

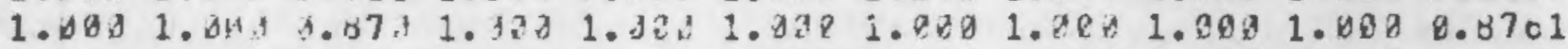

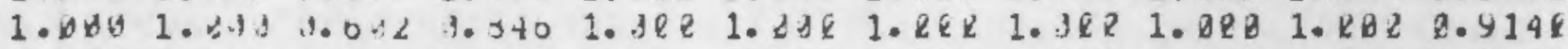

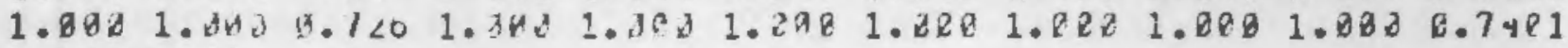
listener $1 i^{2}$

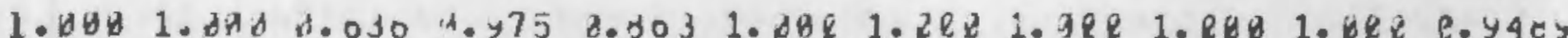

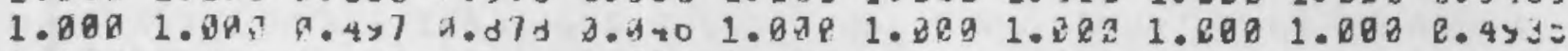

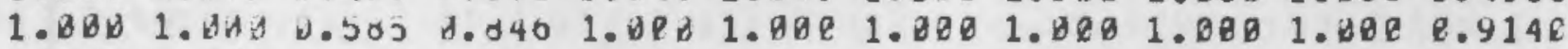

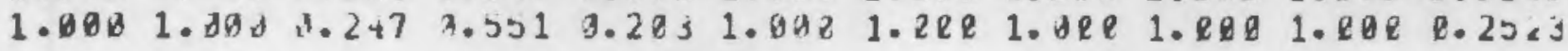
I-19 
TABLE I.5. (Cont.)

\section{1 atener 11}

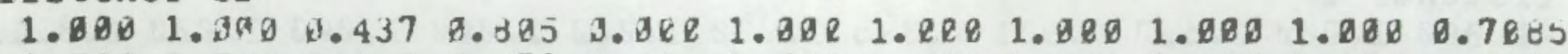

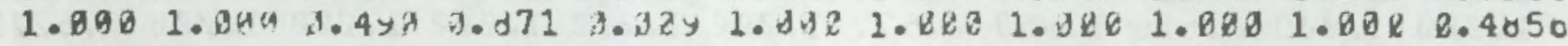

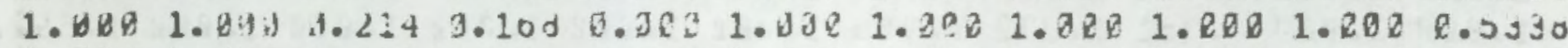

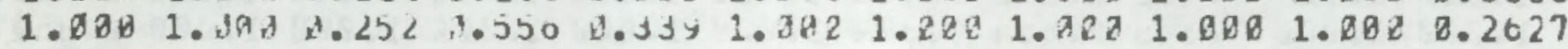
listener 12

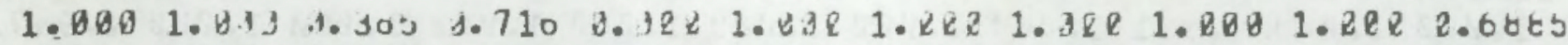

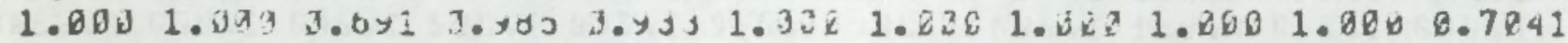

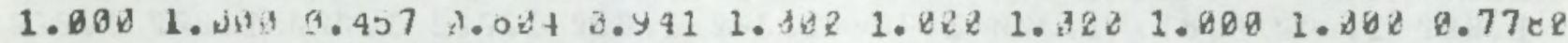

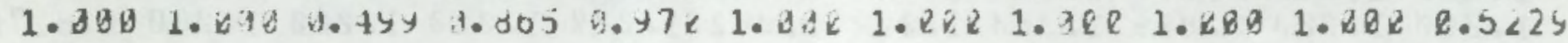
LIstent $1 \mathrm{~J}$

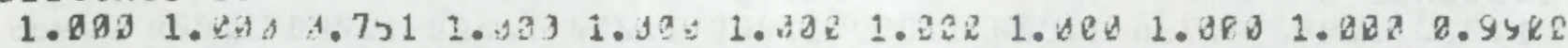

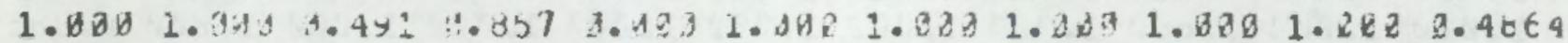

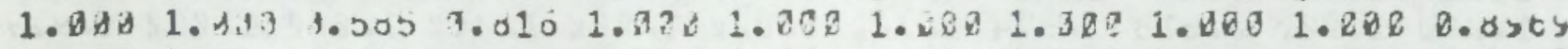

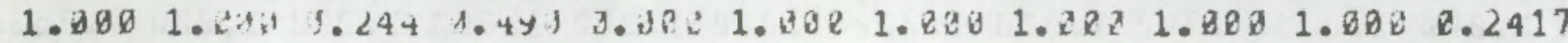
listenter it

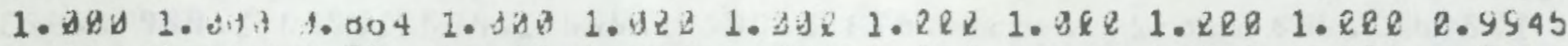

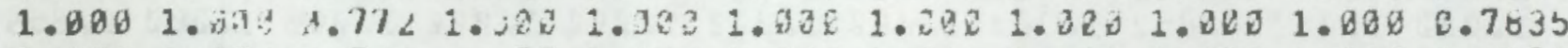

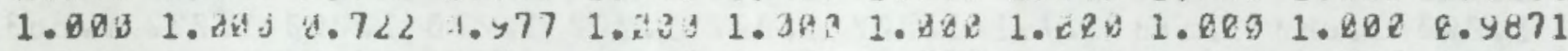

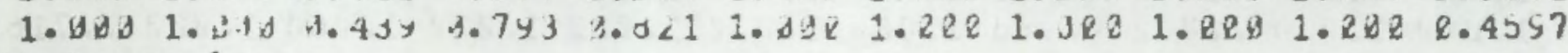
11 otauer is

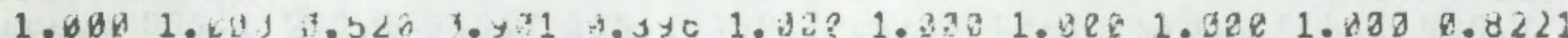

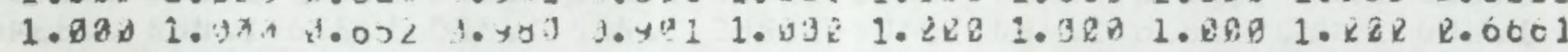

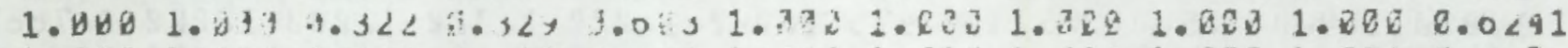

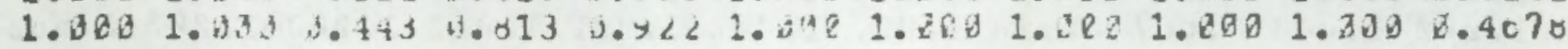
listener 10

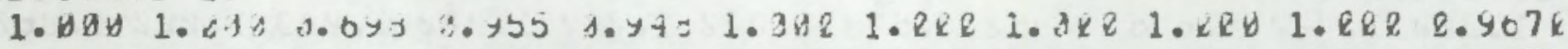

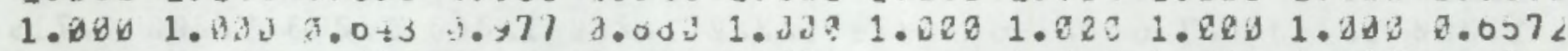

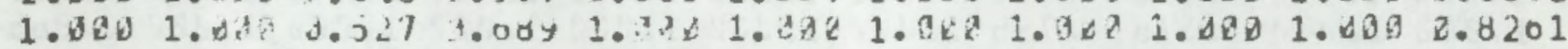

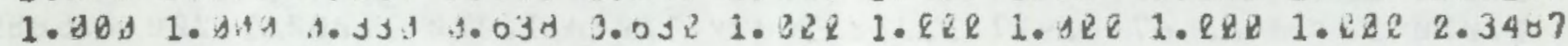
$11 s t a n=L 11$

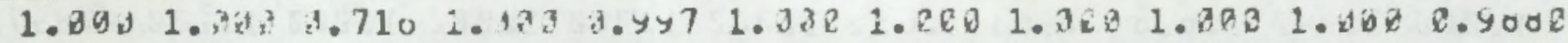

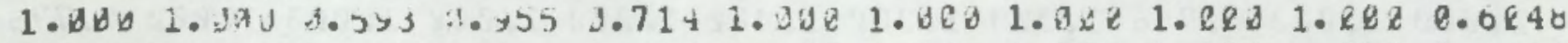

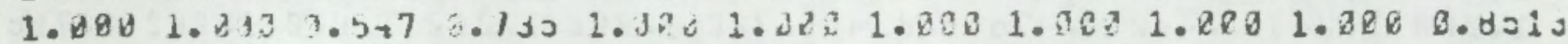

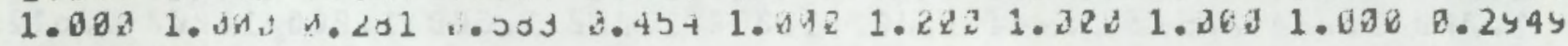
11 steiler 10

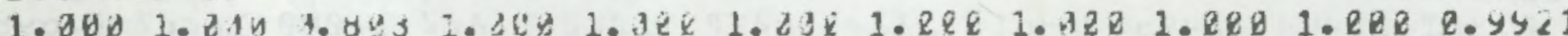

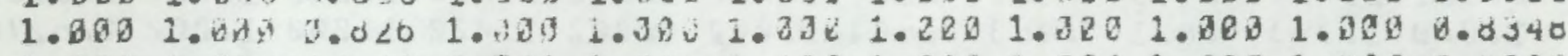

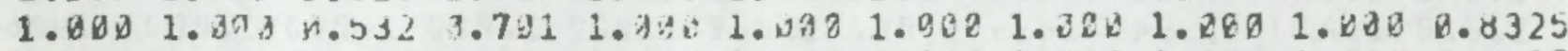

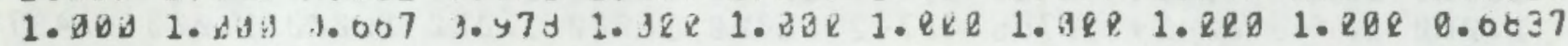

listailer iy

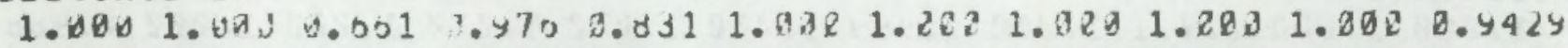

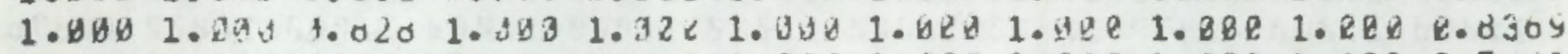

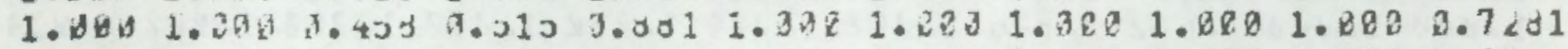

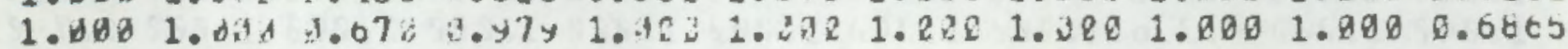
listener $2 \pi$

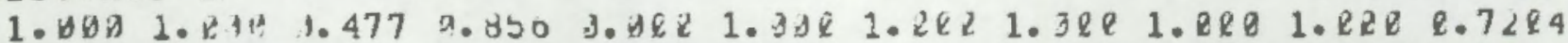

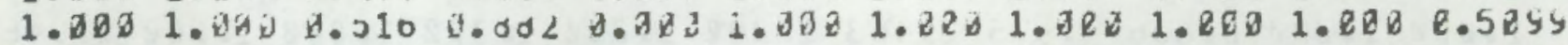

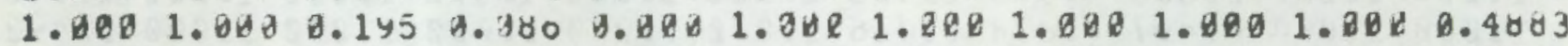

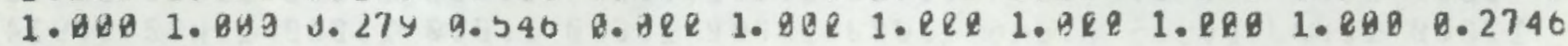




\section{TABLE I.5. (Cont.)}

11 s teluer $<1$

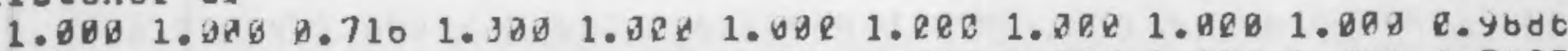

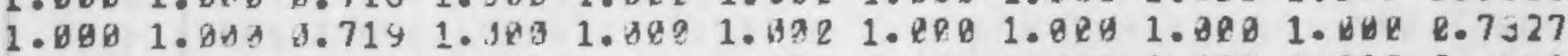

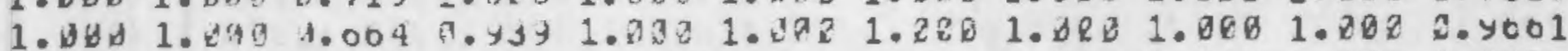

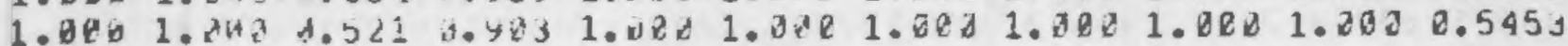
11 stenter 22

1.000 1.84H

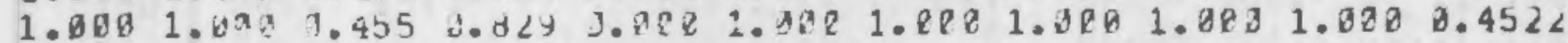
1. J00 1.301-.210

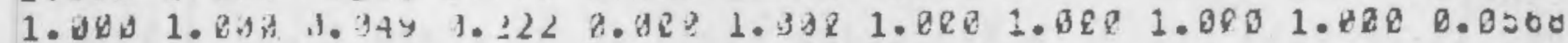
lstener $1 \mathrm{~J}$

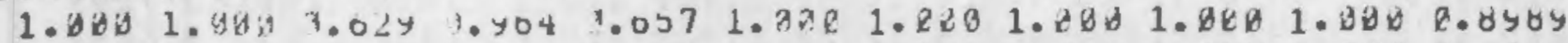

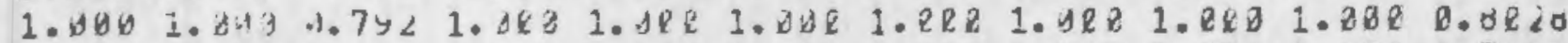

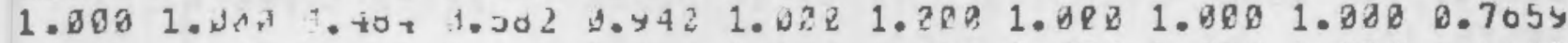

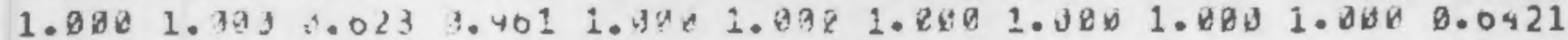
listener $\angle 4$

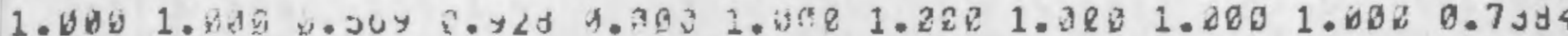

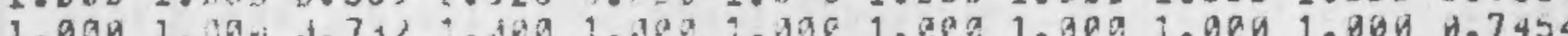
1.

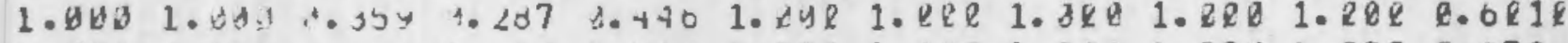

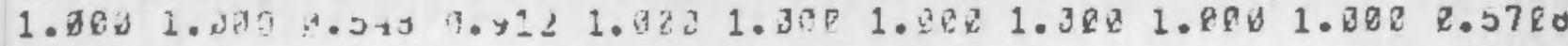

11 stener 20

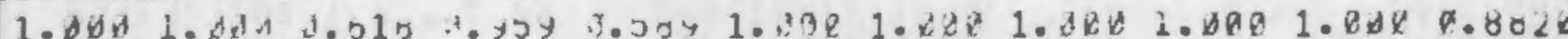

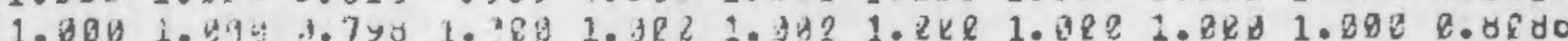
1.

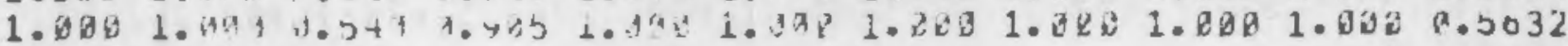
listener 20

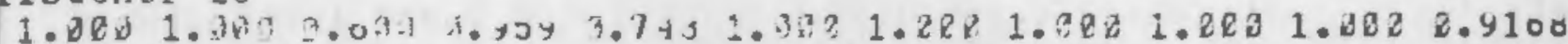

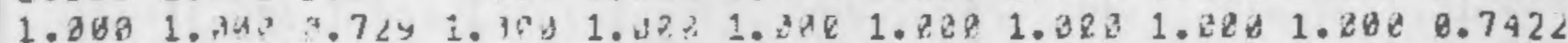

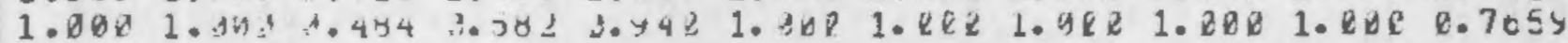

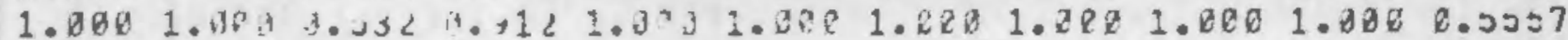
11 stener 27

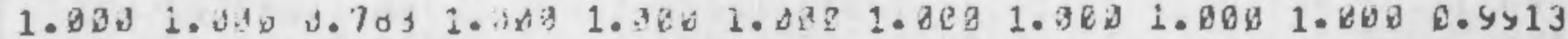
1. पू० 1.

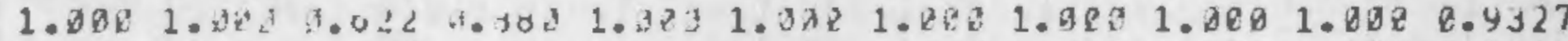

1.

listener 20

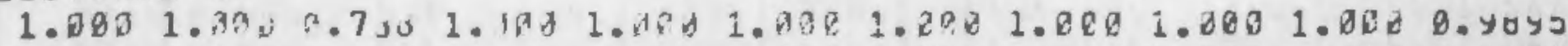

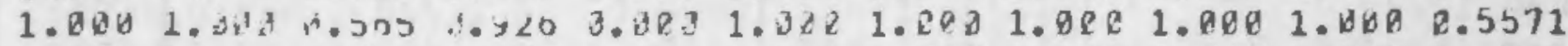

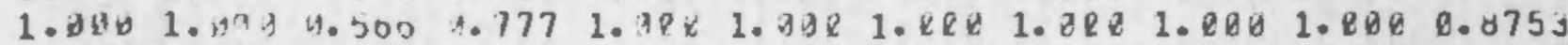

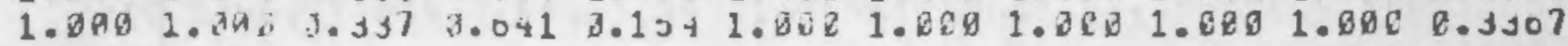

11stener $\angle y$

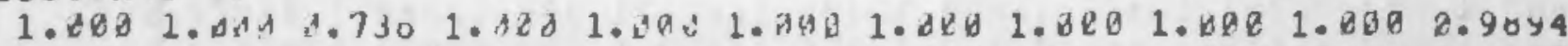

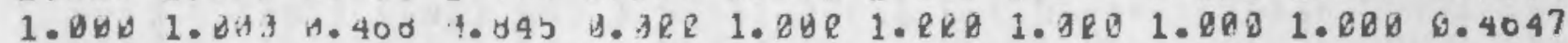

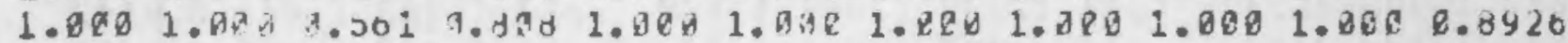

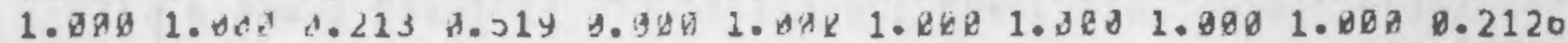
listener $\$ 1$

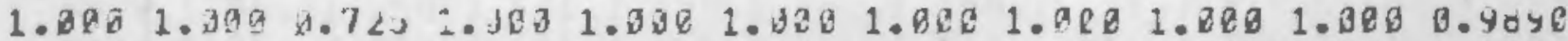

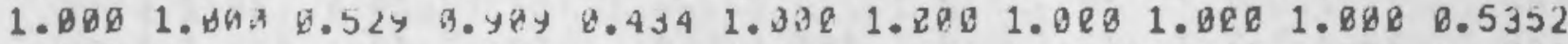

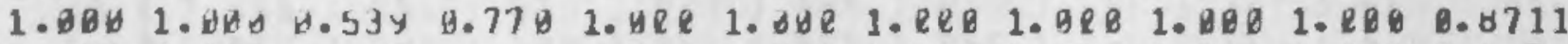

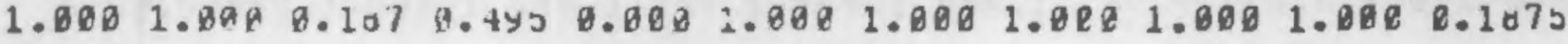


TABLE I.5. (Cont.)

11stener 31

\begin{tabular}{|c|c|c|c|c|c|c|c|c|c|c|}
\hline 1.000 & 1. BHE & $0.38 y$ & .721 & 0.308 & 1.008 & $1 . R E D$ & 1.000 & 1.000 & 1.000 & 0.6890 \\
\hline 1.000 & 1.000 & B. +00 & $0.8<27$ & $0 . D R R$ & $1 . \not B E$ & RRE & $B Q Z$ & 1.880 & 1.000 & 0.4029 \\
\hline 1.020 & $1.30 n$ & 0.315 & 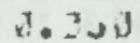 & 3.508 & 1. BतQ & 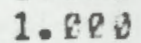 & 1. $0 R Q$ & 1.080 & 1.000 & 0.4681 \\
\hline 1.000 & 1. बैa & 1.223 & 1.450 & $\Delta \cdot 2 l x^{2}$ & 1.008 & $1 . R 2 R$ & 1.808 & 1.000 & 1.080 & 0.22210 \\
\hline isten & $j L$ & & & & & & & & & \\
\hline $1.05 x$ & 1. 36 & צ. & $\lambda \bullet>d$ & נ. נ. & 1.072 & $1.82 x$ & 1 . ख s $x$ & 1.200 & 1.280 & 8.974 \\
\hline 1.010 & 1. 014 & $x .0 y 3$ & $1 . y d y$ & 2 & $\bar{x}$ & 0 & 20 & 00 & 200 & 240 \\
\hline $1 . \triangle B D$ & 1. $0.3 !^{2}$ & ง. 302 & $\therefore 444$ & 3. & 1.392 & $1.2 \times 2$ & 30 ? & 1. & 1.180 & 2.0065 \\
\hline 1.0003 & $\frac{1 . \log _{2} 1}{53}$ & $5 \cdot 13 L$ & $\therefore+t 0$ & $3.34:$ & 2. $3 \times 18$ & 1.228 & 22 & 1. 600 & i. $00 \%$ & 122 \\
\hline $8 d$ & 1. 941 & .1 .535 & $\Delta y x^{3} i$ & & & & & $20 \%$ & 1.08 & 15 \\
\hline 1.460 & 1.010 & 1.740 & & & & & & 100 & 385 & $=91$ \\
\hline $1.0082^{2}$ & 1.540 & $?+13$ & $.1 .4,4$ & 4.713 & 1.322 & $1.92 x^{2}$ & 1.987 & 1.930 & 1.032 & 8.0002 \\
\hline 1.006 & $10 \times ?$ & .200 & $1 . y 20$ & 1. is $t$ & 1.382 & 1.458 & $1 . \pm E B$ & 1.020 & 1.200 & 5.3075 \\
\hline
\end{tabular}

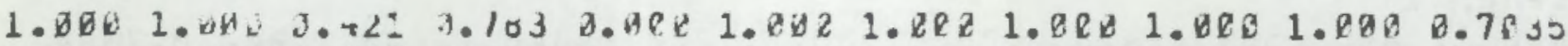

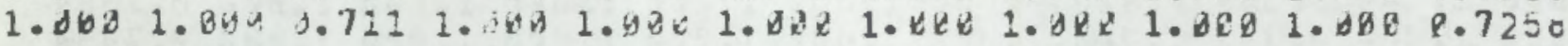

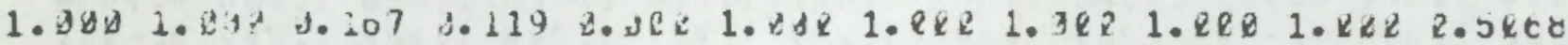

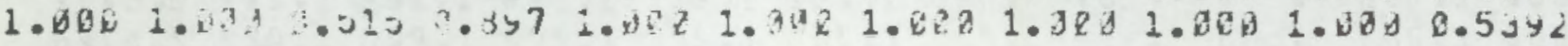

$11 \leq t e n=5$ 10

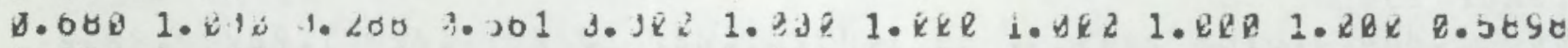

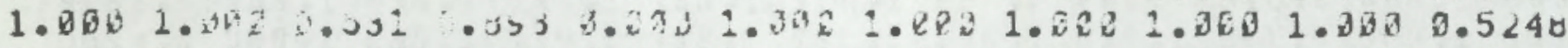

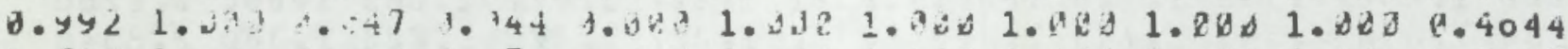

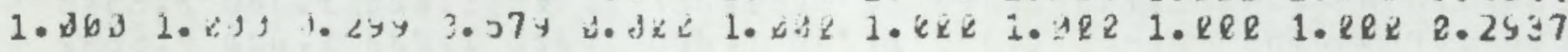

IIstent so

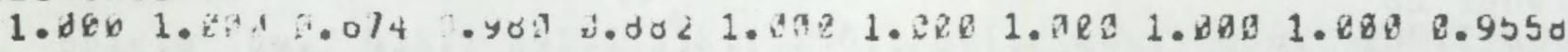

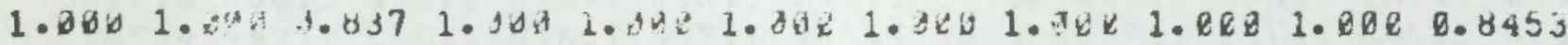
1.

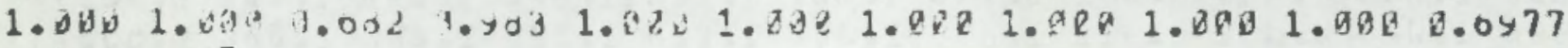
Llstener 37

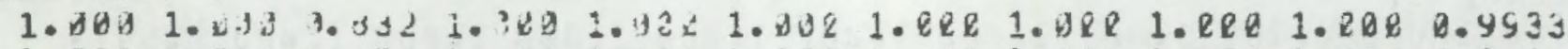

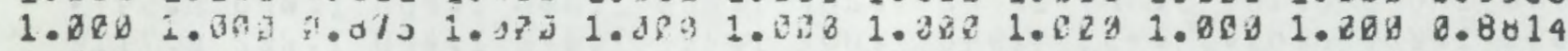
$1.0901 .0 \%$ J. 1.000 1. Listuiler jo

1.000 1.

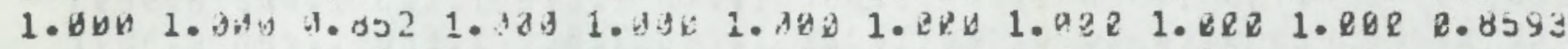

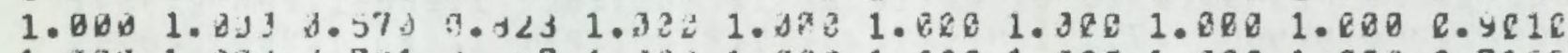

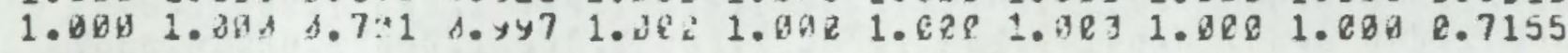
Listener jy

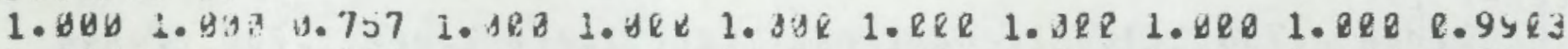

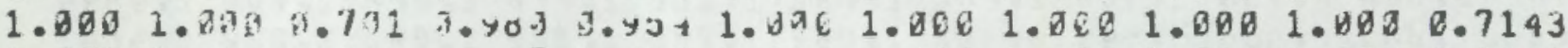

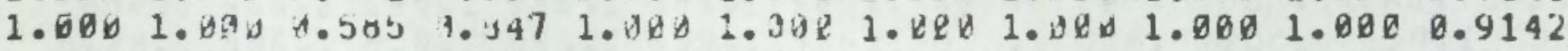

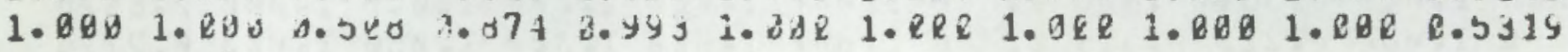
11 conec to

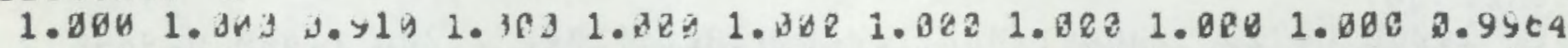

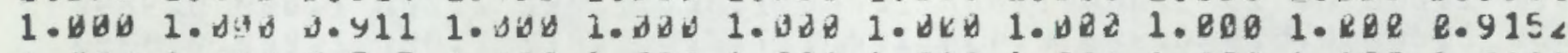
$1.0001 .0080 .7071 .3001 .0001 .3001 .0001 .0801 .0001 .0081 .08 R 2$ 1.0001 .3933 .0739 .4801 .3001 .0821 .8081 .0021 .0001 .0000 .6450 
TABLE I.5. (Cont.)

I1stener il

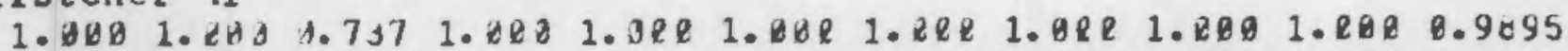

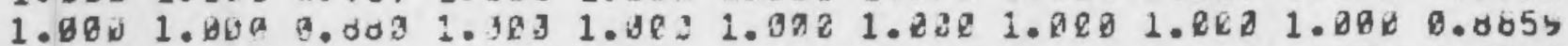

1.0001 .0035 .0040 .4521 .0001 .0021 .0421 .0401 .8001 .0006 .9732

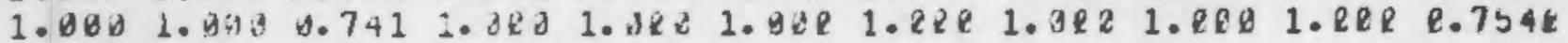

$11=\operatorname{cones} 1 \angle$

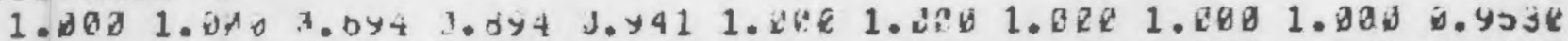

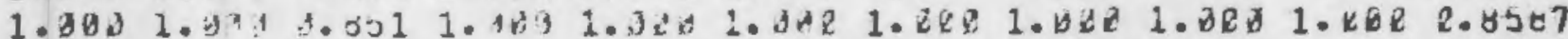

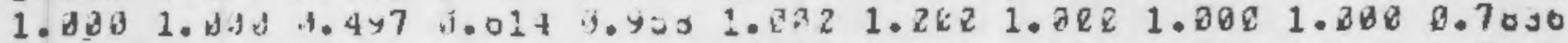

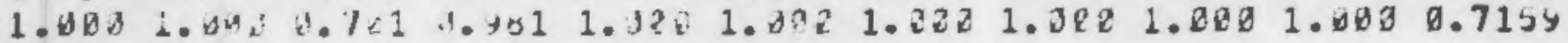

11 stener $\rightarrow 3$

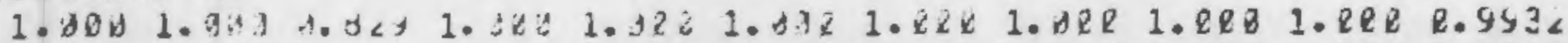

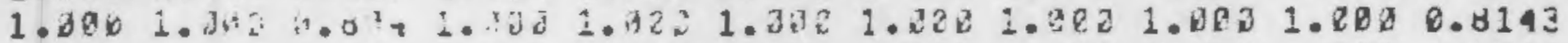

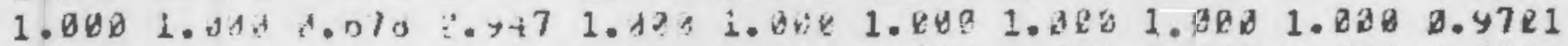

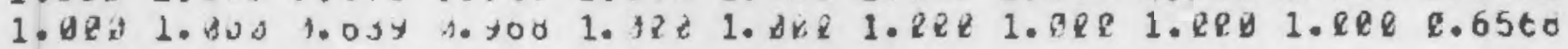

IDocallet to

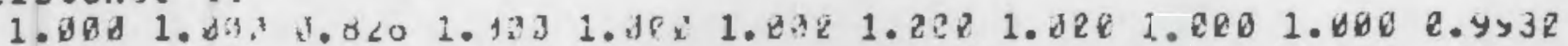

$1.0001 .4039 .0041 .4773 .3401 .0301 .3001 .0201 .0601 .8028 .67 t t$

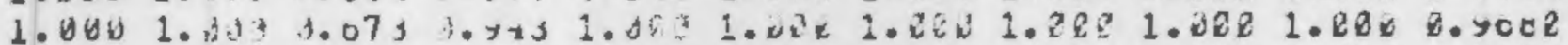

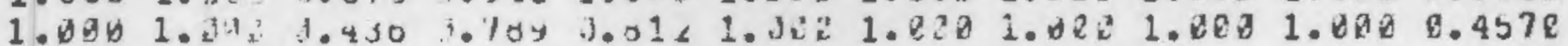

11 stener 45

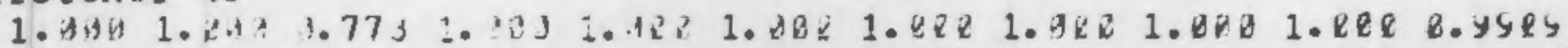

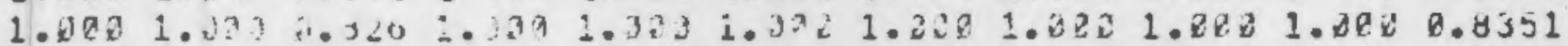

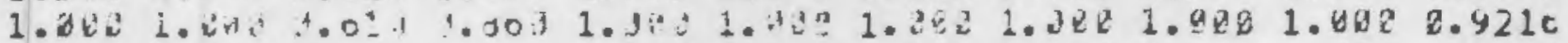

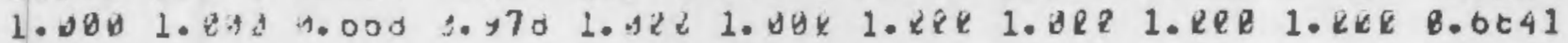

liakeiler to

1.030 1.03

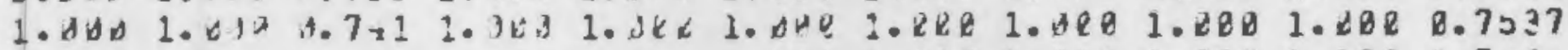

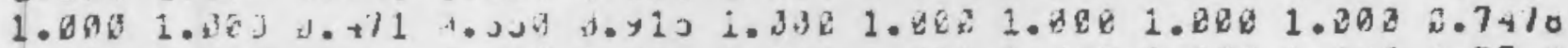

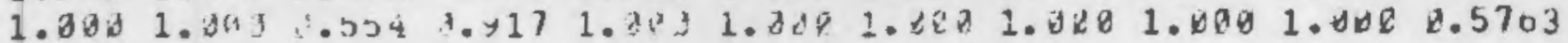

listen $=\mathrm{r}+7$

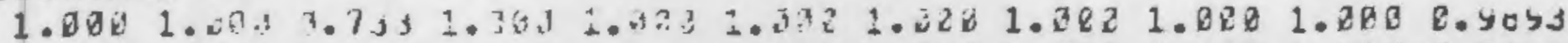

1.D0日 1.2.

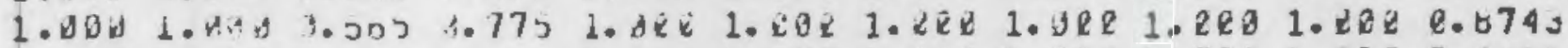

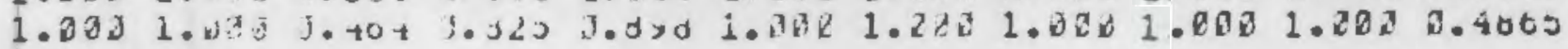

listenar 40

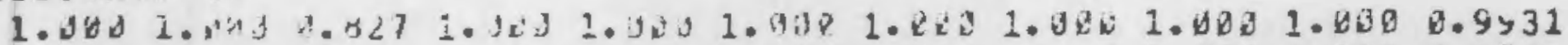

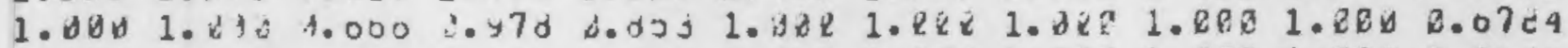

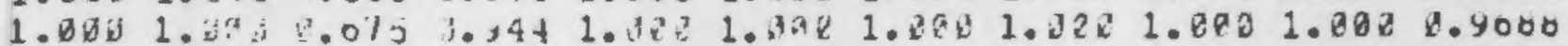

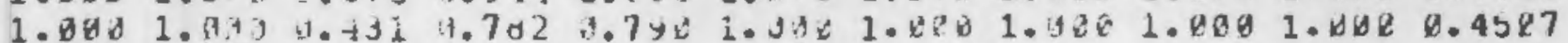

11 stener $4 y$

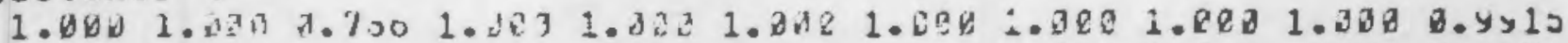

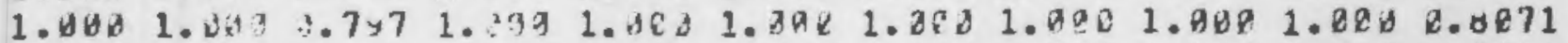

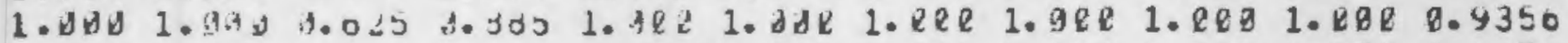

$1.0001 .003 x^{3} .02 \times 3.70+1.3921 .3021 .0201 .9281 .0801 .0000 .0470$

11 stener 5 i

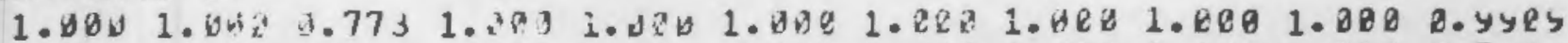

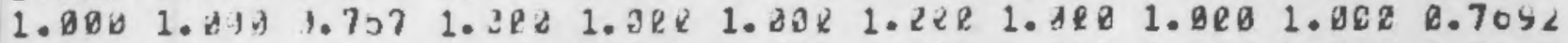

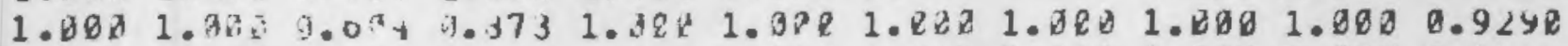

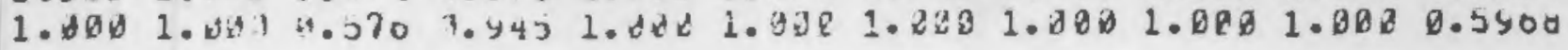

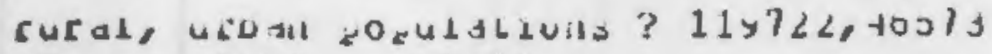

ptrur pturd ptall

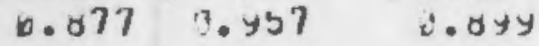

$0.654 \quad 0.620 \quad 2.780$

$0.701 \quad 0.080 \quad 0.7$ >0

$0.41 y \quad 0.005 \quad 8.457$ 


\section{APPENDIX J: RANDOM SELECTION OF POPULATION-WEIGHTED LISTENING POINTS AT THE INDIAN POINT SITE}

The objective of the listener-site-selection process was to identify 50 randomly selected building locations within the EPZ surrounding the Indian Point Nuclear Plant. These locations are assumed to be residential locations and are called "listener sites."

The various steps used in the site selection procedure are described below:

1. A population-distribution map (see Fig. J-1) consisting of a 10-mile-radius circle divided into annular sectors defined by interior circles and radii, was superimposed on topographical maps of the EPZ. Population distribution information consisted of the number of people within each annular sector. These data were used in order to population-weight the random selection process described below.

2. Each annular sector was first assigned a designator, ranging between $A-1$ and $R-10$ (see Fig. J-1). A range of numbers was then assigned to each sector according to the population in that sector. For example, Sector $A-1$, just north of the site, and sectors $\mathrm{B}-1$ and $\mathrm{C}-1$ (moving clockwise) have zero population and thus were not assigned any numbers. Sector $D-1$ has a population of 35 and was assigned numbers 1 to 35 . Sector $E-1$ has a population of 60 and was assigned numbers 36 through 95. This process was continued until each number between 1 and 256,015 (the total estimated population) was assigned to a particular sector. A random number 
generator (available on a Texas Instruments Model TI-59 hand calculator, for example) was then used to select 50 numbers at random between 1 and 256,015. Each number selected represented one site (to be chosen later) within the sector containing that number. Thus, sectors with larger populations had a greater possibility of including chosen listener sites.

3. Having determined the sector locations of each potential listener site, the next step in the procedure involved selecting the actual sites within the respective sectors. This was accomplished by first over-laying a rectangular coordinate grid on each sector of interest on the topographic map. The grid was composed of boxes with dimensions of approximately 1000 feet square, and each box was assigned an $X$ and a $Y$ coordinate according to its location on the grid. The grid was positioned such that the $x$-axis was oriented in the east-west direction and the $Y$-axis was oriented in the north-south direction, and such that all parts of the sector of interest were covered by a positive $(X, Y)$ coordinate pair box. A random number generator was then used to select random pairs of numbers within the $X$ and $Y$ ranges covering the sector of interest. Each X,Y pair was used to select a particular 1000 feet square box on the map. If there were buildings within the box, one of them was arbitrarily chosen as a listener site. If there were no buildings inside the box or if the box fell outside of the sector of interest, that coordinate pair was disregarded and another pair was chosen at random. 
For urban sites in the pink "building-extension" area of the topographic map a residential building was always assumed to exist, and was selected at the center of the pink area in the 1000 feet square box.

4. The above process was repeated until 50 listener sites were randomly chosen. It was found, however, that some major urban communities did not include any 1 istener sites, and thus the chosen sites did not properly reflect the population distribution in the EPZ. Therefore, the selection process was continued until this condition was rectified. Four new urban sites were randomly chosen to replace the four most recently chosen rural sites. This replacement only affected the balance between urban and rural listener sites. Since the subsequent analysis treats urban and rural areas separately, this replacement will not bias the results. It will merely ensure that no major population concentrations are ignored. The above procedure resulted in a pseudo-random sample of 50 specific listener locations, distributed throughout the EPZ as shown roughly on Fig. J-1. 

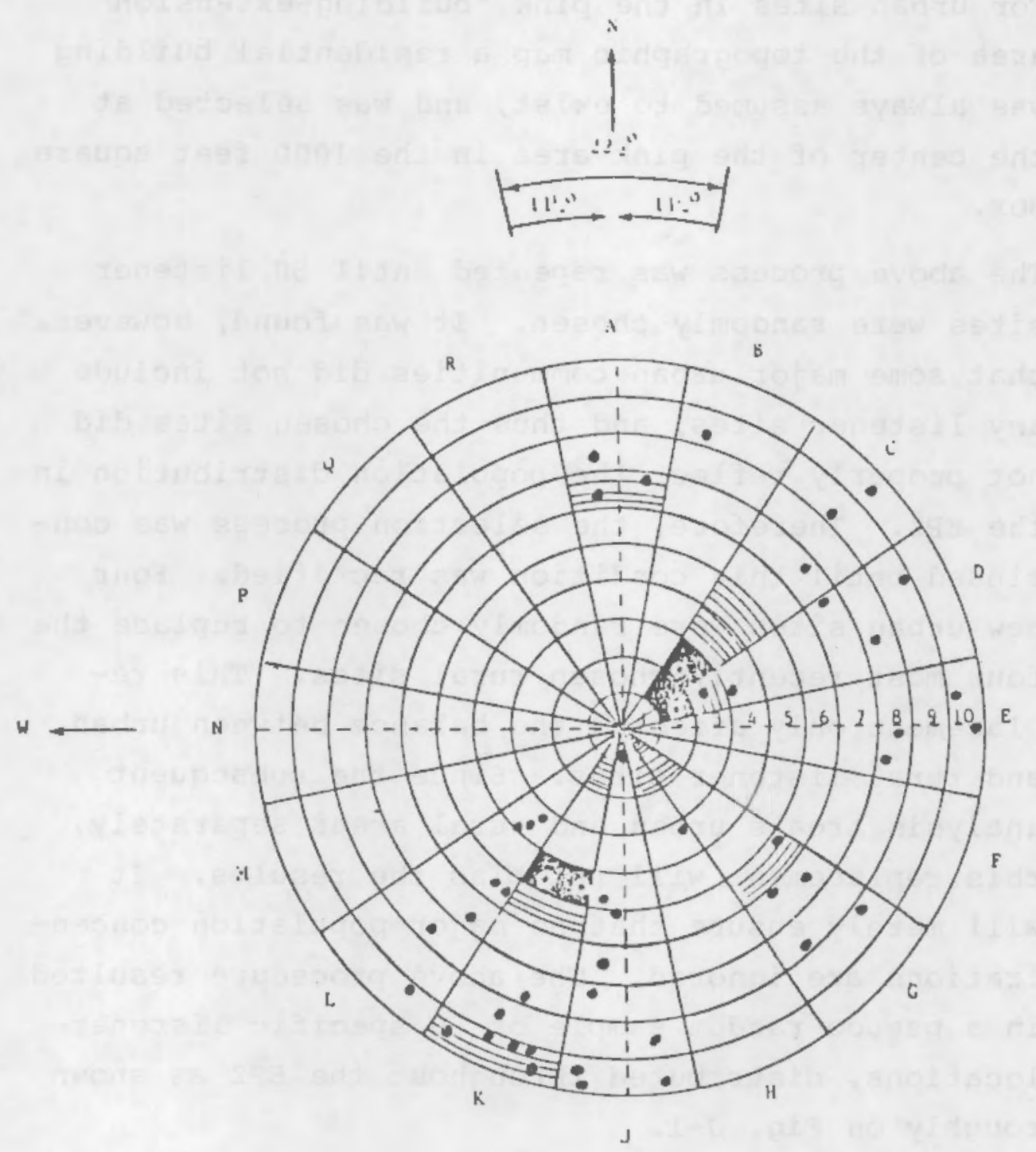

Population Density/Block

$\square$ below $2,000 / \mathrm{mi}^{2}$
$2,000-4,000 / \mathrm{mi}^{2}$
Exy $4,000-10,000 / \mathrm{mi}^{2}$

FIG. J-1. SCHEMATIC SECTOR/ZONE DIAGRAM FOR INDIAN POINT EPZ WITH 1980 POPULATION DENSITY DISTRIBUTION. 


\section{APPENDIX K: SAMPLE SCENARIOS FOR THE EVALUATION OF SIREN ALERTING AT INDIAN POINT}

\begin{tabular}{|c|c|c|c|c|}
\hline Scenario & (1) & (2) & (3) & (4) \\
\hline Season & Summer & Summer & Winter & Winter \\
\hline Time of Day & $\begin{array}{l}\text { Weekday } \\
\text { Afternoon }\end{array}$ & $\begin{array}{l}\text { Late } \\
\text { Night }\end{array}$ & $\begin{array}{l}\text { Weekday Evening } \\
\text { (Rush Hour) }\end{array}$ & $\begin{array}{l}\text { Late } \\
\text { Night }\end{array}$ \\
\hline $\begin{array}{l}\text { General } \\
\text { Weather }\end{array}$ & $\begin{array}{l}\text { Warm, Clear to } \\
\text { Partly Cloudy }\end{array}$ & $\begin{array}{l}\text { Warm, Clear to } \\
\text { Partly Cloudy }\end{array}$ & $\begin{array}{l}\text { Cold, } \\
\text { Overcast }\end{array}$ & Stormy \\
\hline $\begin{array}{l}\text { Home/Vehicle } \\
\text { Windows }\end{array}$ & Open & Open & $\begin{array}{l}\text { Closed } \\
\text { (\& Storms) }\end{array}$ & $\begin{array}{l}\text { Closed } \\
\text { (\& Storms) }\end{array}$ \\
\hline Temperature, ${ }^{0} \mathrm{~F}$ & $80^{\circ}$ & $70^{\circ}$ & $30^{\circ}$ & $30^{\circ}$ \\
\hline Relative Humidity, $\%$ & $65 \%$ & $80 \%$ & $70 \%$ & $90 \%$ \\
\hline $\begin{array}{l}\text { Temperature Gradient, } \\
0 \mathrm{~F} / 100 \text { feet } \\
\text { (meas. heights }=95^{\prime} \& 7^{\prime} \text { ) }\end{array}$ & -1 & +0.5 & -0.5 & -0.5 \\
\hline Wind Direction: & & & & \\
\hline General & SSE & NNE & NW & SE \\
\hline Valleys & Up-Valley & Down-Valley & - & - \\
\hline $\begin{array}{l}\text { Wind Speed, mph } \\
\text { (meas. height=100') }\end{array}$ & $10 \mathrm{mph}$ & $6 \mathrm{mph}$ & $10 \mathrm{mph}$ & $15 \mathrm{mph}$ \\
\hline \multicolumn{5}{|c|}{ Percent of People Located } \\
\hline Outdoors & $20 \%$ & - & $5 \%$ & - \\
\hline In Motor Vehicles & 6 & $1 \%$ & 25 & - \\
\hline Indoors at Work: & & & & \\
\hline Commercial & 23 & 3 & - & $4 \%$ \\
\hline Industrial & 7 & 1 & - & 2 \\
\hline In Home Sleeping & 4 & 95 & - & 95 \\
\hline In Home Radio/TV & 20 & - & 14 & - \\
\hline In Home Noisy & - & - & 3 & - \\
\hline In Home Active & 6 & - & 35 & - \\
\hline In Home Isolated & 4 & - & 24 & - \\
\hline In Home Quiet & 10 & - & 4 & - \\
\hline
\end{tabular}





\section{APPENDIX L: SIREN LOCATIONS FOR THE INDIAN POINT EPZ}

This appendix provides existing and proposed siren locations for the Indian Point EPZ as of 25 August 1981. Siren locations are provided on a set of topographical maps (Figures L-2 through L-12). Figure $\mathrm{L}-1$ shows the relationship of the individual maps to the Indian point EPZ.

A total of $88125 \mathrm{dBC}$ sirens are employed of which 12 are in Orange County (\#1-\#12), 24 are in Rockland County (\#13-\#36), 43 are in westchester County $(\# 37-\# 79)$ and 9 are in Putnam County (\#80-\#88). Table L.I provides a guide for locating the sirens on the topographical maps. 
TABLE L.1. SIREN LOCATION BY MAP.

\begin{tabular}{|c|c|c|c|c|c|}
\hline Siren & Map & Siren & Map & Siren & Map \# \\
\hline 1 & $\mathrm{~L}-3$ & 31 & $L-11$ & 61 & $L-8$ \\
\hline 2 & $\mathrm{~L}-2$ & 32 & $\mathrm{~L}-11$ & 62 & $\mathrm{~L}-8$ \\
\hline 3 & $L-6$ & 33 & $L-11$ & 63 & $L-8$ \\
\hline 4 & $\mathrm{~L}-6$ & 34 & $L-11$ & 64 & L-7 \\
\hline 5 & $L-6$ & 35 & $L-11$ & 65 & $\mathrm{~L}-7$ \\
\hline 6 & $L-6$ & 36 & $L-11$ & 66 & $L-7$ \\
\hline 7 & $L-6$ & 37 & $\mathrm{~L}-12$ & 67 & L-7 \\
\hline 8 & $L-6$ & 38 & $\mathrm{~L}-12$ & 68 & $\mathrm{~L}-7$ \\
\hline 9 & $L-6$ & 39 & $L-12$ & 69 & $L-7$ \\
\hline 10 & $\mathrm{~L}-5$ & 40 & $\mathrm{~L}-12$ & 70 & $L-7$ \\
\hline 11 & $L-7$ & 41 & $\mathrm{~L}-12$ & 71 & $\mathrm{~L}-7$ \\
\hline 12 & $L-7$ & 42 & $\mathrm{~L}-12$ & 72 & $L-7$ \\
\hline 13 & L-7 & 43 & L-12 & 73 & $L-7$ \\
\hline 14 & $L-7$ & 44 & $\mathrm{~L}-12$ & 74 & L-8 \\
\hline 15 & $L-10$ & 45 & $\mathrm{~L}-12$ & 75 & $L-8$ \\
\hline 16 & $L-10$ & 46 & $\mathrm{~L}-12$ & 76 & $\mathrm{~L}-8$ \\
\hline 17 & $L-10$ & 47 & $\mathrm{~L}-12$ & 77 & $L-8$ \\
\hline 18 & $\mathrm{~L}-10$ & 48 & $\mathrm{~L}-11$ & 78 & L- 8 \\
\hline 19 & $L-10$ & 49 & $L-11$ & 79 & $\mathrm{~L}-8$ \\
\hline 20 & $L-10$ & 50 & $\mathrm{~L}-11$ & 80 & L- 8 \\
\hline 21 & $\mathrm{~L}-10$ & 51 & $L-11$ & 81 & L-8 \\
\hline 22 & $\mathrm{~L}-10$ & 52 & $\mathrm{~L}-11$ & 82 & L-7 \\
\hline 23 & $L-10$ & 53 & $\mathrm{~L}-11$ & 83 & L-7 \\
\hline 24 & $\mathrm{~L}-11$ & 54 & $\mathrm{~L}-11$ & 84 & $L-7$ \\
\hline 25 & $L-11$ & 55 & $\mathrm{~L}-11$ & 85 & $L-3$ \\
\hline 26 & $L-11$ & 56 & $\mathrm{~L}-12$ & 86 & $L-3$ \\
\hline 27 & $\mathrm{~L}-11$ & 57 & $\mathrm{~L}-12$ & 87 & $L-7$ \\
\hline 28 & $L-11$ & 58 & $L-8$ & 88 & $L-4$ \\
\hline 29 & $L-11$ & 59 & L-8 & & \\
\hline 30 & $\mathrm{~L}-11$ & 60 & $\mathrm{~L}-8$ & & \\
\hline
\end{tabular}




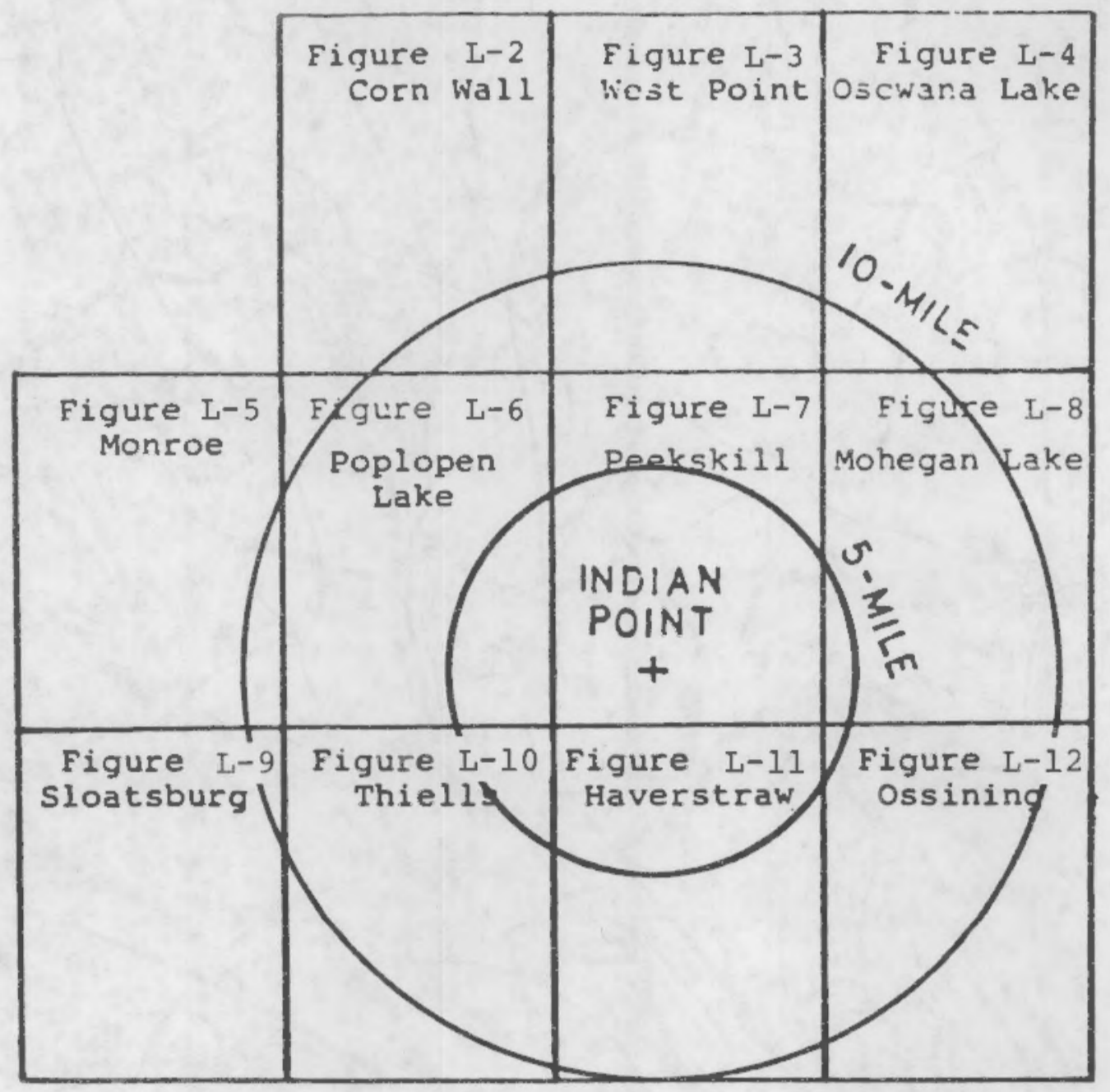

FIG. I-1. SIREN LAYOUT MAP LOCATOR. 


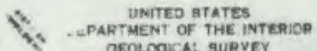

FIGURE L-2

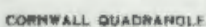

$4:$

10000000

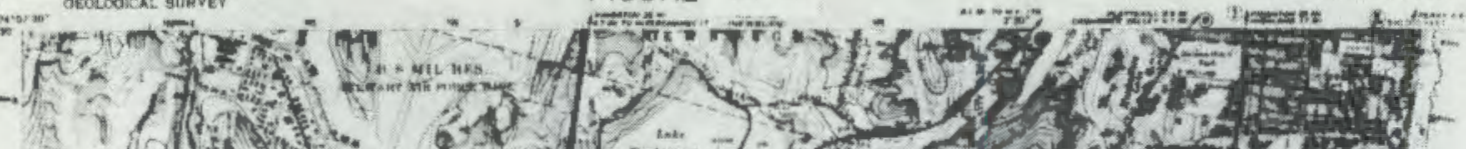

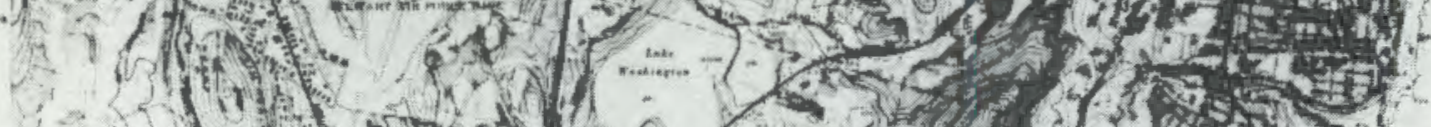

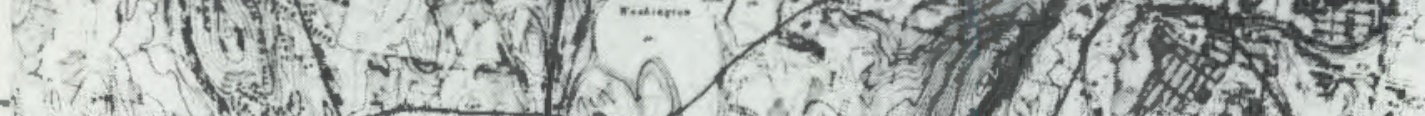

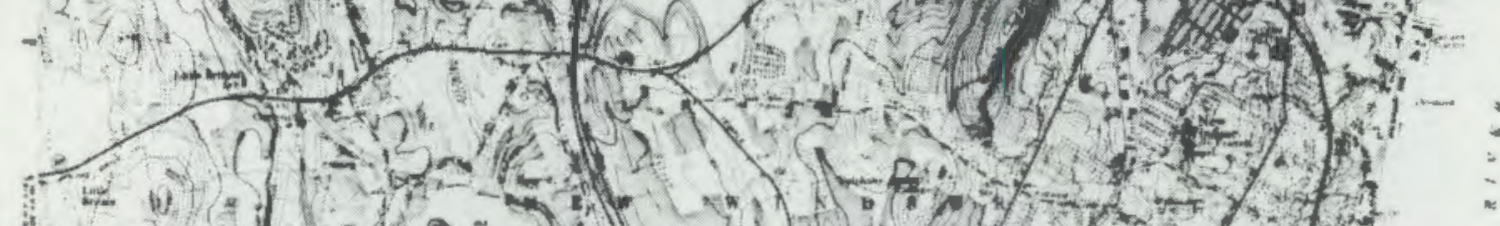

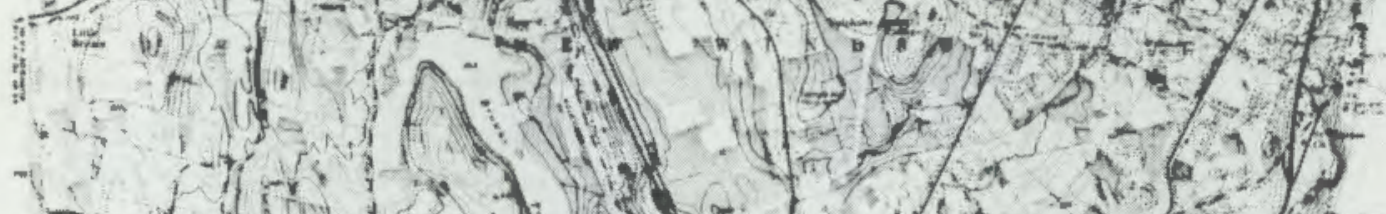

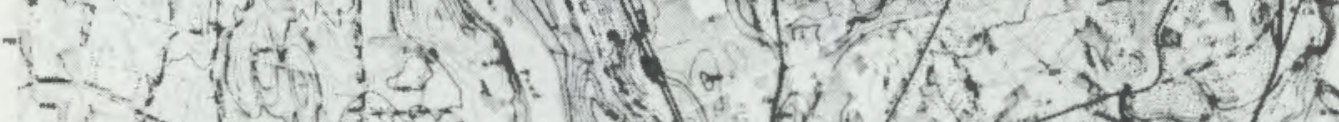

$\left[\begin{array}{c}-1 \\ -1\end{array}\right.$

1.

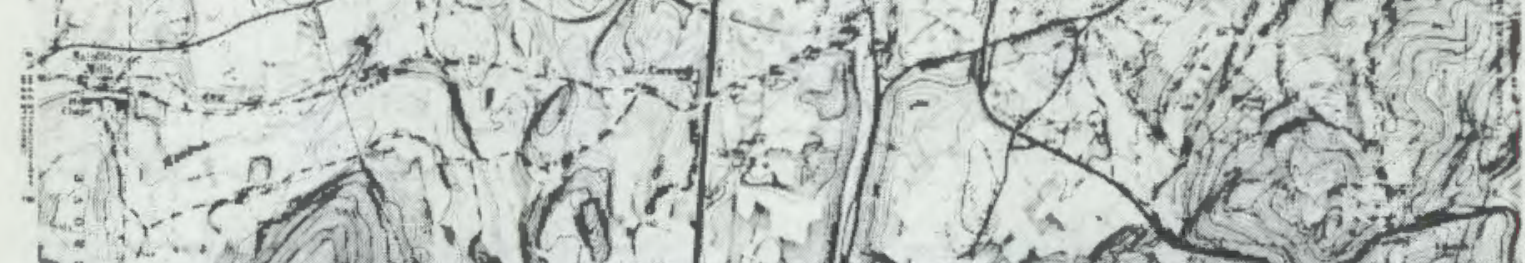

(for)

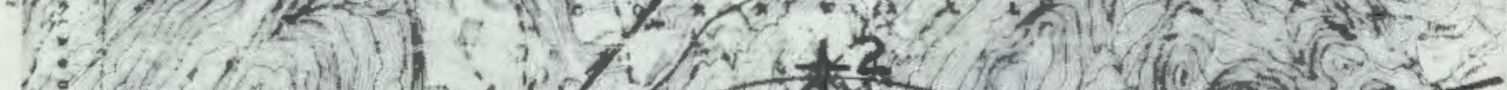

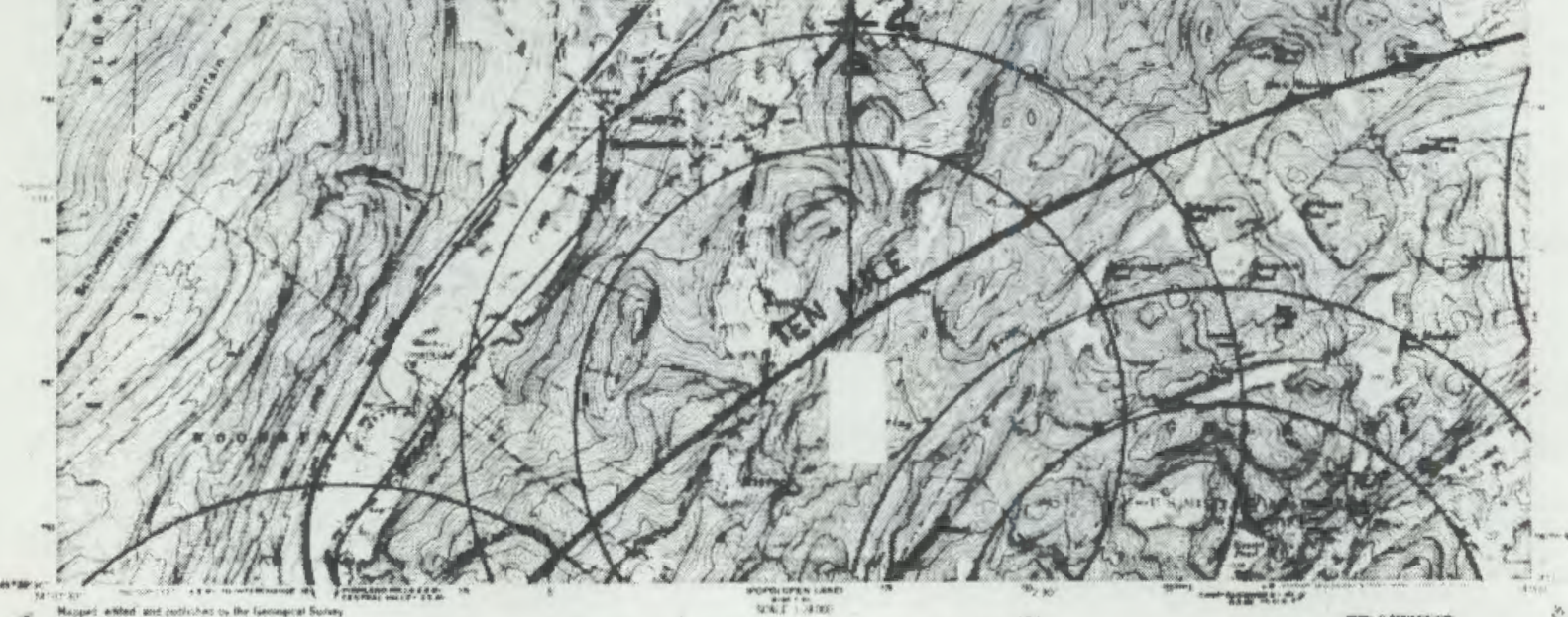

6
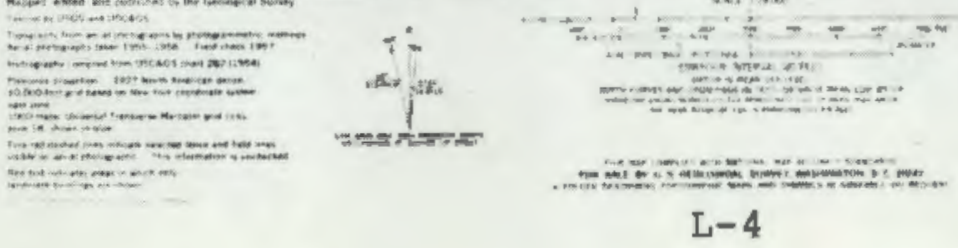

$=-\infty=$

$=-1+$ 


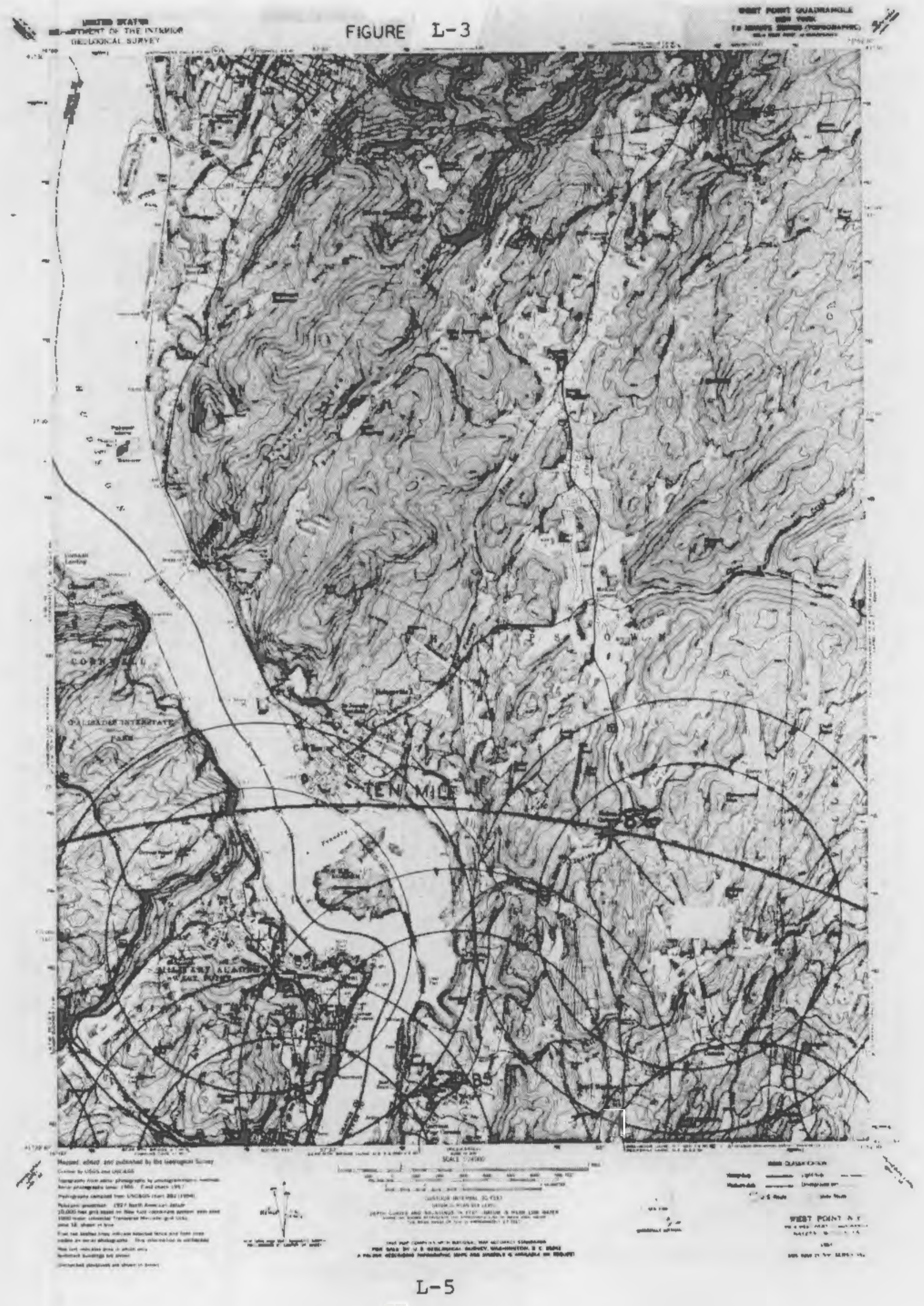




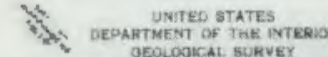

FIGURE L-4

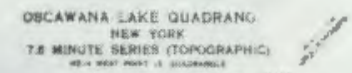
Pof

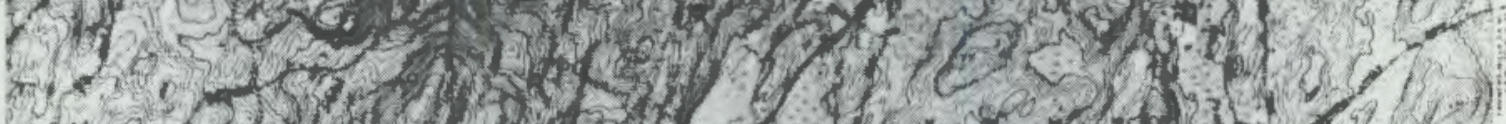

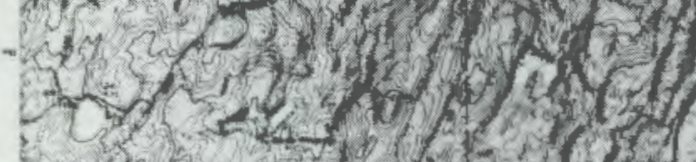

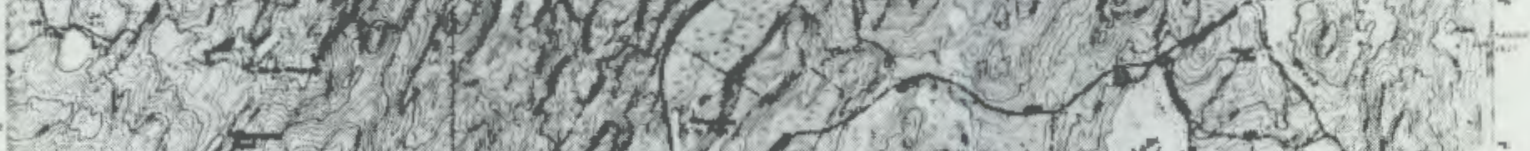

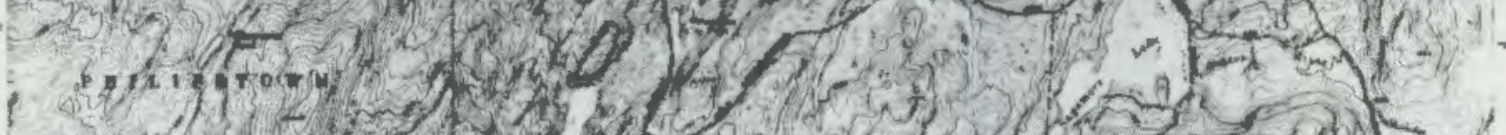

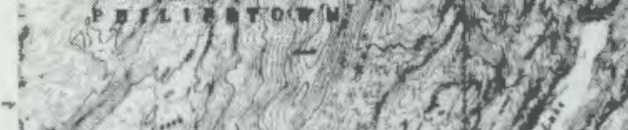

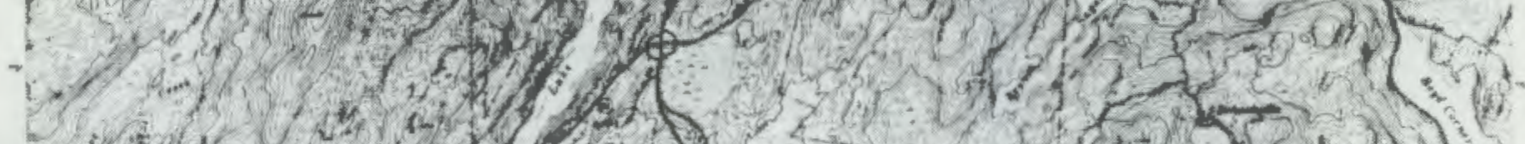

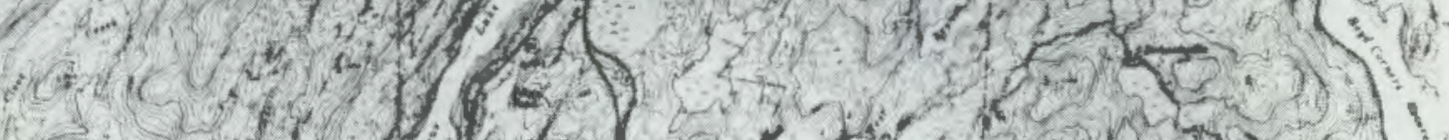

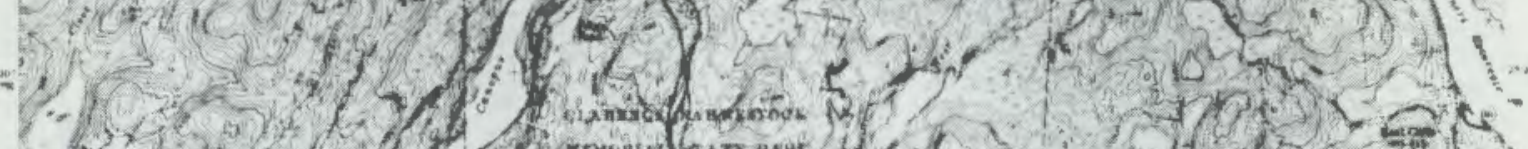

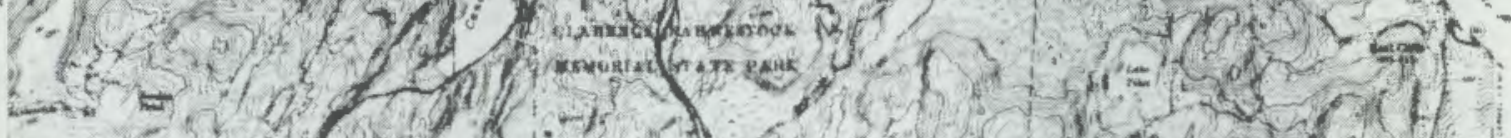

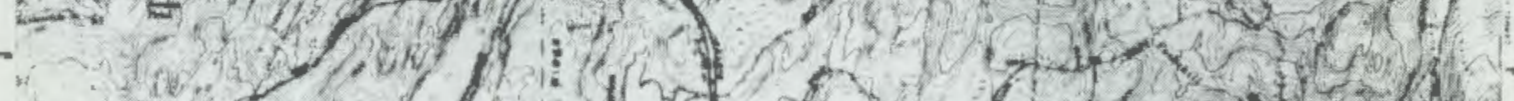

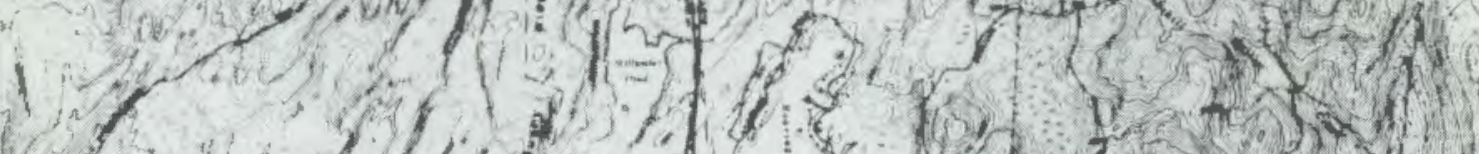

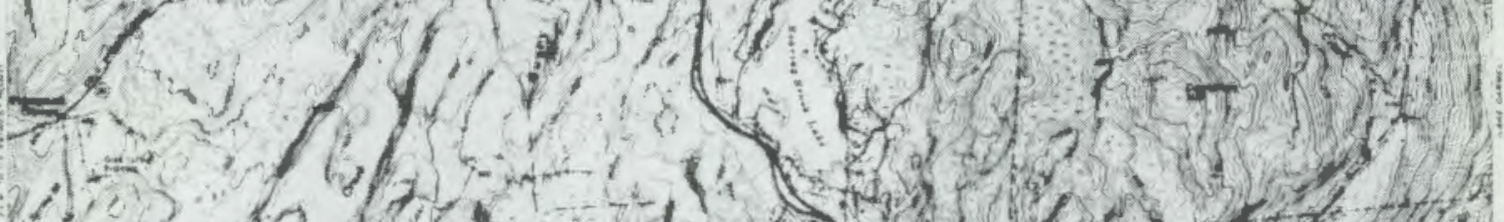

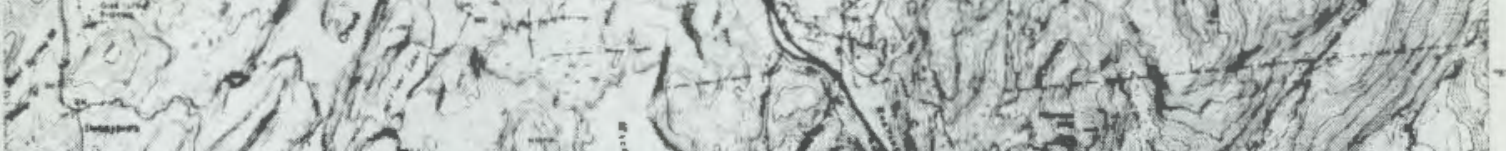

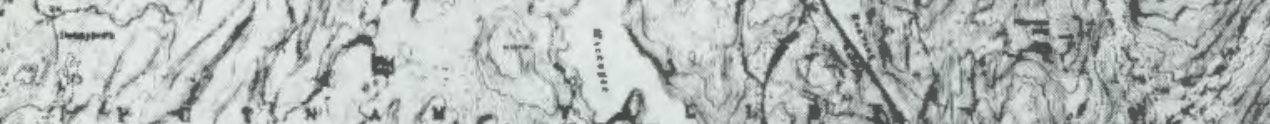

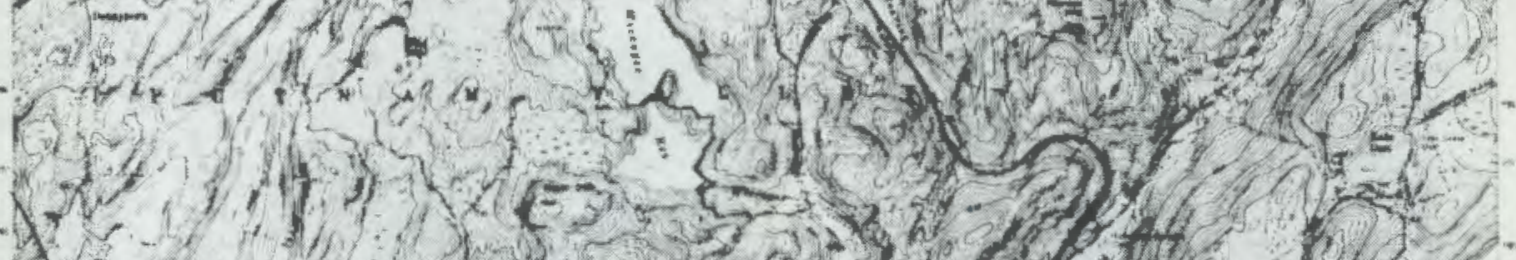

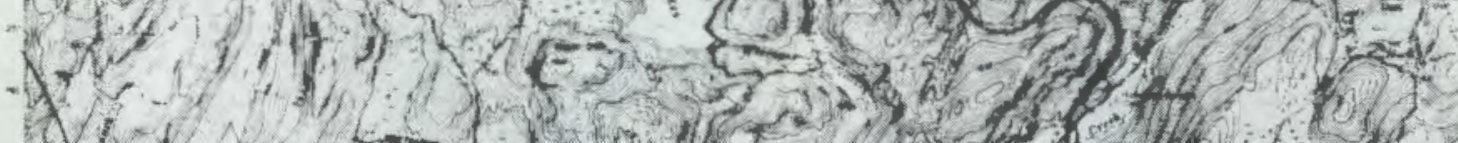

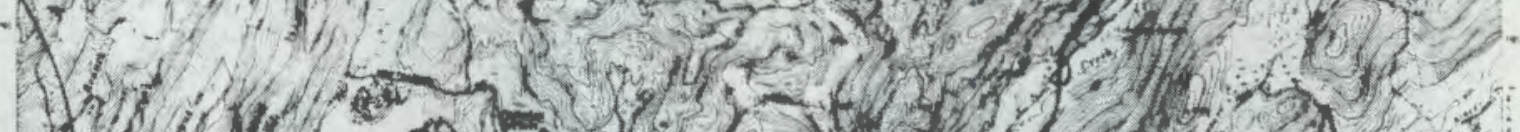

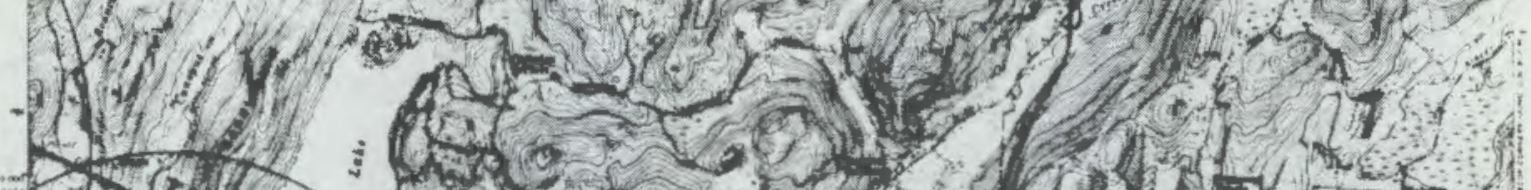

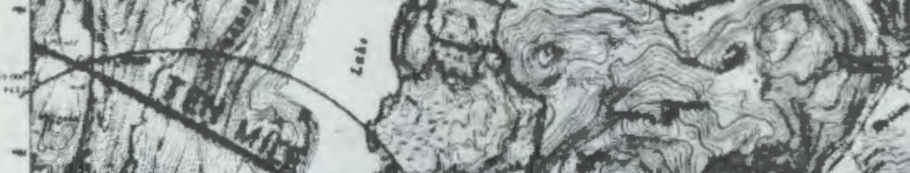

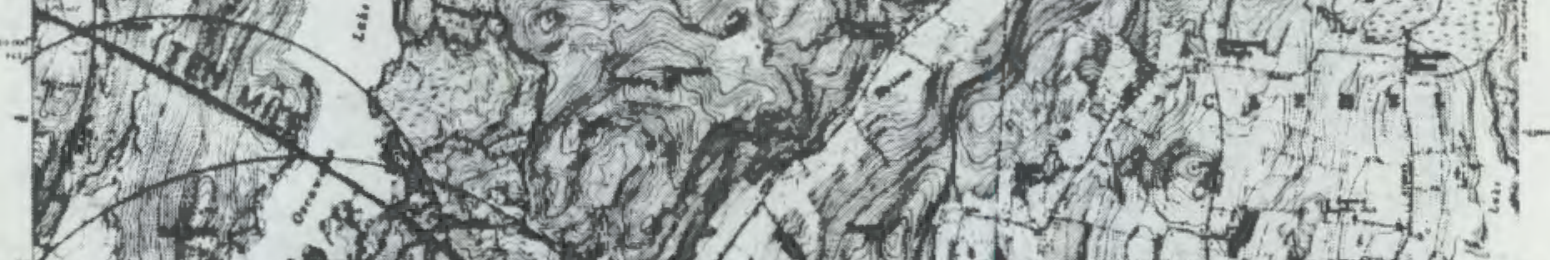
7 (6)

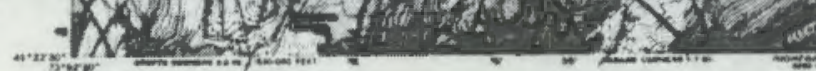

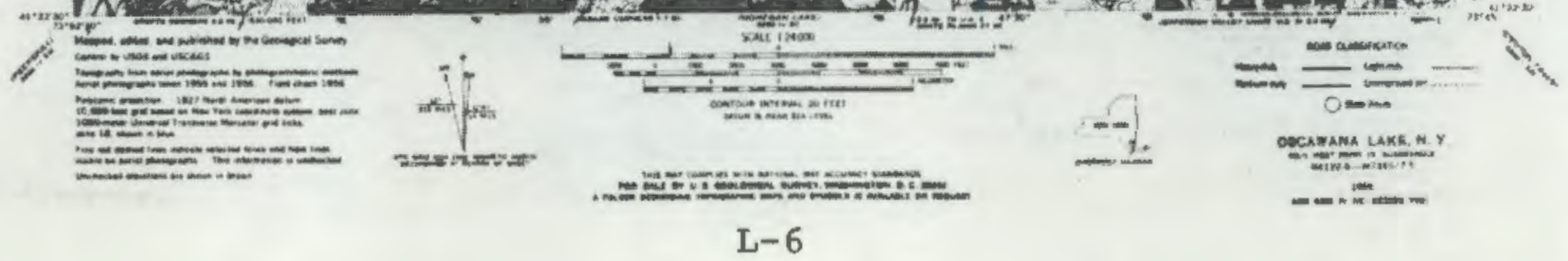




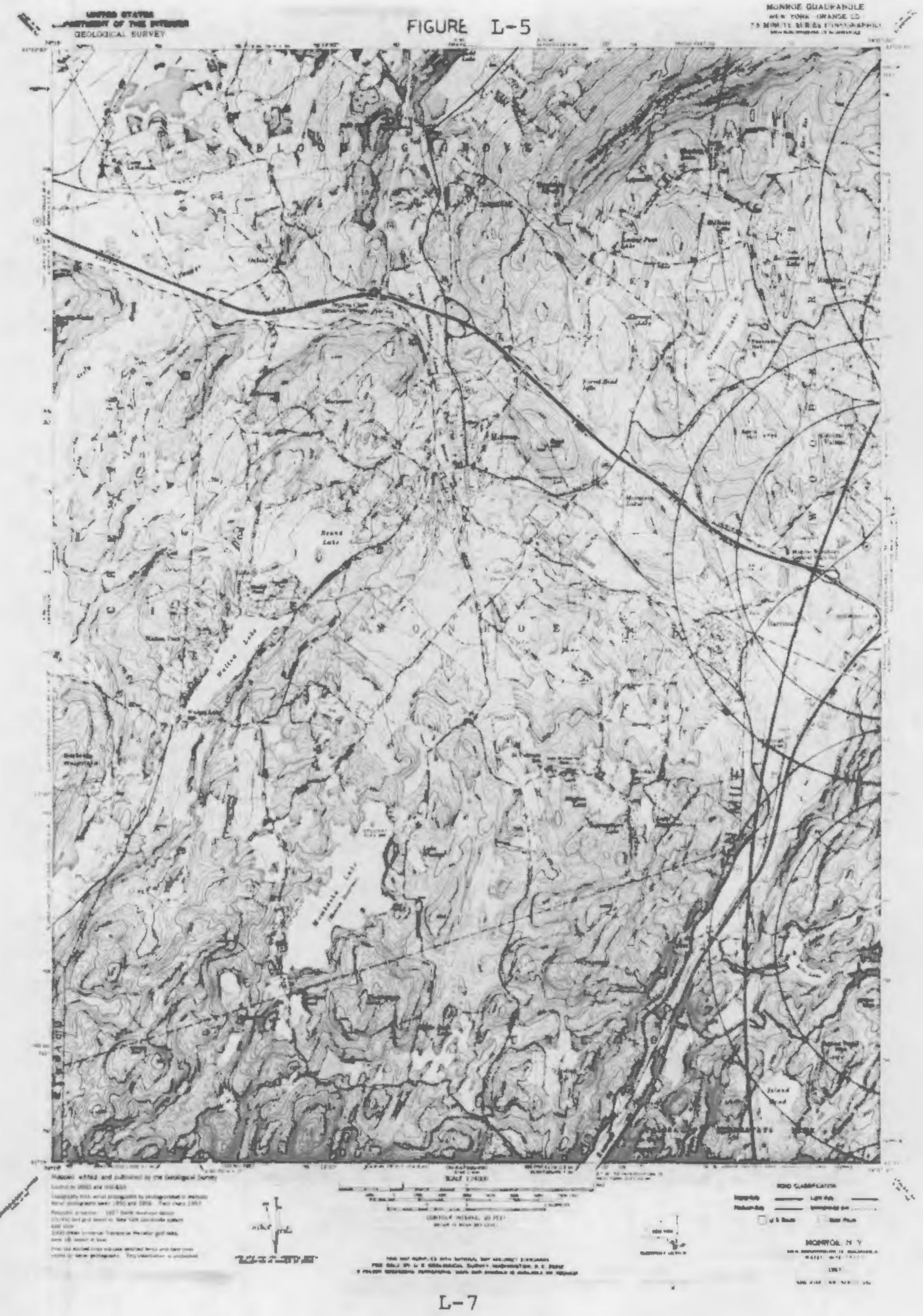




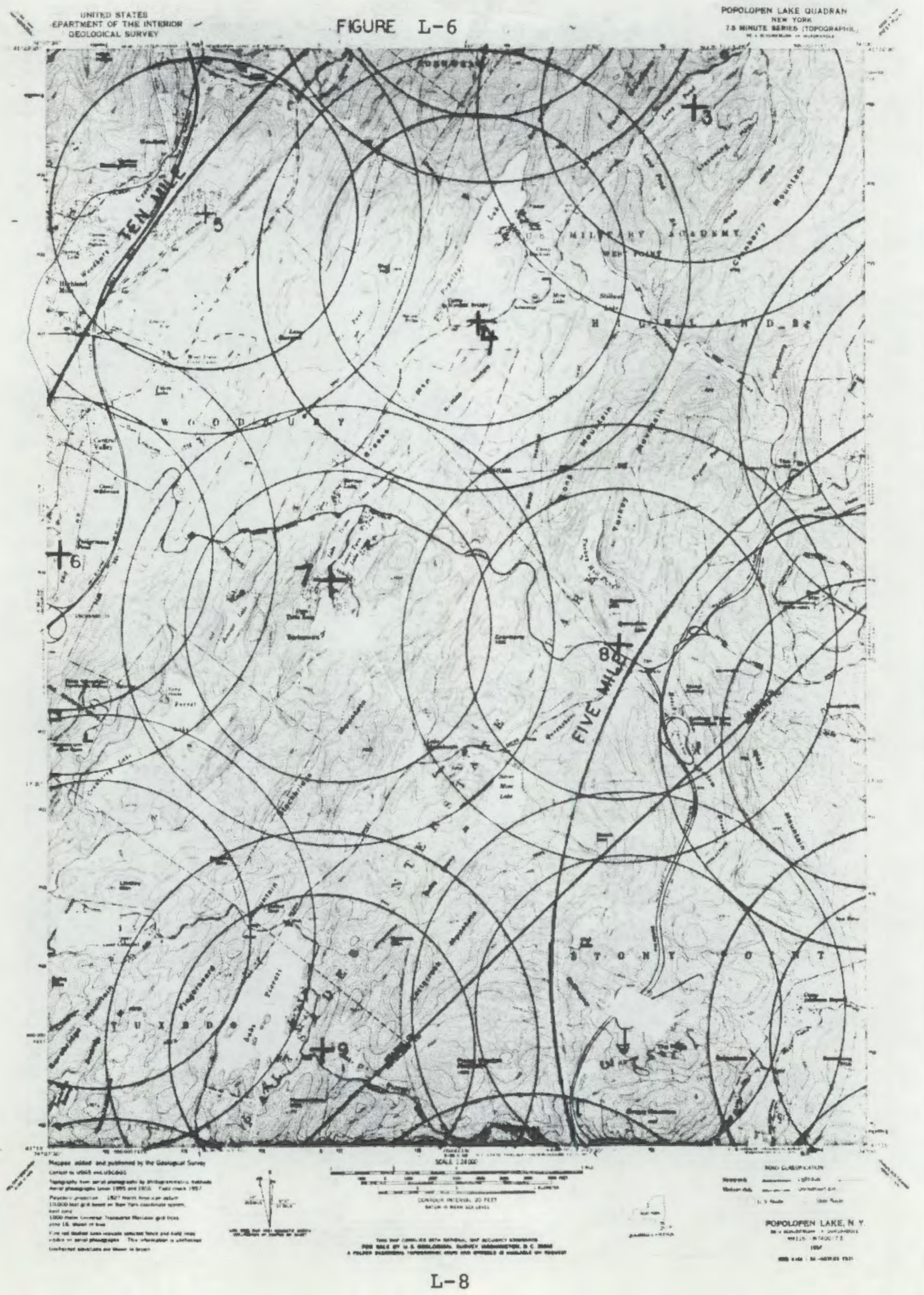


$x$

FIGURE L-

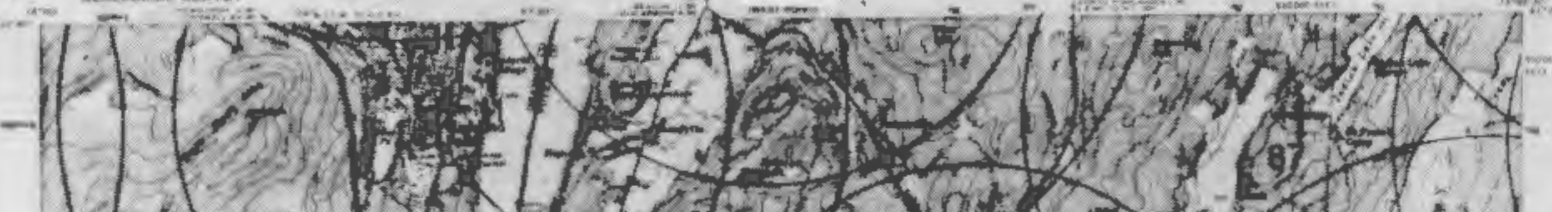

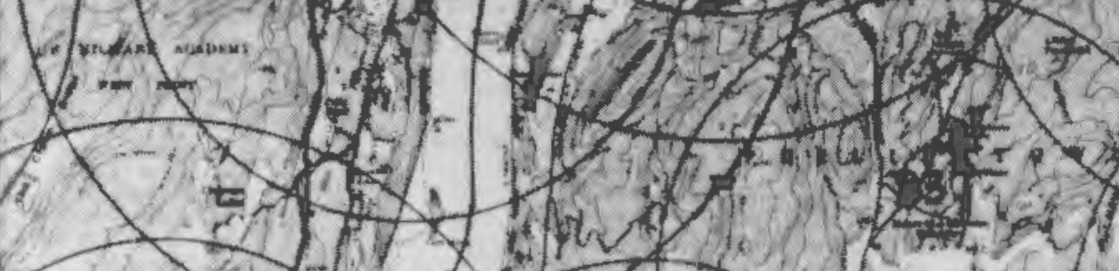

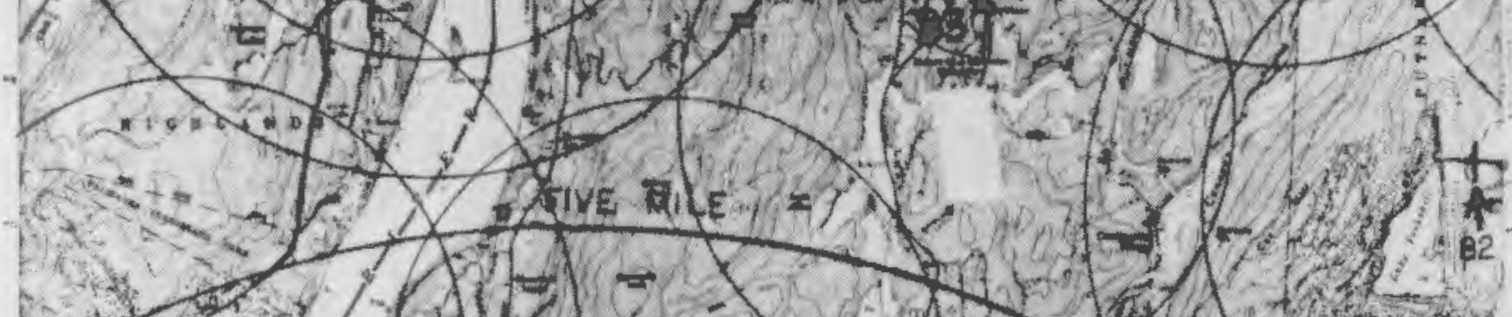

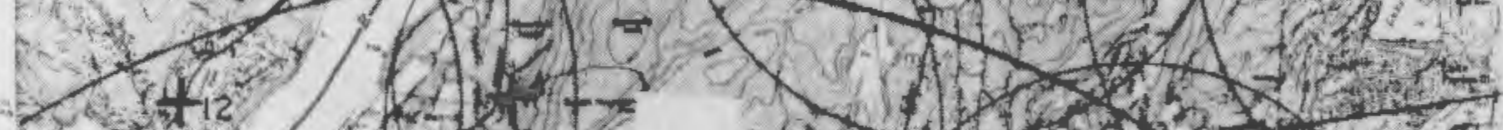

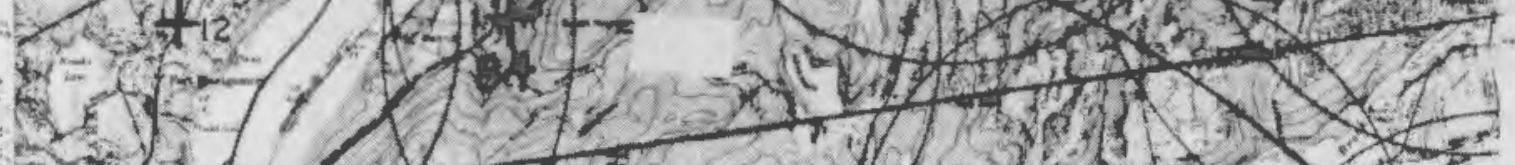

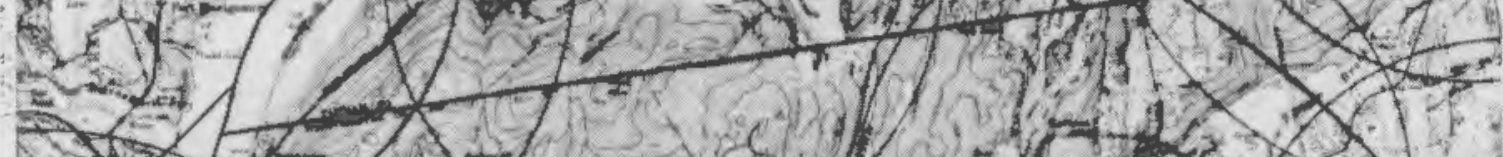
(1)

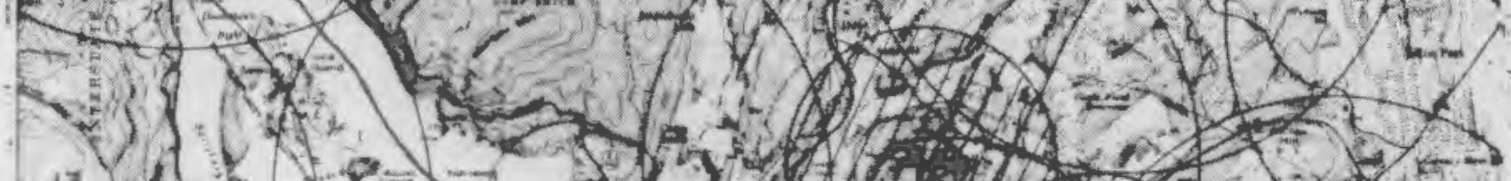

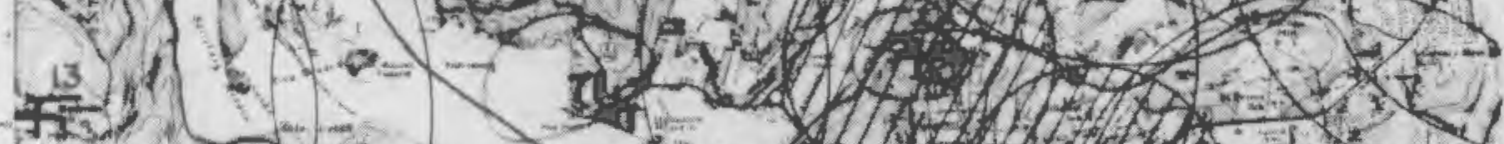
323
$=2$

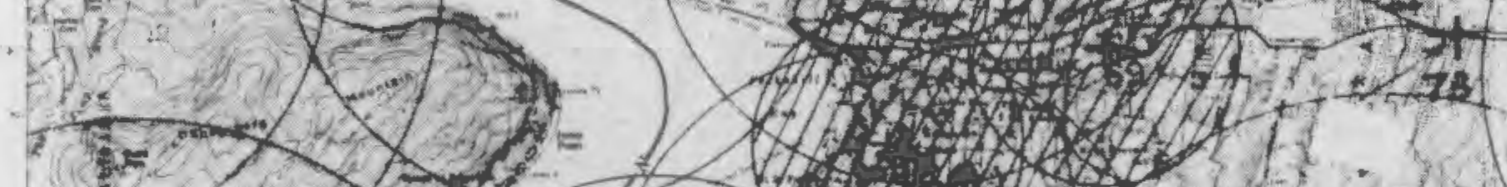

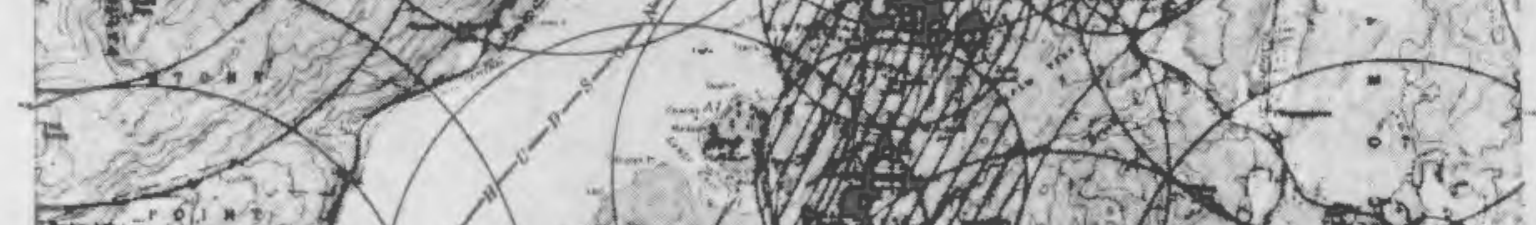

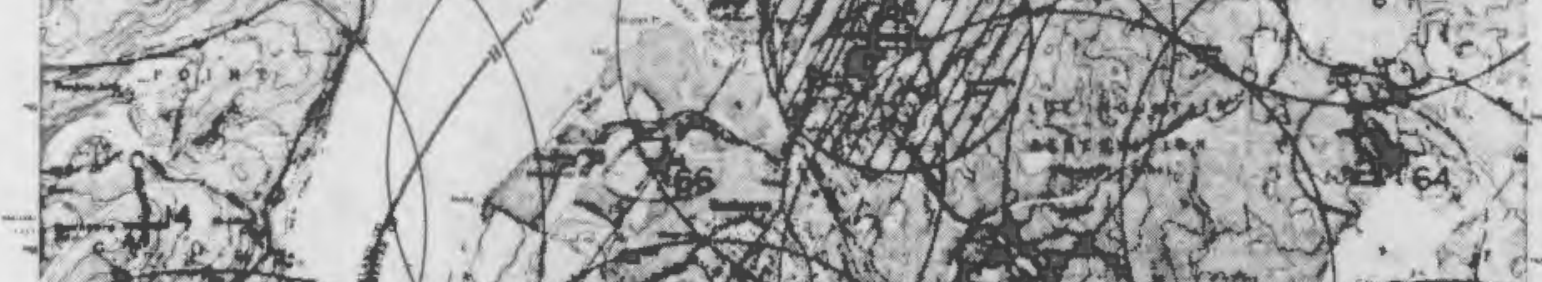

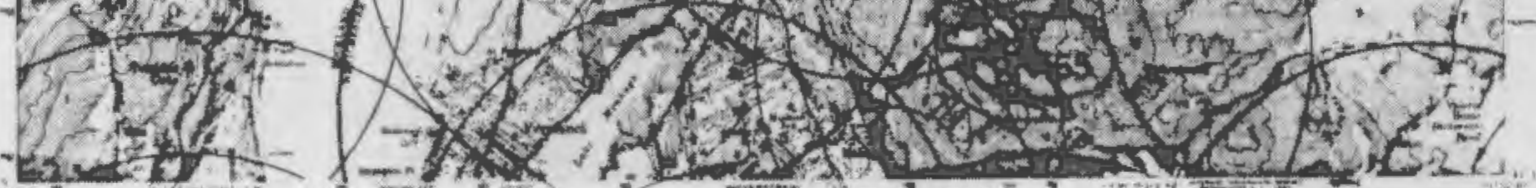

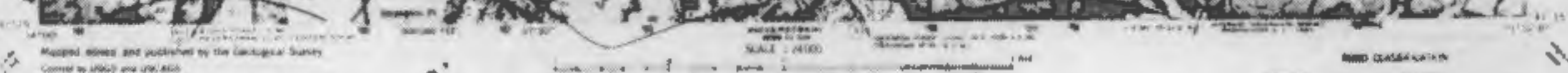
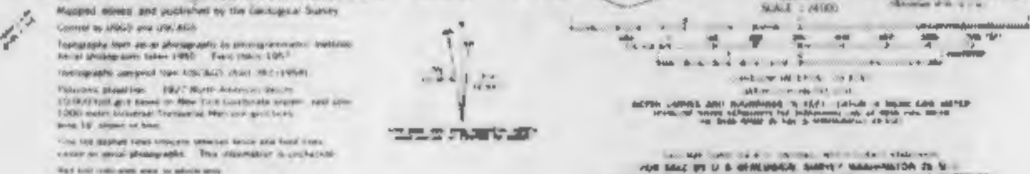$$
==
$$

$-5=$

ansing 


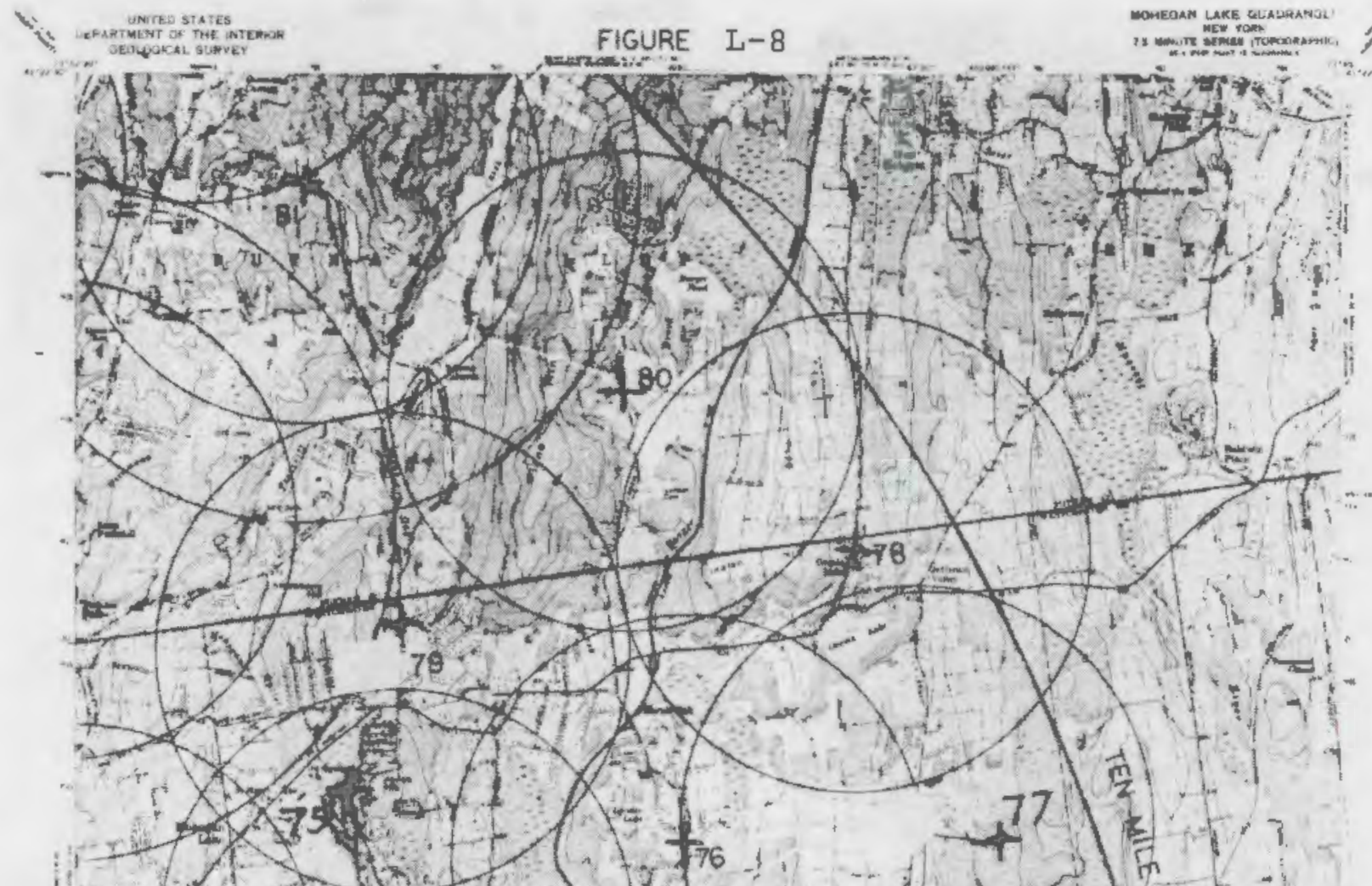

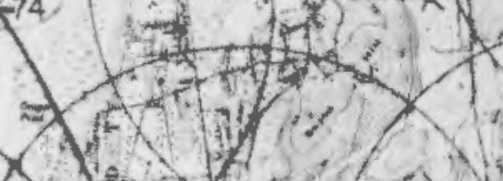

ixe $x^{2}$

i) $z^{2}$

$=1+\frac{\pi}{5}$

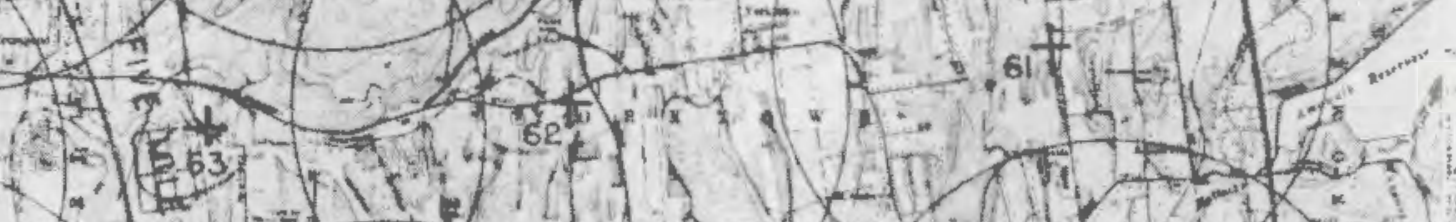

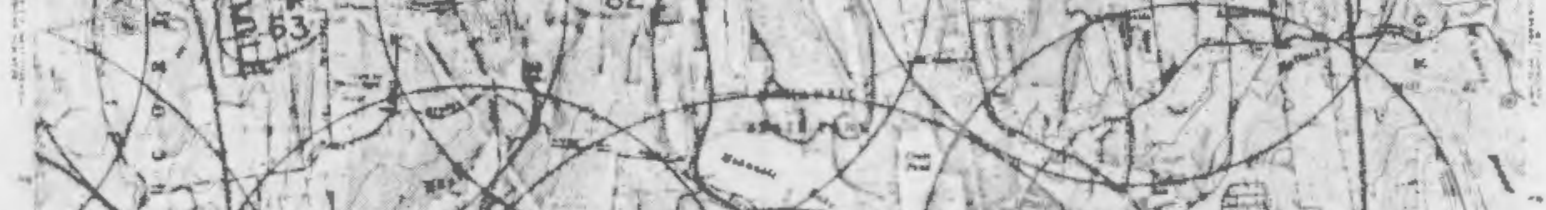

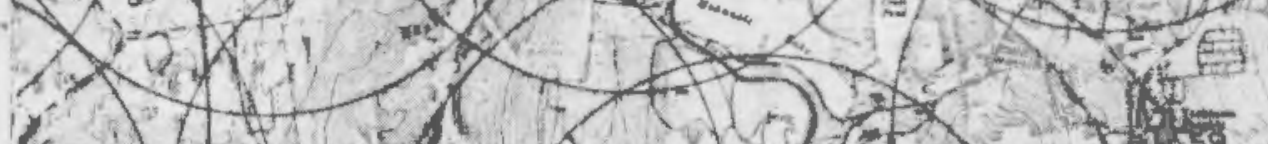

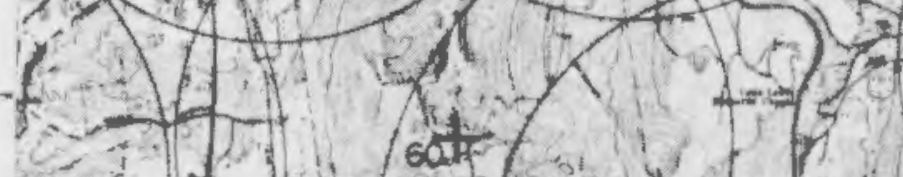

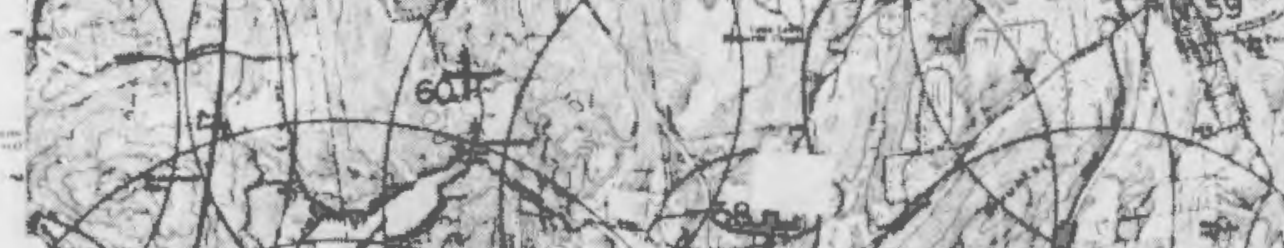

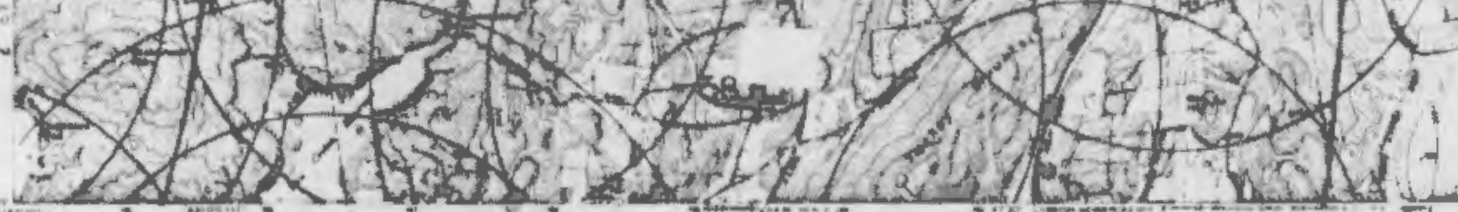

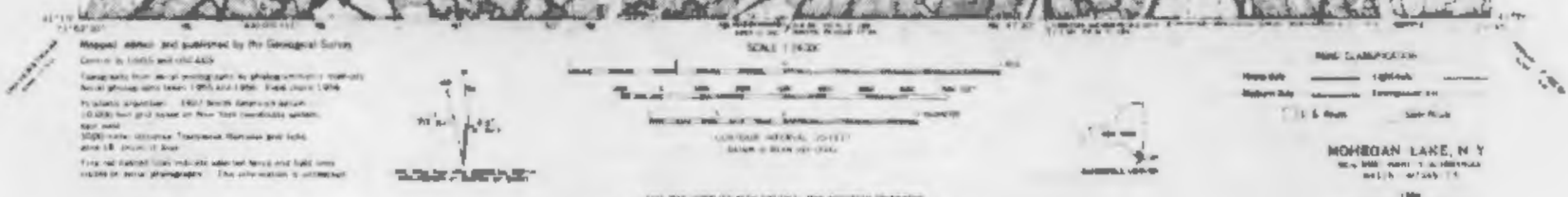




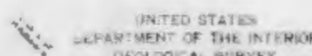

FIGURE L-9

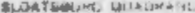

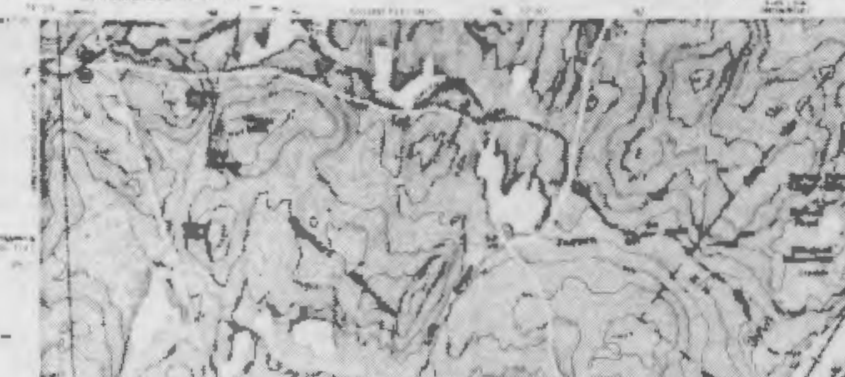

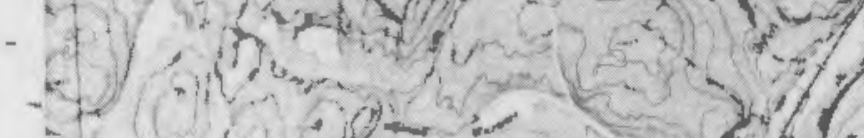

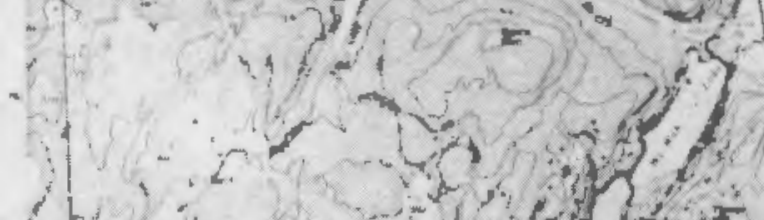

(1)

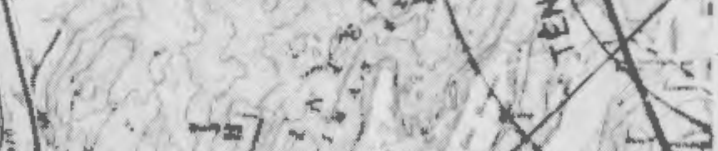

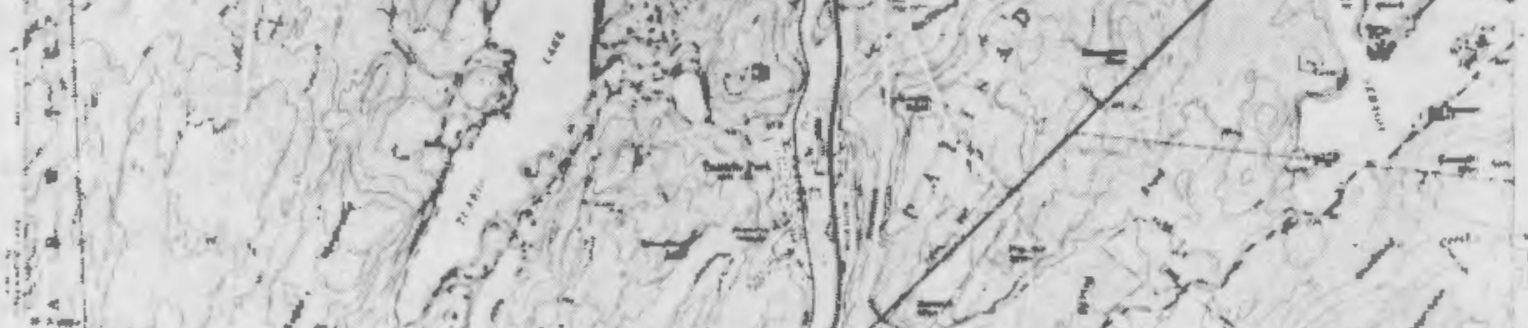

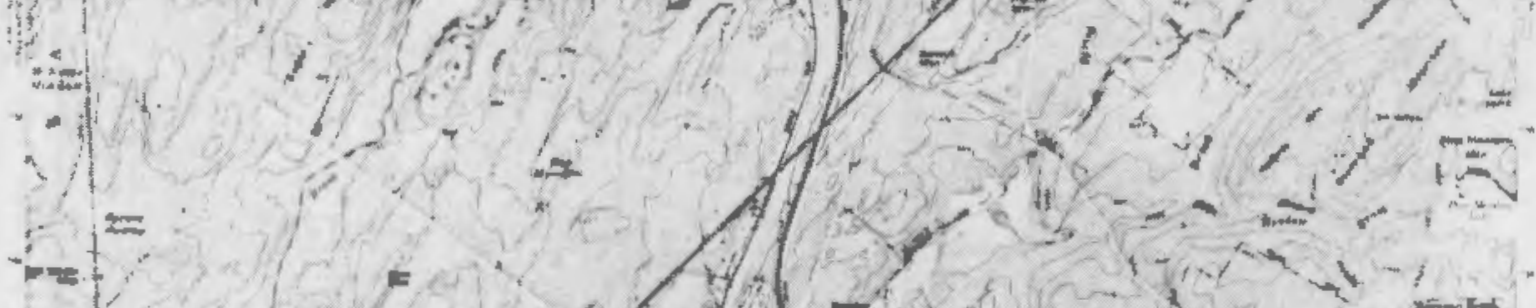

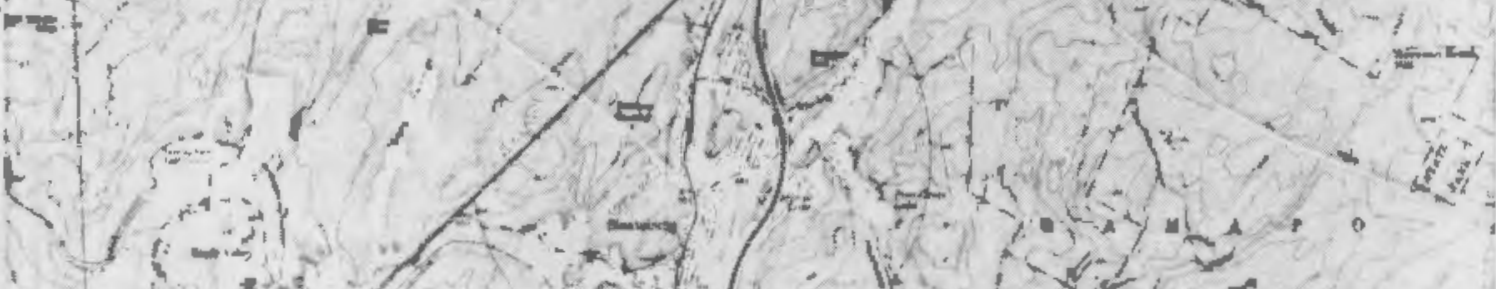

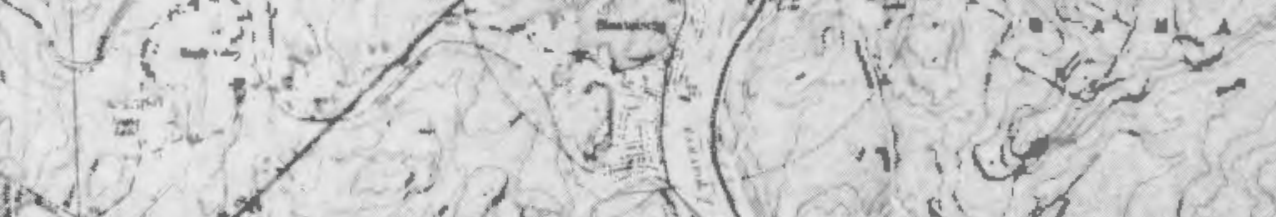

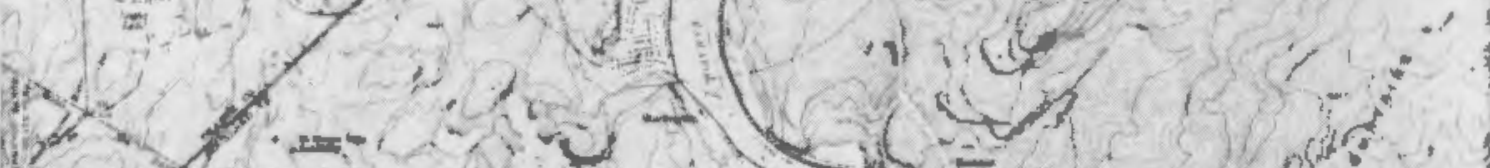

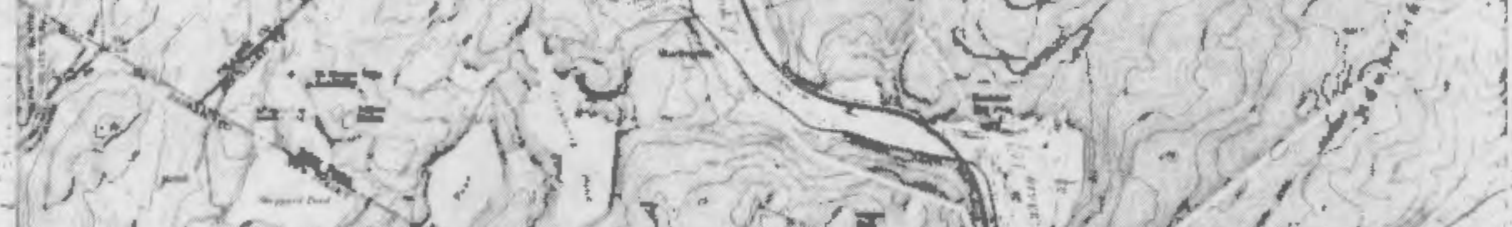

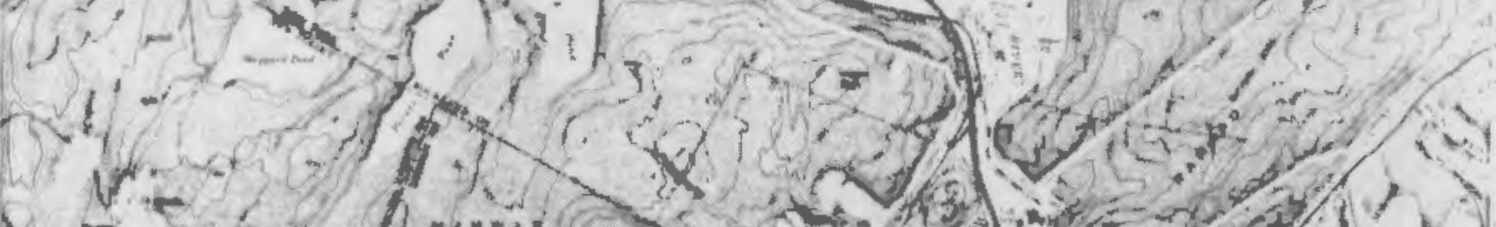

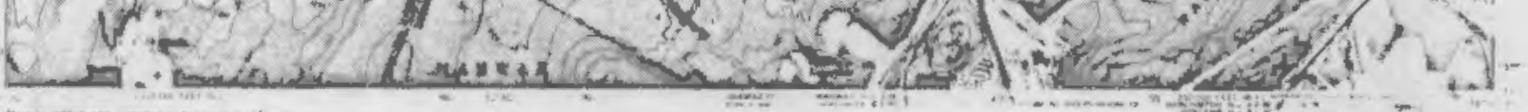

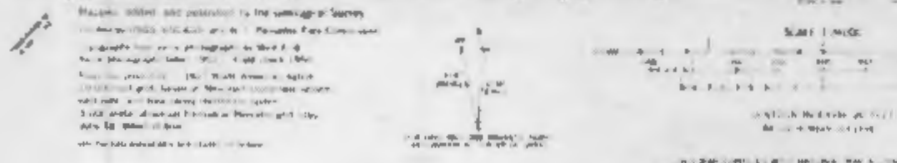


4

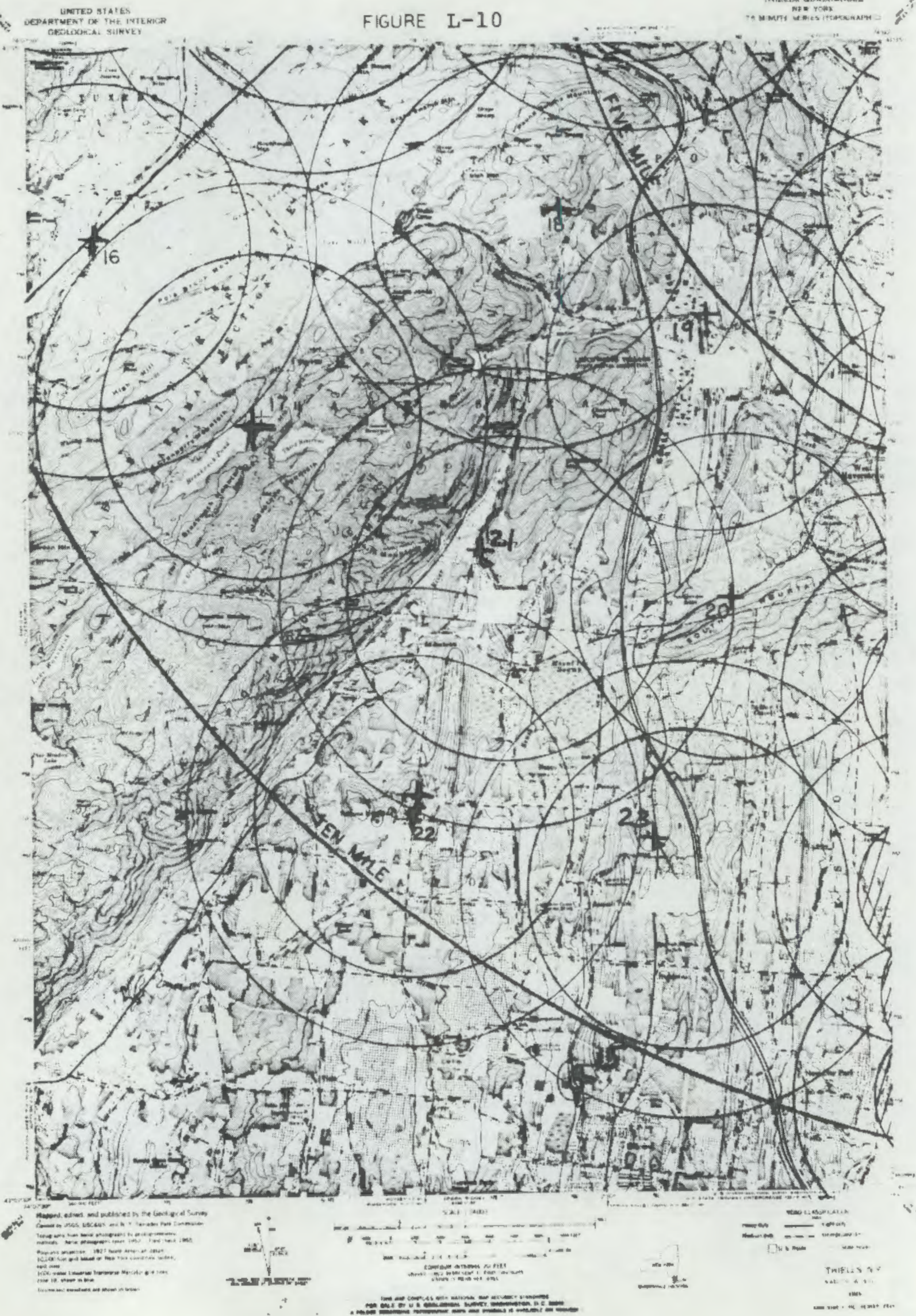




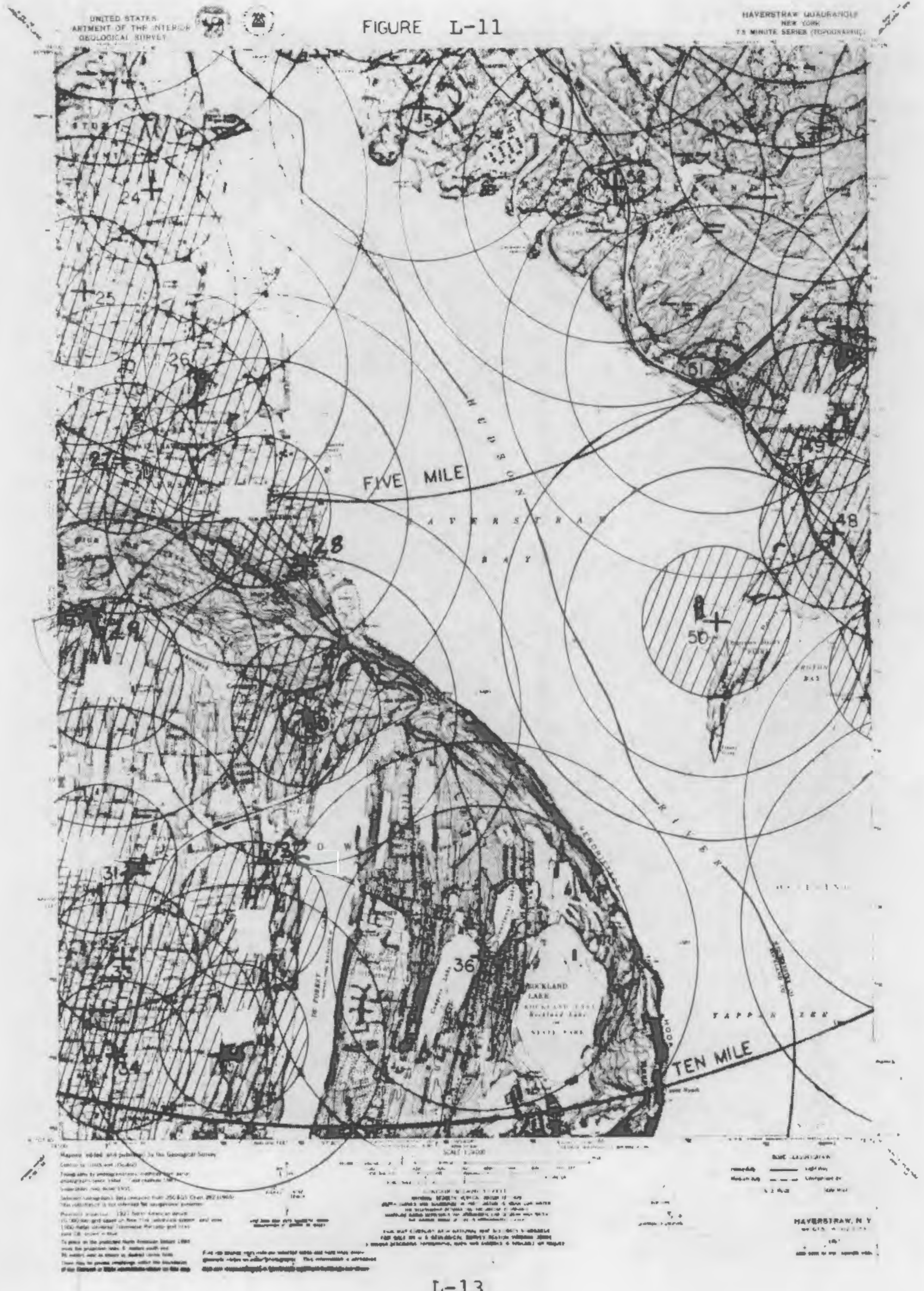




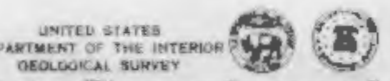

FIGUME L-12

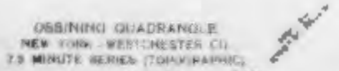

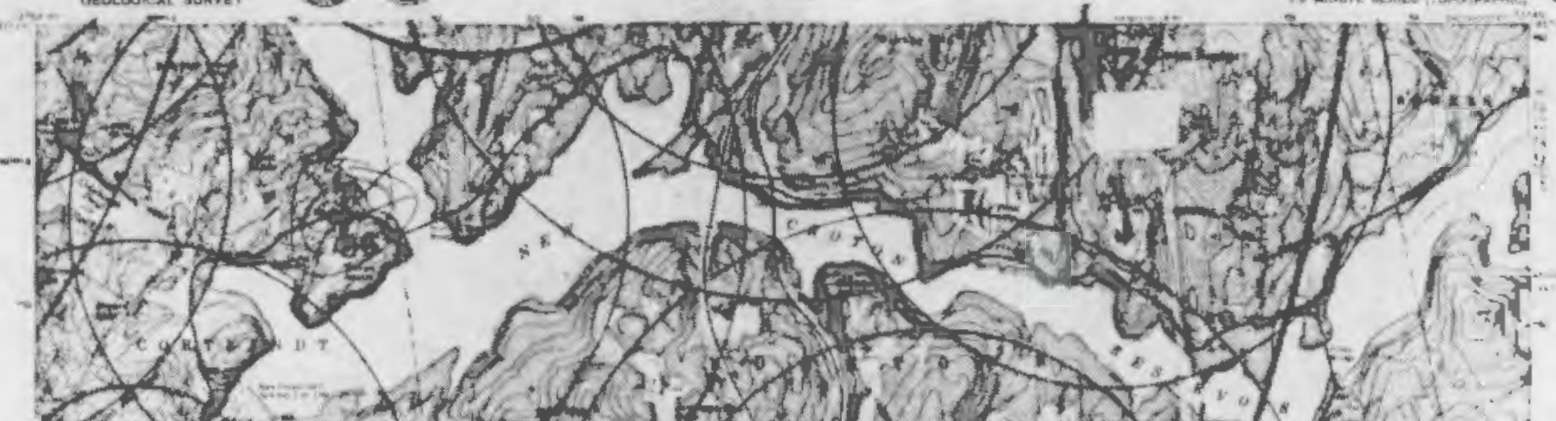

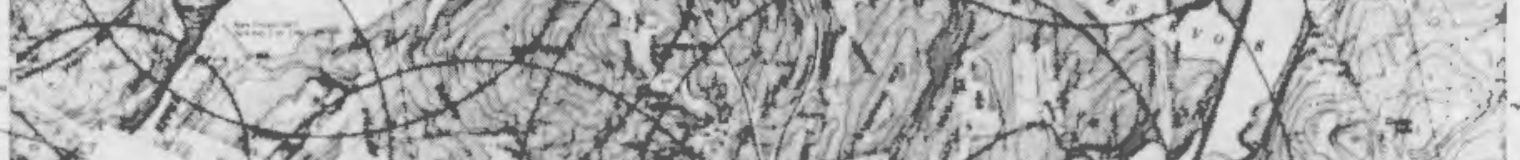

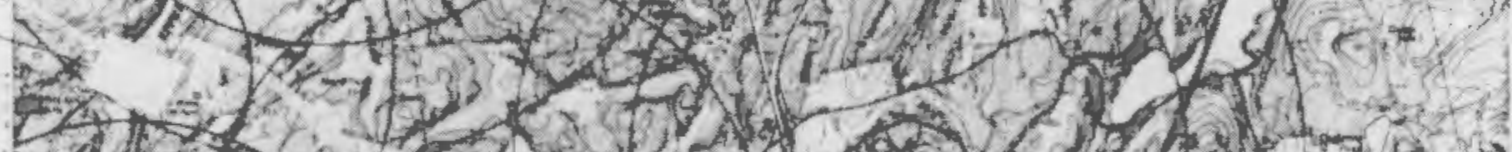

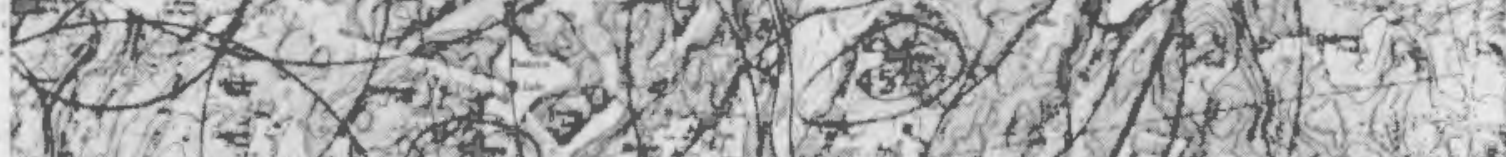

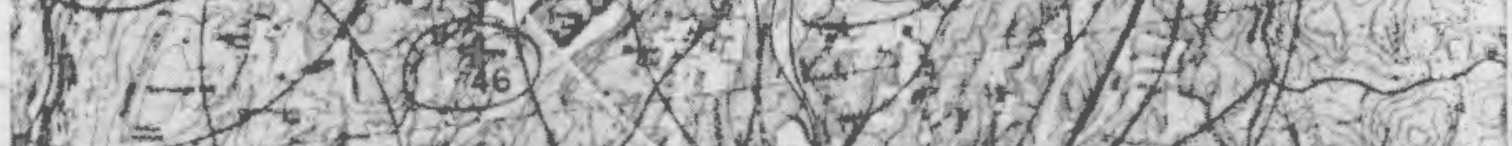

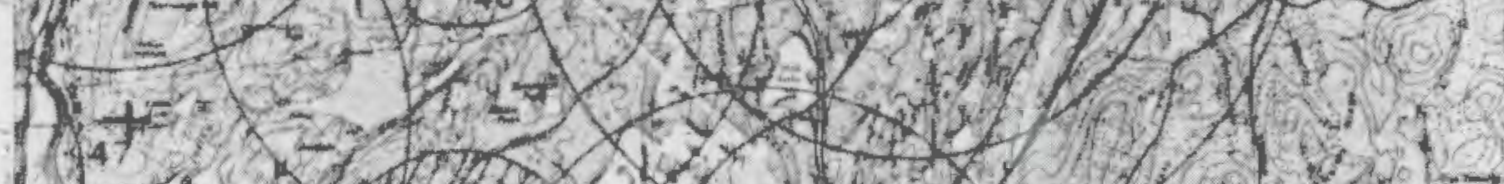

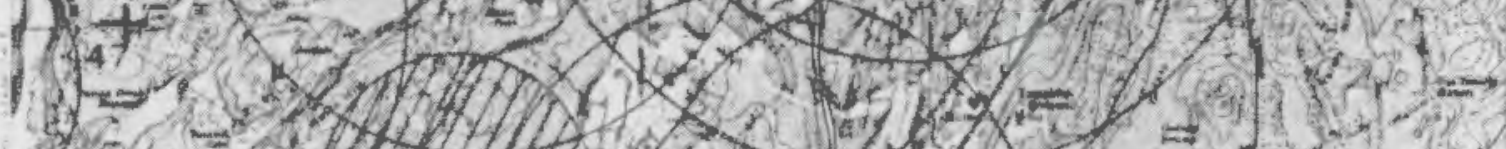

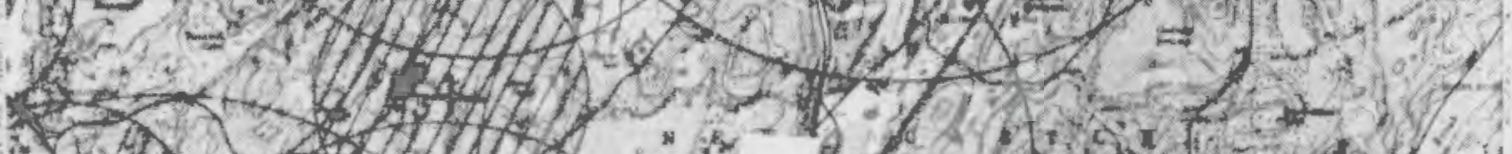

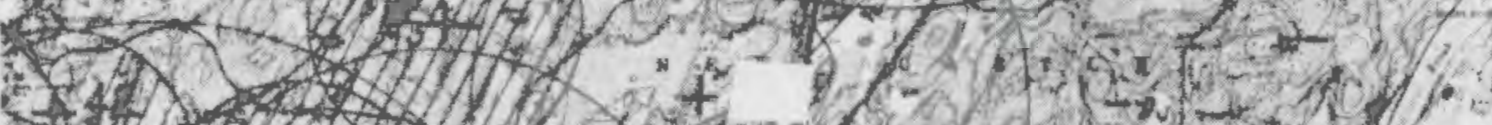

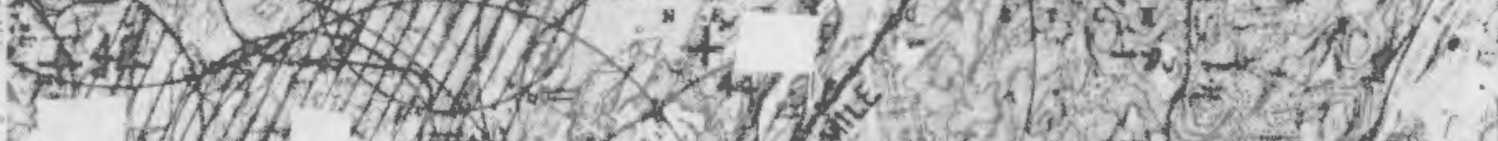

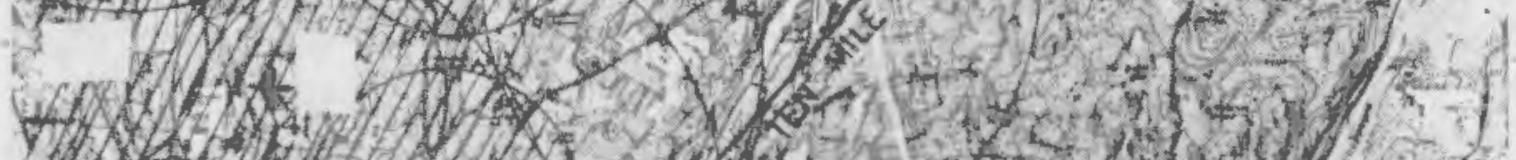

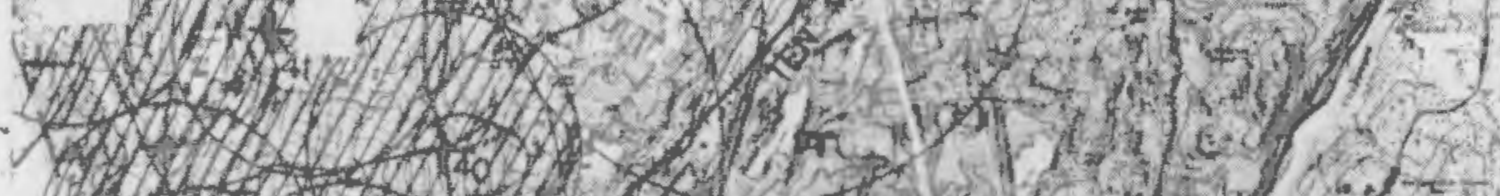

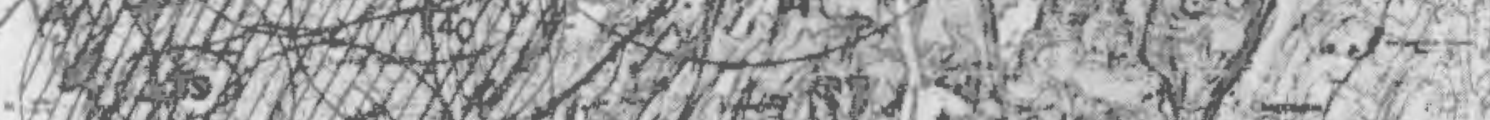

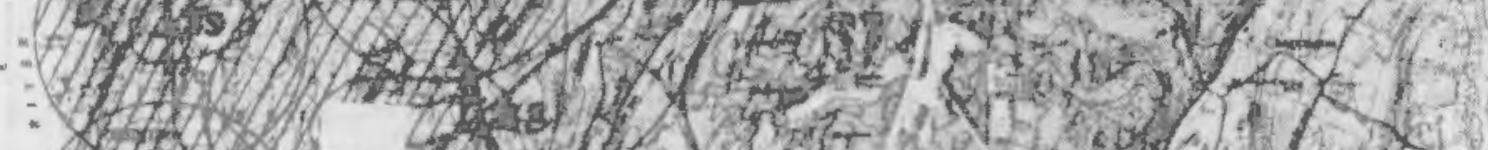

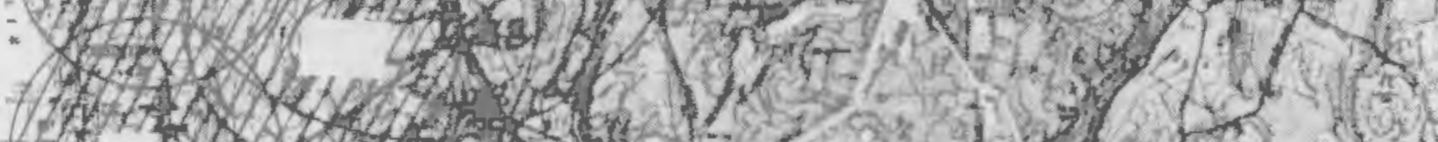

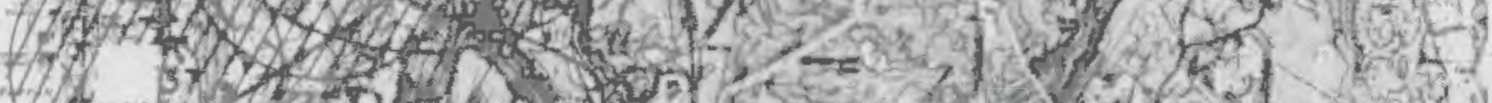

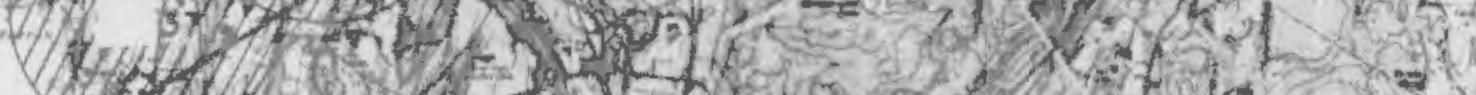

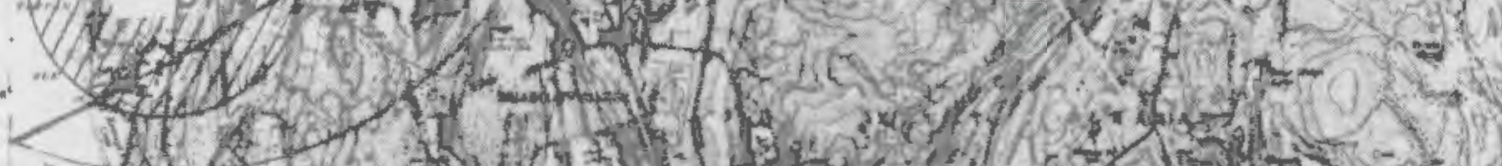

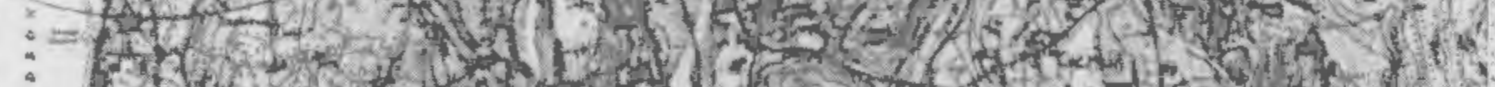

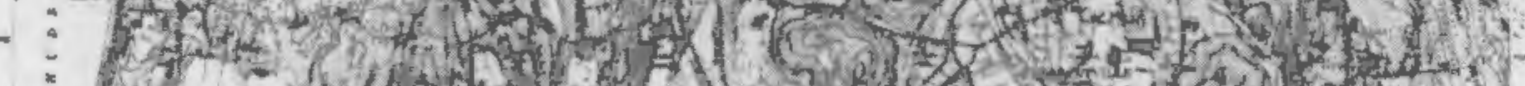

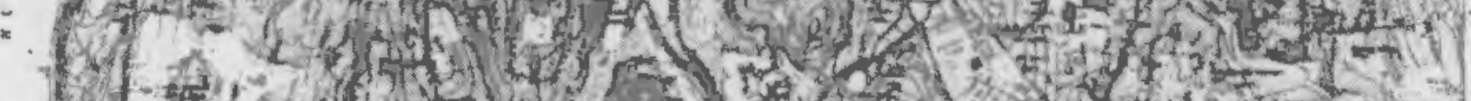

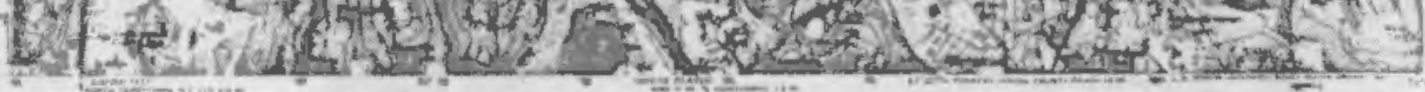

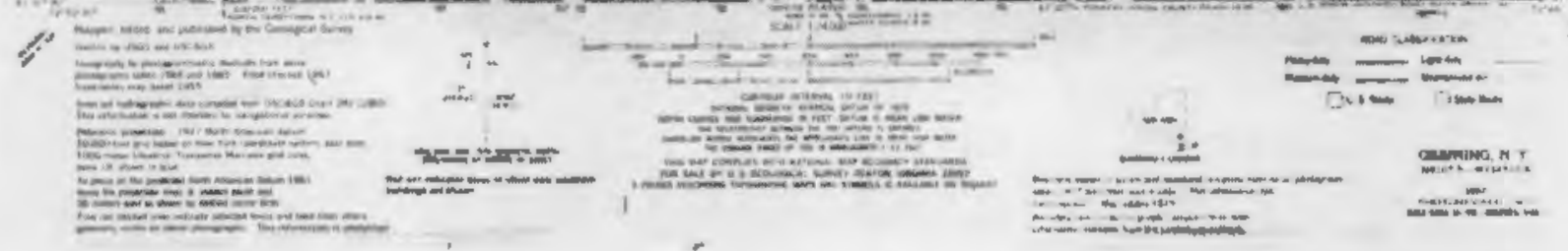


APPENDIX M: ANALYSIS INPUT/OUTPUT DATA FOR INDIAN POINT

This appendix provides listings of computer file input and output data for the zion analysis. Explanation of the terminology used for each listing is provided below.

\section{TABLE M.1. INDIAN-SIRENS}

This file contains input data for each of the Indian point sirens as follows:

- Siren No. number assigned to each siren for use by computer program.

- Siren Name first letter indicates whether the siren is rotating or stationary type ( $\mathrm{R}$ or $\mathrm{S}$ ); the remainder consists of the siren designation, which for this plant is identical to the siren No.

- $x, y, z$

these are the physical coordinates for the siren location; the $x$-axis is oriented eastwest, the $y$-axis is oriented north-south, and the $z$-axis is oriented vertically. The $x$ and $y$ coordinates are in units of $\mathrm{km}$, referenced to the grid shown on the Feb. 1981 NRC Emergency Planning Map for Indian Point (the plant center is located approximately at $x=587.7$, $y=4569.2)$. The $z$ coordinates are in units of feet.

- SPL@100FT

these numbers indicate the rated sound pressure level for each siren at a distance of 100 feet, in $d B$ 


\section{Table M.2 INDIANEARS}

This file contains input data for each of the randomly selected listener locations as follows:

- Site No. number assigned to each site for use by computer program

- Site Name designator for listener site; the first letter indicates whether the site is urban or rural (U or R)

- $x, y, z$ these are the physical coordinates for the listener location; the $\mathrm{x}$-axis is oriented east-west, the $y$-axis is oriented north-south, and the $z$-axis is oriented vertically. The $x$ and $y$ coordinates are in units of $\mathrm{km}$, referenced to the grid shown on the Feb. 1981 NRC Emergency Planning Map for Indian Point (the plant center is located approximately at $x=587.7, y=4569.2)$. The $z$ coordinates are in units of feet

- Rural Road this column indicates whether rural listener sites are within $1000 \mathrm{ft}$ of major highway (NEAR) or beyond $1000 \mathrm{ft}$ (FAR). This information is required for the selection of appropriate outdoor background noise levels.

\section{TABLE H. 3 VAL-HUDSON}

This file contains input data for each of the four sample scenarios as follows:

- Scenario No. number assigned to each scenario (see App. J).

- AMOL molecular absorption, in dB/1000 feet. 
- WIND

- NRES

- NCRM

- $F 1-F 8$ wind direction in degrees $\left(0^{\circ}=\right.$ wind from north, etc.)

residential building outdoor-to-indoor noise reduction, in $\mathrm{dB}$.

commercial building outdoor-to-indoor noise reduction, in $\mathrm{dB}$.

activity fractions.

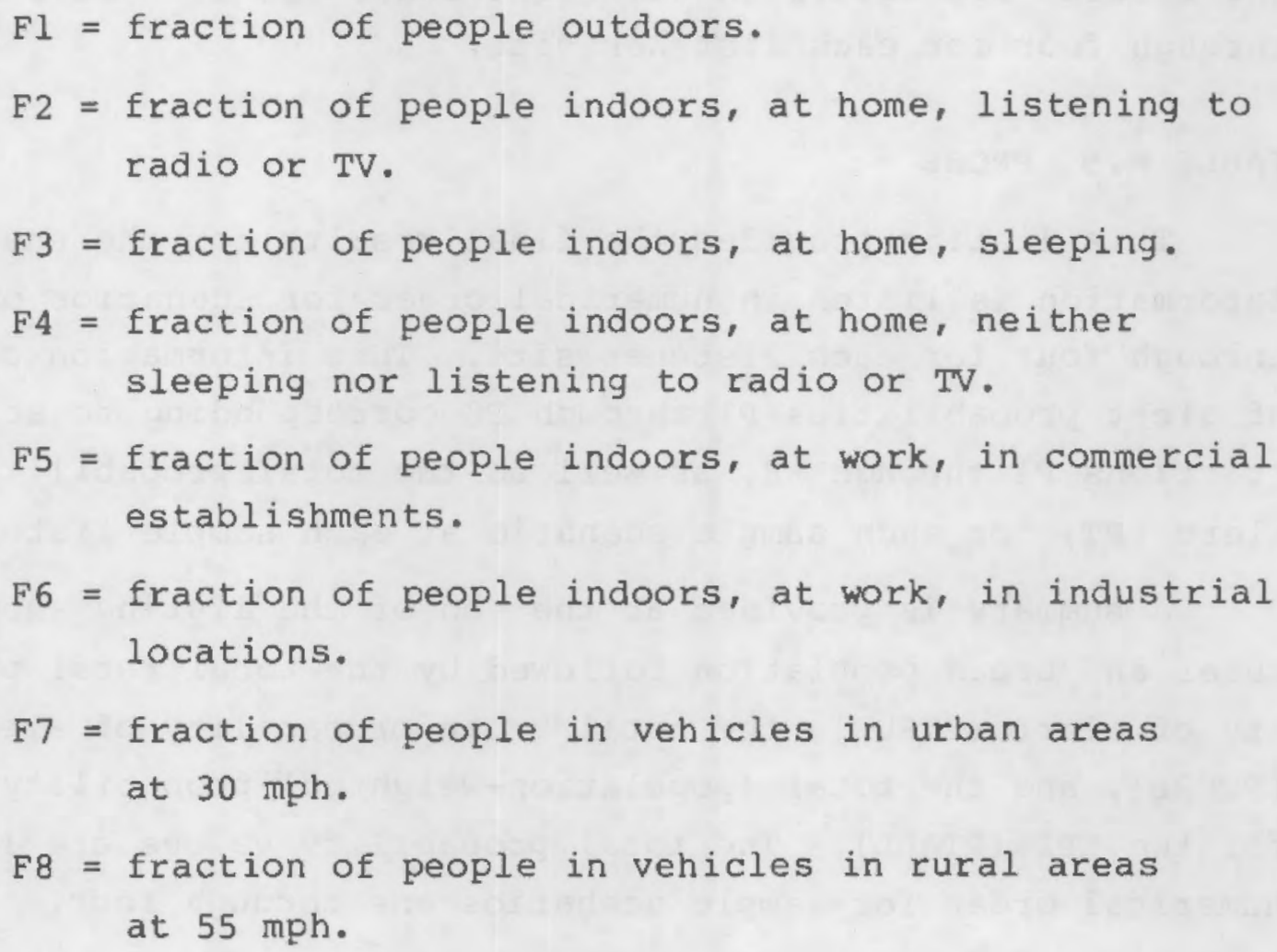

- INP

- PU30

- PR55

- MUL indoor alert probability curve (see Fig. 4-4 of text).

probability of alert for motorists in urban areas at $30 \mathrm{mph}$.

probability of alert for motorists in rural areas at $55 \mathrm{mph}$.

vertical profile of wind speed, $\beta \mathbf{z}$, in $\mathrm{ft} / \mathrm{sec} / \mathrm{ln} \mathrm{ft}$. 
- $\mathrm{ADD}$

vertical profile of air temperature, $a$, in ${ }^{\circ} \mathrm{F} / \mathrm{ln} \mathrm{ft}$.

\section{TABLE M.4 LISTENEROUTPUT}

This listing provides the number, name and outdoor sound pressure level (LOUT, in $\mathrm{dB}$ ) for the "dominant" siren at each sample listener location, for each of the four sample scenarios. The results are listed in numerical order for scenarios one through four for each listener site.

\section{TABLE M.5 PROBS}

This listing provides the final results for the analysis. Information is listed in numerical order for scenarios one through four for each listener site. This information consists of alert probabilities P1 through P8 corresponding to activity fractions Fl through F8, as well as the total probability of alert (PT) for each sample scenario at each sample listener site.

A summary is provided at the end of the listing showing the rural and urban population followed by the total rural probability of alert (PTRUR), the total urban probability of alert (PTURB), and the total (population-weighted) probability of alert for the EPZ (PTALL). The total probability values are listed in numerical order for sample scenarios one through four. 
TABLE M.1

INIIIAN-SIRENS

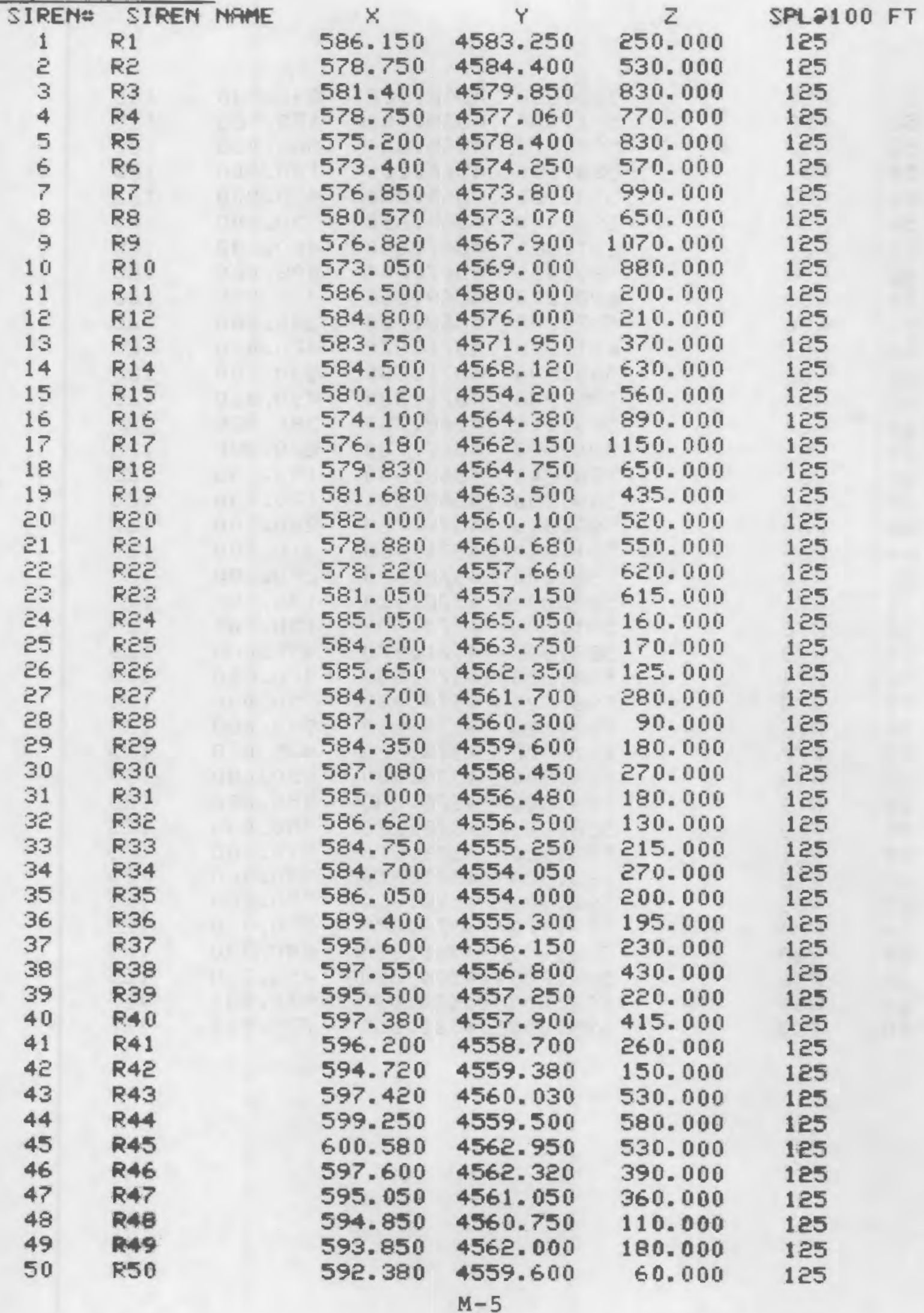


TABLE M.1. (Cont.)

$\begin{array}{ll}51 & R 51 \\ 52 & R 52 \\ 53 & R 53 \\ 54 & R 54 \\ 55 & R 55 \\ 56 & R 56 \\ 57 & R 57 \\ 58 & R 58 \\ 59 & R 59 \\ 60 & R 60 \\ 61 & R 61 \\ 62 & R 62 \\ 63 & R 63 \\ 64 & R 64 \\ 65 & R 65 \\ 66 & R 66 \\ 67 & R 67 \\ 68 & R 68 \\ 69 & R 69 \\ 70 & R 70 \\ 71 & R 71 \\ 72 & R 72 \\ 73 & R 73 \\ 74 & R 74 \\ 75 & R 75 \\ 76 & R 76 \\ 77 & R 77 \\ 78 & R 78 \\ 79 & R 79 \\ 80 & R 80 \\ 81 & R 81 \\ 82 & R 82 \\ 83 & R 83 \\ 84 & R 84 \\ 85 & R 85 \\ 86 & R B 6 \\ 87 & R 87 \\ 88 & R 88\end{array}$

592.350
591.000
593.670
588.550
593.950
596.400
601.620
599.450
602.270
597.300
601.870
598.500
595.900
593.100
590.900
588.200
589.700
589.950
591.350
590.100
588.000
591.600
593.000
594.220
596.620
599.180
601.800
600.500
596.800
598.600
595.920
593.820
590.400
587.170
588.370
590.700
592.500
595.050

$\begin{array}{lll}4562.920 & 230.000 & 125 \\ 4565.100 & 180.000 & 125 \\ 4565.800 & 360.000 & 125 \\ 4566.100 & 100.000 & 125 \\ 4563.330 & 430.000 & 125 \\ 4565.650 & 330.000 & 125 \\ 4567.000 & 460.000 & 125 \\ 4567.700 & 498.000 & 125 \\ 4569.350 & 490.000 & 125 \\ 4568.700 & 290.000 & 125 \\ 4571.870 & 470.000 & 125 \\ 4571.500 & 530.000 & 125 \\ 4571.300 & 490.000 & 125 \\ 4568.750 & 380.000 & 125 \\ 4567.700 & 270.000 & 125 \\ 4568.600 & 150.000 & 125 \\ 4569.500 & 170.000 & 125 \\ 4570.700 & 200.000 & 125 \\ 4571.450 & 310.000 & 125 \\ 4572.450 & 280.000 & 125 \\ 4572.120 & 130.000 & 125 \\ 4574.550 & 150.000 & 125 \\ 4571.970 & 450.000 & 125 \\ 4573.500 & 370.000 & 125 \\ 4574.880 & 750.000 & 125 \\ 4574.550 & 540.000 & 125 \\ 4574.620 & 675.000 & 125 \\ 4576.900 & 650.000 & 125 \\ 4576.300 & 450.000 & 125 \\ 4578.220 & 750.000 & 125 \\ 4579.870 & 510.000 & 125 \\ 4577.450 & 330.000 & 125 \\ 4578.620 & 570.000 & 125 \\ 4576.070 & 250.000 & 125 \\ 4581.350 & 200.000 & 125 \\ 4584.650 & 450.000 & 125 \\ 4580.030 & 570.000 & 125 \\ 4581.650 & 720.000 & 125\end{array}$


TABLE M. 2.

INDI FNERRS

\begin{tabular}{|c|c|c|c|c|c|c|}
\hline SITE & $\Leftrightarrow$ & SITE MAME & $x$ & $Y$ & $z$ & RURAL \\
\hline 1 & R1 & & 587.600 & 4567.820 & 60.000 & FAR \\
\hline 2 & ve & & 590.000 & 4569.950 & 150.000 & - \\
\hline 3 & R3 & & 592.250 & 4570.850 & 380.000 & FAR \\
\hline 4 & U4 & & 584.450 & 4565.120 & 170.000 & - \\
\hline 5 & R5 & & 590.370 & 4564.800 & 150.000 & FAF \\
\hline 6 & R6 & & 583.720 & 4564.600 & 130.000 & FAF \\
\hline 7 & $R 7$ & & 583.350 & 4564.350 & 200.000 & FAIR \\
\hline 8 & 118 & & 586.600 & 4561.220 & 30.000 & - \\
\hline 9 & บ9 & & 586.050 & 4561.600 & 30.000 & - \\
\hline 10 & R10 & & 583.850 & $456 \bar{c} .100$ & 180.000 & FAF \\
\hline 11 & R.11 & & 594.350 & 4564.450 & 490.000 & FAR \\
\hline 12 & u1อ & & 586.820 & 4561.100 & 30.000 & - \\
\hline 13 & R.13 & & 582.550 & 4561.800 & 300.000 & FAR \\
\hline 14 & R14 & & 582.350 & 4561.850 & 340.000 & FAR \\
\hline 15 & R15 & & 586.450 & 4579.100 & 140.000 & NEAR \\
\hline 16 & R 16 & & 589.320 & 4580.100 & 380.000 & NEAR \\
\hline 17 & R17 & & 595.850 & 4576.150 & 500.000 & FAF \\
\hline 18 & R18 & & 596.300 & 4574.900 & 500.000 & FAP \\
\hline 19 & P:19 & & 595.800 & 4562.800 & 350.000 & FAF \\
\hline 20 & บe0 & & 594.100 & 4562.050 & 150.000 & - \\
\hline 21 & Re1 & & 586.750 & 4558.850 & 220.000 & FAF \\
\hline $2 e$ & $\mathrm{Rez}$ & & 581.070 & 4560.400 & 5400.000 & MEAF \\
\hline 23 & $\mathrm{Re3}$ & & 586.350 & 4580.650 & 200.000 & NEAR \\
\hline 24 & UE4 & & 589.950 & 4571.600 & 200.000 & - \\
\hline 25 & Re5 & & 598.850 & $457 \mathrm{c} .650$ & 490.000 & NEAF \\
\hline 26 & R:6 & & 599.850 & 4568.520 & 535.000 & NEAR \\
\hline 27 & $\mathrm{ReT}$ & & 599.150 & 4567.700 & 360.000 & FAF \\
\hline 28 & แอย & & 595.370 & 4559.200 & 380.000 & - \\
\hline 29 & Reg & & 586.000 & 4557.750 & 90.000 & FAF \\
\hline 30 & R30 & & 583.150 & 4557.150 & 285.000 & FAR \\
\hline 31 & R31 & & 579.150 & 4560.220 & 515.000 & FAR \\
\hline 32 & R3e & & 591.320 & 4581.750 & 700.000 & FAR \\
\hline 33 & $\mathrm{R} 33$ & & 596.750 & 4578.270 & 240.000 & FAR \\
\hline 34 & R34 & & 600.100 & 4576.200 & 440.000 & MEAR \\
\hline 35 & R35 & & 598.150 & 4561.600 & 500.000 & MEAR \\
\hline 36 & $R 36$ & & 589.350 & 4555.600 & 145.000 & NEAR \\
\hline 37 & R:S7 & & 582.450 & 4556.600 & 430.000 & FAF \\
\hline 38 & R38 & & 598.850 & 4579.650 & 840.000 & FAR \\
\hline 39 & R39 & & 602.270 & 4570.350 & 440.000 & NEFF \\
\hline 40 & R.40 & & 603.290 & 4569.220 & 460.000 & FAR \\
\hline 41 & R41 & & 589.150 & 4553.570 & 205.000 & NEAR \\
\hline 42 & 142 & & 591.100 & 4570.750 & 310.000 & - \\
\hline 43 & 443 & & 585.150 & 4553.800 & 255.000 & - \\
\hline 44 & U44 & & 585.200 & 4553.350 & 245.000 & - \\
\hline 45 & 145 & & 584.100 & 4553.650 & 280.000 & - \\
\hline 46 & 146 & & 584.150 & 4554.850 & 210.000 & - \\
\hline 47 & $R 47$ & & 583.550 & 4555.100 & 340.000 & FPR \\
\hline 48 & R48 & & 582.150 & 4555.600 & 475.000 & MEAR \\
\hline 49 & $R 49$ & & 580.150 & 4555.750 & 460.000 & FAR \\
\hline 50 & R50 & & 578.550 & 4557.620 & 510.000 & FAR \\
\hline
\end{tabular}


TABLE M. 3.

VAL-HUISDN

SCEN* AMLL WINI NRES NCRM F1 Fe F3 $F 4$ F5 F6 F F F $\begin{array}{llllllllllll} & 0.85 & 158 & 16.31 . & .200 & .200 & .040 & .200 & .230 & .070 & .026 & .034\end{array}$

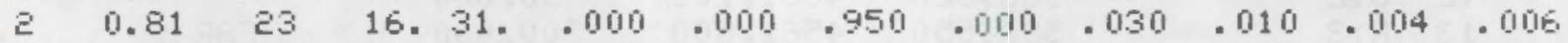

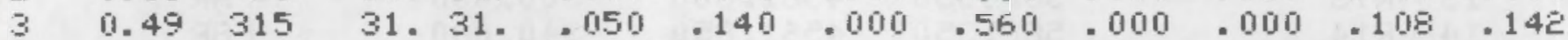

$\begin{array}{lllllllllllll}4 & 0.46 & 135 & 31.31 . & .000 & .000 & .950 & .000 & .040 & .010 & .000 & .000\end{array}$

$\begin{array}{rlllr}\text { IHF } & \text { PU30 } & \text { PR55 } & \text { MUL } & \text { ALII } \\ 1 & 1.000 & 1.000 & 3.750 & -0.350 \\ 3 & 1.000 & 1.000 & 2.250 & 0.170 \\ 3 & 1.000 & 1.000 & 3.750 & -0.170 \\ 1 & 1.000 & 1.000 & 5.620 & -0.170\end{array}$


TABLE M. 4.

LISTENEROUTPUT

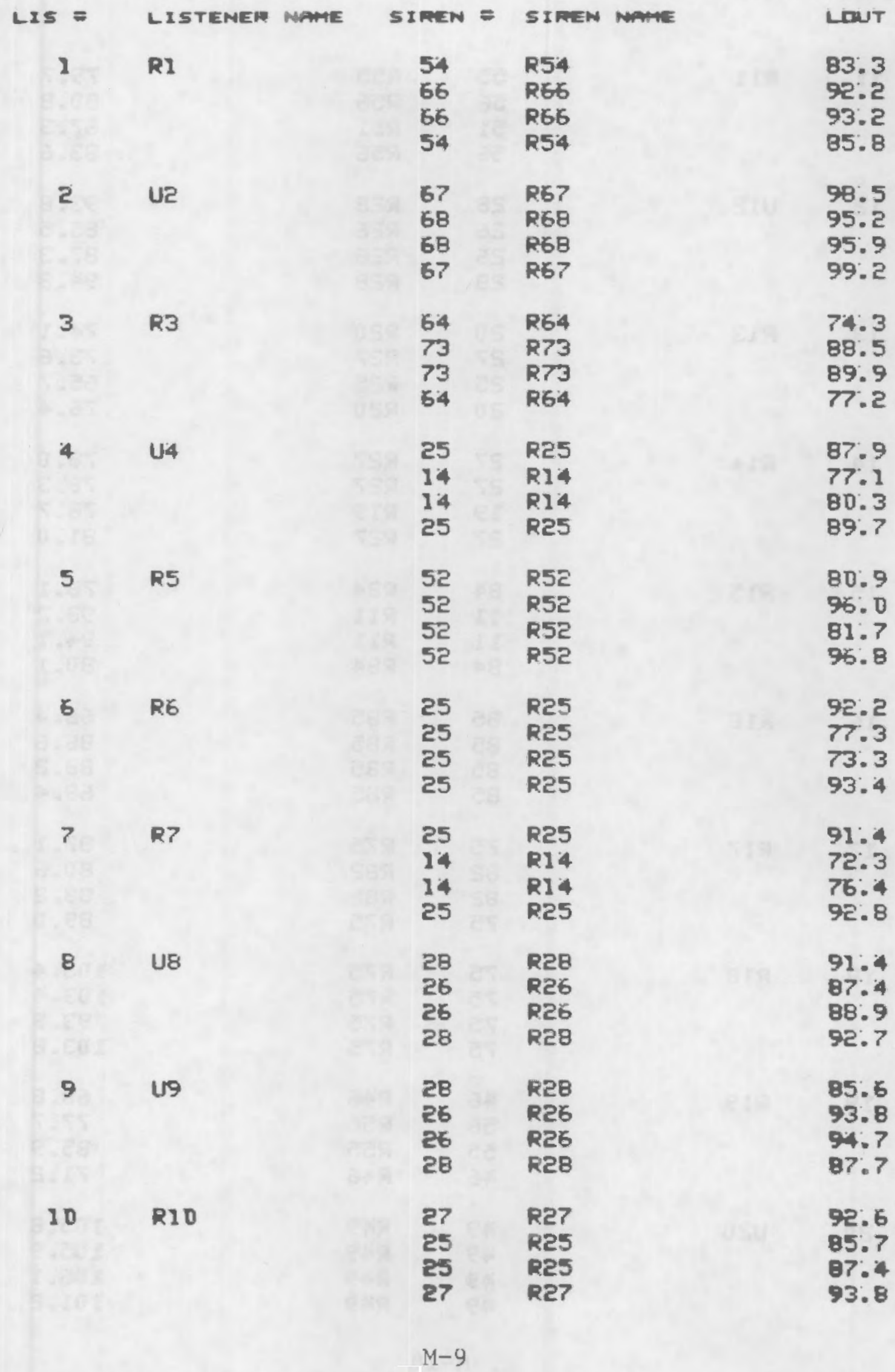


TABLE M.4. (Cont.)

\begin{tabular}{|c|c|c|}
\hline II RII & $\begin{array}{ll}55 & \text { R55 } \\
\mathbf{5 6} & \text { R56 } \\
\mathbf{5 1} & \text { R51 } \\
\mathbf{5 6} & \text { R56 }\end{array}$ & $\begin{array}{l}79: 7 \\
80: 8 \\
67: 3 \\
83: 6\end{array}$ \\
\hline U12 & $\begin{array}{l}\text { R28 } \\
\text { R26 } \\
\text { R26 } \\
\text { R28 }\end{array}$ & $\begin{array}{l}93: 8 \\
85: 5 \\
87: 3 \\
94: 8\end{array}$ \\
\hline R13 & $\begin{array}{ll}20 & \text { R20 } \\
27 & \text { R27 } \\
25 & \text { R25 } \\
20 & \text { R20 }\end{array}$ & $\begin{array}{l}74: 1 \\
73: 6 \\
65: 7 \\
76: 4\end{array}$ \\
\hline R14 & $\begin{array}{l}R 27 \\
R 27 \\
R 19 \\
R 27\end{array}$ & $\begin{array}{l}78: 0 \\
78: 3 \\
76: 7 \\
81: 0\end{array}$ \\
\hline R15 & $\begin{array}{ll}84 & R 84 \\
11 & \text { RII } \\
11 & \text { RII } \\
84 & \text { R84 }\end{array}$ & $\begin{array}{l}76: 1 \\
93: 2 \\
94: 1 \\
80: 1\end{array}$ \\
\hline R16 & $\begin{array}{l}\text { R85 } \\
\text { R85 } \\
\text { R85 } \\
\text { R85 }\end{array}$ & $\begin{array}{l}66: 4 \\
86: 6 \\
88: 2 \\
68.4\end{array}$ \\
\hline RI7 & $\begin{array}{l}R 75 \\
R 82 \\
R 82 \\
R 75\end{array}$ & $\begin{array}{l}\text { B7. } 1 \\
80.6 \\
83.2 \\
89.0\end{array}$ \\
\hline R18 & $\begin{array}{l}R 75 \\
R 75 \\
R>5 \\
R>5\end{array}$ & $\begin{array}{r}103.4 \\
103.4 \\
93.8 \\
103.8\end{array}$ \\
\hline R19 & $\begin{array}{l}R 46 \\
R 56 \\
R 55 \\
R 46\end{array}$ & $\begin{array}{l}68: 8 \\
77: 7 \\
85: 9 \\
71: 2\end{array}$ \\
\hline UटD & $\begin{array}{l}R 49 \\
R 49 \\
R 49 \\
R 49\end{array}$ & $\begin{array}{l}105: 8 \\
105: 9 \\
105: 1 \\
101: 2\end{array}$ \\
\hline
\end{tabular}


TABLE H.4. (Cont.)

\begin{tabular}{|c|c|c|c|c|}
\hline el & R2I & $\begin{array}{l}30 \\
30 \\
30 \\
30\end{array}$ & $\begin{array}{l}\text { R30 } \\
\text { R30 } \\
\text { R30 } \\
\text { R30 }\end{array}$ & $\begin{array}{l}98: 9 \\
94: 0 \\
84: 5 \\
99: 6\end{array}$ \\
\hline 22 & RE2 & $\begin{array}{l}20 \\
20 \\
19 \\
20\end{array}$ & $\begin{array}{l}\text { R2D } \\
\text { R2D } \\
\text { R19 } \\
\text { R20 }\end{array}$ & $\begin{array}{l}92.2 \\
92: 3 \\
79: 6 \\
93.4\end{array}$ \\
\hline 23 & R23 & $\begin{array}{l}11 \\
85 \\
11 \\
11\end{array}$ & $\begin{array}{l}\text { R11 } \\
\text { R85 } \\
\text { R11 } \\
\text { R11 }\end{array}$ & $\begin{array}{l}96: 3 \\
82.1 \\
77: 1 \\
97: 2\end{array}$ \\
\hline 24 & UR4 & $\begin{array}{l}68 \\
70 \\
70 \\
68\end{array}$ & $\begin{array}{l}R 68 \\
R 70 \\
R 70 \\
R 68\end{array}$ & $\begin{array}{l}93: 1 \\
93.7 \\
94.6 \\
94: 2\end{array}$ \\
\hline 25 & R25 & $\begin{array}{l}62 \\
76 \\
76 \\
62\end{array}$ & $\begin{array}{l}R 62 \\
R 76 \\
R 76 \\
R 62\end{array}$ & $\begin{array}{l}89: 7 \\
83: 9 \\
85: 9 \\
91: 3\end{array}$ \\
\hline 26 & R26 & $\begin{array}{l}58 \\
58 \\
58 \\
58\end{array}$ & $\begin{array}{l}\text { R58 } \\
\text { R58 } \\
\text { R58 } \\
\text { R58 }\end{array}$ & $\begin{array}{l}92: 9 \\
73: 1 \\
79: 0 \\
94: 1\end{array}$ \\
\hline 27 & RE7 & $\begin{array}{l}58 \\
58 \\
58 \\
58\end{array}$ & $\begin{array}{l}\text { R58 } \\
\text { R58 } \\
\text { R58 } \\
\text { R58 }\end{array}$ & $\begin{array}{r}104: 2 \\
104.2 \\
99: 6 \\
104: 6\end{array}$ \\
\hline 28 & U28 & $\begin{array}{l}41 \\
42 \\
42 \\
41\end{array}$ & $\begin{array}{l}R 41 \\
R 42 \\
R 42 \\
R 41\end{array}$ & $\begin{array}{l}92: 2 \\
96: 3 \\
97: 0 \\
93: 5\end{array}$ \\
\hline 29 & R29 & $\begin{array}{l}32 \\
30 \\
29 \\
30\end{array}$ & $\begin{array}{l}\text { R32 } \\
\text { R30 } \\
\text { R29 } \\
\text { R30 }\end{array}$ & $\begin{array}{l}87: 9 \\
89: 1 \\
82: 8 \\
90: 5\end{array}$ \\
\hline 30 & R30 & $\begin{array}{l}33 \\
29 \\
29 \\
33\end{array}$ & $\begin{array}{l}\text { R33 } \\
\text { R29 } \\
\text { R29 } \\
\text { R33 }\end{array}$ & $\begin{array}{l}79: 8 \\
78: 7 \\
81: 6 \\
83: 0\end{array}$ \\
\hline
\end{tabular}


TABLE H.4. (Cont.)

\begin{tabular}{|c|c|c|c|}
\hline $31 \quad$ R31 & $\begin{array}{l}21 \\
21 \\
21 \\
22\end{array}$ & $\begin{array}{l}\text { R21 } \\
\text { R21 } \\
\text { R21 } \\
\text { R22 }\end{array}$ & $\begin{array}{l}83: 6 \\
98: 7 \\
99: 3 \\
81: 9\end{array}$ \\
\hline 32 & $\begin{array}{l}83 \\
88 \\
85 \\
83\end{array}$ & $\begin{array}{l}\text { R83 } \\
R 88 \\
\text { R85 } \\
\text { R83 }\end{array}$ & $\begin{array}{l}71: 1 \\
58: 6 \\
62: 7 \\
75: 3\end{array}$ \\
\hline R33 & $\begin{array}{l}79 \\
81 \\
81 \\
79\end{array}$ & $\begin{array}{l}R 79 \\
R 81 \\
R 81 \\
R 79\end{array}$ & $\begin{array}{l}64.6 \\
62: .2 \\
64.1 \\
67.1\end{array}$ \\
\hline R34 & $\begin{array}{l}77 \\
78 \\
78 \\
77\end{array}$ & $\begin{array}{l}R 77 \\
R 78 \\
R 78 \\
R 77\end{array}$ & $\begin{array}{l}80: 9 \\
94: 4 \\
95: 2 \\
83.9\end{array}$ \\
\hline R35 & $\begin{array}{l}46 \\
46 \\
46 \\
44\end{array}$ & $\begin{array}{l}\text { R46 } \\
R 46 \\
R 46 \\
R 44\end{array}$ & $\begin{array}{l}73: 0 \\
93: 1 \\
94: 1 \\
74: 6\end{array}$ \\
\hline R36 & $\begin{array}{l}36 \\
36 \\
36 \\
36\end{array}$ & $\begin{array}{l}\text { R36 } \\
\text { R36 } \\
\text { R36 } \\
\text { R36 }\end{array}$ & $\begin{array}{r}104: 2 \\
99: 2 \\
99: 5 \\
104.5\end{array}$ \\
\hline R37 & $\begin{array}{l}31 \\
31 \\
29 \\
31\end{array}$ & $\begin{array}{l}\text { R3I } \\
\text { R31 } \\
\text { R29 } \\
\text { R3I }\end{array}$ & $\begin{array}{l}79: 4 \\
79: 7 \\
78: 0 \\
82.7\end{array}$ \\
\hline R38 & $\begin{array}{l}80 \\
80 \\
80 \\
80\end{array}$ & $\begin{array}{l}\text { R80 } \\
\text { R8D } \\
\text { R80 } \\
\text { R80 }\end{array}$ & $\begin{array}{l}87: 4 \\
67:-6 \\
69: 1 \\
89: 2\end{array}$ \\
\hline R39 & $\begin{array}{l}59 \\
61 \\
61 \\
59\end{array}$ & $\begin{array}{l}\text { R59 } \\
\text { R61 } \\
\text { R61 } \\
\text { R59 }\end{array}$ & $\begin{array}{l}91: 9 \\
86: 6 \\
88: 2 \\
93.2\end{array}$ \\
\hline$R 40$ & $\begin{array}{l}59 \\
59 \\
59 \\
59\end{array}$ & $\begin{array}{l}R 59 \\
R 59 \\
R 59 \\
R 59\end{array}$ & $\begin{array}{l}71: 6 \\
81: 7 \\
92: 8 \\
72: 9\end{array}$ \\
\hline
\end{tabular}


TABLE M.4. (Cont.)

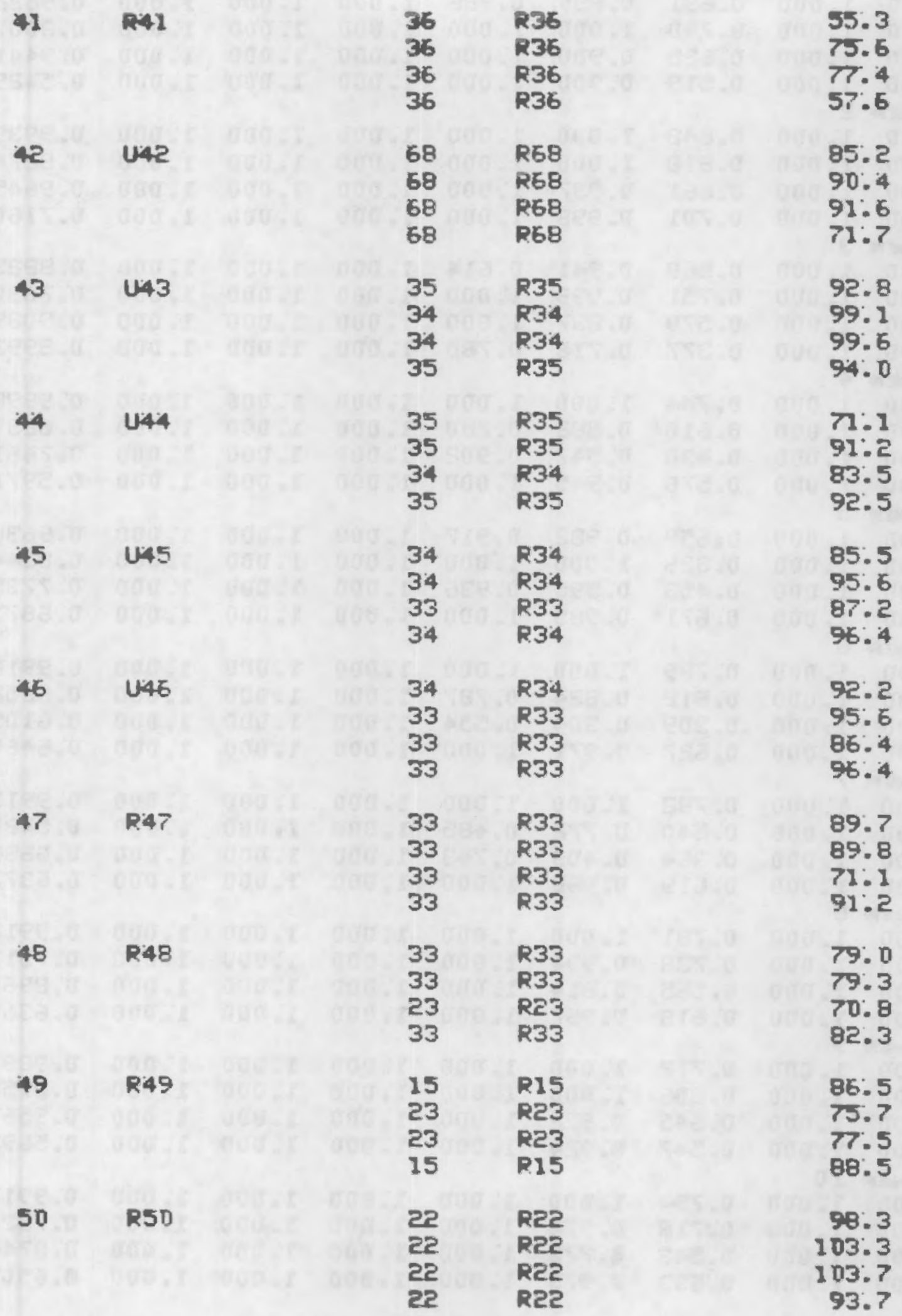


TABLE M. 5 .

PROBS

\begin{tabular}{|c|c|c|c|c|c|c|c|c|}
\hline $\begin{array}{c}\text { Pl } \\
\text { Lisisticinisin }\end{array}$ & ${ }_{1}^{P e}$ & P3 & Fis & PS & P6 & F & Po & PT \\
\hline 1:000 & $1: 000$ & 0.691 & 0.989 & 0.986 & 1:000 & $1: 000$ & $1: 000$ & 0: 9822 \\
\hline $1: 000$ & $1: 000$ & 0.790 & $1: 000$ & 1:000 & $1: 000$ & 1:000 & $1: 000$ & 0.8001 \\
\hline 1:000 & 1:000 & 0.625 & 0.900 & 1:000 & 1:000 & 1:000 & 1:000 & 0.9441 \\
\hline 1:000 & $1: 000$ & 0.519 & 0.900 & $1: 000$ & 1:000 & 1:000 & $1: 000$ & 0.5429 \\
\hline \multicolumn{9}{|c|}{ Lis'sinizin ? } \\
\hline 1:000 & 1:000 & 0.848 & 1:000 & 1:000 & 1:000 & 1:000 & 1:000 & 0.9939 \\
\hline 1:000 & 1:000 & $0: 818$ & 1:000 & $1: 000$ & 1:000 & 1:000 & 1:000 & 0.8274 \\
\hline 1:000 & $1: 000$ & $0: 661$ & 0.937 & 1:000 & 1:000 & 1:000 & 1:000 & 0.9645 \\
\hline 1:000 & 1:000 & $0: 701$ & 0.998 & $1: 000$ & 1:000 & $1: 000$ & $1: 000$ & 0.7160 \\
\hline \multicolumn{9}{|c|}{ Listizinein 3} \\
\hline 1:000 & 1:000 & $0: 569$ & 0.941 & 0.614 & 1:000 & $1: 000$ & 1:000 & 0.8823 \\
\hline 1:000 & 1:000 & $0: 751$ & 0.999 & 1:000 & 1:000 & 1:000 & 1:000 & 0.7630 \\
\hline 1:000 & 1:000 & 0.579 & 0.837 & 1:000 & $1: 000$ & $1: 000$ & 1:000 & 0.9089 \\
\hline 1:000 & 1:000 & 0.377 & $0: 716$ & $0: 780$ & $1: 000$ & $1: 000$ & $1: 000$ & $\mathrm{D} .3993$ \\
\hline \multicolumn{9}{|c|}{ LISTTizNER 4} \\
\hline 1:000 & 1:000 & 0.74 & ס & סD & $1: 000$ & 1:000 & 1:000 & 0.9898 \\
\hline 1:000 & 1:000 & 0.1 & 82 & 80 & ס & 1:000 & 00 & 0.6230 \\
\hline 1:000 & 1.000 & 0.430 & 47 & 02 & 1:000 & 1:000 & $1: 000$ & 0.7461 \\
\hline $1: 000$ & 1:000 & 0.576 & 0.945 & 1:000 & 1:000 & $1: 000$ & $1: 000$ & 0.5971 \\
\hline \multicolumn{9}{|c|}{ LISTENEA 5} \\
\hline 1:000 & 1:000 & 0.659 & 0.982 & 917 & 1.000 & 000 & ס00 & 0.9638 \\
\hline 1:000 & 1:000 & 0.826 & 1:000 & סD & סDa & 000 & 000 & 0.8344 \\
\hline 1:000 & $1: 000$ & 0.453 & 0.595 & 936 & $1: 000$ & $1: 000$ & $1: 000$ & 0.7735 \\
\hline 1:000 & $1: 000$ & 0.671 & 0.985 & 1:000 & $1: 000$ & $1: 000$ & $1: 000$ & 0.6873 \\
\hline \multicolumn{9}{|l|}{ Li STIEMER } \\
\hline 1:000 & $1: 000$ & 0.789 & $1: 000$ & $1: 000$ & 1:000 & 1:000 & $1: 000$ & 16 \\
\hline 1:000 & 1:000 & $0: 612$ & 0.884 & B7 & ס & סטD & סטנ & 52 \\
\hline 1:000 & $1: 000$ & $0: 3$ & 0.304 & 54 & 1:000 & 000 & $1: 000$ & 05 \\
\hline 1:000 & 1:000 & 0.527 & 0.971 & 1:000 & 1:000 & $1: 000$ & $1: 000$ & 0.62 \\
\hline \multicolumn{9}{|l|}{ LIstizinie } \\
\hline 1.000 & 1.000 & 82 & 1:000 & 00 & 000 & DOD & Dot & 0 . \\
\hline 1:000 & $1 \%$ & D: & 72 & 95 & DD & OD & on & \\
\hline $1: 000$ & 1:000 & 0 : & 0.408 & 43 & 1:000 & 000 & 1:000 & D: \\
\hline 1:000 & 1: & D. & 68 & 00 & 1: & 00 & $1:$ & 0: \\
\hline \multicolumn{9}{|l|}{ LIS'TizinE } \\
\hline 1.000 & 1.000 & & 00 & 100 & 000 & 00 & ס0 & D: \\
\hline $1: 000$ & $1:$ & 0 & 24 & 00 & DD & 00 & 00 & 0 . \\
\hline 1.000 & $1: 000$ & 0 : & 0. & 00 & $1: 000$ & 00 & ס0 & D. \\
\hline 1:000 & 1: & D: & 87 & 00 & ס & 00 & 00 & 0 \\
\hline \multicolumn{9}{|l|}{ Lxsirizick } \\
\hline 1:000 & $1: 000$ & D: & 1: & 000 & 1:000 & DOD & 1:000 & D: \\
\hline $1: 000$ & 2:000 & & & 00 & 1:000 & ס & 1:000 & 53 \\
\hline 1:000 & $1: 000$ & 0.545 & 0.922 & 00 & 1:000 & 1:000 & 1:000 & 0.9561 \\
\hline 1:000 & 1:000 & 0.547 & 0.924 & סטו & $1: 000$ & $1: 000$ & 2:000 & 0.5693 \\
\hline \multirow{4}{*}{$\begin{array}{l}1: 000 \\
1: 000 \\
1: 000 \\
1: 000\end{array}$} & & & & & & & & \\
\hline & $2:$ & D. & 2:000 & 00 & 1:000 & 00 & 00 & $0: 9$ \\
\hline & & & & & 1:000 & $\begin{array}{l}00 \\
n n\end{array}$ & & 0.7 \\
\hline & & b. & 73 & & Do & 00 & 1:000 & D.6 \\
\hline
\end{tabular}


TABLE M.5. (Cont.)

LISTEMET 11

1:000 1:000

1:000 1:000

1:000 1:000

1:000 1:000

LISTENER 12

1:000 1:000

1:000 1:000

1:000 1:000

1.000 1:000

LISTENER 13

1:000 1:000

1:000 1:000

1:000 1:000

1:000 1:000

LIstremein 14

1:000 1:000

1:000 1:000

1:000 1:000

1:000 1:000

LISTENER 15

1:000 1:000

1:000 1:000

1:000 1:000

1:000 1:000

LISTENER 16

1.000 1:000

i.000 1:000

1:000 1:000

1.000 1.000

LISTENER 17

1:000 1:000

1:000 1:000

1:000 1:000

1:000 1:000

LISTENER 18

1.000 1:000

1:000 1:000

1:000 1:000

1:000 1:000

LISTENER 19

1:000 1:000

1:000 1:000

1:000 1:000

1.000 1:000

LISTERER 20

1.000 1:000

1.000 1:000

1.000 1:000

$1.000 \quad 1.000$
0. 645

0.659

0.195

0.484

0.805

D. 716

0.540

0.646

0.567

0.561

0.162

0.364

0.621

0.626

D. 369

0.442

0.596

0.799

D. 637

D. 427

0.488

0. 729

D. 555

D. 215

0.735

0.657

0.477

D. 566

0. 887

D. 888

0.632

D. 754

D. 487

D. 617

D. 520

0. 259

D. 905

0.905

D. 779

D. 724
0. 978

0. 935

0.146

D. 864

1:000

D. 973

0.771

0. 978

0. 939

D. 808

D. 116

0.694

0.969

0. 901

0.418

0.812

0.957

1:000

0. 914

0.792

0. 820

0. 981

0.797

D. 521

1:000

0. 933

0.646

D. 938

1:000

1.000

0. 909

1:000

0.818

0. 832

D. 757

D. 921

$0: 726$

1: 000

1. 00

D. 897

D. DoD

1. 000

1:000

0. 001

1.000

0.911

0. 979

1:000

1. 000

1:000

1.000

1:000

0.867

D. 004

0.891

0.733

0.572

0.804

1:000

D.

1.000

1:0Do

1.000

1:000

1:000

1.000

1.000

1:000

1:000

$1: 000$

1.000
1:000

1.000
1:000

1:000

1:000
1:000

1:000

1:000

1:000

1:000

1.000

1:000

1:000

1:000

1:000

1.000

1. 000

1:000

1:000

1:000

1:000

1:000

1:000

1:000

1:000

1:000

1:000

1:000

1. 000

1:000

1:000

1:000

1.000

1:000

1:000

1:000

1.000

1.000

1:000

1:000

1:000

1.000 1:000

1:000 1:000

1.000

1:000

1:000 1:000

1:000 1:000

1:000 1:000

1.000 1:000

1:000 1:000

1:000 1:000

1:000 1:000

1:000 1:000

1. 000

1:000

$1: 0001: 000$
$1.0001: 000$

1.000

1.000

1:000

1:000

1.000

1:000 1:000

1.000 1.000

1:000 1:000

1.000 1.000

1:000 1:000

1.0001 .000
D. 9549

0.6739

D. 5220

0.5091

0.9922

0.7302

D. 8720

0.6639

0. 8798

0. 5698

D. 5047

0. 3853

0. 9369

0.6393

D. 6739

D. 4666

0. 9123

0. 8094

0.9516

0.4518

0.7120

D. 7425

D. 8864

D. 2147

D. 9894

0.6710

0.8018

0.5873

D. 9955

0. 8933

0. 9489

D. 7664

0.7239

0.6304

D. 8504

ठ. 2820

D. 9962

D. 9096

1: 0000

0.7379 
TABLE M.5. (Cont.)

LISTEnTE RI

\begin{tabular}{|c|c|c|c|c|c|c|c|c|}
\hline $1: 000$ & $1: 000$ & 0.852 & 1:000 & 1:000 & 1:000 & 1:000 & 1:000 & 0.9941 \\
\hline $1: 000$ & $1: 000$ & 0.807 & 1.000 & $1: 000$ & $1: 000$ & $1: 000$ & $1: 000$ & 0.8170 \\
\hline 1:000 & $1: 000$ & 0.499 & 0.691 & 0. 999 & 1:000 & סטס & $1: 000$ & 0.8272 \\
\hline 1:000 & $1: 000$ & 0.706 & 0.999 & 1.000 & 1:000 & 1:000 & $1: 000$ & $0: 7205$ \\
\hline LISTERER & 22 & & & & & & & \\
\hline $1: 000$ & $1: 000$ & $0: 789$ & $1: 000$ & 1:000 & 1:000 & 1:00n & $1: 000$ & $0: 9916$ \\
\hline 1.000 & $1: 000$ & 0.790 & $1: 000$ & 1:000 & $1: 000$ & $1: 000$ & 1:000 & 0.8008 \\
\hline 1:000 & $1: 000$ & 0.419 & 0.522 & 0.881 & 1:000 & 1:000 & $1: 000$ & 0.7322 \\
\hline $1: 000$ & $1: 000$ & 0.627 & 0.971 & $1: 000$ & $1: 000$ & $1: 000$ & $1: 000$ & 0.6459 \\
\hline STENEN & 23 & & & & & & & \\
\hline $1: 000$ & $1: 000$ & 0.829 & 1:000 & 1:000 & 1:000 & 1:000 & 1:000 & 0.9932 \\
\hline 1:000 & $2: 000$ & 0.679 & 0.551 & 0.950 & $1: 000$ & 1:000 & $1: 000$ & 0.6935 \\
\hline 1.000 & $1: 000$ & 0.376 & D. 433 & 0.779 & 1:000 & $1: 000$ & $1: 000$ & $0.6 B 24$ \\
\hline $1: 000$ & 1:000 & 0.676 & 0.987 & $1: 000$ & $1: 000$ & $1: 000$ & ססט. & 0.6925 \\
\hline LISTENES & 24 & & & & & & & \\
\hline 1:000 & 1:000 & $0: 798$ & $1: 000$ & 1:000 & 1:000 & 1:000 & 000 & 19 \\
\hline 1:000 & 1:000 & 0.804 & $1: 000$ & 1:000 & סטנ & 00 & סמנ & 38 \\
\hline 1.000 & 1:000 & 0.643 & 0.920 & 1:000 & 1:000 & 1:000 & 000 & 0.9550 \\
\hline 1.000 & $1: 000$ & 0.638 & 0.976 & $1: 000$ & 1.000 & $1: 000$ & 1:000 & 0.6564 \\
\hline LISTENER & 25 & & & & & & & \\
\hline $2: 000$ & $1: 000$ & 0.764 & 00 & 1:000 & 1:000 & 1.001 & 1:000 & 0.9906 \\
\hline 1:000 & $1: 000$ & 0.697 & 0.963 & 0.996 & 1:000 & 1:000 & סט & 18 \\
\hline 1:000 & 1:000 & 0.519 & 0.732 & $1: 000$ & 1:000 & 1:000 & סמס & D. 8500 \\
\hline $1: 000$ & $1: 000$ & 0.598 & 0.958 & $1: 000$ & ס00 & $1: 000$ & 1:000 & 0.6181 \\
\hline I STENER & & & & & & & & \\
\hline 1.000 & $1: 000$ & 0.797 & 00 & 1:000 & 1:000 & 1:000 & 1:000 & $0: 9819$ \\
\hline 1:000 & 1: UDo & 0.552 & 93 & 0.536 & סטו & 1: Don & 1:000 & 0.5604 \\
\hline 1:000 & 1:000 & 0.409 & 0.500 & 0.860 & סטן & $1: 000$ & $1: 000$ & 0.7202 \\
\hline 1.000 & $1: 000$ & 0.637 & 0.975 & $1: 000$ & 1.000 & 1.000 & 1:000 & 0.6547 \\
\hline LISTENER & 27 & & & & & & & \\
\hline $1: 000$ & 1:000 & 0.893 & 1:000 & 1:000 & 1:000 & $1: 000$ & $1: 000$ & 0.9957 \\
\hline $1: 000$ & 1:000 & 0.894 & ספ & 1:000 & סטנ & 1:000 & 000 & 0.8989 \\
\hline 1:000 & 1:000 & 0.705 & 0.968 & 1:000 & 1:000 & 1:000 & 1:000 & 0.9821 \\
\hline 1.000 & 1:000 & D. 762 & 00 & 1:000 & 1:000 & 1:000 & $2: 000$ & 0.7743 \\
\hline LISTEMES & $2 B$ & & & & & & & \\
\hline $1: 000$ & 1:000 & 0.790 & 00 & $1: 000$ & 1:000 & 1:000 & Doo & 0.9 \\
\hline 1:000 & 1:000 & D. 828 & DO & 1:000 & Do & 1:000 & 000 & 0.8 \\
\hline 1:000 & 1: DOD & 0.574 & 47 & 1:000 & I:000 & 1:000 & 000 & 04 \\
\hline 1: Doo & $1: 000$ & 0.628 & 0.972 & 1:000 & $1: 000$ & $1: 000$ & $1: 000$ & 0.6469 \\
\hline LISTREMTH & 2 & & & & & & & \\
\hline 1:000 & 2:000 & 0.744 & DO & 1.000 & סטס & 1:000 & on & D. \\
\hline 1:000 & 1:000 & 0.757 & 100 & 1:000 & 00 & 1:0Do & DD & 88 \\
\hline 1.000 & 1:000 & 0.471 & 0.634 & 0.960 & 00 & 1:000 & 00 & 0.7 \\
\hline 1:000 & 1:000 & $0: 588$ & 0.952 & $1: 000$ & 1:000 & 1:000 & $1: 000$ & 0.6083 \\
\hline LISTEN $=$ & & & & & & & & \\
\hline 1:000 & 1:000 & & & & DO & 1:000 & 1:000 & 0.9560 \\
\hline 1:000 & 2:000 & $0: 6$ & & 949 & 000 & 1:000 & 1:000 & 0.6453 \\
\hline $2: 000$ & 1:000 & 0.451 & 92 & 0.934 & 1:000 & 1:000 & 1:000 & 0.7714 \\
\hline 1.000 & 1:000 & 0.475 & 0.853 & 0.973 & $1: 000$ & 1:000 & 1:0 0 & 0.5000 \\
\hline
\end{tabular}


TABLE M.5. (Cont.)

LISTENT: 31

\begin{tabular}{|c|c|c|c|c|c|c|c|c|}
\hline $1: 000$ & 1:000 & 0.694 & 0.992 & 0.993 & $x: 000$ & 1: Dou & $1: 000$ & 0.9846 \\
\hline ג:000 & $1: 000$ & 0.850 & $1: 000$ & 1:000 & $1: 000$ & $1: 000$ & 1:000 & 0.8577 \\
\hline 1:000 & 1: 000 & b. 702 & 0.966 & 1:000 & $1: 000$ & $\lambda: 000$ & 1:000 & 0.9810 \\
\hline $1: 000$ & $1: 000$ & 0.456 & 0.831 & 0.940 & $1: 000$ & 1:000 & $1: 000$ & \\
\hline TENET & 32 & & & & & & & \\
\hline 1.000 & 1:00D & 0.523 & 0.904 & 0.409 & $1: 000$ & 1:000 & $1: 000$ & 0.8258 \\
\hline .000 & $1: 000$ & 0.313 & 0.312 & $0: 000$ & 00 & DOD & 00 & 0.3174 \\
\hline 000 & 1:000 & 0.100 & 0.071 & 0.000 & סDD & 1.000 & 000 & 0.4796 \\
\hline .000 & I:000 & 0.344 & 0.662 & 0.679 & 00 & 1:000 & 1:000 & 0.3642 \\
\hline & 33 & & & & & & & \\
\hline 00 & 1:000 & 0.419 & 0.779 & $0: 000$ & $1: 000$ & 1:000 & $1: 000$ & 0.7026 \\
\hline 000 & 1:000 & 0.378 & 0.435 & 0.000 & סט, & $1: 000$ & 000 & 0.3788 \\
\hline סDD & 1:000 & 0.129 & ס. & 0.000 & 00 & 1:000 & $1: 000$ & 0.4901 \\
\hline :000 & 1:000 & 0.790 & 0.498 & 0.000 & 1.000 & 1:000 & $1: 000$ & 0.1908 \\
\hline TEMER & 34 & & & & & & & \\
\hline DD & $1: 000$ & 0.660 & 0.98 & 0.918 & סטס & 1:000 & $1: 000$ & 0.9 \\
\hline DD & 1:000 & 0.811 & $1: 000$ & $1: 000$ & 00 & $1: 000$ & 000 & 0.8 \\
\hline 000 & 1:000 & 0.651 & D. 928 & 1.000 & $1: 000$ & 1.000 & $1: 000$ & 0.95 \\
\hline 000 & 1:000 & 0.488 & 0.869 & 0.996 & $1: 000$ & 1:000 & $1: 000$ & 0.513 \\
\hline & 35 & & & & & & & \\
\hline oor & 2:000 & D. & D. & D. & 0 & 000 & 1 & o. \\
\hline 01 & 2:000 & 0.7 & & 1. 000 & 00 & 1: 000 & $1:$ & 0.8 \\
\hline oor & $1: 000$ & 0.6 & D. 5 & 1.000 & ס & $1: 000$ & 300 & 0.9 \\
\hline Dot & & 0.332 & $0.64 \mathrm{C}$ & 0.635 & $1: 000$ & $1: 000$ & $2: 000$ & 0.35 \\
\hline
\end{tabular}

LISTENEN 36

\begin{tabular}{|c|c|c|c|c|c|c|c|c|}
\hline 1.000 & 1:000 & 0.893 & I:D00 & 1:000 & 1:000 & 1:000 & 1:000 & D. 9957 \\
\hline 1:000 & 1:000 & 0.854 & 1.000 & 1:000 & 2:000 & 1:000 & 1:000 & 0.8615 \\
\hline $1: 000$ & 1:000 & 0.705 & D. 968 & 1:000 & $1: 000$ & 1:000 & $1: 000$ & 78 \\
\hline $1: 000$ & 1:000 & 0.762 & $1: 000$ & 1:000 & 1:000 & $1: 000$ & 2: 000 & 0.775 \\
\hline xn & 37 & & & & & & & \\
\hline 1:000 & 1:000 & 0.641 & 0.976 & 0.875 & 1:000 & $1: 000$ & $1: 000$ & D. 9520 \\
\hline 1.000 & $1: 000$ & D. 645 & 0.922 & 0.886 & 00 & 1 & 1:000 & D. \\
\hline $1: 000$ & 1:000 & 0.391 & 0.463 & 0.818 & $1: 000$ & $1:$ & $2: 000$ & 0.699 \\
\hline $1: 000$ & 1:000 & 0.469 & 0.847 & 0.955 & I. & & 00 & 0.2 \\
\hline TEMen & 38 & & & & & & & \\
\hline 1:000 & 1.000 & 0.738 & 1:000 & 1.000 & 1: 000 & $1: 000$ & $1: 000$ & 0.989 \\
\hline 1:000 & 1:000 & D. 468 & 0.627 & D. DOD & Do & 1 & D & D: \\
\hline 1:000 & $1: 000$ & 0.259 & 0.186 & 0.015 & 1 . & 1: & oo & 0.544 \\
\hline 1.000 & 1.000 & 0.569 & 0.941 & 2:000 & 1:000 & L:DoD & $1: 000$ & 0.590 \\
\hline TEME: & 3 & & & & & & & \\
\hline 1.0 & 1:000 & 0.726 & $1: 000$ & 1:000 & $1: 000$ & 1: & 1:000 & 0.991 \\
\hline 1.000 & L: 000 & 0.729 & 0.991 & I. & OD & $1:$ & ססן & $0: 7425$ \\
\hline 2.000 & 2:000 & 0.554 & 0.797 & 2.000 & סמט & I. & סמס & 0.8863 \\
\hline 1.000 & 1.000 & 0.6 .24 & 0.970 & 1.000 & 1:000 & $1: 000$ & ס0 & 0.6 \\
\hline TE & 40 & & & & & & & \\
\hline $1: 80$ & 1:000 & 0.530 & D: & 0: & $\therefore 000$ & & 000 & 0.8 \\
\hline & & 0.570 & & 0.93 & $\mathrm{nn}$ & & oon & $x$ \\
\hline & & 0.6 & 0.-1 & 1.000 & DD & 1. & 000 & 0.9 \\
\hline & $\boldsymbol{T}_{0} 000$ & 0.38 & v: & 0.526 & 100 & 1.80 & סס & D. 31 \\
\hline
\end{tabular}


TABLE M.5. (Cont.)

LISTEMER 41

\begin{tabular}{|c|c|c|c|c|c|c|c|c|}
\hline \multirow{2}{*}{0.751} & \multirow{2}{*}{$1: 000$} & \multirow{2}{*}{0.253} & & & & & \multirow{2}{*}{ 1:Dסט } & \\
\hline & & & & & & & & \\
\hline & $1: 000$ & & 352 & 95 & 00 & & 000 & \\
\hline & 1:000 & .382 & 0.443 & .793 & $: 000$ & 1:000 & $1: 000$ & \\
\hline 0.836 & $1: 000$ & 0.000 & 0.236 & 0.000 & $1: 000$ & 2:D00 & 1:000 & :D. \\
\hline STENER & & & & & & & & \\
\hline 1:000 & 1:000 & 0.713 & $1: 000$ & $\therefore 800$ & 1.000 & 1:000 & 1:000 & \\
\hline $1: 000$ & $1: 000$ & 0.771 & 1.000 & ס0 & 00 & 00 & DD & \\
\hline 1:000 & 1:000 & 0.603 & 0.872 & סDנ & $\mathbf{2}=000$ & 000 & Do & \\
\hline 1:000 & $1: 000$ & 0.279 & D. 581 & 0.448 & 1:000 & DDD & 1:DDD & \\
\hline STENER & & & & & & & & \\
\hline 1.000 & $1: 000$ & 0.796 & 1:000 & 0 & 00 & סD & סטס & \\
\hline $1: 000$ & $1: 000$ & 53 & & & & & & \\
\hline $1: 000$ & 1:000 & D. & 68 & & & & & \\
\hline 1.000 & & 0.635 & & & & & & \\
\hline STEMEF & & & & & & & & \\
\hline 00 & 1: 1 & 3 & 0. & 8 & 2 & ספ & 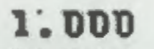 & \\
\hline 1.000 & & 80 & & & & & & \\
\hline 00 & 1: & 0.483 & 0.659 & & & & 00 & \\
\hline 1.000 & $1: 0$ & 0.615 & & & 1. & & & \\
\hline ISTENER & 45 & & & & & & & \\
\hline 1.1 & 1:1 & & 00 & & 1. & & 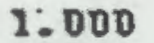 & \\
\hline $1: 000$ & 1: & ट2 & $1: 000$ & & & & 80 & \\
\hline 1.000 & 1:000 & 0.539 & 0.769 & סD & 1:00D & DD & Do & \\
\hline 1:000 & I:DDD & 0.667 & 0.984 & סטו & 1.000 & 00 & D & \\
\hline STENER & & & & & & & & \\
\hline 1 & 1.000 & 0.790 & 1:000 & 00 & Do & & & \\
\hline 1 & 0 & 22 & 1.000 & & & & & \\
\hline 1 & 00 & 7 & 0.746 & & & & & \\
\hline 1.1 & 1: & 0. & 0.984 & 0 & Do & 0 & 0 & \\
\hline I STENER & 47 & & & & & & & \\
\hline & 1: & & & & & & & \\
\hline & & & & & & & & \\
\hline 1:000 & & & 38 & & & & & \\
\hline 1:000 & & $\mathbf{D}$ & $0:$ & & & & & \\
\hline STENER & 4 & & & & & & & \\
\hline 1:000 & 1: & & 0 . & & & & & \\
\hline r. DDD & & & & & & & & \\
\hline & & & & & & & & \\
\hline 1:000 & & & D. & $\mathbf{n}$ & & D & 0 & \\
\hline NER & 4 & & & & & & & \\
\hline 1:000 & 00 & & & & & & & \\
\hline 1.000 & & & & & & & & \\
\hline $1: 000$ & $1: 000$ & & 0.446 & & & & Do & \\
\hline 1:000 & $1: 000$ & 0.559 & 0.934 & DO & 1:000 & oo & 000 & 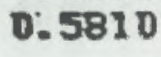 \\
\hline & & & & & & & & \\
\hline & & D. & $\therefore: 000$ & & & & 00 & \\
\hline & & & & & & & & \\
\hline & & & & & & & & \\
\hline$\therefore$ & & & D. 973 & 00 & & 10 & DOD & \\
\hline
\end{tabular}

RUAML, URPAN POPULATIONS ? I46454; II U9:A

\begin{tabular}{|c|c|c|}
\hline $\begin{array}{l}\text { Thum } \\
\text { B: } 931 \\
0: 701 \\
0: 775 \\
0: 507\end{array}$ & $\begin{array}{r}\text { Prune } \\
0.979 \\
0.800 \\
.909 \\
.829\end{array}$ & $\begin{array}{l}\text { PтиL } \\
\text { 0. } 951 \\
0.74 \\
\text { 8. } 833 \\
0.571\end{array}$ \\
\hline
\end{tabular}




\section{APPENDIX N: RANDOM SELECTION OF POPULATION-WEIGHTED LISTENING POINTS AT THE ZION SITE}

The objective of the listener-site-selection process was to identify 50 randomly selected building locations within the EPZ surrounding the $\mathrm{Z}$ ion Nuclear Plant. These locations are assumed to be residential locations and are called "listener sites."

The various steps used in the site selection procedure are described below:

1. A population-distribution map (see Fig. N-1) consisting of a 10-mile-radius circle divided into annular sectors defined by interior circles and radii, was superimposed on topographical maps of the EPZ. Population distribution information consisted of the number of people within each annular sector. These data were used in order to population-weight the random selection process described below.

2. Each annular sector was first assigned a designator, ranging between $\mathrm{A}-1$ and $\mathrm{R}-6$ (see Fig. N-1). A range of numbers was then assigned to each sector according to the population in that sector. For example, Sector A-1, just north of the site, has a population of 99 and was assigned numbers 1 through 99. Sectors B-l through L-1 (moving clockwise over Lake Michigan) have zero population and thus were not assigned any numbers. Sector $\mathrm{M}-1$ has a population of 204 and was assigned numbers 100 to 303 . Sector $\mathrm{N}-1$ has a population of 440 and was assigned numbers 304 through 743. This process was continued until each number between 1 and 301,830 (the total estimated population) was assigned to a particular sector. A random number generator lavail- 
able on a Texas Instruments Model TI-59 hand calculator, for example) was then used to select 50 numbers at random between 1 and 301,830. Each number selected represented one site (to be chosen later) within the sector containing that number. Thus, sectors with larger populations had a greater possibility of including chosen listener sites.

3. Having determined the sector locations of each potential listener site, the next step in the procedure involved selecting the actual sites within the respective sectors. This was accomplished by first over-laying a rectangular coordinate grid on each sector of interest on the topographic map. The grid was composed of boxes with dimensions of approximately 1000 feet square, and each box was assigned an $\mathrm{X}$ and a $\mathrm{Y}$ coordinate according to its location on the grid. The grid was positioned such that the $x$-axis was oriented in the east-west direction and the $\mathrm{Y}$-axis was oriented in the north-south direction, and such that all parts of the sector of interest were covered by a positive $(X, Y)$ coordinate pair box. A random number generator was then used to select random pairs of numbers within the $\mathrm{X}$ and $\mathrm{Y}$ ranges covering the sector of interest. Each $X, Y$ pair was used to select a particular 1000 feet square box on the map. If there were buildings within the box, one of them was arbitrarily chosen as a listener site. If there were no buildings inside the box or if the box fell outside of the sector of interest, that coordinate pair was disregarded and another pair was chosen at random. 
For urban sites in the pink "building-extension" area of the topographic map a residential building was always assumed to exist, and was selected at the center of the pink area in the 1000 feet square box.

4. The above process was repeated until 50 listener sites were randomly chosen. It was found, however, that some of the chosen sites did not properly reflect the population distribution in the EPZ. Therefore, the selection process was continued until this condition was rectified. In particular, six new urban sites were randomly chosen within the city of Kenosha, wisconsin to replace the six sites chosen within the Great Lakes Naval Training Center, which has its own warning system. In addition, the EPZ was assumed to extend about 3 miles north of the $10 \mathrm{mile}$ circle for the purposes of listener site selection, so as to include the entire city of Kenosha. As a result, four of the sample listener sites are located beyond the 10 mile circle in Kenosha. (This was done in response to a request by representatives of the city of Kenosha, since Kenosha has an existing emergency siren system throughout the city that will make up part of the warning system for zion.)

The above procedure resulted in a pseudo-random sample of 50 specific listener locations, distributed throughout the EPZ as shown roughly on Fig. $\mathrm{N}-1$. 


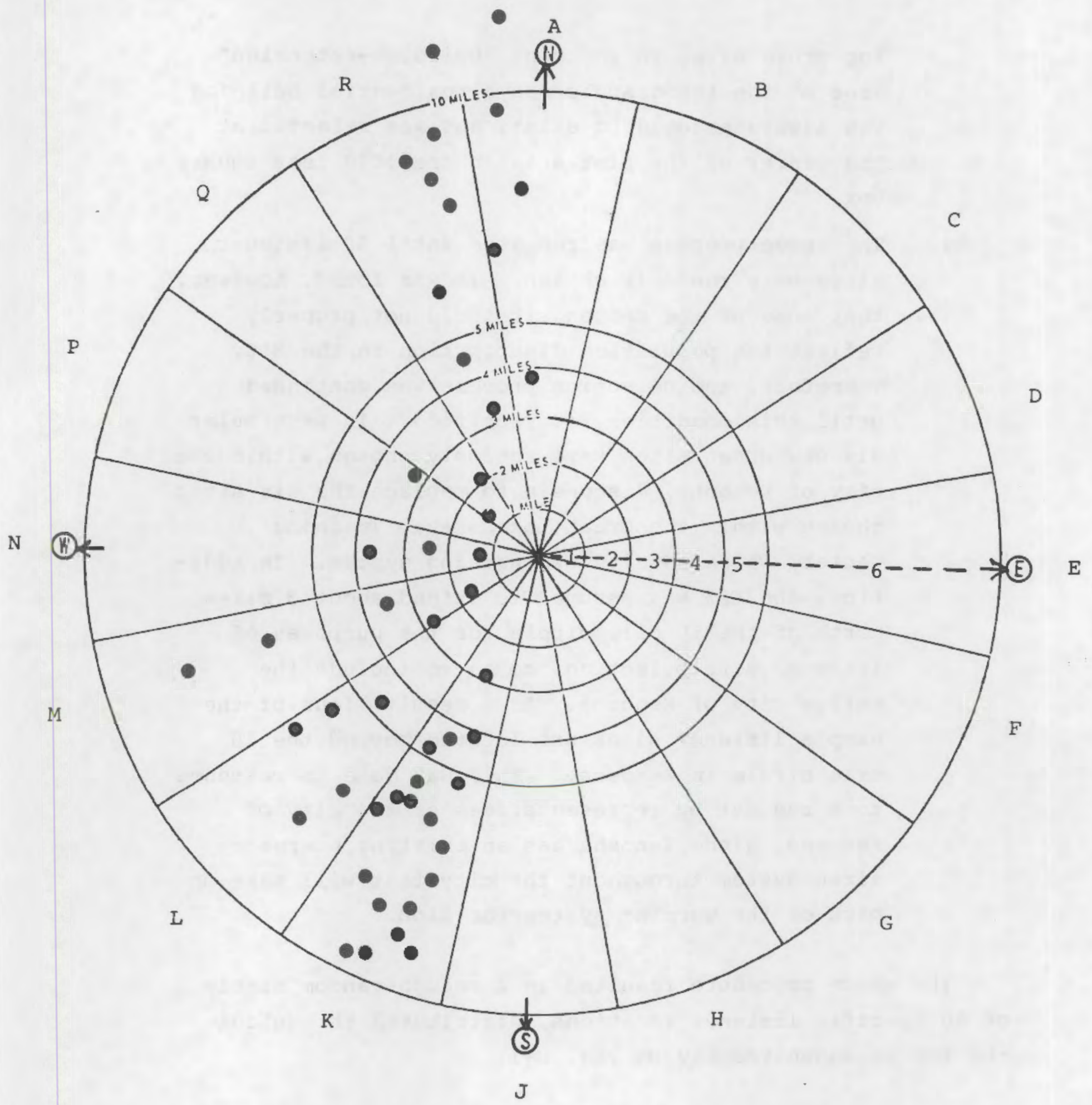

FIG. N-1. RANDOMLY SELECTED LISTENER SITES (APPROX.) AT THE ZION SITE. 


\section{APPENDIX O: SAMPLE SCENARIOS FOR THE EVALUATION OF SIREN ALERTING AT ZION.}

\begin{tabular}{|c|c|c|c|c|}
\hline \multicolumn{5}{|l|}{ Scenar1o } \\
\hline Season & Summer & Summer & Winter & Winter \\
\hline Time of Day & $\begin{array}{l}\text { Weekday } \\
\text { Afternoon } \\
(7 / 11 / 80 \\
\text { d } 1500)\end{array}$ & $\begin{array}{l}\text { Late Night } \\
(7 / 17 / 30 \\
\text { (a 0200) }\end{array}$ & $\begin{array}{l}\text { Weekday } \\
\text { Evening(Rush } \\
1 / 30 / 80 \mathrm{hr} \text { ) } \\
\text { (d } 1800)\end{array}$ & $\begin{array}{l}\text { Late Night } \\
(1 / 7 / 80 \\
\text { e 0200) }\end{array}$ \\
\hline General Weather & $\begin{array}{l}\text { Warm, Clear } \\
\text { to Partly } \\
\text { Cloudy }\end{array}$ & $\begin{array}{l}\text { Warm, Clear } \\
\text { to Partly } \\
\text { Cloudy }\end{array}$ & $\begin{array}{l}\text { Cold, Over- } \\
\text { cast, Light } \\
\text { Precipita- } \\
\text { tion }\end{array}$ & Windy \\
\hline Home/Vehicle Windows & Open & Open & $\begin{array}{l}\text { Closed } \\
\text { (\& Storms) }\end{array}$ & $\begin{array}{l}\text { Closed } \\
\text { (\& Storms) }\end{array}$ \\
\hline Temperature, ${ }^{\circ} \mathrm{F}$ (235' & $71^{\circ} \mathrm{F}$ & $70^{\circ}$ & $17^{\circ}$ & $13^{\circ}$ \\
\hline Dew Point ${ }^{\circ} \mathrm{F}$ & $62^{\circ}$ & $61^{\circ}$ & $16^{\circ}$ & $7.4^{\circ}$ \\
\hline $\begin{array}{l}\text { Temperature Difference } \\
\mathrm{O}_{\mathrm{F}} \text { (meas. heights }= \\
\left.125^{\prime} \& 35^{\prime}\right)\end{array}$ & $-1.3^{\circ}$ & $+1.1^{\circ}$ & $-0.7^{\circ}$ & $-0.8^{\circ}$ \\
\hline \multirow{2}{*}{\multicolumn{5}{|c|}{$\begin{array}{l}\text { Wind Direction: } \\
\text { General }\end{array}$}} \\
\hline & $130^{\circ}$ & $290^{\circ}$ & $328^{\circ}$ & $251^{\circ}$ \\
\hline $\begin{array}{l}\text { Wind Speed, mph } \\
\text { (meas. height } 125^{\prime} \text { ) } \\
\text { (meas. height }=35^{\prime} \text { ) }\end{array}$ & $\begin{array}{r}11.1 \\
6.9\end{array}$ & $\begin{array}{r}11.7 \\
6.1\end{array}$ & $\begin{array}{r}10.8 \\
7.9\end{array}$ & $\begin{array}{l}33 \\
22\end{array}$ \\
\hline & Percent of & eople Located & & \\
\hline Outdoors & $20 \%$ & - & $5 \%$ & - \\
\hline In Motor Vebicles & 6 & $1 \%$ & 25 & - \\
\hline Indoors at Work: & & & & \\
\hline Commercial & 23 & 3 & - & $4 \%$ \\
\hline Industrial & 7 & 1 & - & 1 \\
\hline In Home-Sleeping & 4 & 95 & - & 95 \\
\hline In Home-Rad1o/TV & 20 & - & 14 & - \\
\hline In Home-Noisy & - & - & 3 & - \\
\hline In Home-Active & 6 & - & 35 & - \\
\hline In Home-Isolated & 4 & - & 14 & - \\
\hline In Home-Quiet & 10 & - & 4 & - \\
\hline
\end{tabular}




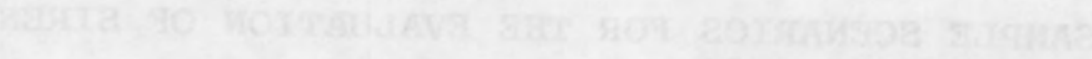

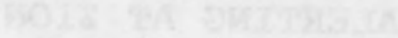

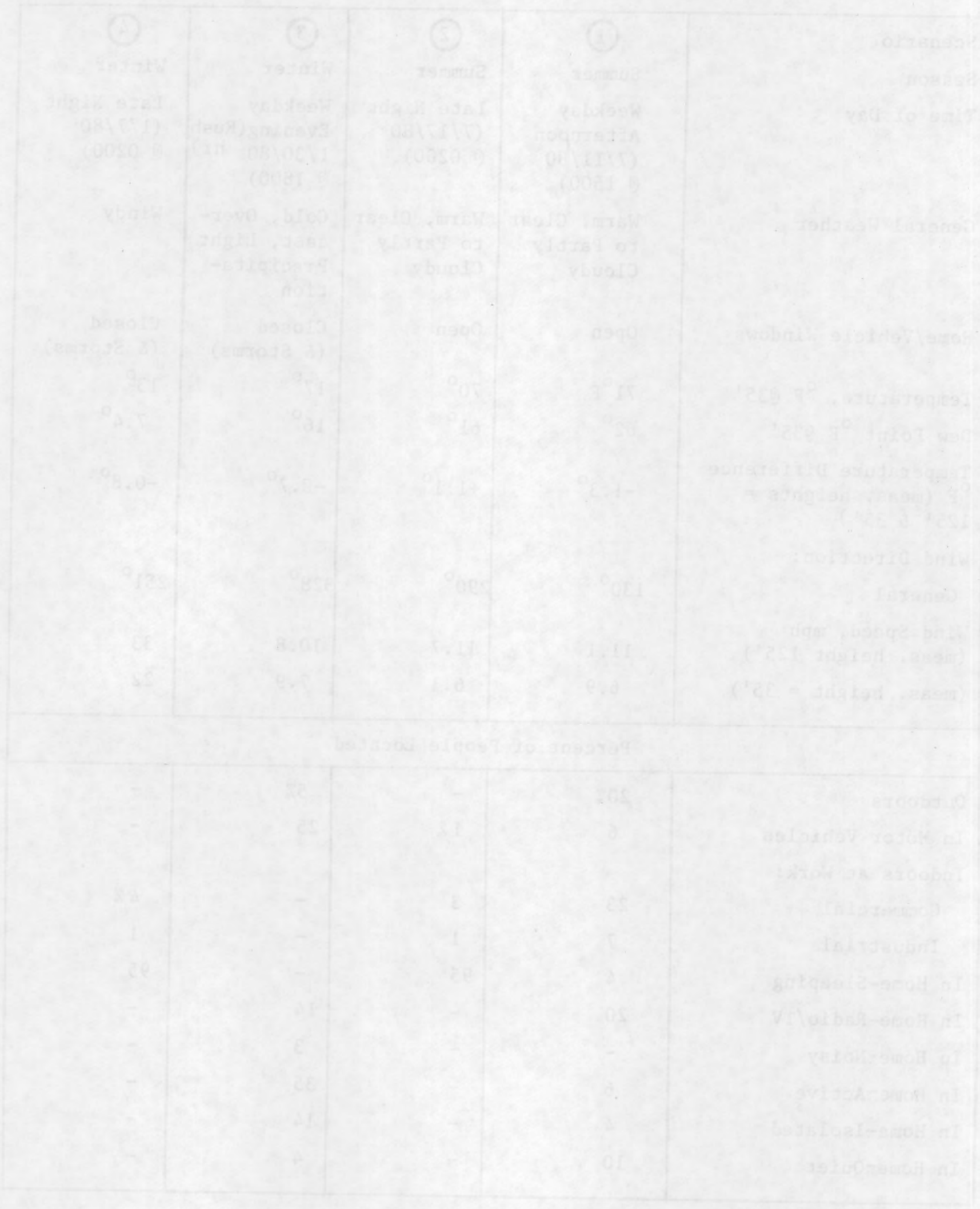




\section{APPENDIX P: SIREN LOCATIONS FOR THE ZION EPZ}

This appendix provides existing and proposed siren locations for the Zion EPZ as of 15 October 1981. Siren locations are provided on a set of topographial maps (Figs. P-2 through $P-6$ ). Figure $P-1$ shows the relationship of the individual maps to the zion EPZ.

A total of 66 sirens are employed, 39 of which are existing and 27 of which are proposed. The proposed sirens are identified using Commonwealth Edison (CE) or Wisconsin Electric (WE) prefixes. Existing sirens have been numbered arbitrarily, using the prefix "I" for those located in Illinois and " $W$ " for those located in Wisconsin. Table P.I provides information on the type, rating, mounting height and status of each siren, as well as a guide for locating the sirens on the topographical maps. 
TABLE P.1. ZION SIREN INFORMATION

\begin{tabular}{|c|c|c|c|c|c|}
\hline $\begin{array}{l}\text { Siren } \\
\text { W. }\end{array}$ & Type & $\begin{array}{c}\text { Pated SPL } \\
(\mathrm{dBC} \text { e } 100 \mathrm{ft} .)\end{array}$ & $\begin{array}{l}\text { Approx. } \\
\text { Mounting } \\
\text { Height (ft) }\end{array}$ & Status & $\begin{array}{l}\text { Location } \\
\text { (Nap Figure } \\
\text { No.) }\end{array}$ \\
\hline $\mathrm{CE}-1$ & Stationary & 115 & 55 & Proposed & $B-6$ \\
\hline $\mathrm{CE}-2$ & Stationary & 115 & 55 & Proposed & $B-5$ \\
\hline $\mathrm{CE}-3$ & Rotating & 123 & 55 & Proposed & $B-5$ \\
\hline $\mathrm{CE}-4$ & Stationary & 115 & 55 & Proposed & $B-5$ \\
\hline $\mathrm{CE}-5$ & Rotating & 126 & 55 & Proposed & $B-5$ \\
\hline $\mathrm{CE}-6$ & Rotating & 123 & 55 & Proposed & $B-3$ \\
\hline$C E-7 A$ & Rotating & 126 & 55 & Proposed & $B-4$ \\
\hline $\mathrm{CE}-8 \mathrm{~B}$ & Rotating & 126 & 55 & Proposed & $B-4$ \\
\hline $\mathrm{CE}-9$ & Rotating & 126 & 55 & Propased & $B-4$ \\
\hline CE-10 & Rotating & 126 & 55 & Proposed & $B-4$ \\
\hline $\mathrm{CE}-11$ & Rotating & 124 & 55 & Proposed & $B-4$ \\
\hline CE-12 & Rotating & 124 & 55 & Proposed & $B-4$ \\
\hline $\mathrm{CE}-13$ & Rotating & 123 & 55 & Proposed & $B-4$ \\
\hline $\mathrm{CE}-14$ & Rotating & 126 & 55 & Proposed & $B-4$ \\
\hline $\mathrm{CE}-15$ & Rotating & 124 & 55 & Proposed & $B-4$ \\
\hline CE-16A & Rotating & 126 & 55 & Proposed & B- 4 \\
\hline $\mathrm{CE}-17$ & Rotating & 126 & 55 & Proposed & $B-4$ \\
\hline CE-18 & Rotating & 126 & 55 & Proposed & $B-4$ \\
\hline $\mathrm{CE}-19$ & Rotating & 123 & 55 & Proposed & $B-4$ \\
\hline $\mathrm{CE}-20$ & Stationary & 115 & 55 & Proposed & $B-4$ \\
\hline $\mathrm{CE}-21$ & Stationary & 115 & 55 & Proposed & $B-4$ \\
\hline
\end{tabular}


TABLE P.1. ZION SIREN INFORNATION (Oont.)

\begin{tabular}{|c|c|c|c|c|}
\hline $\begin{array}{l}\text { Sire } \\
\text { No. }\end{array}$ & Type & $\begin{array}{c}\text { Pated SPL } \\
(\mathrm{dBC} \text { e } 100 \mathrm{ft.})\end{array}$ & $\begin{array}{l}\text { Approx. } \\
\text { Hounting } \\
\text { Height (ft) }\end{array}$ & $\begin{array}{l}\text { Location } \\
\text { (1ap Figure } \\
\text { No.) }\end{array}$ \\
\hline
\end{tabular}

$\begin{array}{lccclc}\text { WE-1 } & \text { Rotating } & 126 & 55 & \text { Proposed } & \text { B-2 } \\ \text { WE-2 } & \text { Stationary } & 115 & 55 & \text { Proposed } & \text { B-2 } \\ \text { WE-3 } & \text { Stationary } & 115 & 55 & \text { Proposed } & \text { B-2 } \\ \text { WE-4 } & \text { Rotating } & 124 & 55 & \text { Proposed } & \text { B-2 } \\ \text { WE-6 } & \text { Rotating } & 124 & 55 & \text { Proposed } & \text { B-4 } \\ \text { WE-7 } & \text { Rotating } & 126 & 55 & \text { Proposed } & \text { B-4 }\end{array}$

I-1 Rotating 125

125

40

Existing

B-6

I-2 Potating 125

40

Existing

B-6

I-3 Rotating 125

40

Existing

B-6

$\mathrm{I}-4$

Rotating

125

40

Existing

B-6

I-5 Rotating 125

40

Existing

B-6

I-6 Rotating 125

40

Existing

B-6

I-7 Rotating

125

40

Existing

B-6

I-8 Rotating 125

40

Existing

$B-6$

I-9 Stationary

115

I-10 Rotating

125

I-11 Stationary

115

I-12 Stationary

115

I-13 Rotating

125

35

Existing

B-6

50

Existing

B-6

40

Existing

B-6

30

Existing

B-6

30

Existing

B-6

I-14 Stationary 115

I-15 Rotating 125

40

Existing

B-6

40

Existing

B-6

I-16 Stationary

115

35

Existing

B-6 
TABLE P.1. ZION SIREN INFOREATION (Cont.)

\begin{tabular}{|c|c|c|c|c|c|}
\hline $\begin{array}{l}\text { Siren } \\
\text { No. }\end{array}$ & Type & $\begin{array}{c}\text { Pated SPL } \\
(\mathrm{dBC} \text { e } 100 \mathrm{ft} .)\end{array}$ & $\begin{array}{l}\text { Approx. } \\
\text { Mounting } \\
\text { Height (ft) }\end{array}$ & Status & $\begin{array}{l}\text { Location } \\
\text { (Map Figure } \\
\text { No.) }\end{array}$ \\
\hline I -17 & Rotating & 125 & 40 & Existing & $B-6$ \\
\hline$I-18$ & Stationary & 115 & 40 & Existing & $B-6$ \\
\hline$I-19$ & Stationary & 115 & 40 & Existing & $B-6$ \\
\hline$I-20$ & Rotating & 125 & 25 & Existing & $B-4$ \\
\hline$I-21$ & Stationary & 115 & 40 & Existsing & $B-4$ \\
\hline$I-22$ & Stationary & 115 & 40 & Existing & $B-4$ \\
\hline$I-23$ & Stationary & 115 & 25 & Existing & $B-4$ \\
\hline$w-1$ & Rotating & 125 & 40 & Existing & $B-2$ \\
\hline$w-2$ & Rotating & 125 & 50 & Existing & $\mathrm{B}-2$ \\
\hline W-3 & Rotating & 125 & 25 & Existing & $B-2$ \\
\hline W-4 & Rotating & 125 & 50 & Exiting & $B-2$ \\
\hline$w-5$ & Fotating & 125 & 40 & Existing & $B-2$ \\
\hline$w-6$ & Potating & 125 & 60 & Existing & $B-2$ \\
\hline$w-7$ & Stationary & 100 & 40 & Existing & $B-2$ \\
\hline$w-8$ & Rotating & 125 & 40 & Existing & $B-2$ \\
\hline $\mathrm{W}-9$ & Rotating & 125 & 60 & Existing & $B-2$ \\
\hline$W-10$ & Stationary & 100 & 40 & Existing & $B-2$ \\
\hline$W-11$ & Fotating & 125 & 60 & Existing & $B-2$ \\
\hline W-12 & Rotating & 125 & 40 & Existing & $B-2$ \\
\hline$w-13$ & Rotating & 125 & 50 & Existing & $B-2$ \\
\hline W-14 & Rotating & 125 & 50 & Existing & $\mathrm{B}-2$ \\
\hline$W-15$ & Rotating & 125 & 40 & Existing & $B-2$ \\
\hline$W-16$ & Stationary & 100 & 50 & Existing & $B-2$ \\
\hline
\end{tabular}




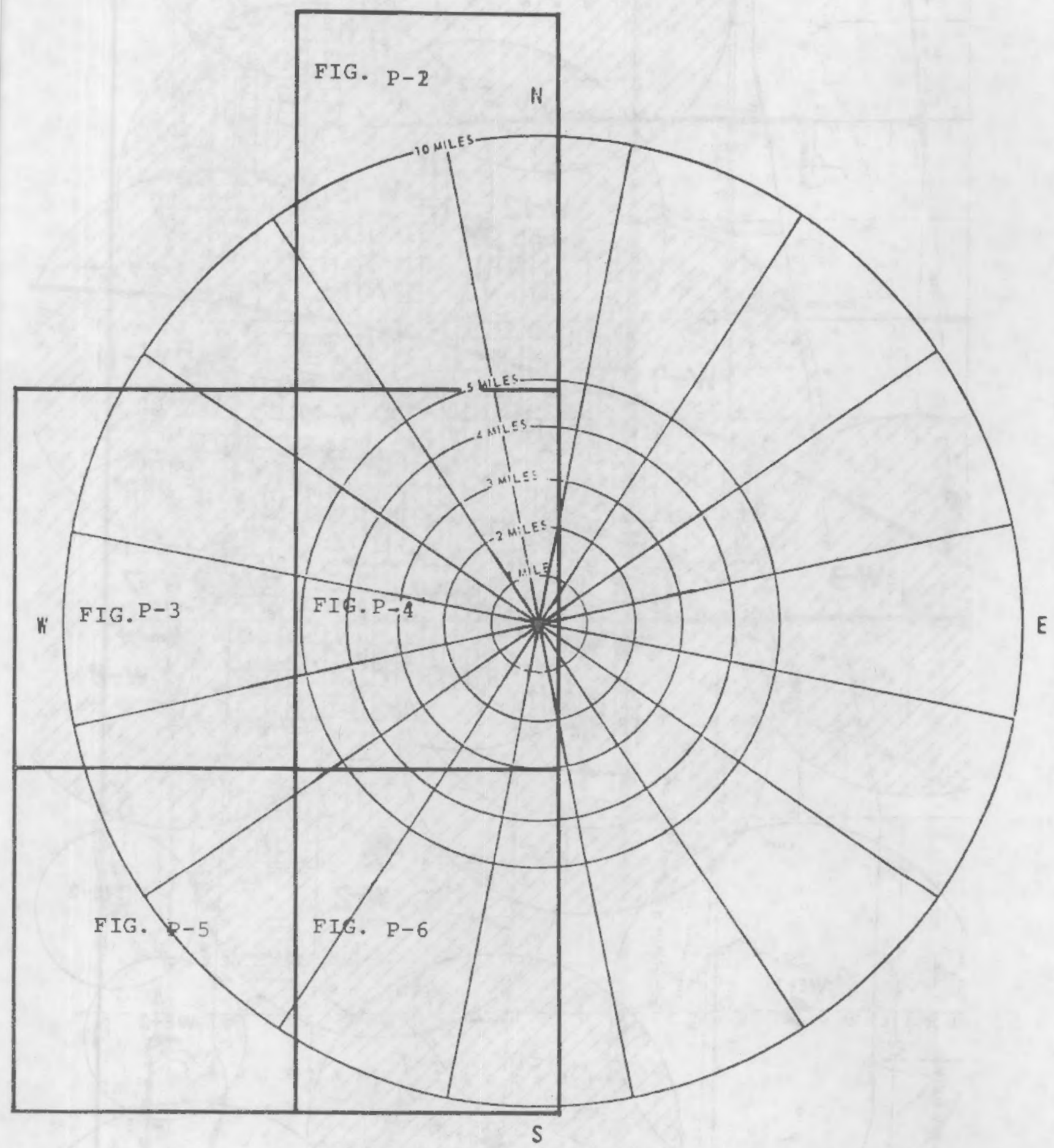

FTG. P-1. ZION SIREN MAP LOCATOR. 


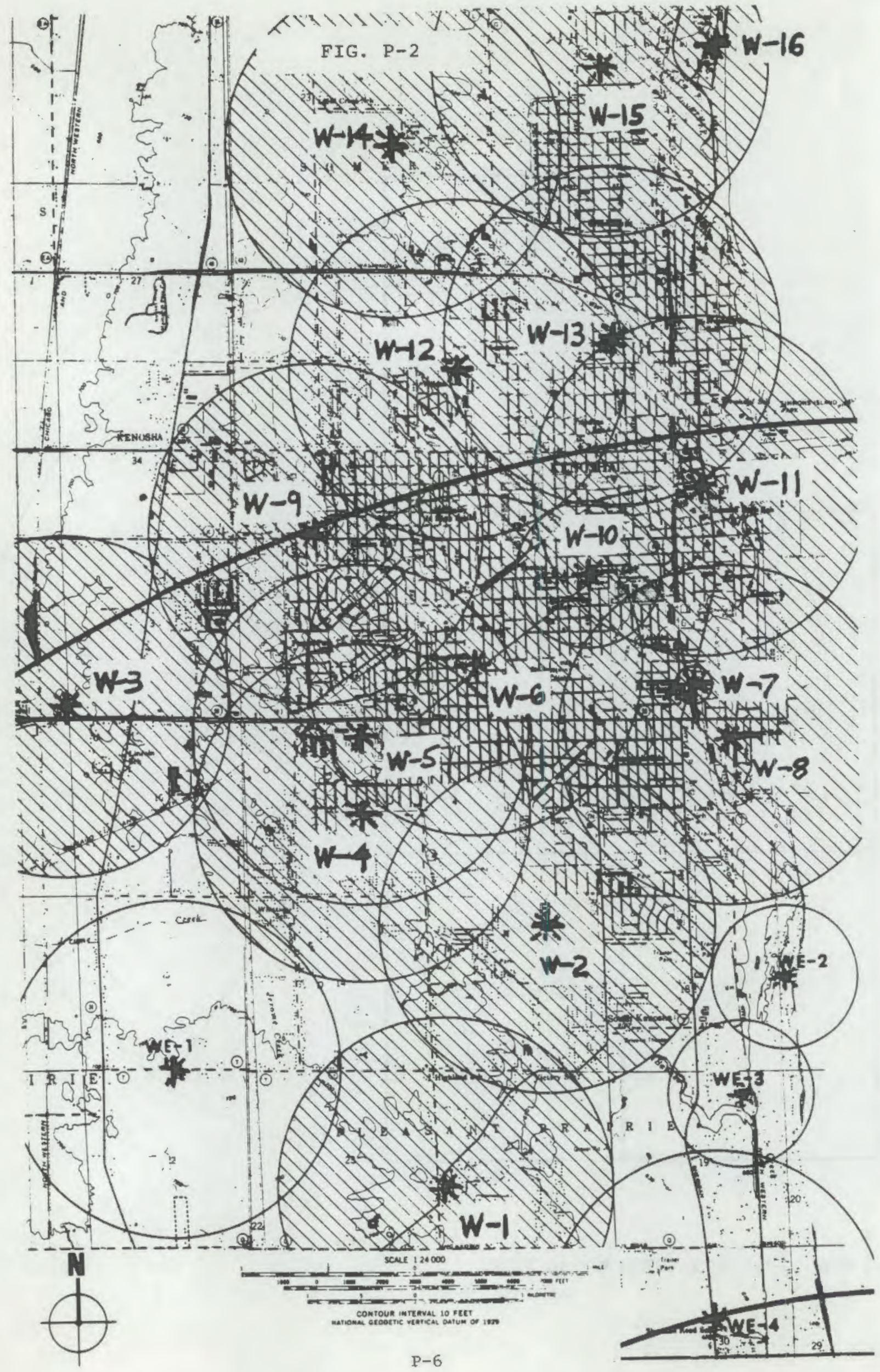




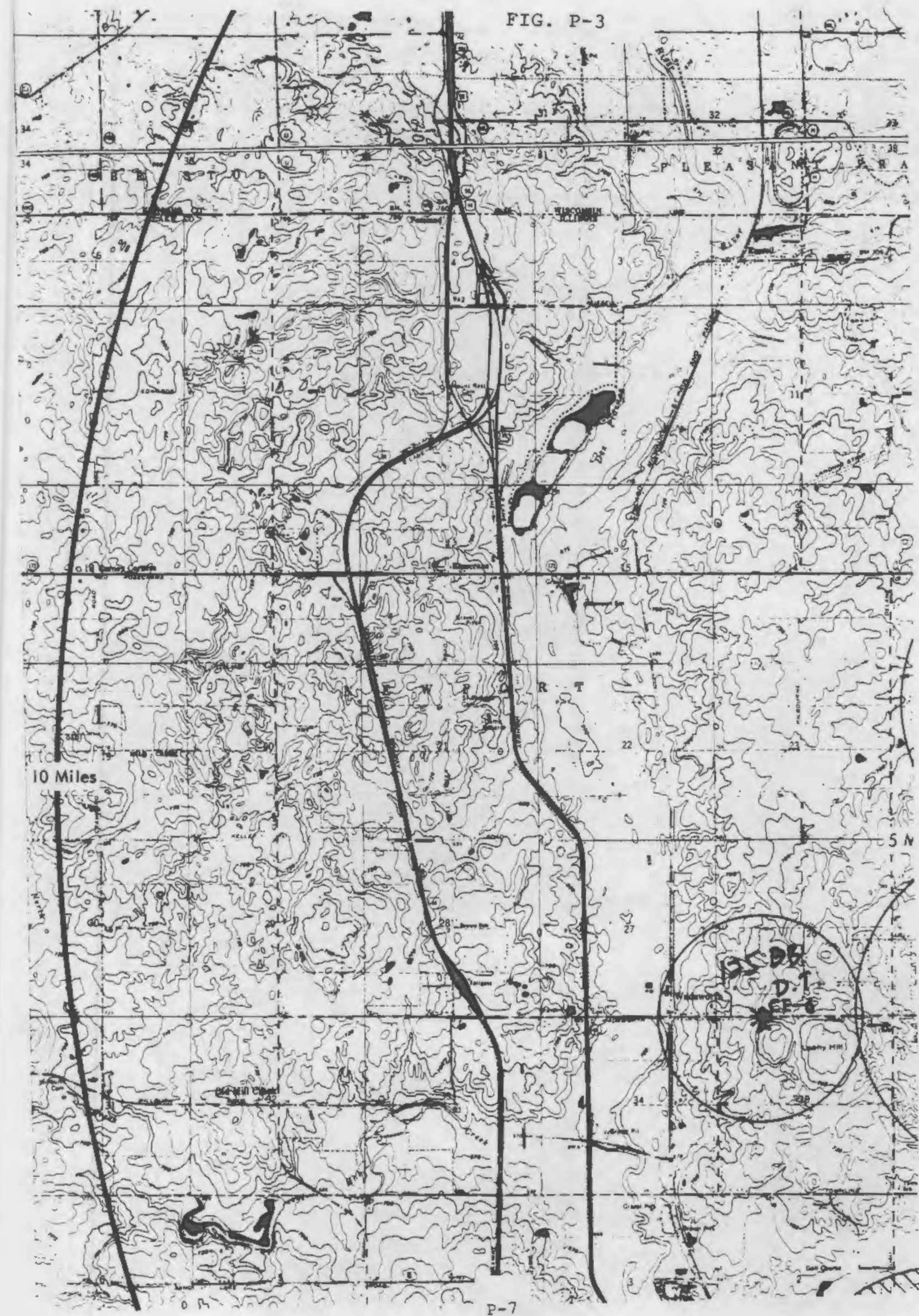




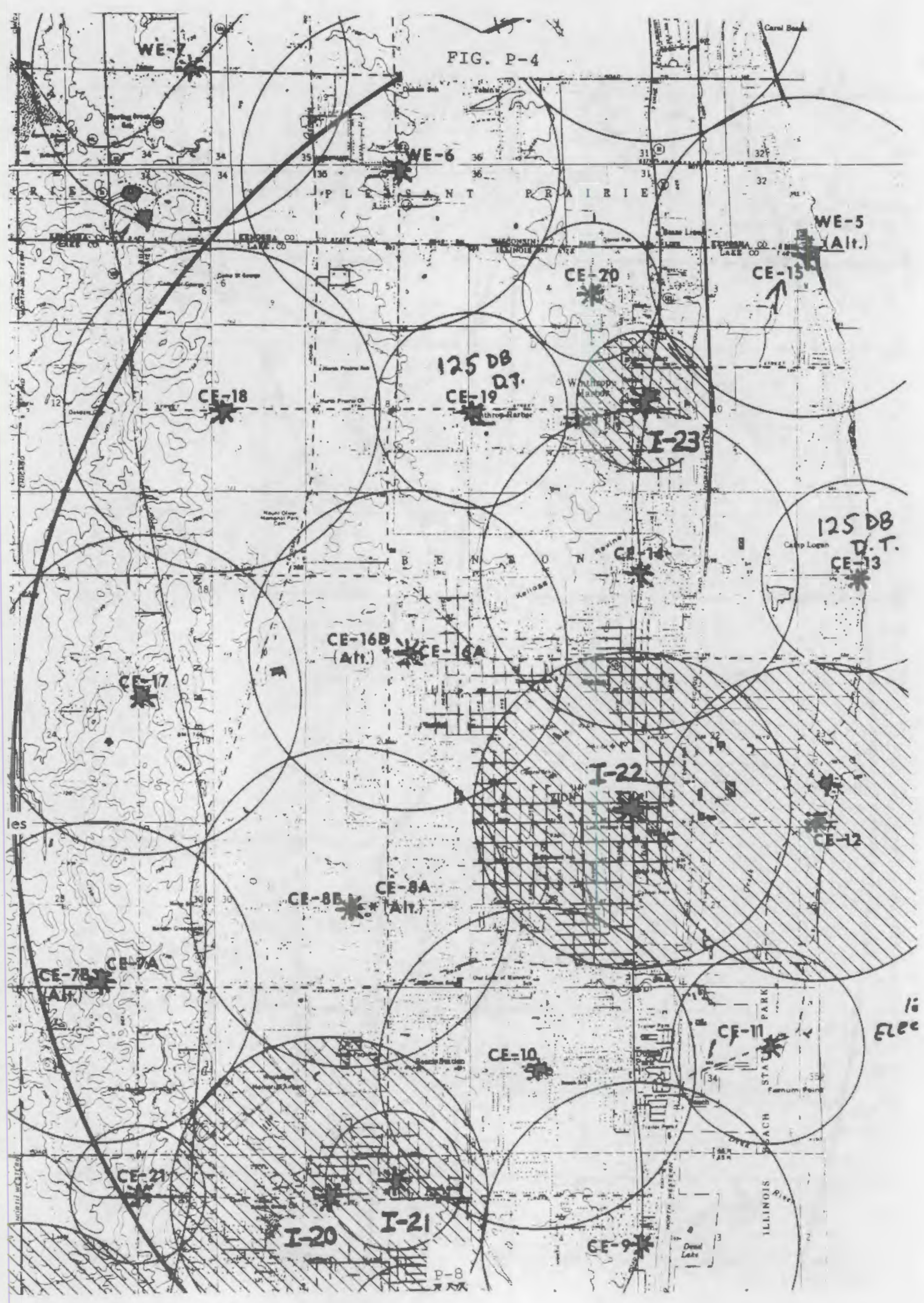




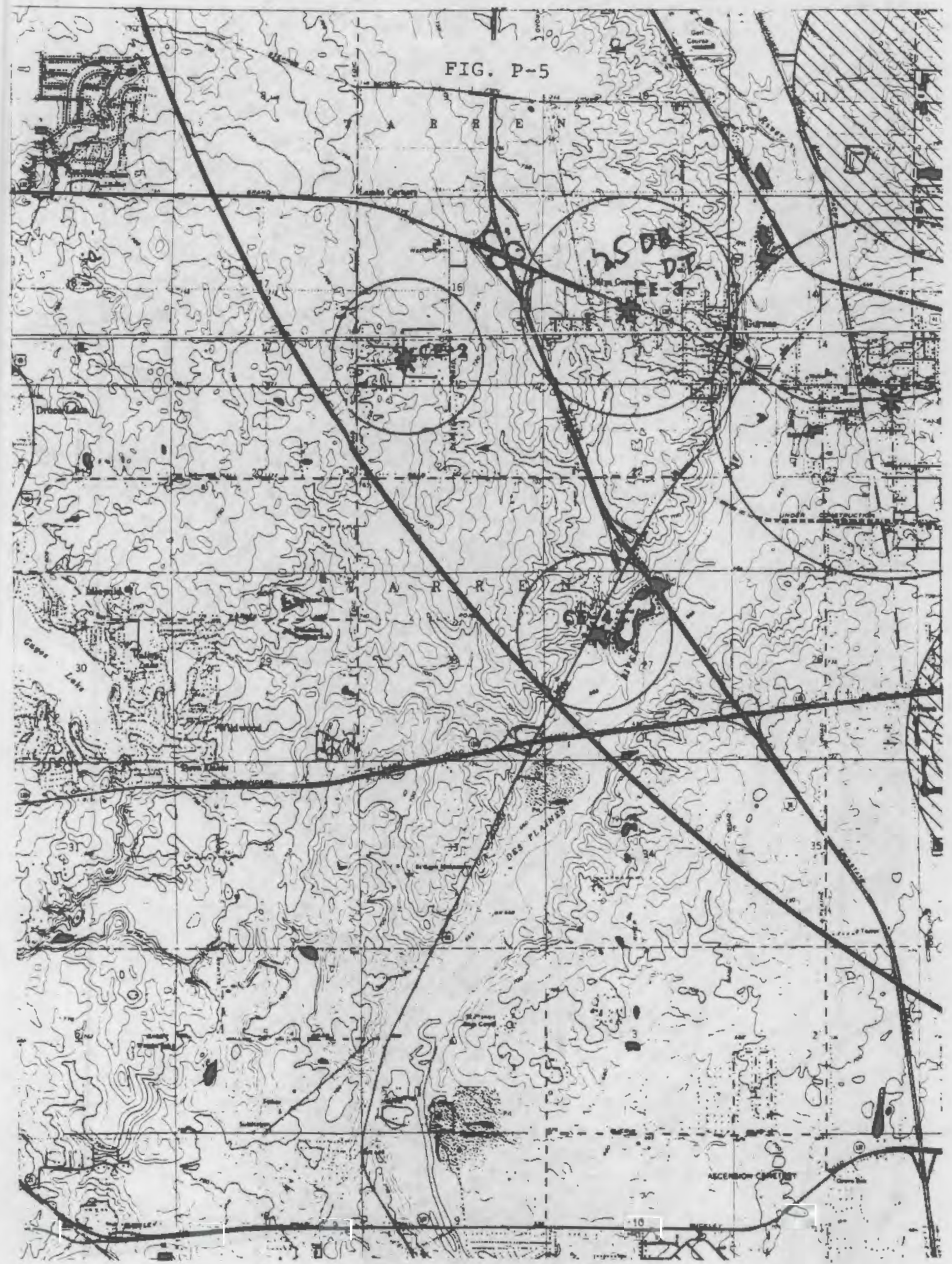




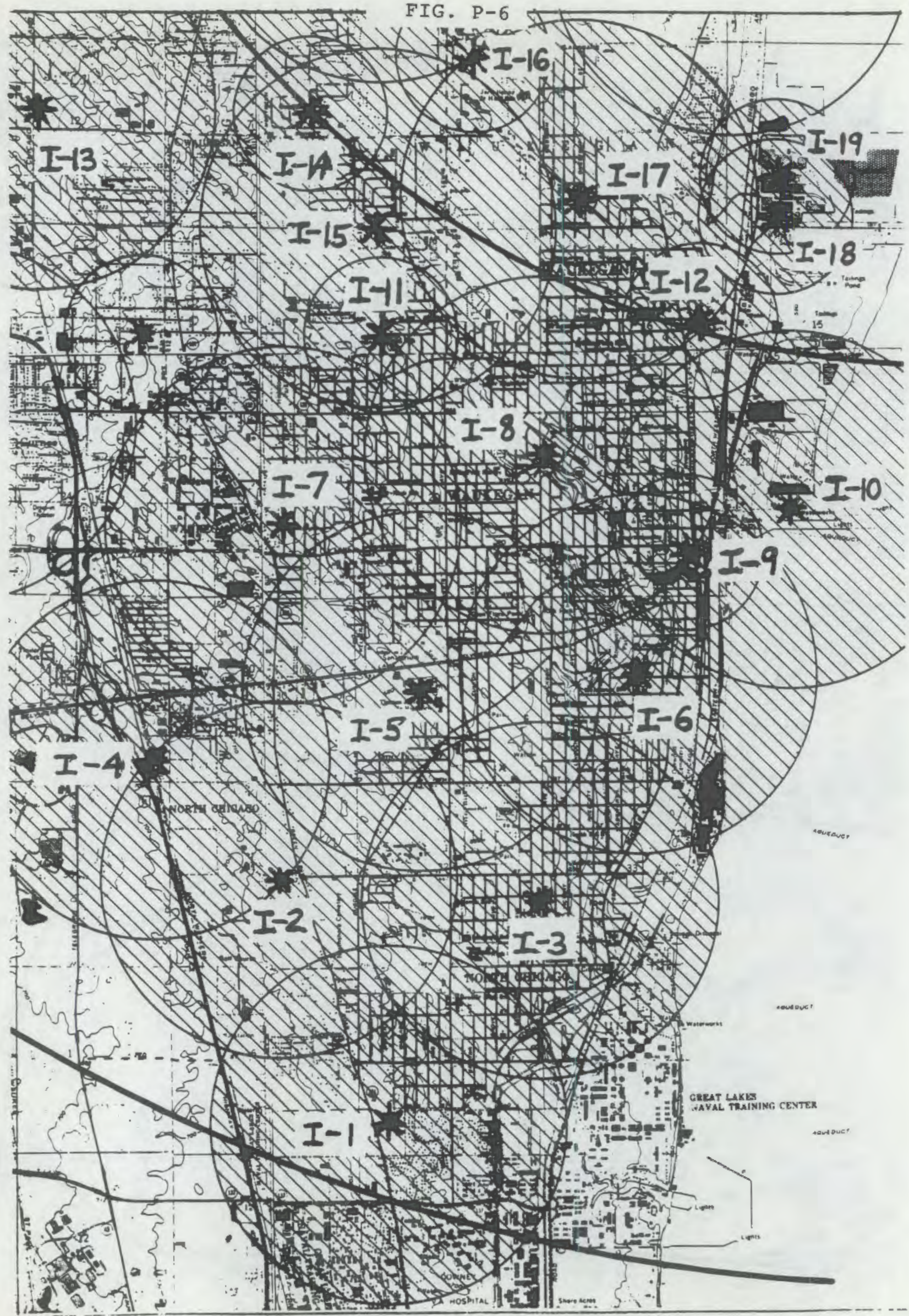




\section{APPENDIX Q: ANALYSIS INPUT/OUTPUT DATA FOR ZION}

This appendix provides listings of computer file input and output data for the Zion analysis. Explanation of the terminology used for each 1 isting is provided below.

\section{Table Q.1. ZIONSPEAKS}

This file contains input data for each of the zion sirens as follows:

- Siren No.

Siren Name
- number assigned to each siren for use by computer program.

- first letter indicates whether the siren is rotating or stationary type ( $R$ or $S$ ); the remainder consists of the siren designation, beginning with a letter and ending with a number. For proposed sirens, the Commonwealth Edison designation is used. Existing sirens are arbitrarily designated, beginning with the letter I (for Illinois) or $W$ (for Wisconsin).

- $x, y, z$
- these are the physical coordinates for the siren location; the $x$-axis is oriented east-west, the $y$-axis is oriented north-south, and the z-axis is oriented vertically. The $x$ and $y$ coordinates are in units of $\mathrm{km}$, referenced to the grid shown on the 
Table Q.1 (Continued)

Feb. 1981 NRC Emergency Planning Map for zion (the plant center is located approximately at $x=434.1, y=4699.4$ ). The $z$ coordinates are in units of feet

- SPLEI00FT - these numbers indicate the rated sound pressure level for each siren at a distance of 100 feet, in $d B$.

Table Q.2 ZIONLISTENS

This file contains input data for each of the randomly selected listener locations as follows:

- Site No. - number assigned to each site for use by computer program.

- Site Name - designator for listener site; the first letter indicates whether the site is urban or rural ( $U$ or $R$ ).

- $x, y, z$

- these are the physical coordinates for the listener location; the $x$-axis is oriented east-west, the $y$-axis is oriented north-south, and the z-axis is oriented vertically. The $x$ and $y$ coordinates are in units of $\mathrm{km}$, referenced to the grid shown on the 
Table Q.2 (Continued)

Feb. 1981 NRC Emergency Planning Map for zion (the plant center is located approximately at $\mathrm{x}=434.1, \mathrm{y}=4699.4)$. The $z$ coordinates are in units of feet.

- Rural Road

- this column indicates whether rural listener sites are within $1000 \mathrm{ft}$ of major highway (NEAR) or beyond $1000 \mathrm{ft}$ (FAR). This information is required for the selection of appropriate outdoor background noise levels.

Table Q.3 2IONSKY

This file contains input data for each of the four sample scenarios as follows:

- Scenario No. - number assigned to each scenario (see Appendix N).

- AMOL

- molecular absorption, in $d B / 1000$ feet.

- WIND - wind direction in degrees $10^{\circ}=$ wind from north, etc.)

- NRES

- residential building outdoor-to-indoor noise reduction, in $d B$. 
Table 0.3 (Continued)

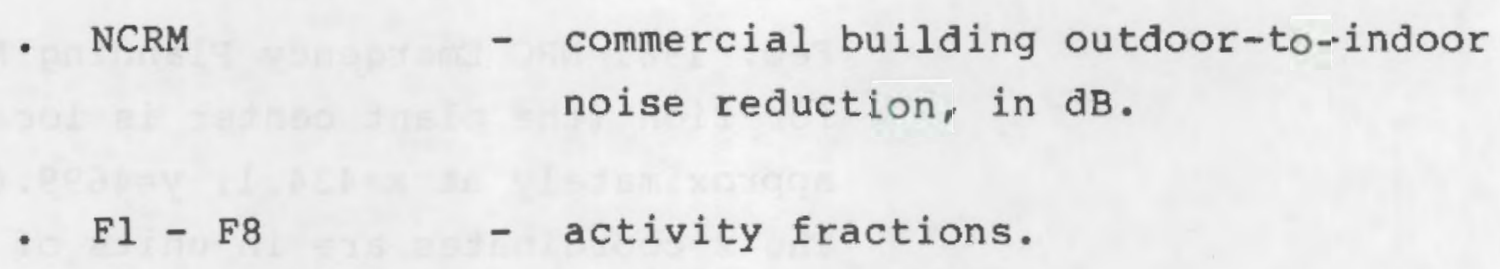

F7 = fraction of people in vehicles in urban areas at $30 \mathrm{mph}$.

F8 = fraction of people in vehicles in rural areas at $55 \mathrm{mph}$. 
Table Q.3 (Continued)

- INP

- indoor alert probability curve (see Fig. 5-4 of text).

- PU30

- probability of alert for motorists in urban areas at $30 \mathrm{mph}$.

- $\quad$ PR55

- probability of alert for motorists in rural areas at $55 \mathrm{mph}$.

- MUL

- vertical profile of wind speed, B $z$, in $\mathrm{ft} / \mathrm{sec} / \mathrm{In} \mathrm{ft}$.

- $A D D$

- vertical profile of air temperature, $a$, in ${ }^{o} \mathrm{~F} / \mathrm{ln} \mathrm{ft}$.

Table Q.4 LISTENEROUTPUT

This listing provides the number, name and outdoor sound pressure level (LOUT, in $d B$ ) for the "dominant" siren at each sample listener location, for each of the four sample scenarios. The results are 1 isted in numerical order for scenarios one through four for each listener site. 
Table Q.5 PROBS

This listing provides the final results for the analysis. Information is listed in numerical order for scenarios one through four for each listener site. This information consists of alert probabilities Pl through P8 corresponding to activity fractions $F 1$ through $F 8$, as well as the total probability of alert (PT) for each sample scenario at each sample listener site.

A summary is provided at the end of the listing showing the rural and urban population followed by the total rural probability of alert (PTRUR), the total urban probability of alert (PTURB), and the total (population-weighted) probability of alert for the EPZ (PTALL). The total probability values are lissted in numerical order for sample scenarios one through four. 


\begin{tabular}{|c|c|c|c|c|c|c|}
\hline SIJE & \# & SITE HHME & $\therefore$ & $y$ & 2 & ËUIFIAL \\
\hline 1 & Li & 1 & 430.5411 & 4713.560 & E.4 01010 & - \\
\hline E & $u$ & $z$ & $4 \xi E .611$ & $4,29.9=0$ & 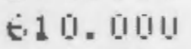 & - \\
\hline 3 & 4 & 3 & 4311.3151 & $4710.5(10)$ & 531.010 & - \\
\hline 4 & u & 4 & 430.11 .10 & 4716.721 & $E=11.0101$ & - \\
\hline 5 & $u$ & 5 & 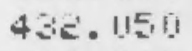 & 4714.9511 & (1) & - \\
\hline$E$ & u & $\dot{t}$ & 430.3111 & 4714.341 & 635.6100 & - \\
\hline 7 & 4 & 7 & $4=5.3 \varepsilon 0$ & $4713.7=0$ & Eit.5. 11101.1 & - \\
\hline 8 & is & $E$ & $4 \div 11.251$ & $471 \leqslant .280$ & EேE. 111111 & - \\
\hline 9 & 4 & $\because$ & $4 \approx 11$. eici & $471=.6011$ & 8.21 .110 & - \\
\hline 10 & $u$ & 10 & 453.1160 & $471=.0811$ & $5-56.11110$ & $=$ \\
\hline 11 & $F$ & 11 & $4 \Sigma \varepsilon \cdot \varepsilon_{0} 0$ & 4.111 .1111 & 0.15 .1111 & IUEHF \\
\hline $1 \dot{8}$ & F: & 12 & $430.3=11$ & 4. UE- IE & $0^{2}=1,1111$ & MEFF \\
\hline 13 & 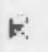 & 13 & 431.360 & 470.160 & 040.501 & FHF \\
\hline 24 & E & 14 & 452.0110 & 4715.050 & 585.11110 & FEF \\
\hline 15 & $F$ & 15 & $4 \vdots 2.340$ & $4114.4 E 11$ & 6.6. & WHEHF \\
\hline 16 & $F$ & $1 \mathrm{t}$ & $4=9.800$ & $470=.3110$ & 700.010 & FHF \\
\hline 17 & - & 17 & $430.14 !$ & AI IE . 11!1! & c. $10.11,1$, & WEEH \\
\hline 15 & iv & $1 \varepsilon$ & 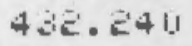 & 47111.711 & $\varepsilon .4 \varepsilon \cdot 1010$ & - \\
\hline 19 & $u$ & $1 \%$ & 430.2411 & 40.93 .540 & 640.100 & - \\
\hline$=10$ & WI & $=11$ & 430.511 & 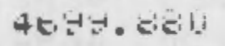 & $t \cdot 0.5 .1111$ & - \\
\hline$\geq 1$ & E' & E1 & $4=8.2 ! 1$ & 4c. H & $725,0141 !$ & DHEAF \\
\hline $2 \overline{2}$ & 4 & $\dot{E z}$ & 431.241 & $4 t:-1,=41$ & $5.55 .41111 !$ & - \\
\hline 23 & F: & $\because \approx$ & $451 . \Sigma=11$ & 4c. & $05=1.11131$ & FAF \\
\hline 24 & F & $=4$ & $4 \therefore 8.7=0$ & $40 \% .940$ & 715.11110 & FHE \\
\hline$\sum 5$ & F. & $=5$ & 424.4111 & 45.96 .351 & t.50. 15011 & FHF \\
\hline E0 & $F$ & Eto & Hここ.こE! & $46+5.510$ & 705.1301 & MEAF \\
\hline$\vec{i}$ & f: & $\dot{1}$ & AEt. Ecil & 40.94 .1410 & PGII. & FAF \\
\hline 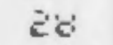 & F! & Ė & $4=5$, sel & $4 t=0.01$ & 6.1. & FHF \\
\hline 25 & F: & $\varepsilon^{\prime \prime}$ & $4=7.45 i$ & 46.51 .561 & إI & HHEFF \\
\hline 51 & F! & 30 & 4et. E.EU & 40.91 .6010 & 715.11010 & VHEAF. \\
\hline 31 & ui & 31 & 428.741 & 46.94 .540 & 705.6110 & - \\
\hline 32 & $i$ & 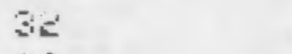 & $43 E . E \mid 11$ & $40 \cdot y^{2} .1180$ & $6.15=01111$ & MEAF \\
\hline 33 & 4 & 3 & 431.541 & 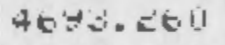 & $\theta=5.111,11$ & - \\
\hline 34 & U & 54 & $4 \leqslant 1.10 i$ & 4E' & 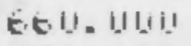 & - \\
\hline ジ & $u$ & $3 c_{1}$ & $4 \leq 11.4=11$ & $46-12.001$ & C.7t. $111 !$ & - \\
\hline 36 & $U$ & Zit & $4=1.11=1$ & $4+.91 .4011$ & $6.55,119 ! !$ & - \\
\hline 37 & $\mathbf{L}$ & $\vec{*}$ & $4=0.5130$ & 4071.360 & EE.5. 3611 & - \\
\hline $8=$ & $w$ & 35 & 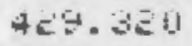 & 46511.740 & E. & - \\
\hline 39 & 4 & 3 & $4 E 8.9110$ & HEGU. PEII & 6.51. & - \\
\hline 40 & U & 41 & $4=8.3011$ & 40.11 .300 & $7 \geq 5.01010$ & - \\
\hline 41 & u & 41 & 430,5111 & $4 t .91 .3010$ & $E 5 E_{1}-11111$ & - \\
\hline 42 & $u$ & $4 \varepsilon$ & $4 \leqslant 11.9111$ & $468: 4=11$ & E.5. 1111 & - \\
\hline 43 & 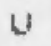 & $4=$ & $4=11.5 \leq 11$ & 4toE. BEI & 6.55 .11111 & - \\
\hline 44 & 4 & 44 & 4311.1011 & $45.81 .=501$ & $E \cdot 5=11011$ & - \\
\hline 45 & f: & $4=1$ & 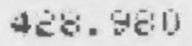 & 4tE' Elli & E. 95.11011 & MEAF \\
\hline 4t. & $B$ & $4 \mathrm{~s}$ & AÉE. lite & $46-610$ & $7 こ 1 . \| 111$ & NEAF \\
\hline 47 & 4 & 47 & $4=9.9611$ & 4tEis. Stil & $6 \cdot 11.0111$ & - \\
\hline 40 & $u$ & 46 & $4: 11.2811$ & Arsis. 7Gi! & 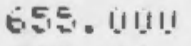 & - \\
\hline 49 & 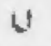 & 49 & АË. 01111 & 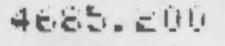 & 715.0111 & - \\
\hline 511 & 4 & 21 & $4 \varepsilon \bar{\gamma} 70$ & $46-55.1+13$ & 7Es . I I! & \\
\hline
\end{tabular}


TABLE Q.2

IDOWEFEKS

\begin{tabular}{|c|c|c|c|c|c|}
\hline SIFEMः & SIFEH HHME & $x$ & $r$ & 2 & SFL-100 \\
\hline 1 & $\therefore E E-1$ & $4 \dot{0} .90 .0$ & $46+2.780$ & 755.11111 & 125 \\
\hline $\bar{E}$ & $S i E-\varepsilon$ & $4=1.1 \varepsilon 0$ & $4 t \rightarrow 1 . \leq \geq 0$ & $790.010 !$ & 115 \\
\hline 3 & E: CE- & AES. UEH & 46.41 .351 & 775.1011 & $1=2$ \\
\hline 4 & $\therefore L E-A$ & $4 E E .700$ & 40.00 .11010 & 730.1110 & 115 \\
\hline 5 & L $L E-5$ & 425.340 & $40 \rightarrow 1.060$ & TEڤ . 0100 & det \\
\hline c. & $F \quad E-E$ & $4=4.481$ & 40.97 .620 & 785.11101 & $1=3$ \\
\hline 7 & $\therefore C E-7 H$ & $4 E$ E. 3411 & $40 \% .0=0$ & 775.13101 & $1=0$ \\
\hline 8 & $F \quad C E-E E$ & $4 E$, SEO & $46 \% B .3=0$ & PEU. DOUIO & $1<0$ \\
\hline 3 & F $L E-G$ & $43 \Xi .301$ & A6. 4.951 & $E=5.0100$ & $1=0$ \\
\hline 20 & C: CE- IO & 431.1411 & $40.56 .0,0$ & 097.000 & 106 \\
\hline 11 & E $C E-11$ & $4=3.400$ & $4 t .35$. St & $E=5.0100$ & 124 \\
\hline $1 \varepsilon$ & E $C E-12$ & 433.501 & 4e. & 641.0100 & 124 \\
\hline 13 & E $C E-1=$ & 434.370 & 47012.4010 & 0.411 .1000 & 183 \\
\hline 14 & F $C E-1+$ & 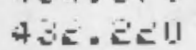 & 4701.5010 & 601.000 & $1=6$ \\
\hline 15 & f: $\quad E-15$ & 433.580 & 470.540 & ES5.000 & 124 \\
\hline 10 & $E \quad E-1 E F$ & $4=9.9511$ & $46111.7 \leq 010$ & $745,1,1,0$ & $1=0$ \\
\hline 17 & F $\overline{\mathrm{CE}}-1 \overline{7}$ & 487.4111 & 47011.420 & $77 c_{1}, 01110$ & $1=t$ \\
\hline $1-$ & E. LE-1E & 425.150 & $4103-1=11$ & 795.6100 & $1=0$ \\
\hline 19 & - LE-19 & $430,0.11$ & 4113.140 & 735.1111 & $1=3$ \\
\hline 30 & $S E E-2 U$ & 431.800 & 4704.340 & 705.0100 & 115 \\
\hline 21 & $\therefore C E-Z 1$ & $4 \dot{\varepsilon} \cdot \overline{0} 0$ & $40.5 .5=0$ & 745.0011 & 215 \\
\hline E & C WE-1 & $4=7.6111$ & 470.640 & 755.0010 & deE \\
\hline$E$ & $\triangle W E-E$ & 453.141 & 4720.380 & 650.0100 & 115 \\
\hline 24 & 3 WE-3 & $4 \Delta \varepsilon^{\prime} .7011$ & 4709.300 & E.5. 1000 & 125 \\
\hline 25 & b. WE-4 & 432.4110 & 4.07 .080 & e.81. 01, & 124 \\
\hline E0 & E UE-E & 420.940 & 4715.4411 & 755.0100 & $1=6$ \\
\hline 87 & E WE-T & 488.0101 & 4710.401 & 775.000 & $1=0$ \\
\hline 28 & f $\quad I-1$ & $4 E 5.840$ & $40.54 .54 i$ & 700.1110 & 2こः \\
\hline 29 & $b \quad d-c$ & $4=7.4+11$ & $46-6.040$ & 750.0100 & $1<2$ \\
\hline 3 & b. $1-3$ & 431.81111 & $40-6.8111$ & 695.11161 & $1=5$ \\
\hline
\end{tabular}


TABLE Q.2 (Continued)

\begin{tabular}{|c|c|c|}
\hline 31 & $E$ & $1-4$ \\
\hline$\therefore 2$ & $F$ & $1-5$ \\
\hline 33 & $R$ & $1-\theta$ \\
\hline 34 & F & $1-7$ \\
\hline 35 & $F$ & $I-E$ \\
\hline 30 & 5 & $1-9$ \\
\hline 37 & $F$ & $I-1 U$ \\
\hline 38 & $\vdots$ & $1-11$ \\
\hline 30 & 5 & $I-1=$ \\
\hline $4 ! 1$ & : & $1-1=$ \\
\hline 41 & $\therefore$ & $1-14$ \\
\hline $4=$ & F & $1-15$ \\
\hline 45 & 3 & $1-1 E$ \\
\hline 44 & f & $1-17$ \\
\hline 45 & 8 & $1-10$ \\
\hline $4 t$ & 5 & $I-2 S$ \\
\hline 47 & $F$ & $I-=0$ \\
\hline 45 & s & $1-\varepsilon d$ \\
\hline 49 & 5 & $1-2 z$ \\
\hline 50 & 5 & $d-z$ \\
\hline 51 & F & $41-1$ \\
\hline 52 & $F$ & $|W|=$ \\
\hline 53 & E: & $4-3$ \\
\hline 54 & $E$ & $w-4$ \\
\hline 55 & F & $w-5$ \\
\hline 50 & 5 & $w-E$ \\
\hline 57 & 3 & wi-7 \\
\hline 58 & E: & $w-5$ \\
\hline 59 & F. & $4-\theta$ \\
\hline E. 1 & 3 & $w-10$ \\
\hline E. 1 & f: & $\mid 1-11$ \\
\hline$t=$ & E & $\omega-1 c^{\prime}$ \\
\hline E. & f & $4-13$ \\
\hline c.4 & F & $41-14$ \\
\hline & E: & $w-15$ \\
\hline 0 & 5 & $4-20$ \\
\hline
\end{tabular}

\begin{tabular}{|c|c|}
\hline 420.9411 & 4ticit. 1 1.11 \\
\hline $4=0.160$ & 4tEE. EEO \\
\hline 432.140 & $40-1.74$ \\
\hline 488.140 & $4 \mathrm{E}+1.1010$ \\
\hline 430.371 & 40.311 .050 \\
\hline $4 \leqslant 1.0611$ & $40 E=7 E 1$ \\
\hline $432.511 !$ & 4 c. 30.141 \\
\hline 489.141. & 40.31 .760 \\
\hline 431.780 & $4 \mathrm{E} \% 1.7 \mathrm{E} 0$ \\
\hline $4 \approx 6.1011$ & $46,5.71,1$ \\
\hline $4=8.351$ & 40 . \\
\hline $48=.44 !$ & At tE. E.5U \\
\hline 429.7811 & 40.94 .181 \\
\hline 431.700 & $4 t \cdot \vec{c} \cdot 6=0$ \\
\hline $4=2.441$ & 40.42 .080 \\
\hline $430.4=1$ & $40 \div 5.1140$ \\
\hline $4=0.10 .0$ & $40-5=501$ \\
\hline $4=3.080$ & 46.55 .640 \\
\hline $420-11010$ & 46.180 \\
\hline 432.3110 & 4703.260 \\
\hline $42 \rightarrow .40 .1$ & $470=5010$ \\
\hline 431.9811 & 4711.4011 \\
\hline $4 \varepsilon^{\prime} t .0 . \bar{B}$ & +13.10101 \\
\hline 4ЕН. 3111 & 4.11 .9410 \\
\hline $4=9.311$ & $4 \because 1=7$ \\
\hline 431.5011 & 4713.241 \\
\hline 438.30 & $471 \div .1=0$ \\
\hline $4 \vdots E, E=1$ & $471=56$ \\
\hline 428.446 & 4714.5810 \\
\hline 431.411 & 4714.140 \\
\hline $4 \vdots \varepsilon .5010$ & 4114.8010 \\
\hline 430.500 & 4726.040 \\
\hline 432.710 & $47 \mathrm{de} .250$ \\
\hline$t=-t .0 .10$ & 4. IE. UEU \\
\hline 431.040 & $4,18,8010$ \\
\hline $43 E .700$ & $471 \leq .941$ \\
\hline
\end{tabular}

740.1901

125

705.01100

$1<5$

720.010010

125

PE. 0 . 1010

125

6.90. 1010

125

E.70. 01411125

t+1. 1010105

PBli. 6100125

E.30.

Fali. out 125

745.11010115

725.

E.5.1111 115

700.11010125

Eंटे. 1110 d25

EE.

715.0100125

725.000115

$674.1100 \quad 115$

E⿺辶. 000125

725.000125

6.75. 1101125

7 ES. 0U1 125

705.100125

c.95. 110105

है⿴囗十⺝⿴囗十 $1=5$

Ec‥ แ10 100

ESE. TIMU 125

75 . 1101 125

Ees.lol 100

EE. 1190 125

690.6010125

670.010125

701.1130105

E.t.1. $10101=5$

tet. bol 201 
TABLE $Q .3$

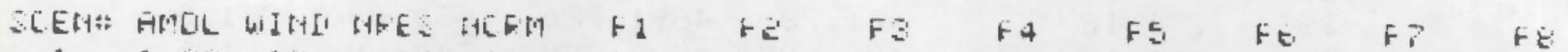

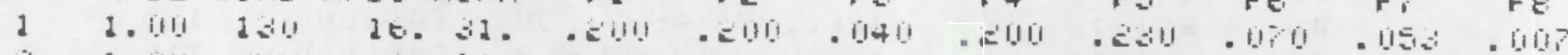

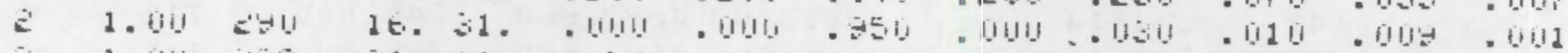

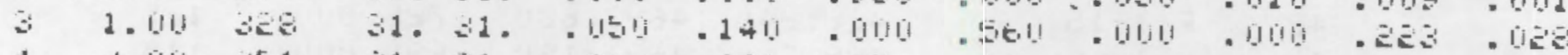

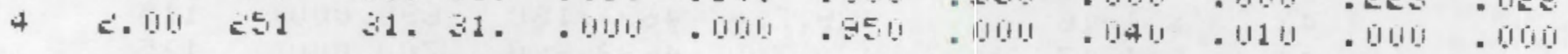

\begin{tabular}{|c|c|c|c|c|}
\hline det & 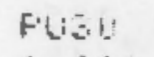 & F'F: & MLIL & AIII \\
\hline 2 & 1. & 1. 1. 1. & 4.571 & -1. Dإل \\
\hline 1 & 1. & 1. & 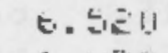 & 11.801 \\
\hline 5 & 1. & 2.1010 & 1. & -11. \\
\hline 1 & 1. 01310 & 1.060 & 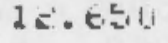 & $-11.8+311$ \\
\hline
\end{tabular}


TABLE 0.4

\section{PROBOUT}

\begin{tabular}{|c|c|c|c|c|c|c|}
\hline $5 *$ & LI & ISTENER & NAME & IIREN \# & IIPEEN NAME & LロUTT \\
\hline 1 & U & 1 & $=$ & $\begin{array}{l}65 \\
64 \\
65 \\
64\end{array}$ & $\begin{array}{ll}\text { F } & W-15 \\
\text { F } & W-14 \\
\text { F : } & W-15 \\
\text { F } & W-14\end{array}$ & $\begin{array}{l}86.5 \\
81: 7 \\
66.6 \\
75.0\end{array}$ \\
\hline e & 11 & $E$ & $x=1$ & $\begin{array}{l}66 \\
65 \\
65 \\
65\end{array}$ & $\begin{array}{ll}\mathrm{S} & \mathrm{W}-16 \\
\mathrm{~F} & \mathrm{~W}-15 \\
\mathrm{~F} & \mathrm{~W}-15 \\
\mathrm{~F} & \mathrm{~W}-15\end{array}$ & $\begin{array}{l}66.6 \\
86.5 \\
66.5 \\
81.8\end{array}$ \\
\hline 3 & U & 3 & -2 & $\begin{array}{l}6 z \\
62 \\
6 z \\
62\end{array}$ & $\begin{array}{l}\text { R } w-1 z \\
\text { R } \quad w-1 z \\
\text { R } w-1 z \\
\text { R } w-1 z\end{array}$ & $\begin{array}{l}99.9 \\
94.9 \\
89.9 \\
98.4\end{array}$ \\
\hline 4 & $u$ & 4 & -27 & $\begin{array}{l}63 \\
63 \\
63 \\
63\end{array}$ & $\begin{array}{ll}\mathrm{F} & w-13 \\
\mathrm{~F} & \mathrm{w}-13 \\
\mathrm{~F} & w-13 \\
\mathrm{~F} & w-13\end{array}$ & $\begin{array}{l}57.2 \\
97.2 \\
87.2 \\
95: 3\end{array}$ \\
\hline 5 & 11 & 5 & $7=$ & $\begin{array}{l}51 \\
63 \\
61 \\
61\end{array}$ & $\begin{array}{ll}F & w-11 \\
F & w-13 \\
F & w-11 \\
F & w-11\end{array}$ & $\begin{array}{r}100.0 \\
87.4 \\
95.0 \\
78.5\end{array}$ \\
\hline 6 & U & 6 & & $\begin{array}{l}56 \\
59 \\
59 \\
56\end{array}$ & $\begin{array}{ll}\mathrm{F} & w-6 \\
\mathrm{R} & w-9 \\
\mathrm{R} & w-9 \\
\mathrm{R} & \mathrm{y}-6\end{array}$ & $\begin{array}{l}91: 4 \\
86.4 \\
86.4 \\
88.1\end{array}$ \\
\hline 7 & $\mathrm{U}$ & 7 & & $\begin{array}{l}55 \\
59 \\
59 \\
59\end{array}$ & $\begin{array}{ll}\mathrm{F} & w-5 \\
\mathrm{~F} & W-9 \\
\mathrm{R} & W-9 \\
\mathrm{~F} & W-9\end{array}$ & $\begin{array}{l}91: 2 \\
92.1 \\
92.1 \\
89.0\end{array}$ \\
\hline 8 & 1 & $E$ & & $\begin{array}{l}56 \\
56 \\
56 \\
56\end{array}$ & $\begin{array}{ll}R & w-6 \\
R & w-6 \\
R & w-6 \\
R & w-6\end{array}$ & $\begin{array}{r}108.5 \\
103.5 \\
108.5 \\
97.8\end{array}$ \\
\hline 9 & $u$ & 9 & & $\begin{array}{l}52 \\
56 \\
56 \\
56\end{array}$ & $\begin{array}{ll}R & W-E \\
R & W-E \\
R & W-E \\
R & W-6\end{array}$ & $\begin{array}{l}84.4 \\
93.7 \\
93.7 \\
91.0\end{array}$ \\
\hline 10 & U & 10 & & $\begin{array}{l}58 \\
58 \\
58 \\
58\end{array}$ & $\begin{array}{ll}R & w-8 \\
R & w-8 \\
R & w-8 \\
R & w-B\end{array}$ & $\begin{array}{r}91: 5 \\
101: 5 \\
101: 5 \\
100.2\end{array}$ \\
\hline
\end{tabular}


TABLE Q.4 (Continued)

11

R. 11

24

$5 E^{\circ}$

5. I. IE-3

8อ. 7

52

R. $\mid W-z$

85.9

SE $\quad$ \&,$-E$

85.9

80.8

12

F. 12

51

F. $b-1$

92.4

51

F | lel-1

R. 1 li -1

51

F. $\mathrm{ll}-1$

$97: 4$

87.4

95.5

13 R 13

EO STE-EO

67.8

E6 F WE-6

25 F LWE-4

EE F WE-

B6.

$75: 0$

81:0

14 F 14

15 F $C E-15$

BE. 4

ES R WE-4

E5 P WE-4

15

F. [E-15

80.8

30. 8

84.6

15 F 15

15 R $C E-15$

EI 5 CE-Ẽ

ह10

E0

S CE-EO

$S$ CE-EO

54.9

85. 0

85. 0

86:.

$16 \quad$ F 16

16

F. [E- $15 \mathrm{~F}$

87. 0

18

F. CE-19

P. CE-18

18

R $[E-16 A$

83.7

83. 7

BE:

17

F 17

14 F CE-14

14 F $[E-14$

99.9

14 F CE-14

89.9

85.9

14

R. $\mathrm{CE}-14$

98.3

15

1) 15

14

R. $\mathrm{CE}-14$

$107: 2$

14 R CE-14

107.2

14 P CE-14

$107 \cdot 2$

14

F. $\mathrm{CE}-14$

19

119

$4951-E 2$

49

$3 T-E E$

49

49

3 I-2E

S I-2E

El

13

$\begin{array}{ll}45 & \text { C I-EE } \\ 16 & \text { R CE-IEA } \\ 16 & \text { R CE-1EA } \\ 16 & \text { R EE-1EA }\end{array}$

70.5

91.3

$91: 3$

87. 7 
TABLE Q.4 (Continued)

\begin{tabular}{|c|c|c|c|c|c|}
\hline$e^{1}$ & R 21 & $\begin{array}{l}8 \\
17 \\
17 \\
17\end{array}$ & $\begin{array}{l}\mathrm{R} \\
\mathrm{R} \\
\mathrm{R} \\
\mathrm{R}\end{array}$ & $\begin{array}{l}\text { CE-8E } \\
\text { CE-17 } \\
\text { CE-17 } \\
{[E-17}\end{array}$ & $\begin{array}{l}85: 0 \\
91: 3 \\
91: 3 \\
87.7\end{array}$ \\
\hline $\mathrm{Ez}$ & แ & $\begin{array}{l}10 \\
10 \\
49 \\
10\end{array}$ & $\begin{array}{l}R \\
R \\
5 \\
R\end{array}$ & $\begin{array}{l}C E-10 \\
{[E-10} \\
I-E 2 \\
{[E-10}\end{array}$ & $\begin{array}{l}88: 7 \\
88: 7 \\
77: 7 \\
84.3\end{array}$ \\
\hline 23 & R 23 & $\begin{array}{r}10 \\
8 \\
8 \\
8\end{array}$ & $\begin{array}{l}R \\
R \\
R \\
\text { R }\end{array}$ & $\begin{array}{l}C E-10 \\
ᄃ E-8 B \\
ᄃ E-8 B \\
ᄃ E-8 B\end{array}$ & $\begin{array}{l}92.9 \\
85.8 \\
858 \\
80.3\end{array}$ \\
\hline 24 & $\mathrm{~F}: 24$ & $\begin{array}{l}8 \\
7 \\
8 \\
7\end{array}$ & $\begin{array}{l}R \\
R \\
R \\
R\end{array}$ & $\begin{array}{l}C E-E B \\
\mathrm{CE}-7 \mathrm{H} \\
\mathrm{EE}-\mathrm{BE} \\
\mathrm{CE}-7 \mathrm{H}\end{array}$ & $\begin{array}{l}96: 3 \\
84.6 \\
91: 3 \\
78: 7\end{array}$ \\
\hline 25 & $\mathrm{R} 25$ & $\begin{array}{r}40 \\
6 \\
6\end{array}$ & $\begin{array}{l}R \\
R \\
R \\
R\end{array}$ & $\begin{array}{l}\mathrm{I}-13 \\
\mathrm{CE}-6 \\
\mathrm{CE}-6 \\
\mathrm{CE}-\mathrm{E}\end{array}$ & $\begin{array}{l}74: 2 \\
81: 7 \\
51: 7 \\
57.6\end{array}$ \\
\hline 26 & F: $2 E$ & $\begin{array}{r}40 \\
6 \\
6 \\
3\end{array}$ & $\begin{array}{l}\mathrm{R} \\
\mathrm{R} \\
\mathrm{R} \\
\mathrm{E}\end{array}$ & $\begin{array}{l}I-13 \\
C E-6 \\
C E-6 \\
C E-3\end{array}$ & $\begin{array}{l}67.5 \\
54.1 \\
54.1 \\
49.2\end{array}$ \\
\hline 27 & R $\equiv 7$ & $\begin{array}{l}40 \\
40 \\
40 \\
40\end{array}$ & $\begin{array}{l}\mathrm{R} \\
\mathrm{R} \\
\mathrm{E} \\
\mathrm{E}\end{array}$ & $\begin{array}{l}I-13 \\
I-13 \\
I-13 \\
I-13\end{array}$ & $\begin{array}{l}80.8 \\
95.8 \\
85.8 \\
93.5\end{array}$ \\
\hline 28 & $F \quad 28$ & $\begin{array}{l}40 \\
40 \\
40 \\
40\end{array}$ & $\begin{array}{l}\mathrm{F} \\
\mathrm{F} \\
\mathrm{F} \\
\mathrm{F}\end{array}$ & $\begin{array}{l}I-13 \\
I-13 \\
I-13 \\
I-13\end{array}$ & $\begin{array}{l}98.1 \\
78.1 \\
88.1 \\
76.3\end{array}$ \\
\hline 29 & R 29 & $\begin{array}{r}34 \\
1 \\
1 \\
1\end{array}$ & $\begin{array}{l}R \\
S \\
5 \\
5\end{array}$ & $\begin{array}{l}I-7 \\
C E-1 \\
{[E-1} \\
C E-1\end{array}$ & $\begin{array}{l}85.3 \\
87.8 \\
87.8 \\
85.9\end{array}$ \\
\hline 30 & R 30 & $\begin{array}{r}34 \\
5 \\
5 \\
5\end{array}$ & $\begin{array}{l}\mathrm{F} \\
\mathrm{R} \\
\mathrm{R} \\
\mathrm{R}\end{array}$ & $\begin{array}{l}I-7 \\
C E-5 \\
C E-5 \\
C E-5\end{array}$ & $\begin{array}{l}85.6 \\
58: 2 \\
88.2 \\
83.7\end{array}$ \\
\hline
\end{tabular}


TABLE Q.4 (Continued)

\begin{tabular}{|c|c|c|c|c|}
\hline $31 \quad 1$ & 31 & $\begin{array}{l}41 \\
41 \\
47 \\
41\end{array}$ & $\begin{array}{l}5 \mathrm{I}-14 \\
\mathrm{~S}-14 \\
\mathrm{R} \\
\mathrm{I}-2 \mathrm{I}-14\end{array}$ & $\begin{array}{l}81: 0 \\
86.0 \\
82.9 \\
83.8\end{array}$ \\
\hline $3 E$ & 32 & $\begin{array}{l}9 \\
9 \\
9 \\
9\end{array}$ & $\begin{array}{l}\text { R CE- } \\
\text { R CE-S } \\
\text { R CE-S } \\
\text { R CES }\end{array}$ & $\begin{array}{c}112: 9 \\
112.9 \\
112.9 \\
112.4\end{array}$ \\
\hline 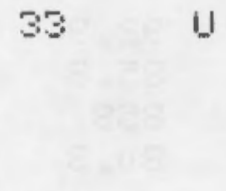 & 133 & $\begin{array}{r}46 \\
44 \\
9 \\
44\end{array}$ & $\begin{array}{ll}5 & I-19 \\
\text { R } & I-17 \\
\text { R } & \text { IE }-9 \\
\text { R } & I-17\end{array}$ & $\begin{array}{l}86.8 \\
89.1 \\
55.8 \\
85.8\end{array}$ \\
\hline U & 134 & $\begin{array}{l}44 \\
44 \\
44 \\
44\end{array}$ & $\begin{array}{l}\text { F I }-17 \\
\text { F I }-17 \\
\text { R I }-17 \\
\text { R I }-17\end{array}$ & $\begin{array}{r}90.2 \\
100.2 \\
100.2 \\
98.7\end{array}$ \\
\hline U & 135 & $\begin{array}{l}44 \\
44 \\
44 \\
44\end{array}$ & $\begin{array}{ll}\text { R } & I-17 \\
\text { R } & I-17 \\
\text { R I } & -17 \\
\text { F I } & -17\end{array}$ & $\begin{array}{r}10 E .8 \\
92: 8 \\
102: 8 \\
81.7\end{array}$ \\
\hline U & 130 & $\begin{array}{l}39 \\
35 \\
44 \\
35\end{array}$ & $\begin{array}{ll}\mathrm{S} & \mathrm{I}-1 \mathrm{E} \\
\mathrm{R} & \mathrm{I}-8 \\
\mathrm{R} & \mathrm{I}-17 \\
\mathrm{R} & \mathrm{I}-8\end{array}$ & $\begin{array}{l}84.5 \\
90.6 \\
86.7 \\
87.1\end{array}$ \\
\hline 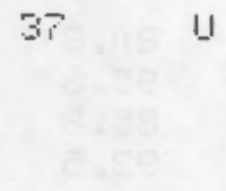 & 37 & $\begin{array}{l}35 \\
38 \\
38 \\
38\end{array}$ & $\begin{array}{ll}E & I-9 \\
5 & I-1 I \\
5 & I-11 \\
3 & I-11\end{array}$ & $\begin{array}{l}90: 2 \\
87: 0 \\
87: 0 \\
85: 0\end{array}$ \\
\hline 4 & 138 & $\begin{array}{l}35 \\
38 \\
38 \\
34\end{array}$ & $\begin{array}{ll}\mathrm{R} & \mathrm{I}-8 \\
\mathrm{~S} & \mathrm{I}-1 \mathrm{I} \\
\mathrm{S} & \mathrm{I}-11 \\
\mathrm{R} & \mathrm{I}-7\end{array}$ & $\begin{array}{l}90.8 \\
80.7 \\
80.7 \\
77.3\end{array}$ \\
\hline $\mathrm{u}$ & 139 & $\begin{array}{l}35 \\
34 \\
38 \\
34\end{array}$ & $\begin{array}{ll}\text { R } & I-B \\
\text { R } & I-7 \\
\text { S } & I-1 I \\
\text { R } & I-7\end{array}$ & $\begin{array}{l}86.5 \\
88.5 \\
81.5 \\
85.2\end{array}$ \\
\hline U & J 40 & $\begin{array}{l}34 \\
34 \\
34 \\
34\end{array}$ & $\begin{array}{ll}R & I-7 \\
R & I-7 \\
R & I-7 \\
R & I-7\end{array}$ & $\begin{array}{l}102: 9 \\
102: 9 \\
102: 9 \\
101.8\end{array}$ \\
\hline
\end{tabular}


TABLE 0.4 (Continued)

\begin{tabular}{|c|c|c|c|c|}
\hline 4 & U 41 & $\begin{array}{l}35 \\
35 \\
35 \\
35\end{array}$ & $\begin{array}{ll}\mathrm{R} & \mathrm{I}-8 \\
\mathrm{R} & \mathrm{I}-8 \\
\mathrm{R} & \mathrm{I}-8 \\
\mathrm{R} & \mathrm{I}-8\end{array}$ & $\begin{array}{r}87.8 \\
102.8 \\
102.8 \\
101.8\end{array}$ \\
\hline 40 & $14 z$ & $\begin{array}{l}33 \\
35 \\
35 \\
35\end{array}$ & $\begin{array}{ll}\mathrm{F} & \mathrm{I}-\mathrm{E} \\
\mathrm{R} & \mathrm{I}-\mathrm{B} \\
\mathrm{R} & \mathrm{I}-8 \\
\mathrm{~F} & \mathrm{I}-8\end{array}$ & $\begin{array}{l}95.2 \\
87.5 \\
87.5 \\
83.0\end{array}$ \\
\hline & U 43 & $\begin{array}{l}33 \\
32 \\
33 \\
32\end{array}$ & $\begin{array}{ll}R & I-6 \\
R & I-5 \\
R & I-6 \\
R & I-5\end{array}$ & $\begin{array}{l}96.0 \\
85.8 \\
91: 0 \\
82.1\end{array}$ \\
\hline & 1) 44 & $\begin{array}{l}30 \\
30 \\
30 \\
30\end{array}$ & $\begin{array}{ll}\mathrm{R} & \mathrm{I}-3 \\
\mathrm{~F} & \mathrm{I}-3 \\
\mathrm{R} & \mathrm{I}-3 \\
\mathrm{~F} & \mathrm{I}-3\end{array}$ & $\begin{array}{l}97: 8 \\
87: 8 \\
87: 8 \\
96: 0\end{array}$ \\
\hline 45 & R 45 & $\begin{array}{l}30 \\
29 \\
29 \\
29\end{array}$ & $\begin{array}{ll}\text { R } & I-3 \\
R & I-2 \\
R & I-E \\
R & I-E\end{array}$ & $\begin{array}{l}88: 3 \\
90.8 \\
90.8 \\
67.3\end{array}$ \\
\hline 46 & R. 46 & $\begin{array}{l}29 \\
29 \\
31 \\
29\end{array}$ & $\begin{array}{ll}\mathrm{R} & I-E \\
\mathrm{~F} & I-E \\
\mathrm{R} & I-4 \\
\mathrm{~F} & I-2\end{array}$ & $\begin{array}{l}95.9 \\
95: 9 \\
89.3 \\
93.7\end{array}$ \\
\hline 4 & 1347 & $\begin{array}{l}30 \\
30 \\
30 \\
30\end{array}$ & $\begin{array}{ll}\mathrm{R} & \mathrm{I}-3 \\
\mathrm{R} & \mathrm{I}-3 \\
\mathrm{R} & \mathrm{I}-3 \\
\mathrm{R} & \mathrm{I}-3\end{array}$ & $\begin{array}{l}89: 0 \\
99.0 \\
99: 0 \\
77.4\end{array}$ \\
\hline 4 & 148 & $\begin{array}{l}30 \\
30 \\
30 \\
80\end{array}$ & $\begin{array}{ll}\mathrm{R} & \mathrm{I}-3 \\
\mathrm{R} & \mathrm{I}-3 \\
\mathrm{R} & \mathrm{I}-3 \\
\mathrm{~F} & \mathrm{I}-1\end{array}$ & $\begin{array}{l}71: 2 \\
91: 2 \\
91: 2 \\
79: 7\end{array}$ \\
\hline 45 & 1149 & $\begin{array}{l}28 \\
28 \\
28 \\
28\end{array}$ & $\begin{array}{ll}R & I-1 \\
R & I-1 \\
R & I-1 \\
R & I-1\end{array}$ & $\begin{array}{r}101: 5 \\
101: 5 \\
96: 5 \\
100: 2\end{array}$ \\
\hline 50 & 1150 & $\begin{array}{l}28 \\
28 \\
28 \\
28\end{array}$ & $\begin{array}{ll}R & I-1 \\
R & I-1 \\
R & I-1 \\
R & I-I\end{array}$ & $\begin{array}{r}103.4 \\
93.4 \\
98.4 \\
102.4\end{array}$ \\
\hline
\end{tabular}


TABLE Q.5

PROBS

\begin{tabular}{|c|c|c|c|c|c|c|c|c|}
\hline $\begin{array}{c}\text { P1 } \\
\text { L } 1 \text { STENEP }\end{array}$ & $\begin{array}{l}\mathrm{PE} \\
1\end{array}$ & F3 & F4 & P5 & $\mathrm{FE}$ & $\mathrm{F} 7$ & $\mathrm{~PB}$ & F'T \\
\hline 1.000 & 1. 000 & 0.730 & 1: 000 & 1: 000 & 1. & 1.001 & 1.000 & 0.98 \\
\hline 1.000 & 1. 0100 & 0.670 & 11.985 & 0.537 & 1:001 & 1. 000 & 1. ono & \\
\hline 1.001 & 1:000 & 0.181 & 0.133 & 0. Dū & 1. & 1.000 & 1.000 & \\
\hline 1.000 & 1. 010 & 0.339 & 0.653 & 0.601 & 1.000 & 1.000 & 1. & \\
\hline I STENER & $e$ & & & & & & & \\
\hline 1. 000 & 1.001 & 11.545 & 0.909 & 0.000 & 1. 1000 & 1. 000 & 1. 001 & $0 . r^{\prime}$ \\
\hline 1. 000 & 1. 0100 & 0.728 & 1:000 & 1.000 & & & 1.001 & \\
\hline 1.000 & 1: 000 & 0.178 & 0.129 & 0.000 & $1: 000$ & & 000 & \\
\hline 1.0101 & 1:000 & 0.452 & 0.825 & 0.935 & iٓ & & 0 & \\
\hline I $\equiv$ TENER & $=$ & & & & & & & \\
\hline 1.0100 & $1: 1$ & 0.860 & .000 & 100 & 10 & 0 & 1.000 & \\
\hline 1.010 & $1: 1$ & .816 & 000 & 00 & & & 00 & \\
\hline 1. 1. & $1: 1$ & .578 & 836 & 00 & & & 100 & \\
\hline 1.0100 & $1: 1$ & 0.691 & 0.959 & 010 & 0 & & 1.000 & \\
\hline$I \Xi$ TENER & 4 & & & & & & & \\
\hline 1.001 & $1: 1$ & 0.780 & 00 & 10 & & & III & \\
\hline 1.001 & $1: 1$ & 0.837 & 00 & & & & 100 & \\
\hline 1.000 & $1: i$ & 0.540 & 71 & 001 & & & 100 & \\
\hline 1.0101 & 1.1 & 0.652 & 0.980 & 00 & 1.1 & & 1.0100 & \\
\hline I $\Xi$ TENER & 5 & & & & & & & \\
\hline $1: 1$ & $1: 1$ & 0.561 & & & & & 1.000 & \\
\hline 1.001 & $1: 1$ & 11.738 & 80 & 10 & & & & \\
\hline 1.001 & $1: 1$ & 11.649 & 11. 925 & 00 & & & & \\
\hline 1. 0101 & 1.1 & 0.4 & 0.758 & 14 & & & & \\
\hline I $\equiv$ TENEF & 6 & & & & & & & \\
\hline $1: 1$ & $1: 1$ & 81 & 10 & & & & & \\
\hline 1. 01010 & $1 . i$ & 7 & 110 & & & & & \\
\hline $1: 1$ & 1. & 0.527 & 0. & & & & & \\
\hline 1. otioi & 1.1 & 0.552 & 1.929 & & & & & \\
\hline$\Xi T E$ & 7 & & & & & & & \\
\hline $1: i$ & $1: 1$ & 79 & & & & & & \\
\hline $1: 1$ & & - & & & & & & \\
\hline $1: 1$ & & . & & & & & & \\
\hline 1. 000 & 1. & 0.566 & 0.539 & 00 & & & 00 & \\
\hline STE & & & & & & & & \\
\hline $1:$ & 1. & & & & & & & \\
\hline 1. 1 & & & & & & & & \\
\hline $1: 1$ & & & & & & & & \\
\hline 1.001 & & 84 & 0. & 000 & & & $\underline{n}$ & \\
\hline I STENEF & 9 & & & & & & & \\
\hline $1: 1$ & 1: & & & & & & & \\
\hline 1.000 & & & & & & & & \\
\hline 1.000 & & & & & & & 1.000 & \\
\hline 1.000 & 1.000 & 0.594 & 11.956 & 010 & $1:$ & & 1:000 & \\
\hline$I \subseteq T E$ & 10 & & & & & & & \\
\hline $1: 1$ & $1: 0$ & & & & & & & \\
\hline $1: 1$ & & & & & & & & \\
\hline $1: 1$ & $1: i$ & & & & & & & \\
\hline 00 & 1 & 0.713 & $1: 000$ & 1.000 & 900 & : 000 & 1. 010 & \\
\hline
\end{tabular}


TABLE Q.5 (Continued)

\begin{tabular}{|c|c|c|c|c|c|c|c|c|}
\hline LISTENER & 11 & & & & & & & \\
\hline $1: 000$ & 1.000 & 0.753 & 1:000 & 1. 010 & 1.001 & 1.000 & 1.000 & 0. 9501 \\
\hline 1.000 & $1: 000$ & 0.721 & 1:000 & 1:000 & 1. 010 & 1. 000 & 1.000 & 0.7346 \\
\hline 1:000 & $1: 000$ & 0.519 & 0.732 & 1: 000 & 1. 0101 & 1.000 & 1:000 & 0.8507 \\
\hline 1.000 & 1:00r & 0.439 & 0.807 & 0.916 & 1. 0101 & 1.000 & $1: 000$ & 0.4634 \\
\hline LISTENER & 12 & & & & & & & \\
\hline $1: 000$ & $1: 000$ & 0.792 & 1:000 & $1: 000$ & 1. 000 & 1: 0101 & 1. $\arg$ & 0.9917 \\
\hline 1.000 & 1: 000 & 0.839 & $1: 000$ & 1: 1010 & 1.000 & 1. 001 & $1: 000$ & 11. 8470 \\
\hline 1:000 & 1:000 & 0.543 & ㅁ. 776 & 1. 0100 & 1: 0100 & 1. Din & 1.000 & 0.8757 \\
\hline 1. 000 & 1.000 & 0.655 & 0.981 & 1.000 & 1.001 & 1. 010 & 1. 000 & $0.67 \Xi 3$ \\
\hline LI STENER & 13 & & & & & & & \\
\hline 1. 000 & 1: 0ิ10ิ & $0.5 E .3$ & 0.924 & 0. 010 & 1:001 & 1: 0100 & 1:0010 & 0.7374 \\
\hline 1: 0110 & 1: 0100 & 0.724 & 1: 010 & 1: กิ10ิ & 1. 000 & 1.0010 & 000 & 0.7382 \\
\hline 1. 0010 & 1.0010 & 0.339 & 0.359 & 7.660 & 1:001 & 1. torio & 1: 1. & 0.6418 \\
\hline 1. 0100 & 1. Dồ & 0.441 & 10. 811 & 0.920 & 1. 0010 & 1:000 & 1. 0010 & 0.4661 \\
\hline LI $\equiv$ TENER & 14 & & & & & & & \\
\hline 1.0010 & $1: 000$ & 0.750 & $1: 000$ & 1.0100 & 1:000 & 1: 0100 & 1: oñ & 0.9500 \\
\hline $1: 000$ & 1. 000 & 0.558 & $11.98 \overline{8}$ & 01.915 & 1.010 & 1. 0100 & 1:0010 & 0,6730 \\
\hline 1.000 & 1:000 & 0.438 & 0.564 & 0.915 & 1.000 & 1.000 & $1: 000$ & 0.7567 \\
\hline 1. 000 & 1.00 & 0.499 & 0.881 & 0.999 & 1:000 & 1. 0101 & 1: 0010 & 0.5244 \\
\hline LI $\Xi T E M E R$ & 15 & & & & & & & \\
\hline 1: & 1. 000 & 0.709 & 0.955 & 1. & 1. 0101 & 1:010 & $1: 000$ & 0.988E \\
\hline $1: 0010$ & 1. 01013 & 0.807 & $1: 000$ & 1. 0010 & 1.0010 & 1:000 & 1:000 & 0.8169 \\
\hline 1. 0010 & 1.000 & 0.655 & 0.899 & 1. 0101 & $1: 0010$ & 1.010 & 1. 0000 & 0.9444 \\
\hline 1.000 & 1:000 & 0.511 & 0.955 & 1. 0100 & 1.000 & 1: 000 & 1:010 & 0.6301 \\
\hline LI $\Xi T E N E R$ & 16 & & & & & & & \\
\hline 1: 000 & 1: 0ini & 0.734 & 1:0100 & 1. 0010 & 1:000 & 1.000 & 1:000 & 0.9594 \\
\hline 1. & 1.000 & 0.655 & 0.993 & 0.995 & 1.000 & 1. 0100 & 1.0010 & 0.7099 \\
\hline 1. 000 & 1.001 & 0.485 & 0.664 & 0.993 & 1.001 & 1:001 & 1: 010 & $0.81 E$ \\
\hline $1: 0010$ & 1:001 & 0.459 & 11. 834 & 11.943 & 1. 0010 & 1:0100 & 1. 0100 & 0.4837 \\
\hline LI $\Xi T E N E R$ & 17 & & & & & & & \\
\hline 1: 1: & 1:001 & 0.860 & 1. 000 & 1. 1010 & 1: 0101 & 1: Ditit & 1:000 & $0: 9944$ \\
\hline 1:0101 & 1.010 & 1.766 & 1:000 & 1: 0100 & 1.001 & $1: 000$ & 100 & 0.7776 \\
\hline 1. $\operatorname{0in}$ & 1. 0100 & 0.579 & 0.857 & $1: \sin$ & 1.000 & 1:001 & 1. 0100 & 0.9099 \\
\hline $1: 000$ & 1:000 & 0.650 & 0.989 & 1.000 & 1: 000 & 1: 000 & $1: 000$ & 0.7051 \\
\hline LI $\equiv$ TENER & 18 & & & & & & & \\
\hline 1.001 & 1. 000 & 10. 914 & 1:0010 & 1:000 & 1: 0170 & $\log$ & 900 & 0 \\
\hline 1:001 & 1: 01010 & 0.914 & 1.000 & 1. 0100 & 1: प010 & 500 & bo & 83 \\
\hline $1: 001$ & 1: 0010 & 0.790 & 1. 010 & 1:001 & 1: 01010 & 1: 0010 & 00 & 10 \\
\hline 1.0010 & 1.000 & 7.788 & 1. 000 & 1:010 & 1.000 & 1: oino & 1.001 & 0.7928 \\
\hline LI $\Xi T E N E R$ & 19 & & & & & & & \\
\hline 1:00 & 1: 00010 & 0.845 & $1: 000$ & 1.001 & $1: 000$ & 1: 010 & 1: 000 & 0 \\
\hline $1: 000$ & $1: 000$ & 0.845 & 1: gno & 1: & 00 & 60 & 00 & 89 \\
\hline 1.000 & 1:000 & $0.6=4$ & 0.8 & 010 & 00 & 00 & 00 & 51 \\
\hline 1:000 & 1:000 & 0.673 & 0.980 & 1:000 & 1.000 & 1: 000 & 1: 1000 & 0.6893 \\
\hline LISTENER & & & & & & & & \\
\hline 1. 0100 & 1.000 & 0.602 & 0.950 & 0.480 & 1:000 & 1: 000 & on & \\
\hline 1: 0100 & 1. 0100 & & 1:000 & 1. 0100 & 1:000 & 1: 0100 & $1: 000$ & a: \\
\hline 1. 000 & 1.000 & 0. & 0.866 & 1. 000 & 1: 0010 & 1. 0010 & 1: onn & \\
\hline 1.000 & 1.000 & 0.547 & 0.925 & 1:010 & 1: 000 & 1: & $1: 000$ & 698 \\
\hline
\end{tabular}


TABLE Q.5 (Continued)

\section{STENER EI}

1.000 1.000

1:000 1:000

1.000 1.000

1.000 1:000

LISTENER ZE

1.000 1.000

1.000 1.000

1.000 1.000

1.000 1:000

LISTENER 33

1.000 1:000

1:000 1:000

1.000 1.000

1.000 1.000

LI $I$ TENER 24

1.000 1:000

1.000 1:000

1.000 1.000

1.000 1.000

LI ITENEP 25

1.000 1:000

$1.000 \quad 1.000$

1.000 1:000

1.000 1.000

LI $\Xi T E N E R E$

1.000 1.000

$0.718 \quad 1.000$

$0.718 \quad 1.000$

0.571 1:000

LI $\$$ TENER $2 ?$

1. 0001.000

$1: 0001: 000$

1.000 1.000

1.000 1:000

LISTENER EE

1.0001 .000

1.000 1:000

$1.000 \quad 1.000$

1.000 1.000

LISTENER 29

1.000 1:000

1.000 1.000

1.000 1:000

1:000 1:000

LISTENER 30

1.000 1.000

1.000 1:000

1.000 1.000

$1.000 \quad 1.000$
10. 711

0. 781

0.599

0. .547

0.753

0.753

0.485

0.495

0.797

0. 720

0. 518

11. 431

0. 829

0.706

0. 599

0.403

10. 569

10. 571

0.454

0.000

0.466

0. 229

0. 0100

10. 000

0. 6.58

0.824

0.518

1. 629

0.845

0.6อ3

0. 552

ㅁ. 362

0.714

0. 805

0.632

0.607

0.718

D. 748

0.555

ग. 485
1: 000

1. 0100

0. 966

0. 925

1. 000

1: 000

0.585

D. 877

1: 000

1. 000

0. 730

0.797

1. 000

0. 999

10. 86.6

0.756

10. 941

0. 985

10. 597

0. 240

0. 843

i. 534

0. 012

0. 000

1: 000

1: 000

1. 000

1: 0000

1. 000

1.000

1. 000

1. 000

1. 000

1. 000

1:000

1.000

0.942

0.999

1. 000

1. 000

1.000

1. 000

1. 000

1. 000

1. 0010

1. 000

0.903

1. 000

1. 000

0.995

1. 000

0.847

1. 000

1. 000

1. 0000

1. 000

$0.513 \quad 1.000$

0. 937

10. 937

1. 000

1. 000

0. 000

1. 0000

5. 000

1: 1000

D. 000

1: 000

$0.000 \quad 1.000$

0. 000

1: 000

0.982

1. 000

0.915

1. 0000

1. 000

1. 0000

1. 000

1. 0100

0. 729

1. 000

1. 000

1. 0000

0.970

0. 793

1. 000

1.000

0.823

1: 000

1. 0000

1. 000

1. 000

0.735

0. 691

1. 000

1. 000

1. 000

1. 000

1.000

1. 000

1. 001

0. 953

1. 000

1. 000

1. 000

1. 000

1. 000

1. 000

1. 000

1. 000

1. 000

1. 000

1. 000

1.000

1. 000

1. 000

1. 000

1. 0000

1. 000

1. 000

1. 000

1. 000

1. 000

1. 000

1. 0ิ10

1. 000

1. 000

1. 0010

1. 010

1. 000

0.798

0.865
1. 000

1. 000

1. 0000

1. 000
1: 000

1. 000

1. 000

1. 000

1. 0000

1.000

1. 000

1. 000

0.9883

0.. 7915

0. 9Еธอ

0.5697

1:000

0. 9901

D. 7654

1.. 7695

0. $520 \mathrm{E}$

1. 000

1.000

0.9919

01. 7339

0.8495

1. 4555

1. 000

1.000

$0.993 E$

1. 000

0. 7205

0. 9อ6อ

0. 426 .

1. 000

1. 0100

1:000

1.. 8520

1. $000 \mathrm{x}$

0.6851

1. 000

0.7754

0. 0100

1.000

0. 7173

1. 000

0. 2379

$1: 000$

0.4335

1: 000

0. 0100

1. g00

0.9633

1: 000

0.8329

$1.000 \quad 0.8454$

1: 0000

0.6477

$1.000 \quad 0.9938$

1. 000

0.6354

1. 000

0.8553

0.3830 
TABLE Q.5 (Continued)

\begin{tabular}{|c|c|c|c|c|c|c|c|c|}
\hline I STENER & 31 & & & & & & & \\
\hline 1.000 & 1:000 & 0.734 & 1.000 & 1.000 & 1. & 1.000 & $1: 000$ & 0.9594 \\
\hline 1.0010 & 1. 000 & 11: 788 & 1.000 & 1. 010 & 1. 000 & 1. mon & $1: 000$ & 0.7984 \\
\hline 1.0000 & 1. 0010 & $n: 474$ & 0.639 & 0.959 & 1.000 & 1.000 & 1: Don & 0. 7988 \\
\hline 1. 0 ngn & 1.000 & 0.578 & 0.935 & 1: 0 काष & 1.001 & 1.001 & 1.000 & 0.5990 \\
\hline LI STENER & SE & & & & & & & \\
\hline 1:000 & 1.000 & 0.946 & 1.000 & 1:000 & 1. $000 \mathrm{n}$ & 1.000 & 1:000 & 0.9979 \\
\hline 1.001 & $1: 000$ & 0. 946 & 1:0001 & 1.000 & 1010 & 000 & 000 & 0.7451 \\
\hline 1:000 & 1: 000 & 0.343 & 10̄ & $\log$ & 1010 & 900 & 1: 0100 & 1.6010 \\
\hline 1.000 & 1.000 & 0.839 & 1.000 & 1.000 & 1.001 & 1.000 & 1.000 & $0.8+70$ \\
\hline LI STENER & & & & & & & & \\
\hline 1. 000 & $1: 000$ & 0.795 & 1.000 & 1. 0000 & 900 & $1: 000$ & 1:000 & 0.9518 \\
\hline $1: 1$ & 1: & 58 & 1. & 10 & & 90 & 00 & 65 \\
\hline 1.000 & 1.000 & 0.510 & 14 & 00 & 90 & 00 & 000 & 0.8406 \\
\hline 1.001 & 1:000 & 0.509 & 0.891 & 1. 000 & 1.000 & $1: 000$ & 1. 000 & 0.5334 \\
\hline I $\equiv$ TENER & 34 & & & & & & & \\
\hline $1:$ & 1. 000 & 1. 769 & $1:$ & 100 & 00 & 07 & 100 & 908 \\
\hline 1. 010 & 1. & 53 & & & & & & 54 \\
\hline 1.001 & $1:$ & 13 & पें & 10 & 90 & & 0 & 853 \\
\hline 1.900 & 1.000 & 0.695 & 0.954 & 1.000 & 1.0100 & 1.001 & 1.010 & 0.7106 \\
\hline I $\equiv$ TENER & & & & & & & & \\
\hline $1:$ & 1.010 & 0.583 & 1. & 90 & 00 & 90 & 00 & 953 \\
\hline $1:$ & $1:$ & 0.7 & $1:$ & & & & & 59 \\
\hline 1.000 & 1. & 0.7 & 0 & $1:$ & & 0 & 0 & 95 \\
\hline 1:000 & $1:$ & 0.453 & $0.5 \Xi 7$ & 0.936 & 1.0100 & 1.000 & 1.0010 & 0.4780 \\
\hline I $\cong$ TENER & & & & & & & & \\
\hline 1. & 1:01010 & 0.773 & 1 i. & 00 & & 90 & 00 & 90 \\
\hline $1: 000$ & 1 & 0. & 1. & 1 & 9 & 0 & 10 & 4.5 \\
\hline 1.0100 & 1. 010 & 0.532 & Ij: & 00 & 010 & 101 & 00 & $0.864 z$ \\
\hline 1.010 & 00 & 0.537 & 0.917 & 1. & 10 & 10 & 70 & 0.5605 \\
\hline I STENER & & & & & & & & \\
\hline $1: 010$ & 1:001 & 10. & $1:$ & & & & 90 & 9198 \\
\hline $1: 0100$ & 1.0 & 0.797 & $1:$ & $1:$ & 113 & 10 & 90 & 174 \\
\hline 1.010 & 1 & 0.621 & 9. & 1 & 10 & 10 & 00 & 33 \\
\hline 1. 01010 & 1.001 & 0.594 & 0.945 & 1.0 & 1.0 & 1.000 & 00 & 42 \\
\hline I $\Xi$ TENER & & & & & & & & \\
\hline 1. & 1 & & & & & & & 10 \\
\hline 1. 0011 & 1 & 0.731 & 1. & 1. & 1019 & 90 & 110! & 41 \\
\hline $\begin{array}{l}1.0010 \\
1.0010\end{array}$ & 000 & 1. 08 & 10. & & & 90 & 00 & $=5$ \\
\hline$I \equiv T$ & & & & & & & & \\
\hline 1.000 & 1.000 & 0.7 & & 00 & & & 90 & 391 \\
\hline 1.000 & 1.000 & 0.751 & 1.0010 & & 00 & 30 & $1:$ & 53 \\
\hline 1.000 & 1.000 & 0.540 & 0.721 & 1. 0010 & 1. 0101 & $1: 001$ & 00 & 445 \\
\hline 1. 00011 & 1:01010 & 0.509 & 0.891 & 1. 0010 & 1.010 & 1. & 1.000 & 0.5337 \\
\hline - I STENAER & & & & & & & & \\
\hline 1:0010 & 1.000 & 0. & & & & 1. & 00 & \\
\hline 1: 10013 & 000 & 0.884 & & & 60 & 90 & $1: 00 \pi$ & 85 \\
\hline 1.001 & 1. 000 & 11.744 & 0.9 & $1:$ & 1. 01010 & 1.001 & $1: 001$ & 958 \\
\hline 1. 0100 & 1.000 & 0.731 & 1. bug & 1. T110 & 1.010 & 1.000 & 1.000 & 17.748 \\
\hline
\end{tabular}




\begin{tabular}{|c|c|c|c|c|c|c|c|c|}
\hline & non & y. $x+\overline{3}$ & 1. 0000 & $1: 000$ & 1.000 & 1. $00 \mathrm{~s}$ & & 0.9897 \\
\hline 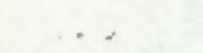 & $\therefore 000$ & 0.883 & 1.000 & 1. 000 & $1: 000$ & & 1:000 & \\
\hline & i. 0000 & 0.743 & 0.997 & 000 & 000 & $1: 000$ & 1.000 & \\
\hline $1: 000$ & $\because .000$ & 0.730 & 000 & 100 & $: 000$ & $: 000$ & $1: 000$ & \\
\hline I STENER & 42 & & & & & & & \\
\hline $1: 000$ & $1.0 \mathrm{non}$ & 0.818 & 1.000 & 000 & 000 & $1: 000$ & 1.000 & 0.958 \\
\hline 1 : & $1: 1$ & 39 & & & & 100 & 1.000 & \\
\hline 1.000 & $1: 1$ & .543 & 78 & & & & & \\
\hline 1.000 & 1.000 & 0.474 & 53 & & & & 000 & \\
\hline STENER & 43 & & & & & & & \\
\hline 1.0 & 1.000 & $0.8 E 6$ & : 000 & 100 & .000 & .000 & $1: 000$ & \\
\hline 1.000 & 1:000 & & 00 & & & 00 & & \\
\hline 1.000 & 1.000 & 0.595 & 961 & & & 100 & & \\
\hline 1.000 & $1: 000$ & 0.459 & 0.835 & & & & Na & \\
\hline I STENER & 44 & & & & & & & \\
\hline & $1: 1$ & 3 & 10 & 0 & & 00 & 100 & hn \\
\hline & & & & & & & & \\
\hline 1: & & & & & & & & \\
\hline $1: 1$ & 1 & 0.661 & 3 & & & 0 & 0 & \\
\hline$I \leq 1$ & & & & & & & & \\
\hline $1: 0$ & 1.000 & 48 & 90 & & & 00 & 100 & \\
\hline 1.000 & $1: 1$ & 75 & & & & 10 & & \\
\hline 1.000 & $1: 1$ & 0.591 & & & & & & \\
\hline 1.000 & $1: 1$ & 0.54 & & & & & 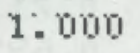 & \\
\hline$I \leq T$ & 46 & & & & & & & \\
\hline & $1: 1$ & & & & & 00 & 900 & 1.9 \\
\hline & & & & & & & & \\
\hline 1 & & & & & & & & \\
\hline 1. & 1 & 0.6 & 0. & 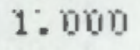 & & 9 & 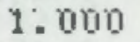 & \\
\hline I ST & 47 & & & & & & & \\
\hline 1. & $1: 1$ & 56 & & & & & & \\
\hline $1: 0$ & $1: 1$ & $\square$ & & & & & & \\
\hline $1: 0$ & $1: 1$ & 0 & & & & & 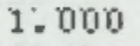 & \\
\hline $1: 0$ & 1.0 & 0.3 & & & & 0 & 0 & \\
\hline$I \equiv T$ & & & & & & & & \\
\hline & & & & & & & & \\
\hline & & & & & & & & \\
\hline & & & & & & & & \\
\hline 1. & & 1i. & & & & & & \\
\hline$I \leq 7$ & & & & & & & & \\
\hline & $1: 1$ & & & & & & & \\
\hline & 1.1 & & & & & & & \\
\hline 1.1 & 1.1 & & & & & & & \\
\hline $1: 0$ & $1:$ & $0: 7$ & & & & 100 & 000 & \\
\hline$E R$ & 50 & & & & & & & \\
\hline & & & & & & & & \\
\hline & & & & & & & & \\
\hline $1: 1$ & $1: y$ & & & & & & & \\
\hline & & 0.7 & 8 & & 00 & 1.000 & & \\
\hline
\end{tabular}

RuRAL, IIREAN PORULATI DNS 733201,268629

$\begin{array}{ccc}\text { FTRUR } & \text { FTURA } & \text { PTALL } \\ 0.956 & 0.974 & 0.972 \\ 0.741 & 0.807 & 0.800 \\ 0.847 & 0.896 & 0.890 \\ 0.508 & 0.591 & 0.582\end{array}$


NUREG/CR-2655

PNL-4226

AN

\section{DISTRIBUTION LIST}

No. of

Copies

OFFSITE

A. A. Churm

DOE Patent Division

$9800 \mathrm{~S}$. Cass Avenue

Argonne, IL 60439

100 U.S. Nuclear Regulatory Commission

Division of Technical Information and Document Control

7920 Norfolk Avenue

Bethesda, MD 20014

2 DOE Technical Information Center

Office of Inspection and Enforcement

Division of Emergency Preparedness

Emergency Preparedness Development Branch

Air Rights Building

4450 Montgomery

Bethesda, MD 20014

Pacific Northwest Laboratory (34)

EH Carbaugh

CJ Card

CD Corbit

PL Cummings

AE Desrosiers

TH Essig

RL. Gilchrist

SC Hawley

WN Herrington II I

EE Hickey

CD Hooker

JL Kenoyer

GJ Laughlin

JC Mann

GA Martin

MA HicLean

IIP Moeller

LH Munson

BL Murphy

BD Pickett

RW Poeton
AV Robinson

PD Robinson

JM Selby

GA Stoetze 1

$\mathrm{KL}$ Swinth

VW Thomas

Technical Information (5)

Publishing Coordination (2) 



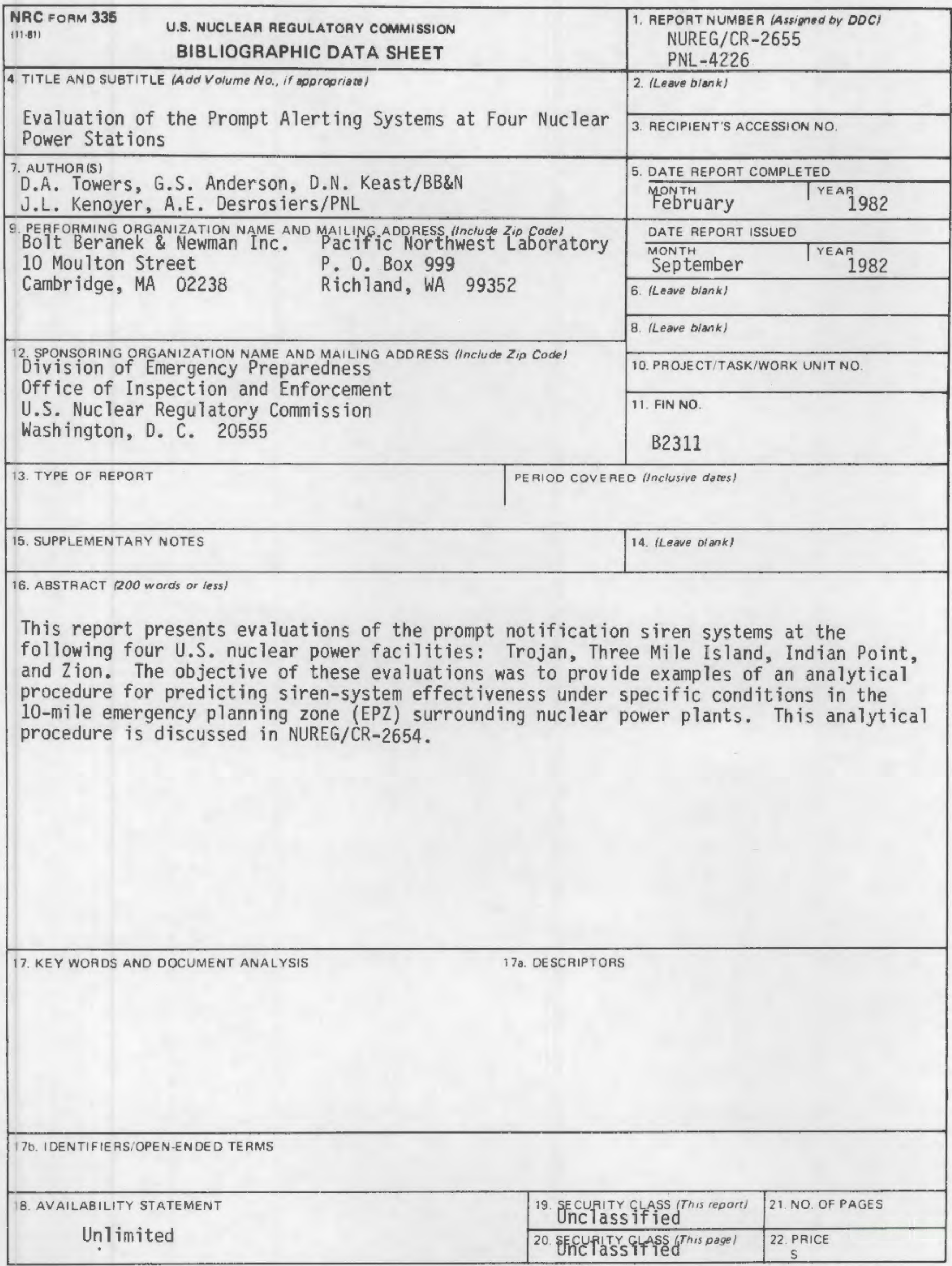


